\title{
Escuelas Creativas
}

\section{Creative schools}
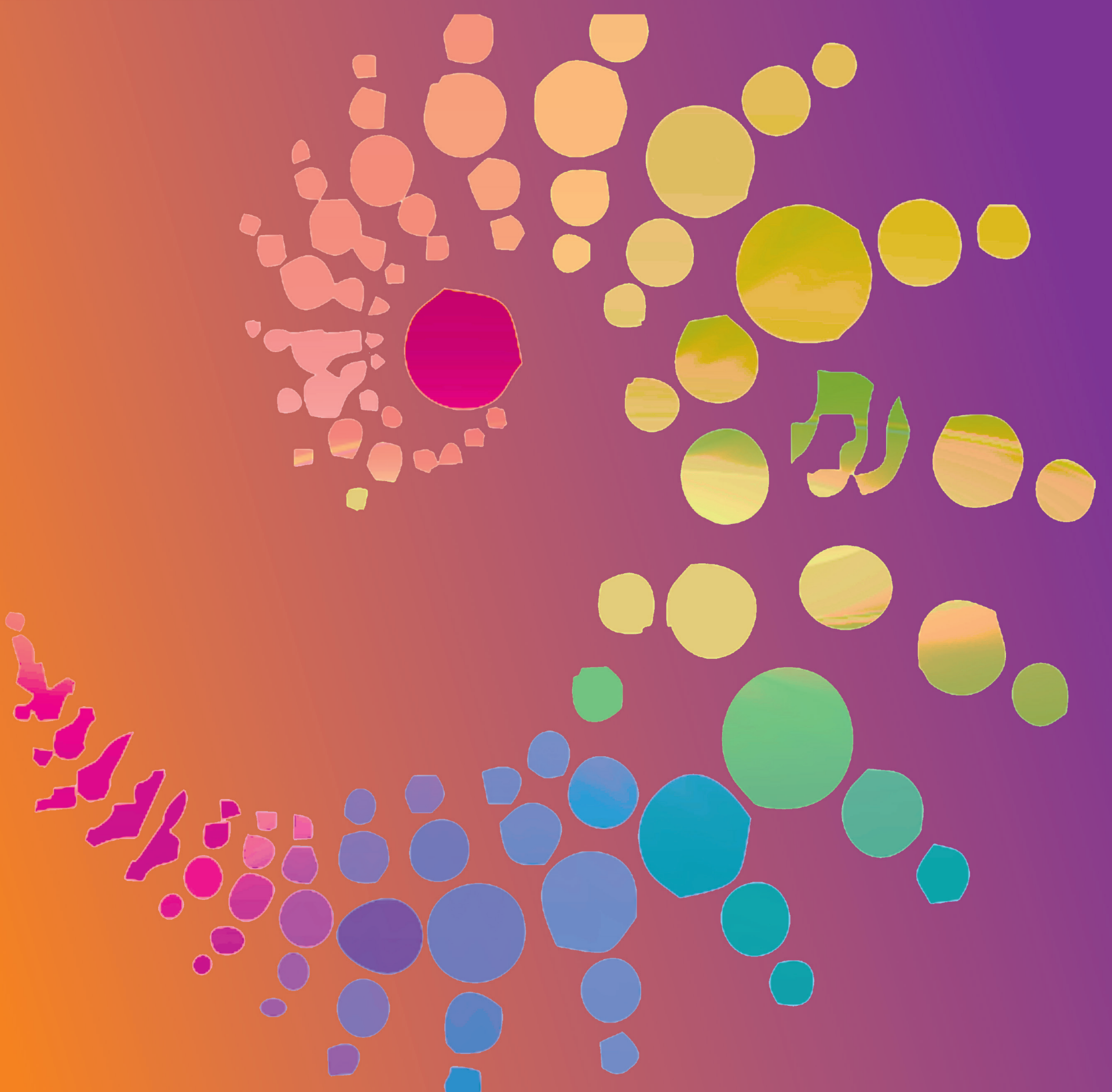

\section{Revista Creatividad y Sociedad}

Revista Científica de la Asociación Española para la Creatividad (ASOCREA) $n^{\circ} 32$, enero de 2020 www.creatividadysociedad.com Creativity and Society Research Journal 


\section{Equipo editorial}

Dirección

Editor General: Francisco García García

Adjunto al Editor General: Óscar Costa Román

\section{Consejo de Redacción}

Francisco García García

Manuela Barcía

Verónica Violant

Vicente Alfonso

José Antonio del Campo

Isidoro Arroyo

Francisco Mechén

\section{Consejo Científico Internacional}

Saturnino de la Torre

Antonio Rodríguez

Fernando de Soussa
Ramón Ferreiro

Guy Aznar

Robert S. Sternberg

David de Prado

Manuel Sánchez Méndez

Manuel Toharia

José Antonio Marina

John F. Cabra

Omar Gardí

María Hernández Herrera

Consejo Asesor

Ángeles Gervilla

Maite Garaingondobil

Juan Delgado

Albertina Mitjans

María Cándida Moraes

Carlos Alberto González

Marga Iñiguez 


\section{Coordinación Técnica}

Irene Juanco Cogolludo

J. Alejandro Pérez Eyzell

Aurora Forteza Martínez

Coordinadores del número

Verónica Violant Holz

Saturnino de la Torre

\section{Revisores de este número}

Arantxa González Montero

Leo Calle Alta

Jesús Vicente Ruiz

Adrián Sánchez Sibony

Raquel Armas Zavaleta

José Manuel Mansilla Morales

Jhon Alexander Pulido

Julio Real García

María José Flores Tena
Inmaculada del Rosal Alonso

Ana Furió Alarcón

Rafael Maroto Gamero

Erika Lucía González Carrión

Noelia Sánchez Sánchez

Eva Matarín Rodríguez

Patricia Gascón Vera

Jaime Martínez Barahona

Irene Real Benlloch

José Alejandro Pérez Eyzell

María Hernández Herrera

Jesús Argumedo Castañeda 


\title{
Indice
}

Editorial

Los jóvenes que hacen teatro son más creativos: ¿mito o realidad?

El potencial creador de la transdisciplinariedad y de la creatividad para la educación contemoporánea

Tiempos y espacios en un encuentro creativo-pedagógico

¿Se puede fomentar el orden desde la creatividad?

Exploración de lenguajes en la formación inicial del profesorado de Educación Infantil

\author{
profesorado de Educación ln fanth
}

El proceso de creación e interpretación de una partitura gráfica como recurso educativo para el desarrollo de la creatividad: una experiencia en la formación de los estudiantes del Grado de Maestro en Educación Primaria

El genio, el duende, el artesano: tres perspectivas estéticas sobre la creatividad

La Realidad Aumentada como recurso creativo en la educación: una revisión global

Nuevas cartografías: Una aproximación a Canal*accessible de Antoni Abad 


\section{Creatividad \\ y Sociedad | or s na}

Creatividad y educación

n’ 32 · enero 2020

\section{Escuelas Creativas}

Creative schools

Verónica Violant Holz

Universidad de Barcelona vviolant@ub.edu https://orcid.org/0000-0003-2464-6845

Saturnino de la Torre Universidad de Barcelona sentipensar@yahoo.es https://orcid.org/0000-0003-3898-0465 
Queremos iniciar este prólogo con una expresión de la que se hace eco S. Torre (1995, p. 271) ya hace varias décadas y que aún siguen vigentes: "si definir es rodear un campo de ideas con una valla de palabras, definir la creatividad es como intentar retener un mar de ideas en un continente de palabras". Pensar en el concepto de la Creatividad es sumergirnos en un pozo sin fondo al estilo de Alicia en el país de las maravillas cuando cayó en la madriguera.

La Crea-tivi-dad, es y representa crear y aportar algo nuevo, compartir y sobrevivir más allá del hecho particular. Al crear, la persona, grupo u organización, genera algo diferente y valioso, lo comparte con los próximos y al hacerlo, la obra sobrevive a la persona o grupo que lo creó. Vivir, convivir y sobrevivir, conforma la tríada que comparten Polinización y Creatividad.

Y esto es lo que quiere representar este número de la revista de Creatividad y Sociedad, que nace del fruto del VII Congreso Internacional en Creatividad ASOCREA, IX Fórum Internacional de Escuelas Creativas RIEC y II Seminario de Resiliencia AIRE Creatividad: Una mirada, al plantear el papel de la creatividad en un mundo plural en la escuela que hoy queremos para las nuevas generaciones. Una escuela acorde a los valores planetarios, ecoformadores y transdisciplinares.

Las demandas de la sociedad actual inciden en la necesidad de adoptar una mirada abierta y global sobre el Arte y la Cultura, la Educación y la Psicología, el Multilenguaje, la Salud y la Resiliencia, a través de la Creatividad, el Emprendimiento y la Ecoformación. Para seguir avanzando en el desarrollo humano, sin renunciar a los avances tecnológicos, conviene inspirarnos en la Naturaleza y adaptar el proceso de polinización biológica al ámbito humano y social mediante la polinización psicopedagógica.

Hablar de polinización psicopedagógica es tener en cuenta el proceso mediante el cual se desenvuelve y actúa los cuatro pasos o momentos que nos llevan al proceso creativo: compartir, conectar, fecundar y fructificar. El primer paso es compartir, expandir, dar a conocer valiéndonos de encuentros, reuniones o acciones externas. 
Esta es una de las funciones de congresos como éste. Un segundo momento es el conectar con uno mismo, el otro o los otros, estableciendo vínculos, haciendo que el mensaje tenga resonancia en la conciencia. Sin esa interiorización, el mensaje se queda en mera información. Eso es lo que ocurre muchas veces en las aulas. El tercer momento es el de fecundar o germinar, el dar vida, el inicio de un nuevo elemento, el conectar lo que viene de fuera con lo de dentro para encontrar nuevo sentido. Es ahí donde se genera el cambio cognitivo, emocional, actitudinal y a nivel mayor institucional y social. Muchas veces tiene lugar en el silencio interior tras una conferencia, un curso, una lectura, una película, o un acontecimiento traumático en la vida. El cuarto momento es el de fructificar, el dar fruto el hacer efectivo y duradero el cambio con repercusiones en los otros. Porque el fruto no sólo es para disfrutarlo, sino que lleva el germen para asegurar la continuidad de la especie con nueva vida. Todo lo bueno se difunde, decía Aristóteles, refiriéndose a los trascendentales del ser. Y la vida, al igual que la verdad, la bondad y la unidad tienden a expandirse y perpetuarse. Y estas reflexiones introductorias nos llevan a los principales agentes polinizadores: la abeja y su entorno de vida como analogía para concebir este congreso con base en la creatividad y la resiliencia.

Coherentes con este planteamiento, el número 32 de la revista Creatividad y Sociedad acoge artículos de investigación y de innovación educativa que ayuden a visualizar la polinización de una escuela creativa transformadora.

Son 9 los artículos que nos adentran en el mundo de la creación e interpretación de hechos significativos en la escuela y de manera específica en la escuela infantil, a través del cine, del teatro y de la magia, pasando por la realizada aumentada que nos ayuda a ver dónde otros no han visto y a sentir lo que uno no se podía ni imaginar que existía.

Comenzaremos este número con el trabajo de Vicente Alfonso y Tomás Motos titulado "Los jóvenes que hacen teatro son más creativos: ¿mito o realidad?" en el que se presenta una interesante investigación sobre la creatividad y la práctica teatral, para continuar con "El potencial creador de la transdisciplinariedad y de la crea- 
tividad para la educación contemporánea", trabajo a cargo de Kênia P. de Queiroz, María J. de Pinto y Marlene Zwierewicz.

El tercer artículo corresponde a Carlota Rodríguez y titulado "tiempos y espacios en un encuentro creativo-pedagógico" y en él se encuentra una interesante reflexión acerca de los movimientos pedagógicos en las actividades extraescolares. Continuamos avanzando en el número de la mano de Romina Caluori, quien bajo el título "¿Se puede fomentar el orden desde la creatividad? Estudio de caso: Aplicación Dr. Panda" nos invita a reflexionar sobre el papel de las aplicaciones móviles en el desarrollo de la creatividad.

El quinto artículo de este número se titula "Exploración de lenguajes en la formación inicial del profesorado de Educación Infantil" y corresponde a Montserrat González. El sexto trabajo incluido en este monográfico corresponde a Marina Buj y bajo el título "La creación e interpretación de partituras gráficas como recurso educativo para el desarrollo de la creatividad", nos acerca a la formación del profesorado en el ámbito musical.

El trabajo titulado "El genio, el duende, el artesano: tres perspectivas estéticas sobre la creatividad" a cargo de Tania A. Rios, ocupa el séptimo lugar y nos hace reflexionar sobre la creatividad y la estética literaria. Mariana D. González y Emilio Abad, nos presentan "La Realidad Aumentada como recurso creativo en la educación: una revisión global" que, ocupando la octava posición, pone de manifiesto el campo de las Realidad Inmersivas en el ámbito educativo. El noveno lugar lo ocupa el trabajo de Laia Manonelles quien aborda el trabajo de Antoni Abad, en el artículo titulado "Nuevas cartografías: Una aproximación a Canal accesible de Antoni Abad".

Cerramos este número con el trabajo, en la sección abierta. de Belén Ramírez y Josefa E. López, quienes reflexionan sobre el cine en su artículo "Títulos de crédito en las películas de James Bond: "marca 007"” 
Digamos para finalizar que la escuela creativa es aquella institución educativa polinizadora que no sólo se ocupa de trasmitir conocimientos y valores personales, sino de polinizar la cultura socialmente organizada; esto es compartir, conectar, dar nueva vida y fructificar en realizaciones innovadoras.

\section{Bibliografia:}

ToRRE, S. DE LA (1995). Creatividad aplicada. Recursos para una formación creativa. Madrid: Escuela Española. 


\title{
Creatividad \\ y Sociedad
}

Creatividad y educación

no 32 - enero 2020

\section{Los jóvenes que hacen teatro son más} creativos: ¿mito o realidad?

\section{Adolescents who study theatre are more creative: myth or reality?}

\author{
Vicente Alfonso Benlliure \\ Universitat de València \\ vicente.alfonso@uv.es \\ https://orcid.org/0000-0001-6010-0474 \\ Tomás Motos \\ Universitat de València \\ tomas.motos@uv.es \\ https://orcid.org/http://0000-0001-9336-306X
}




\section{Resumen}

Cuando entrevistamos a los jóvenes que practican teatro estos manifiestan que el teatro les ayuda en gran medida a afrontar los retos que les plantea su vida. Uno de los aspectos que los adolescentes suelen destacar es cómo la práctica del teatro les permite incrementar su creatividad. El objetivo de este estudio es comprobar si la percepción de los jóvenes es cierta cuando les pedimos que la pongan en práctica y comparar los niveles de creatividad de esos adolescentes con los niveles de jóvenes que no practican teatro. Un grupo de 222 jóvenes de edades comprendidas entre los 13 y 21 años participaron en el estudio. Comparamos a los jóvenes que hacen teatro con los que no lo hacen. Después dividimos el grupo de jóvenes "actores" en dos grupos según su grado de experiencia con el teatro y volvimos a comparar los tres grupos. Los resultados ponen de manifiesto que no existen diferencias cuando comparamos dos grupos (Teatro no/ Teatro si) pero sí cuando la comparación se hace entre los tres grupos (Teatro no/Teatro menos de dos años/Teatro dos años o más). Las diferencias aparecen tanto en medidas objetivas de pensamiento divergente (fluidez, flexibilidad y originalidad) como en medidas subjetivas de autopercepción creativa. Estos resultados ponen de manifiesto no solo que la práctica del teatro promueve la creatividad sino que es necesario un determinado nivel de experiencia para que ese impacto se manifieste.

\section{Abstract}

When we speak with young people who practice drama, they say that it helps them to face life's challenges. One of the aspects that teenagers often emphasize is how drama practice allows them to increase their creativity. The objective of this study is to check whether the perception of young people is true when we ask them to put it into practice and compare the levels of creativity of these adolescents with the levels of young people who have no experience with drama. A group of 222 young people between the ages of 13 and 21 participated in the study. We compared young people who practice drama with those who do not. Then we divided the group of young "actors" into two groups according to their level of experience with the theatre and we went back to comparing the three groups. The results showed that there were no differences when we compared two groups (Drama no / Drama yes) but when the comparison was made between the three groups (Drama no / Drama experience for less than two years / Drama experience for two years or more) the differences appear in objective measures of divergent thinking (fluency, flexibility and originality) and also, in subjective measures of creative self-perception. These results show that drama involvement promotes creativity but a certain level of experience is necessary for that impact to be significant.

\section{Key words}

Theatre $\cdot$ Creativity $\cdot$ Divergent Thinking

- Personal Development · Youth

\section{Palabras clave}

Teatro $\cdot$ Creatividad · Pensamiento Divergente

· Desarrollo personal · Juventud 


\section{Introducción}

La juventud es un momento muy especial de transición entre la infancia y la edad adulta, en el que se construyen identidades y se formaliza la incorporación a una vida social más amplia. Los adolescentes viven un intenso periodo evolutivo y, en pocos años, han de ser capaces de tomar las riendas de sus vidas, sus familias, comunidad, etc. Los científicos tienen un papel fundamental para mejorar, a través de la generación de conocimiento, la probabilidad de que los adolescentes se conviertan en ciudadanos capaces y comprometidos (Lerner y Steinberg, 2011).

La literatura sobre el desarrollo positivo juvenil sugiere que el estudio de las interacciones sociales y de las actividades de ocio con los pares, amigos y otros grupos puede ayudar a entender mejor cómo se refuerzan los factores naturales de protección en la juventud de nuestros días. La práctica de teatro lleva implícita esa participación e interacción social con el grupo de iguales. Neelands (2009) defiende que la importancia real del teatro con jóvenes y adolescentes reside en los procesos de implicación y participación social y artística y en la experimentación de una serie de situaciones y vivencias más que en los resultados o productos artísticos que puedan ser elaborados.

"Ver" y "hacer" teatro (Deldime, 1995) son dos perspectivas complementarias. El presente trabajo se focaliza en los efectos del "hacer teatro" y forma parte de un proyecto de investigación que indaga en las creencias implícitas que los jóvenes tienen sobre el teatro, el impacto percibido de dicha experiencia y los efectos sobre su desarrollo personal. Los resultados de las primeras fases del proyecto pueden consultarse en Motos y Alfonso-Benlliure (2018) y Motos, Alfonso-Benlliure y Fields, (2019). En esencia, los adolescentes reportan que hacer teatro les ayuda a explorar su identidad, a mejorar las relaciones con otros jóvenes, a expresar y gestionar mejor sus emociones y especialmente, a ver las cosas desde diferentes perspectivas, ser más abiertos y tolerantes y ser más creativos. 
No son muchos los estudios destinados a analizar el impacto de la actividad teatral en el desarrollo creativo-personal de los jóvenes. Es necesario recopilar y analizar más evidencias sobre el impacto del teatro en el desarrollo personal. Esa información debe servir para construir una sólida base teórica que explique el cómo y el porqué de dicho efecto en los jóvenes (Hughes y Wilson, 2004).

Kosnik (2014) señala que una de la lagunas más importantes en la literatura especializada es la insuficiente presencia de la opinión real de los jóvenes, pues la mayoría de estudios observan a través de los ojos del adulto y, a menudo, a través de una lente educativa (¿qué está aprendiendo el adolescente al participar en actividades teatrales?). Desde nuestra perspectiva, añadimos que también es necesario complementar los estudios cualitativos con estudios cuantitativos que permitan consolidar las evidencias. Si bien el uso de métodos cualitativos (análisis participativo, entrevistas semiestructuradas, etc.) resulta de gran valor para conocer cómo viven los jóvenes su experiencia teatral consideramos imprescindible complementarlos con estudios de carácter cuantitativo (e.g., uso de instrumentos con garantías psicométricas) para fortalecer el potencial de las investigaciones y la posibilidad de replicar los resultados.

El objetivo de este estudio es comprobar si esas percepciones subjetivas se confirman cuando complementamos la perspectiva cualitativa con otra de carácter cuantitativo y comparamos esas medidas con las de otros jóvenes que no hacen teatro.

Entre los trabajos previos que indagan sobre la influencia que la práctica del teatro tiene en el desarrollo psicológico y las habilidades ligadas al pensamiento creativo podemos citar el trabajo de Motos (1992), en una investigación con alumnado de Secundaria. El citado autor concluye que las actividades dramáticas favorecen la fluidez, la elaboración, la implicación personal y el lenguaje metafórico. Por su parte, Silva, Ferreira, Coimbra \& Menezes (2017), aplicaron la escala de Complejidad Socio-cognitiva en el Ámbito Teatral (SSCDT) a 222 sujetos con mayor o menor experiencia en la interpretación. Los resultados del estudio muestran que la complejidad cognitiva aumenta con la experiencia teatral. Hughes \& Wilson (2004) Ilevaron a cabo un estudio en el Centro de Investigaciones en Teatro Aplicado (Applied Theatre 
Los jóvenes que hacen teatro son más creativos: ¿ mito o realidad?

Research, CATR) de Gran Bretaña, utilizando tanto cuestionarios, entrevistas cualitativas y workshops (grupos de discusión). El estudio implicó a doscientos cincuenta jóvenes y sus resultados también sugieren que la práctica teatral facilita el desarrollo creativo de los participantes. Y lo hace a través fundamentalmente de tres efectos: les ayudaba a conocerse, a tener iniciativa y a tomar riesgos. Conocerse mejor ayuda a expresar la propia diferencia, tan importante para que las propuestas personales sean originales. Tener iniciativa ayuda a emprender proyectos, a que las ideas no se queden en el plano intelectual y se materialicen en decisiones y propuestas concretas. Tomar riesgos es consustancial a la creatividad puesto que la divergencia nunca tiene el éxito asegurado y sin capacidad para tolerar cierta dosis de riesgo, los jóvenes no pueden contrarrestar la fuerza de las expectativas sociales. Según estos autores, el teatro ofrece a los jóvenes caminos que implican retos que demandan creatividad y suscitan incertidumbre y riesgo, pero en un entorno que ellos perciben como benigno y seguro y en el que pueden probar diferentes formas de ser y responder a los demás.

Karakelle (2009) Ilevó a cabo un estudio experimental con estudiantes de postgrado. La mitad de ellos participaron en un programa de actividades teatrales de diez semanas de duración y la otra mitad integraron el grupo control . Todos ellos cumplimentaron pruebas de creatividad antes y después de la intervención. Una semana después de finalizar la experiencia teatral, se aplicó una prueba posterior a ambos grupos. Los resultados mostraron que la práctica teatral puede ayudar a mejorar dos aspectos fundamentales del pensamiento divergente: la fluidez y la flexibilidad. Uno de los trabajos más recientes al respecto es el de Méndez (2019). Estudiantes de la ESO participaron en grupos de improvisación teatral y posteriormente, su rendimiento en una prueba de creatividad fue contrastado con el de un grupo control que no había recibido instrucción teatral. Los resultados muestran que el grupo experimental mostró un avance significativamente mayor que el grupo control y que las diferencias entre el grupo que hacía teatro y el que no eran significativas en medidas de fluidez, flexibilidad y originalidad. 
Moga, Burger, Hetland y Winner (2000) llevaron a cabo un meta-análisis para sopesar las evidencias de una asociación significativa entre la los estudios artísticos (incluidas las artes escénicas) y el pensamiento creativo. Sus conclusiones fueron que los resultados varían en función del tipo de investigación (correlacional o experimental) y de la modalidad expresiva creativa evaluada (verbal o figurativa). Según los autores, los estudios correlacionales encuentran una relación moderada entre actividad artística y creatividad pero por limitaciones de la propia metodología, no pueden resolver la duda de si los estudiantes ligados a las prácticas artísticas ya eran diferencialmente más creativos antes de implicarse en sus estudios. Con respecto a los trabajos experimentales, la relación entre arte y creatividad también es moderada pero significativa, aunque solo cuando se evalúa creatividad figurativa, no para la verbal. Así pues, los hallazgos de este estudio meta-analítico no permiten llegar a conclusiones definitivas sobre la relación arte-creatividad.

En definitiva, a tenor de los resultados disponibles a día de hoy, solo podemos sospechar pero no concluir que la educación a través del teatro tiene un efecto positivo significativo sobre la creatividad (Winner, Goldstein \& Vincent-Lancrin, 2014). Por ello, son necesarios más estudios para confirmar esas sospechas. Muchas de las investigaciones mencionadas toman como referencia la percepción subjetiva de los adolescentes sin complementarlas con otras fuentes. Asímismo, pocos comparan los efectos de la práctica teatral con poblaciones análogas que no llevan a cabo esas prácticas. El objetivo de este estudio es comprobar si esas percepciones subjetivas en torno a su creatividad, se confirman cuando evaluamos creatividad más allá de la autopercepción. Se hipotetiza que los jóvenes con experiencia en la práctica del teatro tendrán una mayor autopercepción creativa que los que no la tienen y también un mayor rendimiento real en tareas de pensamiento divergente. 


\section{Metodología}

\subsection{Participantes}

Un grupo de 222 jóvenes de edades comprendidas entre los 13 y 21 años ( $X=$ $15,6)$ participaron en el estudio. El 61\% eran chicas y el 39\% restante chicos. Todos ellos estudian en 15 Centros de Educación Secundaria de la ciudad de Valencia y pueblos del área de influencia. Un total de 87 no hacen teatro y los135 restantes sí. El 54,1\% de los que hacen teatro lo llevan haciendo menos de dos años ( $N=73$ ) y el 45,9\% restante durante un periodo de dos años o más ( $N=62)$. Su experiencia proviene de la asignatura optativa de Taller de Dramatización en la Educación Secundaria Obligatoria, del Bachillerato Artístico o de algún taller extracurricular.

\subsection{Procedimiento.}

El contacto con los jóvenes actores tuvo lugar aprovechando la celebración en el Espacio Inestable de Valencia de la V "Trobada de Teatre Jove" (2018). Este encuentro con los jóvenes actores sirvió para una primera toma de contacto. La recogida de datos y administración de las pruebas tuvo lugar de forma colectiva en las aulas de sus centros educativos a los que se acudió previa cita con los equipos directivos. El resto de participantes que no hacían teatro estudian en los mismos centros que aquellos que sí tienen experiencia en el mundo del teatro.

La administración de las pruebas fue coordinada por un psicólogo experto en el procedimiento y contó con el apoyo del profesor responsable de cada aula. La administración de las pruebas tuvo una duración media de cincuenta minutos. Todos los participantes lo hicieron de forma voluntaria dando su consentimiento explícito. 


\subsection{Instrumentos}

- Cuestionario de datos demográficos:

Este cuestionario recogía información básica como el género, la edad, el curso, el centro en el que estudian. A los estudiantes que hacen teatro también se les preguntó por la modalidad por la que habían accedido a la práctica teatral, el tiempo que llevaban haciendo teatro y tres preguntas a contestar en una escala de 1 a 10: 1.- Grado de satisfacción con la experiencia de hacer teatro; 2.- grado de utilidad del teatro sobre su vida personal; y 3.- probabilidad de seguir haciendo teatro en un plazo de 5 años.

- PIC-J. Prueba de imaginación creativa para adultos (Artola et al., 2008). Este instrumento evalúa el DT a través de cuatro tareas (tres verbales y una gráfica). En este estudio solamente utilizamos las tareas verbales. Las tareas consisten en un ejercicio de identificación de problemas a partir de la visualización de una imagen en una lámina, un test de usos alternativos y un test de consecuencias. Las tareas verbales ofrecen puntuaciones en los criterios de Fluidez (Número de respuestas dadas), Flexibilidad (tipos de respuestas ofrecidas por el sujeto) y originalidad (infrecuencia estadística de las respuestas). De acuerdo con el manual de prueba, tiene una Alfa de Cronbach de .85 y niveles aceptables de validez (Artola et al., 2008)

- SAC, Self-assessment of creativity scale (Cropley, Kaufman, White, \& Chiera, 2014). Adaptado de Kaufman y Baer (2004), este cuestionario evalúa la percepción que los participantes tienen sobre su propia creatividad. Les pide que respondan, en una escala Likert de 6 puntos, a ítems como "Me considero una persona creativa" o "Me doy cuenta de cosas y detalles que pasan desapercibidos a otras personas". Su alpha de Cronbach es de .81. 


\subsection{Análisis Estadísticos}

El Análisis de varianza (ANOVA) permite comparar las medias de diferentes grupos en una o varias variables. Utilizamos este tipo de análisis para comprobar si existen diferencias entre los jóvenes que hacen teatro y los que no en primer lugar, y entre éstos últimos y los que sí lo practican en función del tiempo de experiencia en segundo lugar. En el primer análisis el factor fue la variable dicotómica Experiencia Teatral (si/no) y en el segundo el Grado de experiencia teatral (nula/menos de dos años/dos años o más). Las variables dependientes fueron las variables de creatividad (fluidez, flexibilidad, originalidad, pensamiento divergente verbal y creatividad auto-percibida).

Por otro lado, los análisis correlacionales Utilizamos este tipo de análisis para evaluar las relaciones entre la satisfacción con el teatro, la utilidad percibida, las expectativas de futuro y el tiempo de experiencia con el teatro. Los análisis estadísticos fueron realizados utilizando el Programa Estadístico SPSS 25.

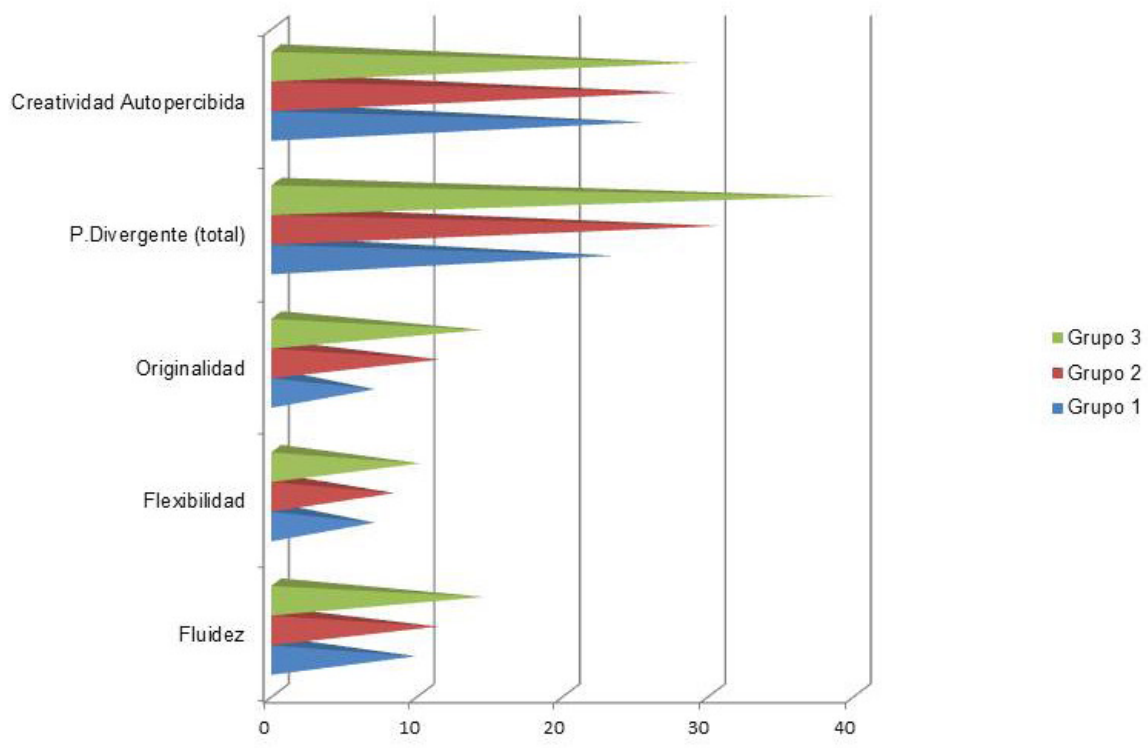

Figura 1. Comparación Creatividad auto-percibida, P. divergente verbal, Fluidez, Flexibilidad y Originalidad entre los tres grupos. 


\section{Resultados}

Al comparar a los jóvenes que hacen teatro y a los que no, un primer ANOVA nos muestra diferencias significativas en la variable: la autopercepción creativa $\left(F_{(1}\right.$, 219) 4,57; p < 0.05). En el resto de variables (Fluidez, Flexibilidad y Originalidad) no encontramos diferencias significativas entre los jóvenes que hacen teatro y los que no. Tampoco en la variable pensamiento divergente global.

Para comprobar si el tiempo que llevan haciendo teatro puede ser una variable relevante, llevamos a cabo un segundo ANOVA que nos permite comparar tres grupos: Ios sujetos que no hacen teatro (grupo 1), los que lo llevan haciendo menos de dos años (grupo 2) y los que lo llevan haciendo dos años o más (grupo 3). En este segundo análisis encontramos diferencias no solo en Autopercepción creativa ( $F$ (1, 218) 4,05; $p<0.05)$ sino en el resto de variables de creatividad: Fluidez, $(F(1,218)$ 6,83; $p<0.05)$. Flexibilidad, ( $\left.F_{(1,218)} 8,27 ; p<0.01\right)$. Originalidad, $\left(F_{(1,218)} 13,10\right.$; $p<0.01)$. Pensamiento Divergente Verbal $\left(F_{(1,218)} 10,56 ; p<0.01\right)$.

Las pruebas post hoc (Tukey, DHS) nos permiten ahondar en las diferencias en creatividad entre los tres grupos y observar qué grupos tienen un rendimiento mayor. Las comparaciones grupo a grupo ponen de manifiesto que las diferencias son significativas entre el grupo que lleva más de dos años haciendo teatro (grupo 3) y el grupo que no tiene experiencia teatral (grupo 1) tanto en creatividad objetiva, medida con la prueba de pensamiento verbal divergente $(X 1=23,21$ y $X 3=38,45)$, como en creatividad subjetiva o autopercibida $(X 1=25,26$ y X3=28,91). Las diferencias entre el grupo que no hace teatro y el que lleva menos de dos años haciendo teatro (grupo 2) no son significativas en ninguna de las medidas de creatividad. Las diferencias tampoco son significativas cuando comparamos los dos grupos que sí hacen teatro (ver gráfico 1). 


\begin{tabular}{|l|l|l|l|}
\hline & Satisfacción & Utilidad & Expectativa \\
\hline Menos de dos años & $100 \%$ & $56,4 \%$ & $57,3 \%$ \\
\hline Dos años o más & $86,5 \%$ & $86,1 \%$ & $75,8 \%$ \\
\hline
\end{tabular}

Tabla 1. Porcentaje de jóvenes con valoraciones altas o muy altas en niveles de Satisfacción, Utilidad y Expectativa futura sobre la práctica teatral

Por otro lado, a los adolescentes que practican teatro les preguntamos por su grado de satisfacción con la experiencia, la utilidad que le perciben para su día a día y la probabilidad de que en cinco años sigan haciendo teatro. En la tabla 1 encontramos los porcentajes de alumnos con valoraciones altas o muy altas al respecto. Como podemos observar, el grado de satisfacción con la práctica teatral es extremadamente elevado en los dos grupos. Aunque ambos grupos tienen altas percepciones de utilidad y expectativa, los jóvenes que llevan más tiempo haciendo teatro lo perciben como una práctica más útil en sus vidas y para su desarrollo personal y también tienen una expectativa de futuro más elevada de seguir en contacto con las actividades dramáticas que aquellos que llevan menos de dos años con la experiencia.

Finalmente, los análisis correlacionales muestran que a mayor tiempo de experiencia con el teatro mayor la satisfacción con la vivencia $(r=.31, p<0.05)$ y también la expectativa de hacer teatro en un plazo de cinco años ( $r=.35, p<0.05)$. La satisfacción con el teatro y la percepción de utilidad están significativamente relacionadas $(r=.42, p<0.01)$. La expectativa de hacer teatro en cinco años está significativamente ligada al grado de satisfacción ( $r=.38, p<0.01)$, la percepción de utilidad $(r=.61$, $\mathrm{p}<0.01$ ) y al grado de experiencia (ver tabla 2).

\begin{tabular}{|l|l|l|l|}
\hline & 1 & 2 & 3 \\
\hline 1. Satisfacción & & & \\
\hline 2. Utilidad & $.42^{\star \star}$ & & \\
\hline 3. Expectativa & $-38^{\star \star}$ & $.61^{\star \star}$ & \\
\hline 4. T haciendo teatro & $.31^{\star}$ & .18 & $.35^{\star}$ \\
\hline
\end{tabular}

Tabla 2. Correlaciones de Pearson entre las variables Satisfacción, Utilidad, Expectativa futura y Tiempo haciendo teatro 


\section{Discusión}

El objetivo del presente trabajo era comprobar si el impacto percibido por los jóvenes implicados en actividades teatrales en relación a su creatividad se confirma al compararlo con el de otros jóvenes que no practican teatro.

Los resultados expuestos dan lugar a una serie de interesantes reflexiones. Cuando el análisis se reduce a dos grupos, los que hacen teatro y los que no, la única diferencia que encontramos es en la auto-percepción: los jóvenes que hacen teatro se ven a sí mismos como más creativos que los demás. Pero cuando comparamos sus respuestas con las de jóvenes que no hacen teatro, estas no son significativamente más fluidas, ni más flexibles, ni más originales que las de sus compañeros.

Este resultado sorprende inicialmente hasta que nos paramos a pensar que la experiencia teatral no funciona como una "varita mágica". Es necesario un cierto tiempo de inmersión en la experiencia teatral para que su impacto sea detectable. De hecho, cuando distinguimos entre los alumnos que hacen teatro según su mayor o menor experiencia teatral, podemos comprobar que cuando esta práctica se dilata en el tiempo sí puede favorecer significativamente el pensamiento divergente. Los jóvenes que llevan haciendo teatro más de dos años tienen una mayor fluidez de ideas, pues la experiencia dramática aporta gran variedad de estímulos y vivencias; también muestran una mayor la flexibilidad de ideas, probablemente porqué el teatro facilita la toma de perspectiva y un acercamiento a la realidad desde diferentes enfoques enriqueciendo las definiciones personales de la realidad. Finalmente, la originalidad también se ve potenciada por las experiencias teatrales probablemente porque éstas promueven la tolerancia al riesgo, el autoconocimiento y la autoconsciencia emocional, fuentes necesarias para expresar creativamente la individualidad de cada joven.

Los ejercicios dramáticos conllevan interacción social, cooperación, intercambio de puntos de vista, vivencia de emociones, resolución de conflictos, etc. Las relaciones entre la práctica del teatro y el desarrollo de habilidades cognitivas superiores 
como la creatividad podría explicarse en base a que ésta experiencia ofrece condiciones óptimas para poner en práctica tanto habilidades divergentes (generación de una importante cantidad de ideas, redefinición de problemas, pensamiento analógico, etc) como convergentes (análisis de problemas, evaluación de las ideas, etc). Participar en grupos de teatro permite hacer y experimentar cosas, proponer ideas y desarrollarlas, y una oportunidad para pensar de forma crítica, independiente y activa (Kuyumcu, 2012). Pero la creatividad va más allá de la esfera cognitiva o intelectual. Los modelos explicativos de la creatividad más aceptados hoy en día son aquellos que atienden a su naturaleza multifacética y entienden que en ella participan de forma interactiva tanto componentes cognitivos (inteligencia, conocimientos... ) como afectivo-personales (actitud, personalidad, motivación....) y socioculturales (dominios, ámbitos...). La experiencia teatral es capaz de atender a dicha complejidad pues en ella pueden estar implicadas todas las dimensiones relevantes del desarrollo humano: motora, intelectual, lingüística, social, emocional. . Cuando los jóvenes improvisan o representan una escena trabajan aspectos actitudinales, desarrollan dimensiones de su personalidad, viven emociones de gran intensidad, se abren a un mundo de experiencias, asumen riesgos, y desarrollan habilidades de comunicación, gestión, negociación, y solución de problemas relevantes para el desarrollo de su creatividad.

Cuando la experiencia con las actividades dramáticas se alarga en el tiempo, va dejando una huella relevante en las capacidades creativas de los jóvenes. Las actividades dramáticas se caracterizan por brindar un espacio y una oportunidad de explorar o reinventar la realidad y percepción de uno mismo (Kim, Stembridge, Lawrence, Torres., Miodrag, Lee, y Boynes, 2015). Posiblemente, el mediador cognitivo que permite y facilita la exploración de la identidad a través de la práctica teatral es la apertura mental. Esta promueve la redefinición de los problemas, la toma de actitudes más abiertas y tolerantes con la información, las situaciones y las personas. Podríamos decir que la experiencia teatral funciona como una especie de mapa: no es la realidad, pero la representa y permite explorarla, conocerla, hacerse una idea de ella (Villalva, 2010). Cada adolescente representa a su manera el papel, de la manera 
que le es propia, pero los límites de la variación, o de la espontaneidad, están definidos en el propio papel con mayor o menor flexibilidad. La práctica teatral facilita a los adolescentes una especie de "laboratorio social de pruebas" en el que pueden explorar, cuestionar y trabajar en la construcción de significados para las circunstancias actuales (Gallagher, 2007). Ese laboratorio se convierte en un "espacio de seguridad" donde la creatividad es el "modus operandi" (Gallagher y Ntelioglou, 2013) y donde es posible "ensayar" la vida.

En definitiva, la experiencia teatral pone a sus participantes en situación de desplegar y practicar su potencialidad creativa, utilizando la integración de los distintos lenguajes (corporal, verbal, plástico, rítmico musical) desde una óptica interdisciplinar o transdisciplinar (Motos, 2009). El valor de la investigación aquí presentada es poner de manifiesto que esas diferencias existen cuando se evalúa la creatividad de una forma objetiva, a través de ejercicios en los que los jóvenes tienen que ponerla en práctica.

Por otro lado, la mayor parte de los alumnos que hacen teatro hacen valoraciones muy positivas de su experiencia, perciben su participación como una inversión en una actividad que después va a repercutir positivamente en sus vidas y, además, tienen elevadas expectativas de seguir con la práctica a medio plazo. Si bien el grado de satisfacción es similar en ambos grupos de teatro, la percepción de utilidad y las expectativas de futuro son evidentemente mayores en el grupo de jóvenes que más tiempo lleva haciendo teatro. A mayor experiencia con el teatro mayor es la sensación subjetiva de que la actividad genera influencias positivas sobre el desarrollo personal. En general, estos "veteranos" del teatro consideran que dicha implicación les permite aprender recursos de utilidad para su vida cotidiana pues les proporciona habilidades que luego pueden ser empleados en otros espacios y momentos de la vida. Hacer teatro supone "un aprendizaje continuo" y una posibilidad de transferir lo aprendido en la clase de teatro a las situaciones cotidianas en contextos dentro del centro educativo como fuera de él (Motos y Alfonso-Benlliure, 2019). El uso del teatro en los procesos educativos puede ayudar a desarrollar la capacidad de transferencia al acercar los contenidos "que se aprenden" a los contenidos "que se necesitan". 
Consistentemente, este grupo de jóvenes con dilatada experiencia teatral también concibe su futuro estrechamente ligado a la actividad dramática que tanto valoran y se ven a sí mismos haciendo teatro en un plazo temporal de cinco años.

Así, pues, al planteamiento que titula el presente artículo, "Los jóvenes que hacen teatro son más creativos: ¿mito o realidad?, podemos responder que la creencia, pese a su popularidad y asentamiento cultural, no es mítica sino que responde a una realidad. Pero no es suficiente con hacer teatro de forma temporal y/o anecdótica. Es necesario vivir el teatro, creérselo, implicarse en él y mantener la experiencia durante el tiempo necesario para que deje una huella significativa en el desarrollo de los jóvenes que lo practican. La importancia real del teatro con jóvenes tiene mucho que ver con el hecho de brindar la oportunidad de experimentar situaciones útiles y significativas, que resultan útiles para la solución de los problemas y retos cotidianos que los jóvenes han de afrontar en una etapa tan exigente de sus vidas. Ese bagaje de experiencias y aprendizajes influye sobre su desarrollo creativo, proporcionándoles una mayor amplitud de ideas, una mayor flexibilidad cognitiva a la hora de entender y razonar y una mayor originalidad en los productos de su imaginación. En esta línea, Motos (2009) afirma que el teatro ofrece a los jóvenes la oportunidad de tomar distancia respecto a sus problemas cotidianos proporcionándoles una oportunidad para probar actitudes diferentes a las propias. Hacer teatro permite a los jóvenes "ir más allá de la realidad inmediata", crear mundos alternativos y aprender a "dar forma" a sus propias vidas. 


\section{Bibliografía}

Artola, T., Barraca, J., Martín, C., Mosteiro, P., Ancillo, I., \& Poveda, B. (2008). PlC-J, Prueba de Imaginación Creativa-Jóvenes. Madrid: TEA Ediciones.

Cropley, D. H., Kaufman, J. C., White, A. E., \& Chiera, B. A. (2014). Layperson perceptions of malevolent creativity: The good, the bad, and the ambiguous. Psychology of Aesthetics, Creativity, and the Arts, 8(4), 400. https://doi.org/10.1037/a0037792

DelDime, R. (1995) Théâtre: art vivant. Carnières-Morlanwelz: Lasman.

GallaGHER, K. (2007). Conceptions of creativity in drama education. In L. Briesler International Handbook of Researh in Arts Education. (pp. 1229-1239). Dordrech: Springer.

Gallagher, K., y Ntelloglou, B. Y., 2013). Drama, Listening, Risk and Difference: On the Pedagogical Importance of (not) Knowing the Other. En M. Anderson y J. Dunn (Eds.), How Drama Activates Learning: Contemporary Research and Practice (pp. 94108). London. Bloomsbury.

HugheS, J. \& WILSON, K. (2004). "Playing a part: the impact of youth theatre on young people's personal and social development", Research in Drama Education, 9, No. 1, 57-72. https://doi.org/10.1080/1356978042000185911

Kaufman, J. C., \& Baer, J. (2004). Sure, i'm creative - but not in mathematics!: Self-reported creativity in diverse domains. Empirical studies of the Arts, 22(2), 143-155.

KarakelLE, S. (2009). Enhancing fluent and flexible thinking through the creative Drama process. Thinking Skills and creativity, 4 (2), pp. 124-129.

https://doi.org/10.1016/.tsc.2009.05.002

Kim, A., Stembridge, S., Lawrence, C., Torres, V., Miodrag, N., Lee, J., y Boynes, D. (2015). Neurodiversity on the stage: The effects of inclusive theatre on youth with autism. International Journal of Education and Social Science, 2(9), 27-39. Recuperado de: unw.ijessnet.com/wp-content/uploads/2015/10/4.pdf 
Los jóvenes que hacen teatro son más creativos: ¿mito o realidad?

Kosnik, C. (2014). How Theatre Participation Impacts High Schoolers and College Students. Doctoral disertation. Arizona State University.

Kuyumcu, F. N. (2012). The importance of "Art Education" courses in the education of prospective teachers. Procedia-Social and Behavioral Sciences, 51, pp. 474-479.

Lerner, R.M., y Steinberg (2011). Handbook of adolescence psychology (2a ed.) Hoboken, NY: John Wiley and Sons.

MénDEZ, E. (2019). Improvisación teatral en educación. Recuperando la espontaneidad como impulso del proceso creativo (Tesis Doctoral). Universidad de Oviedo.

Moga, E.; Burger, K.; Hetland, L. \& Winner, E. (2000). Does Studying the Arts Engender Creative Thinking? Evidence for Near but not Far Transfer. Journal of Aesthetic Education, 34 (3-4), pp. 91-104. DOl: 10.2307/3333639

Motos T. (1992) Las técnicas dramáticas como procedimiento didáctico para la enseñanza de la Lengua y la Literatura, Enseñanza. Anuario Interuniversitario de didáctica, 10-11, 75-92.

Motos T. (2009). El teatro en la educación secundaria: fundamentos y retos. Creatividad y sociedad: Revista de la Asociación para la Creatividad, 14, 2-10.

Motos T., \& Alfonso-Benlliure, V. (2018). Beneficios de hacer teatro en el desarrollo positivo en adolescentes de Valencia. Revista de investigación en educación, 16(1), 34-50.

Motos, T., \& Alfonso-Benlliure, V. (2019). El teatro como recurso para afrontar los retos de la adolescencia. Didacticae: Revista de Investigación en Didácticas Específicas, (5), 115-129.

Motos, T., Alfonso-Benlliure, V., \& Fields, D. L. (2019). The impact of theatrical experiences on young adults in Spain. Research in Drama Education: The Journal of Applied 
Theatre and Performance, 24(2), 192-200. DOl: 10.1080/13569783.2018.1494562

NeElAndS, J. (2009). Acting together: ensemble as a democratic process in art and life. Research in Drama Education: The Journal of Applied Theatre and Performance, 14(2), 173-189. https://doi.org/10.1080/13569780902868713

Silva, J. E., Ferreira, P., Combra, J. L., \& Menezes, I. (2017). Theater and Psychological Development: Assessing Socio-Cognitive Complexity in the Domain of Theater. Creativity Research Journal, 29(2), 157-166. doi:10.1080/10400419.2017.1302778

VILLALVA, M. B. (2010). La metáfora teatral en la interacción social. Revista Internacional de Sociología, 68(1), 19-36. DOl:10.3989/ris.2008.06.17

Winner, E., Goldstein, T. R., \& VIncent-Lancrin, S. (2014). Does arts education foster creativity? The evidence so far. En L. O'Farrell, S. Schonmann \& E. Wagner (Eds.) International yearbook for research in arts education, Vol 2, pp: 95-100. Münster. New York: Waxmann 


\section{Creatividad y Sociedad}

El potencial transformador de la transdisciplinariedad y de la creatividad para la educación contemporánea

\section{The transforming potential of transdisciplinarity and creativity for contemporary education}

Kênia Paulino de Queiroz Souza Universidade Federal do Tocantins - UFT (Brasil) keniaqueiroz06@hotmail.com, https://orcid.org/0000-0002-7352-824X

Maria José de Pinho Universidade Federal do Tocantins - UFT (Brasil) mjpgon@mail.uft.edu.br, https://orcid.org/0000-0002-2411-6580

Marlene Zwierewicz Universidade Alto Vale do Rio do Peixe - UNIARP (Brasil) marlenezwie@yahoo.com.br, https://orcid.org/0000-0002-5840-1136

Marina Haizenreder Ertzogue Universidade Federal do Tocantins - UFT (Brasil) marina@mail.uft.edu.br, https://orcid.org/ 0000-0002-7888-988

Recibido: 29 de mayo de 2019

Aceptado: 15 de diciembre de 2019

Para citar este artículo: Paulino de Queiroz Souza, K., de Pinho, M., Zwierewicz, M. y Haizenreder Ertzogue, M. (2020) El potencial transformador de la transdisciplinariedad y de la creatividad para la educación contemporánea. Escuelas creativas. Creatividad y Sociedad (32) 28-52.

Recuperado de http://creatividadysociedad.com/wp-admin/Artículos/32/32.2.pdf 


\section{Resumen}

Las discusiones contemporáneas a respeto del escenario educacional demandan la articulación de las dimensiones de naturaleza ontológica, epistemológica y metodológica como condición esencial para transitar de la fragmentación para la conexión de los conocimientos y de estos con lo que está entre ellos, más allá y por medio de ellos. Con el objetivo de presentar una reflexión acerca de la perspectiva transdisciplinaria y las posibilidades que ofrece para la conexión de los conocimientos en el escenario educacional contemporáneo, presentando la propuesta de las Escuelas Creativas como un ejemplo práctico, este estudio es constituido de una revisión bibliográfica, con el apoyo del enfoque cualitativo, priorizando el análisis de aportes de pensadores contemporáneos como Morin (2009, 2015), Nicolescu (2005, 2014) y Torre (2005, 2008, 2016). Los referenciales teóricos han señalado que, a partir de la transdisciplinariedad y de la creatividad, las perspectivas educacionales se abren a la conexión entre los diferentes tipos de conocimiento y su articulación con la realidad, estimulando la superación de la dicotomía entre el sujeto y el objeto y, consecuentemente, la consideración del ser que conecta y trasciende las dimensiones de la realidad y los niveles de percepción. Emerge, por lo tanto, la necesidad de revolucionar el modo de pensar de los educadores, como también un nuevo hacer pedagógico a partir de la conexión de saberes, vidas y seres, como partes interconectadas de una dimensión planetaria.

\section{Palabras clave}

Creatividad · Transdisciplinariedad · Conexión

- Educación

\section{Abstract}

Contemporary discussions regarding the educational scenario demand the articulation of the dimensions of an ontological, epistemological and methodological nature as an essential condition to move from fragmentation to the connection of knowledge and these with what is between them, beyond and through from them. With the aim of presenting a reflection on the transdisciplinary perspective and the possibilities it offers for the connection of knowledge in the contemporary educational scenario, presenting the proposal of the Creative Schools as a practical example, this study is constituted by a literature review, with the support of the qualitative approach, prioritizing the analysis of contributions of contemporary thinkers like Morin (2009, 2015), Nicolescu $(2005,2014)$ and Torre (2005, 2008, 2016). Theoretical references have indicated that, from transdisciplinarity and creativity, educational perspectives open to the connection between different types of knowledge and its articulation with reality, stimulating the overcoming of the dichotomy between the subject and the object and, consequently, the consideration of the being that connects and transcends the dimensions of reality and the levels of perception. The need therefore arises to revolutionize the way of thinking of educators, as well as a new pedagogical work based on the connection of knowledge, lives and beings, as interconnected parts of a planetary dimension.

\section{Key words}

Creativity · Transdisciplinarity · Connection

- Education 
El potencial transformador de la transdisciplinariedad y de la creatividad para la educación contemporánea

\section{Introducción}

La educación se ha desarrollado en un escenario de constantes construcciones y reconstrucciones. Uno de los motivos que moviliza el carácter dinámico de la educación está reservado a la búsqueda por una educación diferenciada, que atienda a las necesidades del ser humano, de la sociedad, del planeta y de la vida en él.

Esa búsqueda proporciona reflexiones acerca de las diferentes formas de educación, especialmente la que defiende la necesidad de superar la tendencia tradicional, pautada en la enseñanza fragmentada y aislada, distante de las situaciones problemáticas que la sociedad enfrenta a diario. Ese cambio, sin embargo, requiere una mirada ampliada, que conecte enseñanza y realidad, y por lo tanto, saberes, vidas y entornos.

Para comprender como esa conexión global pode materializarse y proporcionar alternativas transformadoras para pensar y repensar la vida a partir de la propia vida educacional, este artículo objetiva presentar una reflexión sobre la perspectiva transdisciplinaria y las posibilidades que esta ofrece al contexto educacional para la reconexión de los conocimientos, mientras también colabora para trascenderlos. Mientras sus objetivos específicos son: I) presentar el concepto de trandisciplinariedad y su aporte para la interconexión entre contenidos curriculares con lo que está entre, más allá y a traves de las asignaturas, o sea, entre los contenidos curriculares y la vida; II) presentar conceptos de creatividad y su relación con la complejidad, la ecoformación y la propia transdisciplinariedad; III) contextualizar la creatividad y la transdisciplinariedad en la propuesta de las Escuelas Creativas. 


\section{Metodología de investigación}

Metodológicamente, el estudio está constituido por uma revisión bibliográfica con el respaldo del enfoque cualitativo, priorizando el análisis de aportes de pensadores contemporáneos como Morin (2009, 2015), Nicolescu (2005, 2014) y Torre (2005, 2008, 2016). Esos autores posibilitan la reflexión a partir del pensamiento complejo, de la transdiciplinariedad y de la creatividad. Son dimensiones que posicionan el saber y el hacer educacional en escenarios de construcciones, deconstrucciones y reconstrucciones como bases del constante aprender para el presente y futuro.

Este tipo de investigación posibilita el análisis de investigaciones precedentes, aproximando el investigador al objeto de estudio.

Aunque sea común la exigencia de "algun tipo de trabajo de esa naturaleza, hay investigaciones desarrolladas exclusivamente a partir de fuentes bibliográficas" (Gil, 2006, p. 65). Ese es el caso de la presente investigación.

Además, la opción del abordaje cualitativo ha posibilitado describir y contextualizar resultados de investigaciones precedentes sobre los dos conceptos: creatividad y transdisciplinariedad. Ese abordaje es fundamental para la comprensión de particularidades y que involucran significados que no se expresan por medio de datos cuantitativos y que para Minayo (2010, p. 23), no pueden ser reducidos a la operacionalización de las variables".

\section{Resultados y discusiones}

Los resultados son presentados y discutidos en tres seciones: en la primera se presenta el concepto de trandisciplinariedad y el aporte para la interconexión entre contenidos curriculares con lo que está entre, más allá y a traves de las asignaturas, o sea, entre los contenidos curriculares y la vida; en la segunda parte se presenta el 
El potencial transformador de la transdisciplinariedad y de la creatividad para la educación contemporánea

concepto de creatividad y su relación con la complejidad, la ecoformación y la propia transdisciplinariedad; y en la tercera parte se busca personificar la creatividad y la transdisciplinariedad en la propuesta de las Escuelas Creativas.

\subsection{Transdisciplinariedad: una interconexión de los conocimientos curriculares con la vida}

En busca de nuevos aprendizajes, diferentes enfoques del conocimiento han sido alternados. De este modo, ha surgido la transdiciplinariedad, como proposición de la trascendencia de los límites del campo disciplinar.

La transdiciplinariedad "se refiere a aquello que está al mismo tiempo entre las asignaturas, por medio de las diferentes asignaturas y más allá de cualquier asignatura. Su objetivo es la comprensión del mundo presente, para el cual uno de los imperativos es la unidad del conocimiento (Nicolescu, 1999, p. 51).

Esa percepción referente a los espacios existentes entre las asignaturas, por medio y más allá de ellas escapa al pensamiento clásico. Dimensiona algo más de lo que presentan las asignaturas, contribuye así para que sean percibidas las aperturas que interconectan diversos saberes, el sujeto y el entorno que forma parte de este proceso, porque no es constituido de "un mero movimiento epistemológico, disciplinario o cultural; es ante todo, una nueva mirada que tiene su proyección en la vida y en la esfera social" (Torre et al., 2008, p. 31).

La transdiciplinariedad es la valoración de los diferentes saberes que componen la vida planetaria, desde la mirada interconectada. En ese proceso, se mueve de un extremo al otro, estimulando la observación de más de dos puntos distintos, más de dos objetos separados, pues posibilita la percepción del puente que los conecta. Para Nicolescu (1999), esa percepción entre dos objetos es el tercer término, es decir, el tercero incluido que el sujeto visualiza en el medio de dos campos. 
A diferencia de esa concepción, la visión moderna, predominante en el siglo XX, no se adecua a la contemporaneidad para atender a la complejidad de diferentes dimensiones humanas. El pensamiento moderno comprende solo lo que se ve de concreto y aislado, lo que es objetivamente reconocido por la ciencia, y siempre a partir de dualidades opuestas en un único nivel de realidad, sin considerar la percepción del sujeto.

Cuando considerada en el contexto educacional, la transdiciplinariedad corre diferentes riesgos, como cualquier otra concepción, pues, como lo ha advertido Nicolescu (1999), no es porque sea una visión diferenciada y agregadora que será suficientemente buena como para ser perfecta como un nuevo modelo para la educación. Puede ser interpretada de modo equivocado en su significado, ya que la transdisciplinariedad proporciona una nueva propuesta de diálogo entre las asignaturas, tanto en las dimensiones culturales, históricas, como en las epistemológicas, que aun no se mencionaba.

Es una concepción con una mirada ampliada, que busca la reconstrucción y la conexión de viejos y nuevos puentes para crear y recrear perspectivas que redimensionarán un contexto educativo anteriormente desilusionado, pero que ahora reaviva la llama del encantamiento (Nicolescu, 1999).

Esa visión vive en un mundo lleno de avances que involucran la cibernética y la informática, a menudo, priorizando "eficacia por la eficacia" (Nicolescu, 1999, p. 16), sin reconsiderar las consecuencias que esa búsqueda puede tener en la vida humana, social, cultural y planetaria. Mientras tanto, la humanidad ha vivenciado problemas cada vez más transnacionales, perceptibles en que "descarga ecológica, exclusión social, explotación sin límites de los recursos naturales, búsqueda frenética y deshumanizadora de ganancias, aumento de las desigualdades se encuentran en el cerne de las problemáticas contemporáneas" (Morin, 2015, p. 5). 
El potencial transformador de la transdisciplinariedad y de la creatividad para la educación contemporánea

La frialdad humanística en la búsqueda de su propio crecimiento económico, del poderío, independientemente del sacrificio, está envuelta en la pérdida de valores humanos, sociales, culturales y ambientales, valores sagrados. Mallart (2009, p. 29) confirma esa frialdad al afirmar que los problemas vivenciados actualmente tienen sus causas vinculadas a iniciativas individualistas, dirigidas a atender a lo que está "más cerca, espacial y temporalmente, y desatender las previsibles consecuencias futuras de nuestras acciones".

En ese escenario de caos, la transdisciplinariedad busca nuevas miradas, nuevas actitudes, indagando lo que está puesto para transponer barreras e interconectar conocimientos con la vida. Para ello, se mueve por los diferentes niveles de realidad y estimula una nueva percepción sobre la vida.

Ese proceso puede ser de menor o mayor intensidad, pues depende de la "adopción de los tres pilares metodológicos de la transdisciplinariedad: los niveles de Realidad, la lógica del tercero incluido y la complejidad..." (Nicolescu, 1999, p. 132), Son esos tres pilares los que proporcionan, en cada asignatura, el descubrimiento de nuevos entendimientos que podrían ser imperceptibles.

La realidad no es comprendida a partir de un único nivel. Esa comprensión también depende de la lógica del tercero incluido, pues señala que hay multidimensionalidad, estimula la percepción de que hay más de dos lados. Es decir, "el conjunto de los niveles de Realidad y su zona complementar de no-resistencia constituyen el Objeto transdisciplinario" (Nicolescu, 1999, p. 61). Como en la óptica transdisciplinaria, una realidad está compuesta por una diversidad compleja y también posee una unidad abierta, es decir, los diversos niveles de realidad no se presentan de forma simplificada y cerrados en sí mismos, sino que solo existen porque coexisten y tienen apertura para que se muevan de un nivel a otro a partir de sus elementos complejos. 
Para comprender ese mundo complejo se hace necesaria una nueva metodología, que permita comprender cómo interactúan el sujeto y el objeto entre si (Nicolescu, 2014). La transdisciplinariedad propone una comprensión a partir de la conexión entre las diferentes dimensiones metodológica, ontológica y epistemológica. hacer (metodológico) no se disocia del ser (ontológico) en la condición de sujeto que actúa, tal como ese sujeto, para que realice algo, necesita conocerse (epistemológico) y apropiarse del saber; en esa perspectiva, "todo conocer es inseparable del ser y del hacer" (Moraes, 2014, p. 25).

Sommerman (2011) reafirma que, de esos tres pilares, surgen la epistemología y la metodología de la investigación transdisciplinaria. Esa perspectiva trans "es reconocida como principio epistemológico que implica una actitud de apertura del espíritu humano al vivenciar un proceso que involucra una lógica diferente, una manera de pensar más elaborada... y depurada de la realidad para que ella se haga presente" (Moraes, 2008, pp. 119-120).

Esa perspectiva converge con lo que Morin (2001, p. 10) define como pensamiento complejo: "es animado por una tensión permanente entre la aspiración a un saber no en cuotas, no cerrado, no reductor y el reconocimiento de lo inconcluso, de la incompletad de todo el conocimiento". En este sentido, Petraglia (2012, p.143) explicita: "el pensamiento complejo que nutre y es nutrido por la transdisciplinariedad".

Existe, por lo tanto, una complementariedad entre la transdisciplinariedad y la complejidad (Nicolescu, 2005). En esa comprensión, Nicolescu (1999, p. 38) dice, todavía, que "la lógica del tercero incluido es una lógica de la complejidad y hasta mismo, quizá, su lógica privilegiada, en la medida en que permite cruzar de modo coherente los diferentes campos del conocimiento".

Esa lógica se mueve en el campo de la complejidad y también lo complementa, desde su percepción de la realidad, al incluir diferentes niveles y agregar diversos campos como no contradictorios. Por un lado está la simplicidad, por otro, la complejidad; sin embargo, va más allá de esa comprensión, al darse cuenta de que entre los 
El potencial transformador de la transdisciplinariedad y de la creatividad para la educación contemporánea

dos hay un tercero lado, el sujeto como tercero incluido (Moraes, 2015). Hay, por lo tanto, una visión de interconexión entre la complejidad, la simplicidad y el individuo con su percepción, que se origina de las influencias tanto extrínsecas como intrínsecas.

Ante a este complejo apoyo, la perspectiva transdisciplinaria contribuye a que ese conocimiento, en lugar de ser fragmentado, sea interconectado, unido. Morin (2007, p.25) advierte que "para ser transdisciplinario se requiere un conocimiento complejo. No se puede ser transdisciplinario simplemente yuxtaponiendo elementos. Es necesario saber los elementos de las diferentes asignaturas". Es a partir de la comprensión de que la realidad es multidimensional y multirreferencial, presentándose en diversos aspectos, que se obtendrá conciencia compleja y saber transdisciplinario para reconectar lo que la concepción simplificadora ha separado, como ejemplo, las asignaturas. Para Nicolescu (2005, p. 3), "The transcendence, inherent in transdisciplinarity, is the transcendence of the Subject. The Subject can not be captured in a disciplinary camp".

La transdisciplinariedad tiene la visión de reconocimiento y valoración de la diversidad, sin embargo, no significa que sea sin rigor, pues, de acuerdo al art. 14 de la Carta de la Transdisciplinariedad, "rigor, apertura y tolerancia son las características fundamentales de la visión transdisciplinaria" (Torre, Pujol \& Moraes, 2013, p. 26). En este pensamiento, la perspectiva transdisciplinaria busca valorar diferentes conocimientos, diferentes niveles de realidad y de percepción, conectando la naturaleza, la sociedad y el ser humano.

\subsection{Creatividad: miradas potenciadoras}

La creatividad es un laberinto, cuando se busca conceptuarla, haya vista que se mueve por varios caminos y difícilmente se logra llegar a un destino específico, si no hay un foco definido. No es una concepción exclusivamente del campo educacional y, bajo la percepción del sentido común, también es usada para expresar la novedad o algo encantador y diferente. 
Torre realizó un interesante trabajo, buscando registrar las diferentes conceptualizaciones de creatividad. Explicitó en su obra Creatividad Aplicada (2008) los diferentes conceptos clásicos y actuales de los académicos de la creatividad, así como hacer referencias a algunos citados en la obra Comprender y evaluar la creatividad (2006). Para el autor, eran actuales en la primera década del siglo XXI. Sin embargo, los conceptos aquí explicitados siguen siendo considerados contemporáneos. La tabla presenta el año 2008 como fecha de la publicación colectiva por Torres de Creatividad aplicada, en la cual no fue especificada la fecha de publicación individual de los conceptos por los autores mismos. A partir de la inmensa lista que presentó, algunos se destacan:

\begin{tabular}{|c|c|}
\hline Autores & Conceptos de creatividad \\
\hline Alencar, E. e Flith, D. & $\begin{array}{l}\text { La creatividad no ocurre al azar, sino que está profundamente influenciada } \\
\text { por factores ambientales, considerando los momentos de creación como } \\
\text { resultados de complejas circunstancias sociales. }\end{array}$ \\
\hline Csikszentmihalyi, M. & $\begin{array}{l}\text { La creatividad es el resultado de la interacción de un sistema compuesto } \\
\text { por tres elementos: una cultura que contiene reglas simbólicas, una persona } \\
\text { que aporta para el campo y un ámbito de expertos que reconocen y validan } \\
\text { la innovación. Creatividad es cualquier acto, idea o producto que cambia un } \\
\text { campo ya existente o transforma un campo existente en otro. }\end{array}$ \\
\hline De Bono, E. & Es una aptitud mental y una técnica del pensamiento. \\
\hline González Quintián, C. A. & $\begin{array}{l}\text { La creatividad, comprendida a partir del formativo como dimensión humana, } \\
\text { transformadora del ser y del entorno, es concepto integral, que incorpora la } \\
\text { visión energética como fuente de transformación y desarrollo humano. }\end{array}$ \\
\hline Guilford, J. P. & $\begin{array}{l}\text { Capacidad o aptitud para generar alternativas a partir de una información } \\
\text { dada, con énfasis en la variedad, cuantidad y relevancia de los resultados. }\end{array}$ \\
\hline Menchen, F. & $\begin{array}{l}\text { Para liberar la creatividad que todos tenemos dentro de nosotros, necesi- } \\
\text { tamos invertir una gran cuantidad de energía psíquica. Ni las recompensas } \\
\text { extrínsecas, tampoco las capacidades cognitivas, por si solas, garantizan el } \\
\text { despertar de la creatividad. }\end{array}$ \\
\hline Mitjans, A. & $\begin{array}{l}\text { Concibe la creatividad como un complejo proceso de la subjetividad huma- } \\
\text { na en su simultánea condición de subjetividad individual y social, que se ex- } \\
\text { presa en la producción de algo que es considerado al mismo tiempo nuevo } \\
\text { y valioso en un determinado campo de la acción humana. }\end{array}$ \\
\hline Moraes, M. C. & $\begin{array}{l}\text { La naturaleza tiene con ella misma una creatividad intrínseca a la propia } \\
\text { esencia de la materia y permite la aparición de nuevos sistemas, de nuevas } \\
\text { totalidades/partes, de algo nuevo y creativo [...]. De ese modo, la creatividad } \\
\text { es una propiedad clave de la materia vida, en función del reconocimiento de } \\
\text { la energía, como principio generados de procesos de cambios y de evolu- } \\
\text { ción que ocurren en la naturaleza en su conjunto [...]. }\end{array}$ \\
\hline
\end{tabular}




\begin{tabular}{|l|l|}
\hline Torrance, E. P. & $\begin{array}{l}\text { Creatividad es el proceso de ser sensible a los problemas, a las deficiencias, } \\
\text { a las lagunas del conocimiento [...]; de reunir una información válida; de } \\
\text { definir las dificultades e identificar el elemento no válido; de buscar solucio- } \\
\text { nes; de hacer suposiciones o formular hipótesis y modificarlas, si necesario, } \\
\text { perfeccionándolas; y, finalmente, de comunicar los resultados. }\end{array}$ \\
\hline Torre, S. de la & $\begin{array}{l}\text { La creatividad, desde una perspectiva interactiva y psicosocial, se convierte } \\
\text { en motivación en la persona, desafío y persistencia en el proceso, estímulo } \\
\text { en el entorno y satisfacción en el resultado. } \\
\text { Creatividad es dejar una marca personal, institucional o social. } \\
\text { Es hacer algo nuevo para el bien de los demás. } \\
\text { La creatividad es un bien social, una decisión y un desafío futuro, diferen- } \\
\text { ciándose de otros conceptos psicosociales por su carácter alocéntrico, po- } \\
\text { liédrico, ético y constructivo, paradoxal y problemático. }\end{array}$ \\
\hline
\end{tabular}

Tabla 1. Académicos de la creatividad y sus conceptos

Fuente. Tabla elaborada a partir de los conceptos explicitados por Torre (2008).

Es posible observar que reconocidos académicos en el área de la creatividad han presentado diferentes concepciones, que han corroborado para los estudios del área, representando una diversidad de pensamientos. Sin embargo, en un punto, algunas de las diferentes percepciones se cruzan. Las perspectivas interactivas y transformadoras que Csikszentmihalyi, Menchén, Moraes, Torrance y Torre presentan, las cuales aportan con la sociedad contemporánea y post-contemporánea, ya que las instituciones educativas creativas buscan atender a las necesidades humanas, sociales y ambientales, en una dimensión del todo de la vida planetaria, realizando transformaciones en el presente y en el futuro del universo.

Esas concepciones se cruzan en algunos puntos, pero en otros siguen caminos diferentes. Están los que defienden que la creatividad se origina de un único campo, como el ejemplo de la aptitud mental, como dice Bono. Ya, en la concepción de creatividad que Torre y Csikszentmihalyi presentan, la perspectiva es de interactividad. Sin embargo, las divergencias añaden elementos a la cultura presente, aportando para la construcción de contextos y de miradas diferentes, lo que es siempre saludable cuando se trata de investigación.

Los puntos de convergencia - específicamente de Csikszentmihalyi y Torre son los conceptos de que la creatividad no está restringida a la persona, al entorno, o a las organizaciones y, aún menos, que en cada uno de esos campos exista una 
sola cara. Pero hay un complemento de diversos factores y medios que corroboran con el desarrollo creativo.

Según Torre (2005, p. 21), además de estar interconectados - la persona, el entorno, las organizaciones -, existe una multiplicidad de componentes inferenciales que la creatividad considera que "comparte el cerebro y el corazón, el pensamiento y los sentimientos, la razón y la intuición, la actitud y la aptitud".

Es el compartir del todo, que involucra ser, estar, hacer y vivir en una realidad dada y la interpreta y transforma a partir del vivenciar, pues la creatividad se encuentra en las decisiones, acciones e interrelaciones que el ser construye cotidianamente. La tomada de consciencia en relación a la vida, a su entorno, hace con que el ser humano repiense y replanee sus actitudes y laboriosamente aporte con diferentes ideas, para transformar en contextos más dinámicos, colectivos y de vivencia agradable en comunidad.

Para Torre (2005), la creatividad es un atributo personal y social, que puede ser potenciado por la persona y por el entorno estimulante, pues el entorno, que proporciona las condiciones y la libertad para expresarse, imaginar, actuar, es como puertas abiertas al mundo de los sueños, en el que, al ingresar, el aluno se siente autorrealizado. Eso hace con que resplandezca su alegría en el hablar, en relacionarse, convivir y, además de eso, en comunicar sus expresiones, generando el placer por el entorno de estudio, que, en ese caso, no se limita a cuatro paredes, pues es él diverso, dinámico y atractivo.

Además de ese aspecto, el autor se posiciona, en su campo teórico, en relación a la concepción de creatividad que él cree como valor social, al reafirmar: "con relación a la perspectiva psicosocial y socio afectiva, en la cual nos ubicamos, la importancia de la interacción social, la creatividad ha sido destacada, entre otros por T. M. Amabile, A. P. Hare, R. W. Woodman y después por Sternberg y Csikszentmihalyi" (Torre, 2005, p. 82). 
El potencial transformador de la transdisciplinariedad y de la creatividad para la educación contemporánea

Además de estar situado en una visión teórica, "perspectiva interactiva1 y psicosocial" (Torre, 2005, p. 83), él también presenta los académicos que han discutido tal visión de creatividad, convergiendo en algunos puntos y destacando que no se trata de una concepción exclusivamente psicológica.

En esa misma discusión, Ribeiro y Moraes (2014, p. 211) comprenden que Torre concibe la visión psicosocial en una "dimensión que dice respeto, simultáneamente, a la psicología individual y a la vida social, ella termina la tendencia en poner en una red interactiva el 'yo' y el 'otro',2 potenciando la fuerza de los elementos que influyen la naturaleza compleja de la creatividad".

Es percibida una visión que busca conectar y hacer interactuar diferentes contextos, seres y medios para valorar la colectividad, cambiando y transformando culturas que conviertan en bien social. Para Ribeiro y Moraes (2014, p. 211), "esa interacción ocurre en un movimiento dinámico, recursivo y autoeco-organizador, una vez que la acción de uno influencia a de los demás y viceversa, respetándose mutuamente en la condición de autor y coautor del proceso creativo". Ante eso, la interacción entre elementos intrínsecos y extrínsecos complementa la integración de una expresión de la creatividad.

Frente a la multimensionalidad humana en el espacio escolar, la creatividad puede surgir en diversas dimensiones, ya que "la persona creativa es aquella capaz de mirar donde otros ya observaron y ver aquello que ellos no han logrado ver" (Torre, 2005, p. 101). Es volverse y observar con una mirada atenta, como de un investigador que logra ir más allá de lo visto por todos de aquel entorno. Es ver lo implícito, lo oculto, que se revela indirectamente en el habla, en las acciones y en las expresiones. Eso requiere tiempo, reflexión y esfuerzo para ver lo que todavía no ha sido percibido por la comunidad.

La persona creativa, además de ver lo que muchos no podían percibir, transforma su percepción en un bien mayor para el colectivo al que pertenece, por medio de 
ideas, comunicaciones y acciones. Para Csikszentmihalyi (1998, p. 47), la persona creativa "es alguien cuyos pensamientos y actos cambian un campo o establecen un nuevo campo. Es importante recordar, sin embargo, que un campo no puede ser modificado sin el consentimiento explícito o implícito del ámbito responsable de él”.

El autor explicita la importancia del cambio en un contexto, de la transformación de una cultura a partir del reconocimiento de los expertos de aquél campo. Es decir, para ser creativo es importante hacer, por su entorno, algo que sea reconocido como un bien a aquella comunidad. Csikszentmihalyi (1998) reafirma que tales personas se destacan en su comunidad por sus actitudes transformadoras y por el modo con que se adaptan fácilmente a los entornos o a nuevas circunstancias; no se dejan influenciar por las adversidades, pero buscan alcanzar los objetivos propuestos.

Para Torre (2008), todas las personas son capaces de crear, sin embargo, la manifestación de creatividad no es igual en todos, pues, por motivos diversos, no logran expresarse del mismo modo. De ese modo, se puede percibir la importancia de la motivación de naturaleza tanto intrínseca como extrínseca en el escenario educacional, buscando potenciar y florecer la creatividad, ya que nada es obligatorio, es necesario espontaneidad, libertad y placer.

Sobre esa motivación, Torre (2008, p. 108) afirma que "la creatividad es como un grano de trigo, una semilla que, dejada libremente, llega a nacer, pero crece frágil, cuando no salvaje. Solo produce su riqueza cuando es cultivada" Cultivo ese que puede advenir del propio contexto educativo.

La creatividad necesita estar presente más allá del espacio educativo, es necesario ganar el mundo, es decir, estar en las calles, plazas, organizaciones, profesiones, en todas las dimensiones de la sociedad, pues, siendo como algo vivo, necesita estar en la vida (Torre, 2005). En la Escuela Creativa, la creatividad es expresada en todas las dimensiones escolares: diversos espacios, personas, planos, proyectos, planeamientos, objetivos, prácticas pedagógicas en general e intencionalidades. Eso 
El potencial transformador de la transdisciplinariedad y de la creatividad para la educación contemporánea

porque desde su visión hay un diferencial, es posible percibir la importancia de su función social ser, de hecho, direccionada a los valores humanos, ambientales y sociales.

Es importante que esa visión sea motivada constantemente y que haya un entorno también estimulador. De esa forma, Torrance (1974, p. 45) afirma que las "condiciones motivadoras y facilitadoras, ciertamente, tienen un rol en la función creativa". Para ello, los cambios son importantes, desde que comiencen a partir de la mirada que se amplíe de la consciencia de esa necesidad de modificaciones y transforme las clases en más dinamismo e interacción, de forma que los alumnos y toda la comunidad educativa sean partícipes de ese proceso.

Para que fluya la creatividad en un campo complejo de múltiplas dimensiones, es necesario primeramente repensar la propia forma de ver la vida. Es importante percibir que la linealidad no logra contemplar el todo de un contexto. En ese camino, se comprende que el término "creatividad", para Ribeiro y Moraes (2014, p. 91), es "concebido como un fenómeno humano de naturaleza compleja que se manifiesta como urgencia, a partir de procesos autoeco-organizadores, los cuales provocan la búsqueda de niveles más profundos de percepción de la realidad". Y todavía, como resultado, genera transformaciones y auto-transformaciones en ese contexto. Según Torre (2016, p. 490), ese enfoque de creatividad "involucra una mirada compleja e transdisciplinaria que va más allá del cognitivo, del proceso psicológico simple, del producto en si mismo".

En ese sentido, sería posible presentar, como una mirada diferenciada, una perspectiva de creatividad a partir de la interconexión entre la complejidad, transdisciplinariedad y ecoformación, como se muestra en la Figura 1: 


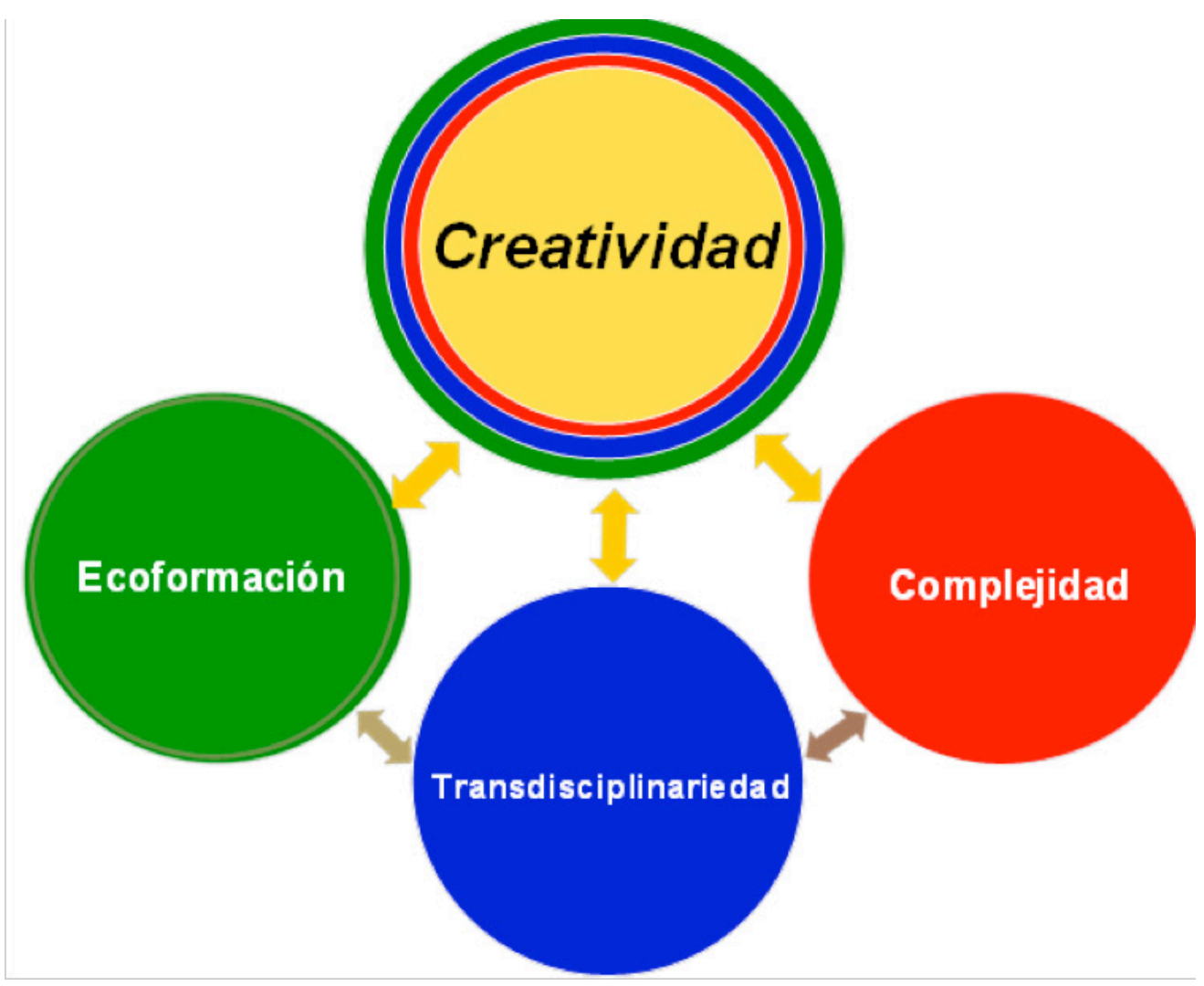

Figura 1. Perspectiva de creatividad a partir de la mirada compleja, transdisciplinaria y ecoformadora. Fuente: (Souza, 2016).

Por lo tanto, comprender la creatividad, en la visión compleja, transdisciplinaria y ecoformadora es percibir el ser humano y el ambiente conectados con el mundo, así como la interconexión entre la vida y el escenario educativo, ya que busca superar las adversidades educacionales para obtener diferentes construcciones del conocimiento; y, todavía, separándose de sus certezas individualistas, para pensar colectivamente, abriéndose a las fruiciones de nuevas ideas.

Considerar las acciones pedagógicas en esa concepción de creatividad es percibirlas com una visión diferenciada, que busca alcanzar objetivos que parten de la vida y tienen resultados para la vida, es decir, que tienen como principio el bien individual, social y planetario (Zwierewicz, 2011). Esa perspectiva creativa camina conectada al pensamiento complejo, a la transdisciplinariedad y a la ecoformación, al comprender que todo está interconectado. Camina por un camino de diferentes miradas, que se integra a la multidimensionalidad y a la multirreferencialidad de la realidad tanto social como personal, de forma complementar y compartida en el ámbito escolar. 
El potencial transformador de la transdisciplinariedad y de la creatividad para la educación contemporánea

En ese sentido, Torre (2005, p. 17) observa que "la creatividad es fruto de la interacción sociocultural y solo será plena cuando engendradas mejorías sociales o culturales"; pues, además de un concepto aislado, es conectada con el ser humano, el planeta, la vida; y el actuar, pensar y crear parten de la dimensión intrínseca conectada a la extrínseca. Por lo tanto, hablar de esa creatividad es comprender a un contexto educativo complejo a favor de una significativa acción social, epistemológica, histórica y cultural, ya que tales dimensiones componen la vida en sociedad.

\subsection{Las interconexiones en el contexto educacio- nal en Escuelas Creativas}

La educación transformadora a partir de la visión transdisciplinaria se presenta de forma abierta a lo nuevo, a la creatividad, y es flexible a los cambios. Torre (2012, p. 60) afirma que, ante a tantas transformaciones, "las instituciones creativas son las que mejor se adaptan al entorno y sobreviven a los cambios acelerados".

Las instituciones se convierten en ejemplos de la materialización de una educación transdisciplinaria cuando están interesadas en ultrapasar una enseñanza tradicional, que prioriza la memorización en vez del acceso, de la profundización, de la construcción y de la difusión de conocimientos que se articulen a las demandas de la realidad. Para Torre (2013, pp. 162-163), son consideradas Escuelas Creativas las que "logran reencantar la educación en los docentes y discentes, al fundir pensamiento, emoción, acción y trascendencia, cuatro conceptos 'reconectados' por medio de la expresión sentipensar". En ese sentido, la propuesta del sentipensar une lo pensar y el sentir en la misma medida, considerando que "no basta conocer para saber, es necesario dar vida, experimentar, es decir, incorporar la dimensión emocional junto a la cognitiva (Sentipensar) en los aprendizajes" (Zwierewicz \& Torre, 2009, p. 157).

Según Torre (2009b), las Escuelas Creativas se mueven por las preguntas que abren los caminos de la interconexión en el escenario educativo. Plantean sobre la forma de agregar al currículo estrategias flexibles, dinamizadas y creativas, y demues- 
tran querer conocer, querer cambiar algo que, desde el punto de vista de quien lo plantea, necesita un nuevo significado.

Las preguntas revelan el deseo de transformaciones a partir de una nueva mirada hacia las prácticas pedagógicas; un pensamiento que va al encuentro de la complejidad y de la transdisciplinariedad, al buscar integraciones al currículo, de forma más abierta a los cambios, ya que "el pensamiento complejo es definido por su capacidad de vincular, integrar e incluir" (Torre, Pujol \& Moraes, 2013, p. 132) diferentes realidades.

Ante esto, se puede ver la perspectiva de la creatividad de las Escuelas Creativas, desde la mirada compleja y transdisciplinaria. Csikszentmihalyi (1998, p. 24) corrobora esa visión, al afirmar que "la creatividad generalmente supone cruzar las fronteras de los".

En esa concepción, las Escuelas Creativas son las que poseen más facilidad de adaptarse a los cambios en su entorno, especialmente cuando son vistas como organizaciones que buscan relacionarse entre si, com un desarrollo colectivo y sistematizado. Perciben al ser humano en su relación con el otro y con la naturaleza, ubicando la complejidad de ese proceso como un importante elemento que contribuye para que sean más flexibles y abiertas a las transformaciones, adaptables y atractivas, convirtiéndose capaces de autodesarrollarse. De ese modo, se abre a la flexibilidad y a la creatividad para también generar condiciones de impulsar o dar un nuevo significado a las transformaciones, pudiendo, incluso, preconizarlas.

Esa creatividad no tiene un valor exclusivamente personal e individualista, pues, como lo afirma Torre (2009a, p. 56), "el concepto de creatividad está evolucionando de consideraciones individualistas a organizativas y sociales". Luego, el autor presenta su percepción de creatividad a partir de la mirada compleja, al referirse a la visión de recursividad (Morin, 2009), afirmando que "la creatividad es causa y efecto al mismo tiempo, cuando ocurre en una organización" (Torre, 2009a, p. 57). 
El potencial transformador de la transdisciplinariedad y de la creatividad para la educación contemporánea

El autor justifica esa comprensión a partir de los estudios de la obra Creatividad, de Csikszentmihalyi (1998), que parte de una visión sistémica de la creatividad.

La Escuela Creativa es impulsada por la educación transdisciplinaria, en la que se permite vivenciar la imprevisibilidad, la contextualidad, la intuición como posibilidades de cambios agregados a su autoorganización, y todavía propicia el pronóstico de dificultades, problemas y posibles soluciones futuras. Es la institución que busca desarrollar colectivamente un trabajo de prevención. Según Menchén Bellón (2012, p. 349), es importante buscar "crear sinergias y trabajar en equipo, aprendiendo unos con los otros y aportando al crecimiento mutuo, mediante una relación de interacción fluida. Lo más importante no es crecer mucho, pero crecer juntos". En esa visión, muchas instituciones educativas han caminado en el sentido de la enseñanza y aprendizaje apuntando a la valoración y transformación de un ser que sea emancipador, transformador e interconectado a la dimensión planetaria.

\section{Consideraciones finales}

La visión de una educación transformadora que la complejidad y la transdiciplinariedad, añadidas a la creatividad, proporciona busca la interconexión del conocimiento - una vez fragmentado - en su práctica educativa, de forma global, creativa y ecoformadora. Para que haya un trabajo transdisciplinario, primero el sujeto necesita ser transdisciplinario.

La transdisciplinariedad va más allá del hacer, es parte del ser, del vivir de modo transdisciplinario. Eso se observa cuando se recuperan los ejes centrales de los resultados del estúdio.

La transdisciplinariedad va más allá de los métodos y conocimientos científicos: busca comprender la dimensión actual en su amplitud y complejidad de ser, al percibir puertas en las disciplinas, para ver puentes entre ellas; al transitar e interconectar 
diversos conocimientos que forman parte de la vida en el planeta y que llevan a darse cuenta, en el contexto analizado, de que cada elemento constitutivo del entorno social, ambiental, humano y cultural, tiene un significado interconectado.

Esta interconexión compone una perspectiva creativa que valora las construcciones colectivas, desde una perspectiva compleja, transdisciplinaria y ecoforma, ya que la complejidad se basa en la visión de construir juntos. Por lo tanto, echar un vistazo al todo no es disociar la ciencia y el otro conocimiento que conforma la vida humana, ambiental y social. De este modo, ser, saber y hacer están interconectados con la conciencia de vivir en sociedad de una manera solidaria y humanista.

Esta mirada social compleja, transdisciplinaria y ecológica, mas humana y diferenciada, que se ocupa de la formación integral del estudiante en su totalidad, en la concepción de Torre (2005), sigue el camino de la creatividad a través de la interactividad entre el ser humano y el medio ambiente: prácticas resignificantes. Para este autor, si la creatividad no tiene como objetivo hacer el bien a sí misma y a su entorno, se pierde en el camino, pierde la sensación de estar insertada en el escenario educativo y, en consecuencia, en la sociedad y la vida. Por lo tanto, en esta concepción de la creatividad, buscamos trascender lo que ya existe, superarlo con la acción creativa de nuevas posibilidades de intervención en la realidad social, especialmente en el escenario educativo.

En este sentido, las Escuelas Creativas proporcionan, desde la transdisciplinariedad y la creatividad, la apreciación de sus construcciones y su identidad, en la que el alumno es protagonista, piensa críticamente y tiene voz en su proceso educativo, porque así será el autor de su propio conocimiento Valoran los planes, proyectos y acciones que están comprometidos con la realidad actual y futura, que cumplen con el ser, la sociedad y la naturaleza en un proceso que no tiene una visión dicotómica de la enseñanza, pudiendo buscar el proceso de unión en una educación compleja en su pensamiento y repensar la vida. 
El potencial transformador de la transdisciplinariedad y de la creatividad para la educación contemporánea

Por lo tanto, la complejidad se materializa metodológicamente, a partir de la transdisciplinariedad que trasciende el ser, saber y hacer a partir de las conexiones con diversos saberes. De este modo, la educación transdisciplinaria proporciona condiciones reflexivas para que las instituciones sean creativas. A la medida que esas instituciones se desarrollan en la búsqueda de un bien común, que se construyen y reconstruyen en un constante transformarse, se abren a las posibilidades que conectan el ser humano, la sociedad y el planeta.

\section{Bibliografía}

CSIIKSZENTMIHALYI, M. (1998). Creatividad: el fluir y la psicologia del descubrimiento y la invención. Barcelona, Espanya: Paidós.

Gil, A. C. Métodos e técnicas de pesquisa social [Métodos y técnicas de investigación social]. (5a ed.). São Paulo: Atlas: 2006.

MaLlaRT, J. I. N. (2009). Ecoformação para a escola do século XXI [Ecoformación para la escuela del siglo XXI]. Zwierewicz, M. \& Torre, S. (Coords.), Uma escola para o século XXI: escolas criativas e resiliência na educação [Una escuela para el siglo XXI: Escuelas Creativas y resiliencia en la educación] (pp. 29-41). Florianópolis, Brasil: Insular.

Menchén Bellón, F. (2012). Criatividade, conceito e perspectivas [Creatividad, conceptos y perspectivas]. Suanno, M. \& Rajadell, N. P. (Orgs.), Didática e formação de professores: perspectivas e inovações [Didáctica y formación de profesores: perspectivas e innovaciones]. Goiânia, Brasil: CEPED. (Entrevista concedida a João Henrique Suanno).

Minayo, M. C. S. Pesquisa social: teoria, método e criatividade [Investigación social: teoría, método y creatividad] (29a ed.). Petrópolis: Vozes, 2010.

MoraEs, M. C. (2015). Transdisciplinaridade, criatividade e educação: fundamentos 
ontológicos e epistemológicos [Transdisciplinariedad, creatividad y educación: fundamentos ontológicos y epistemológicos]. Campinas, Brasil: Papirus.

MoraEs, M. C. (2014). Educação e sustentabilidade: um olhar complexo e transdisciplinar. Moraes [Educación y sostenibilidad: una mirada compleja y transdisciplinaria], M. C. \& Suanno, J. H. (Orgs.), O pensar complexo na educação: sustentabilidade, transdisciplinaridade e criatividade [El pensar complejo en la educación sostenibilidad, transdisciplinariedad y creatividad] (pp. 21-42). Rio de Janeiro, Brasil: Wak.

MoraEs, M. C. (2008). Ecologia dos saberes: complexidade, transdisciplinaridade e educação: novos fundamentos para iluminar novas práticas educacionais [Ecología de Ios saberes: complejidad, transdisciplinariedad y educación: nuevos fundamentos para iluminar nuevas prácticas educativas]. São Paulo, Brasil: WHH (Willis Harman House).

Morin, E. (2015). Ensinar a viver: manifesto para mudar a educação [Enseñar a vivir: manifiesto para cambiar la educación] (E. A. Carvalho \& M. P. Bosco, trads.). Porto Alegre, Brasil: Sulina.

Morin, E. (2009). Educação e complexidade: os sete saberes e outros ensaios [Educación y complejidad: los sietes saberes y otros ensayos]. Almeida, M. C. \& Carvalho, E. A. (Orgs.), Educação e complexidade: os sete saberes e outros ensaios [Educación y complejidad: Ios siete saberes y otros ensayos] (5a ed.), E. A. Carvalho, trad., pp. 1-104). São Paulo, Brasil: Cortez.

Morin, E. (2007). Desafios da transdisciplinaridade e da complexidade [Retos de la transdisciplinariedad y de la complejidad]. Audy, J. L. N. \& MorosinI, M. C. (Orgs.), Inovação e interdisciplinaridade na universidade [Innovación e interdisciplinariedad en la universidad] (pp. 22-28). Porto Alegre, Brasil: DIPUCRS.

Morin, E. (2001). Introdução ao pensamento complexo [Introducción al pensamento complejo) (3a ed.). Lisboa, Portugal: Instituto Piaget. 
El potencial transformador de la transdisciplinariedad y de la creatividad para la educación contemporánea

Nicolescu, B. (2014). From Modernity to Cosmodernity. Science, Culture, and Spirituality [De la modernidad a la cosmodernidad: ciencia, cultura y modernidad]. Nova York, United States: Suny.

Nicolescu, B. (2005). Transdisciplinarity: past, present and future [Transdisciplinariedad: pasado, presente y futuro]. In 2 Congresso Mundial de Transdisciplinaridade. Vila VelhaNitória. Disponível em http://cetrans.com. br/assets/textos/transdisciplinarity-past-present-and-future.pdf.

Nicolescu, B. (1999). O manifesto da transdisciplinaridade [El manifiesto de la transdisciplinariedad] (L. P. Souza, trad.). São Paulo, Brasil: Triom.

Petraglia, I. (2012). Educação e complexidade: os sete saberes na prática pedagógica [Educación y complejidad: Ios siete saberes en la práctica pedagógica]. Moraes, M. C. \& Almeida, M. C. (Orgs.), Os sete saberes necessários à educação do presente: por uma educação transformadora [Los siete saberes necesarios a la educación del presente: por una educación transformadora] (pp. 129-147). Rio de Janeiro, Brasil: Wak.

Ribeiro, O. C., Moraes, M. C. (2014). Criatividade em uma perspectiva transdisciplinar: rompendo crenças, mitos e concepções [Creatividad en una perspectiva transdisciplinaria: rompendo creencias, mitos y concepciones]. Brasília, Brasil: Liber Livro.

SouzA, K. P. Q. (2016). Práticas pedagógicas criativas: uma perspectiva transdisciplinar na escola do século XXI [Prácticas pedagógicas creativas: una perspectiva transdisciplinaria en la escuela del siglo XXI]. (Dissertação de Mestrado). Universidade Federal do Tocantins. Palmas, Brasil.

Sommerman, A. (2011). Complexidade e transdisciplinaridade [Complejidad y transdisciplinariedad]. Terceiro Incluido, 1(1), 77-89, jan./jun. 2011. Artigo 7. ISSN 2237 o79X NUPEAT-IESA-UFG. 
ToRrance, E. P. (1974). Pode-se ensinar criatividade? [¿Es posible enseñar creatividad?]. São Paulo, Brasil: EPU.

TorRe, S. (2016). Entrevista a Marilza Vanessa Rosa Suanno. Polyphonía - RevisTa dE Educação BÁsica do Cepae, (27) 1, jan./jun. 2016, Goiânia, Brasil: UFG.

ToRRE, S. (2013). Movimento de escolas criativas: fazendo parte da história de formação e transformação [Movimiento de escuelas creativas: haciendo parte de la historia de formación y transformación]. ZwEREwICz, M. (Coord.), Criatividade e inovação no ensino superior: experiências latino-americanas e europeias em foco (pp. 141 162) [Creatividad e innovación en la enseñanza superior: experiencias latinoamericanas y europeas en discusión]. Blumenau, Brasil: Nova Letra.

ToRRE, S. (2012). Instituciones educativas creativas: instrumento para valorar el desarrollo de instituciones creativas (VADECRIE). Barcelona, Espanya: Circulo Rojo.

ToRRE, S. (2009a). Escolas criativas: escolas que aprendem, criam e inovam (Escuelas Creativas: escuelas que aprenden, crean e innovan]. Zwirewicz, M. \& Torre, S. (Coords.), Uma escola para o século XXI: escolas criativas e resiliência na educação [Una escuela para el siglo XXI: Escuelas creativas y resiliencia en la educación] (pp. 55-69). Florianópolis, Brasil: Insular.

ToRrE, S. (2009b). Rede de escolas criativas: em direção a uma escola do século XXI [Red de Escuelas Creativas: rumbo a una escuela del siglo XXI]. Zwirewicz, M. \& Torre, S. (Coords.), Uma escola para o século XXI: escolas criativas e resiliência na educação [Una escuela para el siglo XXI: Escuelas creativas y resiliencia en la educación] (pp. 101-116). Florianópolis, Brasil: Insular.

TORRE, S. (2008). Criatividade aplicada: recursos para uma formação criativa [Creatividad aplicada: recursos para una formación creativa]. Tradução de WIT Languages. São Paulo, Brasil: Madras. 
El potencial transformador de la transdisciplinariedad y de la creatividad para la educación contemporánea

ToRRE, S. (2005). Dialogando com a criatividade [Dialogando con la creatividad]. Tradução de Cristina Mendes Rodríguez. São Paulo, Brasil: Madras.

Torre, S., Moraes, M. C., Tejada, J., Pujol, M. A., Morin, E., Motta, R., Pineau, G., Ciurana, E. R., \& Mallart, J. (2008). Decálogo sobre transdisciplinaridade e ecoformação [Decálogo sobre transdisciplinariedad y ecoformación]. TorRe, S., PujoL, M. A. \& MoraEs, M. C. (Orgs.), Transdisciplinaridade e ecoformação: um novo olhar sobre a educação [Transdisciplinariedad y ecoformación: una nueva mirada sobre la educación] (S. Vidigal, trad., pp. 21-59). São Paulo, Brasil: Triom.

Torre, S., Pujol, M. A., \& Moraes, M. C. (Orgs.). (2013). Documentos para transformar a educação: um olhar complexo e transdisciplinar [Documentos para transformar la educación: una mirada compleja y transdisciplinaria]. Rio de Janeiro, Brasil: Wak.

Zmeremicz, M., \& Torre, S. (Coords.). (2009). Uma escola para o século XXI: escolas criativas e resiliência na educação [Una escuela para el siglo XXI: Escuelas creativas y resiliencia en la educación]. Florianópolis, Brasil: Insular.

ZWEREMICZ, M. (2011). Formação docente transdisciplinar na metodologia dos projetos criativos ecoformadores - PCE [Formación docente trandisciplinaria en la metodologia de los Proyectos Creativos Ecoformdores - PCE]. Torre, S., ZWIEREMICZ, M. \& Furlanetto, E. C. (Org.). Formação docente e pesquisa transdisciplinar - criar e inovar com outra consciência [Formación docente e investigación transdisciplinaria - crear e innovar con otra consciencia] (pp. 141-158). Blumenau, Brasil: Nova Letra. 


\title{
Creatividad \\ y Sociedad
}

Creatividad y educación

no 32 - enero 2020

\section{Artes y artesanías: Un encuentro creativo - pedagógico}

\section{Arts\&Crafts: A creative-pedagogical meeting}

\author{
Carlota Rodríguez Silva \\ Universitat de Barcelona \\ rodriguezsilvacarlota@gmail.com \\ https://orcid.org/0000-0002-8507-1232
}


Resumen

Siguiendo otras obras con líneas temáticas similares ${ }^{1}$ y publicaciones anteriores en la Revista Creatividad y Sociedad ${ }^{2}$, el texto presenta una experiencia vivida en un aula de clases extraescolares de Arts\&Crafts, a través de un relato, el cual vertebra el sentido de este producto. Así, en el cuerpo del texto se presentan una serie de reflexiones pedagógicas a raíz de lo que se genera en esta experiencia (el tiempo, el espacio, los materiales), articulándolas desde la tríada creatividad-educación-salud como tierra fértil para co-construir un aula inclusiva y para enriquecer tanto la experiencia educativa como el oficio docente.

\section{Palabras clave}

Actividades extraescolares · Artes · Creatividad - Educación · Salud

\section{Abstract}

Following some other works in similar topics and some previous publications in this Creativity and Society Journal, the text introduces an experience lived in a classroom of Arts\&Crafts' after-school activities, through a narration which articulates the meaning of this product. So, in the body of the text there are presented some pedagogical considerations in the wake of what has been generated in this experience (the time, the space, the materials), articulating them from the triad creativity-education-health as fertile land to co-create an inclusive classroom and enrich the educational as much as teaching craft.

\section{Key words}

After-school activities · Arts · Creativity

- Education · Health

1 Pujol, M. A., De la Torre, S. y Lorenzo, N. (Coords). (2014). Escuelas y aulas creativas. Reflexiones y experiencias. Barcelona: Institut de Ciències de l'Educació-Universitat de Barcelona. Recuperado de http://diposit.ub.edu/dspace/handle/2445/62186

2 Morales, J. G. (Coord.). (Septiembre de 2013). Creatividad y arte. Creatividad y Sociedad. Revista de la Asociación para la Creatividad (20). Recuperado de http://www.creatividadysociedad.com/numeros/cys20.html

Pérez, A. (Coord.). (Diciembre de 2013). Creatividad y educación. Creatividad y Sociedad. Revista de la Asociación para la Creatividad (21). Recuperado de http://www.creatividadysociedad.com/numeros/cys21.html 


\section{Introducción}

En el presente artículo se articulan una serie de reflexiones sobre la atención y el cuidado del tiempo y el espacio de las clases extraescolares, tejidas a través del significado y el sentido de un relato sobre un momento concreto en una clase concreta de la materia de Arts\&Crafts. En primer lugar, se encontrarán los objetivos y la metodología del texto, para dar paso a la presentación del contexto educativo y el planteamiento de las actividades extraescolares desde donde se habla, introduciendo la especificidad de la experiencia vivida que se relatará más tarde. Este apartado enlaza con la descripción sobre cómo se plantean las clases desde este lugar, conjugándola con reflexiones pedagógicas sobre este planteamiento y pensándolas con la tríada creatividad-educación-salud. Para ello, se entra al aula a través de una fotografía que abre ese espacio-tiempo concreto del que se habla, ya que es la parte central que teje la totalidad del presente artículo. Siguiendo este punto, se encuentra el apartado 'Un encuentro creativo-pedagógico' en el que se despliega el relato pedagógico que da sentido a las reflexiones que se van conjugando. Por último, se llegan a unas conclusiones sobre la experiencia vivida, los movimientos pedagógicos relatados y las reflexiones que se han ido desprendiendo de los mismos.

Si bien se ha elaborado una búsqueda de investigaciones en torno a las actividades extraescolares en el contexto estatal, se ha detectado que - prestando atención a aquellos que versan sobre la Educación Primaria, ya que es la etapa vital en la cual se enmarca la experiencia educativa que se trae a colación - los estudios se estructuran en torno a cuestiones como el rendimiento escolar o la procrastinación académica en estudiantes que asisten a dichas clases. Así mismo, también hay un gran volumen de investigaciones que abordan la noción de salud desde las actividades extraescolares, centrándose en aquellas que se articulan en base a la actividad física y el deporte. Como propuesta complementaria a los textos ya existentes, se presenta este artículo que expone aquello que tiene que ver con las sesiones extraescolares en relación a Arts\&Crafts y los movimientos pedagógicos que de ellas nacieron, con especial atención al tiempo y el espacio que ellas mismas encarnan y las complejidades que se desprenden de las mismas. 


\section{Objetivo}

El objetivo del presente texto es compartir las reflexiones pedagógicas que devienen de una experiencia educativa vivida en un aula de Arts\&Crafts, a través de un relato que teje el nudo de significados y de movimientos que se exponen en relación al mismo, pensando dicha experiencia con la tríada creatividad-educación-salud.

\section{Método}

En relación al planteamiento metodológico de este artículo, pese a no tratarse de una investigación y, por tanto, no se pueda hablar de un método o metodologías al uso, se ha elaborado este texto desde el siguiente paradigma: el método como estrategia, guía, en la que nos apoyamos para construir el proceso de indagación, el cual nos ofrece movimientos y alternativas, así como el abrirse a lo inesperado. En palabras de Morin, Roger y Motta (2003, p. 18) "el método como camino, como ensayo generativo y estrategia «para» y «del» pensamiento. El método como una actividad pensante del sujeto viviente, no abstracto. Un sujeto capaz de aprender, inventar y crear «en» y "durante» el caminar." Por tanto, en este sentido, tendría más que ver con la mirada cualitativa del mundo.

Siguiendo esta misma línea de pensamiento, Larrosa (2016) habla sobre la experiencia como aquello que "es atención, escucha, apertura, disponibilidad, sensibilidad, vulnerabilidad, ex/posición." (p. 38). El autor también nos habla de la experiencia así: "La experiencia suena a finitud. Es decir, a un tiempo y a un espacio particular, limitado, contingente, finito." (p. 41). Aquí también añade que quizás hablar sobre la experiencia sea también hablar sobre un modo de habitar los tiempos y los espacios educativos, "unos espacios que podemos habitar como expertos, como especialistas, como profesionales, como críticos. Pero que, sin duda, habitamos también como sujetos de experiencia. Abiertos, vulnerables, sensibles, temblorosos, de carne y hueso." (pp. 41-42). Por tanto, se constituye el cuerpo del texto en base 
a estas consideraciones metodológicas, sobre el ex/poner una experiencia vivida y socializarla, con el ánimo de seguir pensando con ella el oficio docente.

\section{El contexto educativo}

En este apartado se desglosan aquellas cuestiones que formulan el contexto educativo específico del que se habla: la escuela, las actividades extraescolares, el grupo y la dinámica del aula. Este apartado pretende ofrecer una contextualización profunda del marco educativo, social, cultural y organizativo en el que se enmarcan las actividades extraescolares de Arts\&Crafts.

\subsection{La escuela}

La actividad extraescolar, que se presenta en el cuerpo de este texto y en el relato, sucede en el ámbito de los colegios concertados, que presentan una realidad distinta a la de las instituciones públicas. Las escuelas concertadas son aquellos centros escolares cuya administración es privada, pero la financiación es mayoritariamente pública, con puntuales contribuciones por parte de las madres y los padres cuyas hijas e hijos1 acuden a estudiar al centro. Por tanto, se posicionan como el 'intermedio' entre las escuelas públicas y las privadas. En concreto, la escuela que se presenta está localizada en la ciudad de Barcelona, en la zona de l'Eixample (o Ensanche).

En este centro se ofrecen un paquete de actividades extraescolares variadas, que devienen de una contratación a una empresa privada y externa, que es quien se encarga de hacer las propuestas educativas y la contratación del personal, el abastecimiento y la distribución del material, y demás operaciones para que las extraescolares tengan lugar. En estas actividades, la persona a cargo del aula debe presentar rendición de cuentas, cubriendo y entregando informes de seguimiento, así como evaluar el progreso de los estudiantes en la materia que se pone en juego, entre- 
gando esta evaluación al terminar el trimestre con las calificaciones a los estudiantes. Por tanto, pese a ampararse en un marco de lo no-lectivo, presenta unas estructuras lógicas propias también del sistema educativo público en el contexto estatal.

Las actividades ocurren dentro del propio centro escolar, pero es un tiempo del que se ocupa el personal que "viene de fuera". Tanto la administración en general, como el personal que ejecuta las actividades tanto a nivel administrativo como técnico, la selección y contratación del profesorado, o el material del que se dispone, son relativos a la empresa privada y a la relación que se promueve entre la empresa y la escuela y la comunicación que entre ellas exista. No obstante, también existe otro nivel, que se corresponde con la comunicación de la empresa y familias, llevándola a cabo a través de reuniones iniciales y periódicas en los niveles administrativos, o mediante el profesorado a cargo de las actividades y las propias familias. Es decir, intervienen diversos actores educativos en la ejecución de estas actividades que se presentan en el texto, por tanto, todos ellos resultan fundamentales para la activación y la consecución de las clases extraescolares.

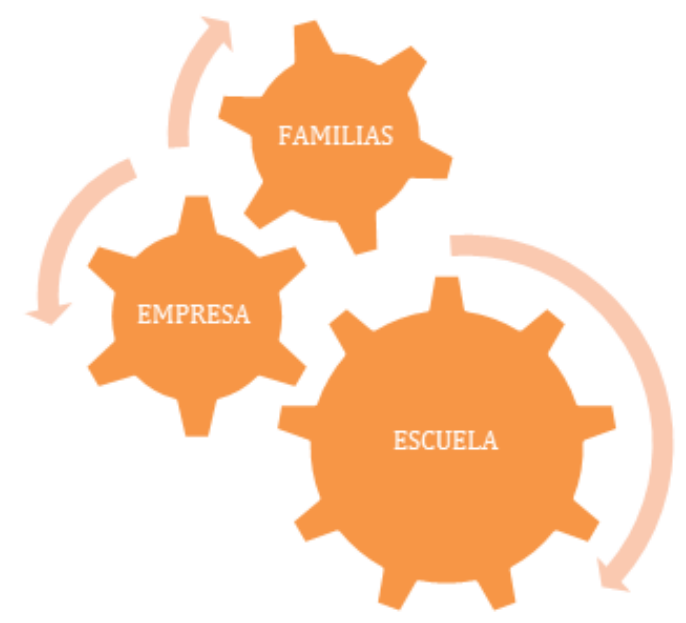

Figura 1. Relaciones entre los agentes educativos para la ejecución de las actividades extraescolares. (Elaboración propia)

Por tanto, si pensamos estas relaciones como un engranaje, todas ellas son piezas fundamentales para que las actividades extraescolares ocurran, habiendo entre ellas relaciones que establecen y determinan la ejecución de las clases. 


\subsection{Las actividades extraescolares}

Y, ahora bien, ¿a qué hacemos referencia cuándo hablamos de actividades extraescolares? Esta cuestión resulta vital, ya que manifiesta la contingencia de la experiencia y la reflexión sobre la praxis pedagógica que deviene de la misma. En el caso de la experiencia concreta que se expone, la actividad extraescolar está entendida como aquella actividad "fuera" del horario lectivo de la escuela y que es, supuestamente, de libre elección. Estas pertenecen a un tiempo muy específico, aquel tiempo disponible institucionalizado del que habla Trilla (1998, p. 43) y que define de la siguiente manera: "tiempo que los niños tienen comprometido con otra institución y bajo la custodia de adultos que asumen un rol específicamente educativo." En un intento por completar esa noción, parece pertinente traer a colación a Rodríguez (1978), quien desarrolla un análisis de la palabra extraescolar, la cual está constituida de dos partes, el 'extra' y 'escolar' y que juega con una doble significación del prefijo 'extra':

La primera "fuera de" hace referencia a un tiempo y un espacio, la segunda "además de" igualmente hace referencia a un tiempo y un contenido. Cuando con el "fuera de" hace referencia al tiempo, está claro que se trata de una actividad fuera del tiempo escolar, fuera del horario, fuera del tiempo previsto para desarrollar las áreas y los distintos programas. [...] Al referirnos a la otra acepción del prefijo "además de", también hacemos referencia al tiempo en el sentido de ser algo que va a ocupar un tiempo "sobre" el que nos ocupa la actividad propiamente escolar. (Rodríguez, 1978, p. 14)

Bajo las definiciones anteriores, parece que el significado de 'actividad extraescolar' queda vislumbrado. En el contexto estatal, se han llevado a cabo diferentes estudios que abordan la cuestión de las actividades extraescolares, desde Educación Infantil a la Educación Secundaria Obligatoria. No obstante, centrándonos en la etapa de Educación Primaria, que es la que nos interesa para esta experiencia - ya que el grupo de estudiantes del que se habla pertenecía al primer ciclo de Educación Primaria - es importante destacar que estas investigaciones se han centrado en cuestiones tales como el rendimiento académico (Carmona, Sánchez y Bakieva, 
2011; Cladellas, Clariana, Badía y Gotzens, 2013, entre otras) o la procrastinación académica (Clariana, Cladellas, Gotzens, Badia y Dezcallar, 2014, entre otras) en relación a los estudiantes que están inscritos a dichas actividades. Así mismo, también existe un amplio abanico de estudios sobre las actividades extraescolares en relación a la actividad física, y por tanto sobre la noción de salud (Hernández y Conejo, 2010; Plaza, Jové, Hernández y Reverter, 2013; Arufe-Giráldez, Chachón, Zurita, Lara y Castro, 2017; Vivo, Valero-Valenzuela y Manzano, 2018, entre otros). Por otra parte, también existen investigaciones precedentes sobre la relación entre la creatividad y las sesiones extraescolares (Alfonso-Benlliure y Valadez, 2013). A colación de las mismas, quizás sería interesante estudiar la figura que encarnan los docentes en ellas o cómo se relacionan las estudiantes con la figura de la maestra o el maestro de las clases extraescolares, o si existen diferencias entre esta figura y la del profesorado de la escuela, quizás abriendo nuevas vías en las investigaciones sobre la temática que aquí se aborda.

\subsection{El grupo}

En relación a una de las aclaraciones anteriores, el grupo de aula sobre el que gira el relato pedagógico era un grupo de Educación Primaria. Estaba compuesto por una totalidad de 9 estudiantes, de los cuales 8 pertenecían a $2^{\circ}$ EP y 1 a $1^{\circ}$ EP. Aunque parezca mínima esta diferencia, a la hora de ejecutar las manipulaciones para elaborar nuestras manualidades, era una diferencia notable, que hacía que este niño se frustrase por la comparación que él realizaba con sus compañeras y compañeros.

Así mismo, 5 de los estudiantes se reconocían como niños y 4 como niñas. En el grupo también existían diferencias culturales, ya que dos de los estudiantes provenían de una familia china - quienes a menudo se comunicaban en chino en la clase - y una de las estudiantes de una familia multicultural, con raíces rusas. El resto provenían de familias catalanas. Pese a estas amalgamas, ninguno de los niños ni de las niñas poseían dificultades para comunicarse en castellano y/o catalán. En 
cuanto al inglés, existía una notable diferencia en las posibilidades enunciativas y comprensivas de cada una, pero esto mismo era uno de los objetivos principales de las sesiones.

\subsection{La dinámica del aula}

Las clases extraescolares de Arts\&Crafts tenían lugar una vez por semana, durante una hora. En esta hora, se desarrollan las siguientes acciones:

Recogida de los niños y las niñas en el patio, con la asignación de un número en inglés, según su progresiva llegada. Esta recogida siempre iba aparejada a un recibimiento cálido, con abrazos y caricias, atendiendo también a las conversaciones que aquí se abrían. (Qué tal les había ido el día, cómo se sentían, si tenían ganas de hacer cosas hoy...)

Subida al aula, procurando conservar el orden asignado y cuidar la transición de un tiempo a otro. En ocasiones, el control de esta situación resultaba un poco difícil, ya que a esta hora convergen todas las estudiantes de la escuela terminando el horario escolar.

Elección del sitio que se decidía ocupar ese día, en un intento por fomentar la autonomía y la libertad de los cuerpos en el aula, así como respetar los sentimientos y las emociones de los estudiantes. (Una cuestión a la que se alude en el relato).

Toma de la merienda, mientras se escucha música relajante adaptada a su edad. Este momento inicial también servía para la apertura de la sesión, retomando lo elaborado en la clase anterior y explicando la propuesta para la tarea actual. 
- Explicación de la obra, la autora o autor y el vocabulario relacionado con la actividad.

Realización de la tarea.

- Recogida de material y del aula.

- Autoevaluación del comportamiento en la sesión y regulación emocional en asamblea. Este punto se lleva a cabo a través de un semáforo de la conducta, diseñado con los siguientes colores y mensajes:

$\square$ Verde $\longrightarrow$ Great job!

Amarillo $\longrightarrow$ Good day!

$\square$ Naranja $\longrightarrow$ Think about it...

$\square$ Rojo $\longrightarrow$ Parental contact.

- Repaso final sobre el vocabulario de la sesión y la actividad a elaborar.

- Entrega de las estudiantes a las personas encargadas de recogerlas a la salida de la escuela o a los monitores que las acompañan hasta que las puedan venir a recoger.

Las unidades didácticas varían en objetivos y contenidos y, por tanto, actividades. A nivel general, se propone una actividad que articula una serie de conocimientos (tanto a nivel lingüístico, es decir, el vocabulario relacionado con la misma, como a nivel artístico, es decir, abarcando diferentes artistas y movimientos). En este sentido, se propone un aprendizaje que conecta la teoría con la práctica, a través del desarrollo de actividades manuales que se relacionan con el movimiento o el artista o, como 
se expondrá en el relato, con una época o festividad señalada. En este caso, también se acompaña de imágenes o vídeos que introducen a los estudiantes en el mundo a explorar. Por ejemplo, en la sesión del drac de Sant Jordi, se presentó un vídeo de animación en inglés que cuenta la historia de San Jorge, la princesa y el dragón.2

\section{Artes y artesanías}

Lo mismo que Georgia O'Keeffe, cada uno de nosotros es el creador o artífice de su propia vida. Se puede emular a otros, vivir para agradar a los demás o descubrir aquello que es único y de valía para nosotros y, plasmarlo, llegar a ser eso. Esta tarea dura de por vida. (Carl Rogers, 1986, p.55)

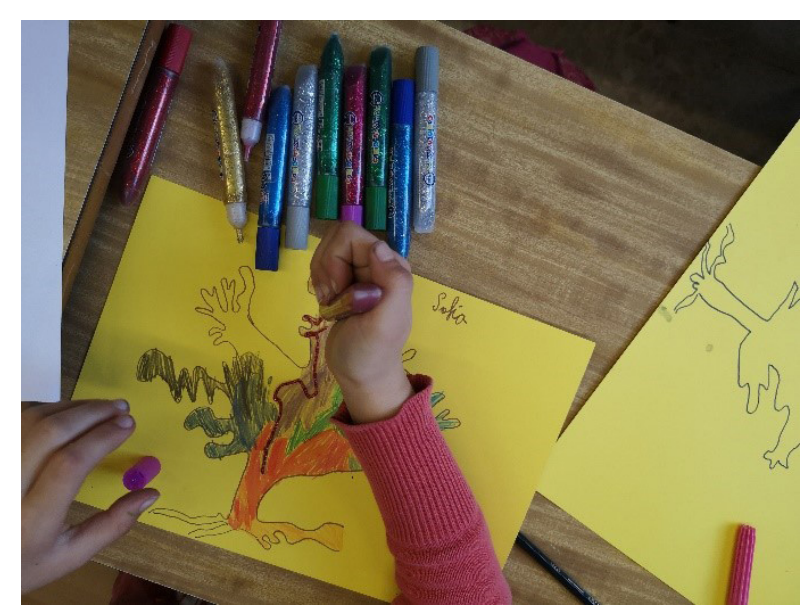

Figura 2. El árbol de la vida de Sofía. (Basado en Gustav Klimt, 1909. Fotografía propia)
Hablemos del árbol de la vida de Sofía, del de Klimt, del de Dani. Hablemos del mío o del tuyo. Hablemos de lo que tenemos en común, que es lo que nos ha traído hasta aquí, que no es más ni menos que el sentido de la creatividad, de la educación o de la salud. Hablemos de

cómo estas dimensiones vitales toman sentido - o cómo pueden tomarlo, no tan solo de manera exclusiva - a través del ejercicio de las artes y la artesanía. Robinson (2015, p. 272) escribe que "la vida de la mayoría de las personas no sigue una línea recta. La gente suele tomar rumbos inesperados, descubre nuevos intereses o aprovecha oportunidades inesperadas", por ejemplo, como las ramas y las raíces de los árboles. 
Una de esas raíces podría ser aclarar la noción que gatilla el texto: ¿qué es eso de Arts\&Crafts? Es la práctica de artes plásticas que se entiende como una manera de que las más pequeñas desarrollen su gusto por las manualidades y la producción de imitaciones de ciertas obras famosas o propuestas creativo-lúdicas. No obstante, el objetivo principal de la actividad extraescolar es el aprendizaje de la lengua extranjera, inglés, de una forma que resulta más atractiva y entretenida para los niños y las niñas. Por lo tanto, resulta conveniente preparar el vocabulario relacionado con la actividad, presentarlo, repasarlo y ponerlo en práctica a través de las manualidades que se confeccionan, así como la comunicación con las pequeñas y las consignas básicas en las dinámicas del aula: "Can I go to the toilet, please?" "Teacher, can you help me?" "Can I borrow that pencil?" Desde este punto de vista, se proponen estas sesiones como un espacio de aprendizaje interdisciplinar, un camino para el aprendizaje del inglés, como lengua extranjera y madre del movimiento que da nombre a la materia, y lo relacionado con la elaboración de proyectos en el marco de las artes y artesanías.

El movimiento de Arts\&Crafts es conocido por haber nacido en Gran Bretaña en un sentido reaccionario a la industrialización y a la mecanización de las ocupaciones laborales (dejando de ser oficios para convertirse en engranajes de una maquinaria). Esto supone una contradicción en sí misma, ya que la concepción de las actividades se basa en la producción de manualidades prácticamente en serie, como en The Factory3 (aunque esto no aplica exclusivamente a las propuestas desde dicho ámbito, ya que es una práctica común en los centros escolares). Y aquí parece conveniente preguntarse: ¿cuál es el sentido, entonces, de esta oferta educativa? ¿Podríamos hablar realmente entonces de creatividad, tal y como se acostumbra a hacerlo en relación a estas prácticas? Marín (2000) p. 416 asegura que "Copia, monotonía, reiteración o inexpresividad son términos totalmente contradictorios con el mundo del arte, cuyo atractivo radica en ser siempre nuevo, original y sorprendente."

Al hilo de los anteriores pensamientos, la siguiente metáfora, convenientemente hilada sobre la industrialización, el sistema educativo y la salud: 
La industrialización puede causar un enorme deterioro del medio ambiente. [...] Las substancias químicas y los productos de desecho se vierten en ríos y mares, lo cual contamina el medio ambiente y daña los ecosistemas delicados. El humo de fábricas y motores satura la atmósfera y provoca numerosos problemas de salud a las personas que lo respiran. (Robinson, 2015, p. 73)

Así mismo, conviene aclarar que en el presente texto se entiende la noción de salud siguiendo la reformulación de la Organización Mundial de la Salud en 1946 (OMS en Violant, Molina y Pastor, 2011, p. 21-23), y, por lo tanto, diríamos que la salud es una condición dinámica, que implica un bienestar en distintos niveles (abarcando desde el físico y el mental hasta el social -y creo que incluso podríamos decir el espiritual) y, por tanto, un concepto complejo, entendido desde lo integral que atinge a lo objetivo (por ejemplo, el funcionamiento físico) y a lo subjetivo (por ejemplo, las percepciones y los sentimientos), a la relación entre lo individual y lo social y que también implica una dimensión ecológica (relación entre las personas y el medio ambiente).

Si nos relacionamos con la noción de la salud desde aquí, parece guardar un estrecho vínculo con la educación en tanto que espacio pedagógico en el que desarrollar comportamientos, hábitos y relaciones sanas, (con una misma, con las demás y con el mundo) donde se respeten las necesidades individuales y colectivas. Y, así mismo, entendiendo la educación, la escuela, el aula, como expresiones mínimas de la sociedad y el lugar donde se producen y reproducen las condiciones y características sociales de la comunidad donde se encuentran inmersas. "La escuela debe responsabilizarse de la trasmisión de aprendizajes relacionados con la adquisición de habilidades para la vida, y específicamente para el bienestar y la salud." Violant, Molina y Pastor, 2011, p. 127). 
Desde esta perspectiva, parece ser evidente el vínculo que alberga la tríada creatividad-educación-salud. En este sentido, también existen voces que han reparado en el beneficio de la creatividad y su exploración en lo educativo para la salud (Mitjáns, 2002; Violant, 2006), ya no tan solo como medidas curativas o terapéuticas, como, por ejemplo, desde el campo de la arteterapia, sino como la posibilidad-de-ser y posibilidad-de-hacer que proporciona bienestar y felicidad. En palabras del maestro Csikszentmihalyi (1998, p. 153): "El vínculo entre el fluir y la felicidad depende de si la actividad que produce el fluir es compleja, de si conduce a nuevos retos y, por tanto, a un crecimiento tanto personal como cultural."

Todo ello me lleva a cuestionar lo siguiente: ¿Cómo se plantean las actividades extraescolares desde aquí? ¿Existe un interés real por el bienestar del niño y de la niña en el espacio-tiempo al que hacemos referencia? ¿Están las actividades diseñadas y propuestas para que exista un desarrollo personal y colectivo en torno a lo educativo? En el caso específico de Arts\&Crafts, ¿hay una pedagogía en la materia que abogue por un ejercicio realmente creativo y que fomente la salud de las niñas y los niños? ¿Estamos ante un acto educativo real o tan solo ante un espacio-tiempo que mantenga 'entretenidas' a estas criaturas? Quizás algunas palabras que arrojan luz a esta cuestión: "La creatividad puede ser una capacidad, una habilidad, una técnica, un proceso, un resultado, un objetivo o un método, pero también un valor educativo." (De la Torre, 2006, p. 256). Una de las cosas que yo he aprendido en compañía de las niñas y los niños del siguiente relato, es que, al final, independientemente de cómo se elaboren las propuestas, la vida en el aula siempre se acaba imponiendo.

\subsection{Un encuentro creativo-pedagógico}

Creo que la verdadera creatividad no es una técnica ni una materia, sino un modo de enseñar, una actitud, una disponibilidad básica que se funda en la confianza en los demás. [...] Educar el dibujo significa respetar, ayudar, descubrir juntos: entonces el niño hará cosas estupendas. (Francesco Tonucci, 1979, p.101) 
A continuación, se expone el relato pedagógico4 que vertebra el sentido del presente artículo, el cual narra la experiencia vivida en mi última sesión en el aula con el grupo de Arts\&Crafts. No obstante, antes de iniciar la lectura, unas palabras de Betancourt (2006, p. 201) "La creatividad es encuentro: surge en muchas ocasiones como encuentro combinatorio."

\section{verde dragón, mano dragón}

Tras muchas tardes compartidas, llegó el momento de decir adéu, goodbye a esta aventura. Una más de las emprendidas en el presente año. Esa tarde, como siempre, fui a buscarlas a nuestra esquina del patio. Un patio de colores verdes y grises, con un gran árbol pintado en una pared y la cara de un señor que nunca he sabido quién es - probablemente una figura conocida en Cataluña-. Llegaron, me abrazaron, me contaron algunas cosas y me enseñaron otras. Les asigné sus números para hoy y los dejé con Carla mientras me encaminé al patio pequeño para recoger a Yuan, porque es muy pequeñito para venir él solo y se aboga por una menor autonomía con las más pequeñas.

Ya el día anterior terminando la actividad de Georgia O'Keeffe, les había presentado a Carla y les había mentido diciéndoles que estaría con nosotras para ayudarnos, como una nueva amiga, una nueva profesora. Digamos que mi excusa es la de no robarles su protagonismo, no robarle el protagonismo a la materia, no robarle el protagonismo a nuestro espacio-tiempo en el aula, que era nuestro tan solo por una hora. Porque lo importante no soy yo, no son mis circunstancias, ni siquiera lo más importante son cada una de ellas desde el sentido más individualista, lo importante somos nosotras en ese espacio y en ese momento en concreto, lo que hacemos de ese espacio-tiempo, lo que tenemos, precisamente, entre las manos. 
Para ese día ya había programado y planificado la actividad, que tomó un sentido y un significado mucho menos liviano de lo que en un primer momento había pensado. Llegamos a nuestra aula, a nuestro espacio-tiempo, le di al 'play' como cada día para escuchar algo de música relajante, y hablamos un poco de lo que había pensado para ese día y cómo lo haríamos. Les repartí la materialidad para ello: las cartulinas y los colores. Ocupé la mesa del fondo, contra la pared, al lado de Dani, quien había decidido ese día corporeizar ese espacio, un poco más alejado de sus compañeras que de costumbre. Dani y yo fuimos las primeras en interactuar con la pintura verde que dispuse a mi izquierda.

Le cogí su manito y la recorrí con el pincel, dejando de ser una parte de su cuerpo para convertirse en el drac de Sant Jordi. Luego presionamos el dragón cuidadosamente contra la cartulina de color amarillo que Dani había elegido. Sus colores preferidos siempre fueron el azul, el amarillo y el verde. Igual que Pau tiene una especial relación con el naranja, igual que Dalai con las tonalidades violetas y rosas, igual que Marc con el azul y el rojo agratanado, como buen blaugrana. Y fue así como, una a una, convertimos sus manos en cuerpos de dragón, en los cuerpos del dragón de Sant Jordi. Fue así como fui despidiéndome silenciosamente, acallando el amor, una a una de esas personitas que tan inconscientemente me habían brindado la oportunidad de ser-con-ellas.

Esta exposición abre el hilo para pensar varias cuestiones pedagógicas. No obstante, empecemos con la figura central del relato: Dani. Dani es un niño que se calma mucho o se frustra mucho según las actividades que se traigan al aula, dependiendo de lo agitado que se encuentre su mundo interior ese día. Es una cuestión a la que hay que poner especial atención y cuidado, algo que hay que tener siempre en mente cuando se está preparando una actividad.5 De la misma manera que hay 
que escuchar las necesidades de Dani y del resto de sus compañeras, también es importante hacerlo con las necesidades del docente, ya que sobre esta cuestión no se recibió información, ni mucho menos formación, denotando así, el compromiso educativo y ético del cuidado a los momentos pedagógicos fuera del currículo académico escolar. Por lo tanto, también se provoca un posicionamiento muy concreto de la figura de la maestra que "viene de fuera", comprometiéndonos directamente en cómo nos relacionamos con la noción de esa figura y de ese espacio-tiempo que se comparte con las niñas y los niños. Así es que hablamos sobre la creación del vínculo, el encuentro con el otro en el acto educativo, el cuidado y la atención a las necesidades del otro, para sentirnos una parte más en la comunidad y, a la vez, una parte especial, importante, de la misma.

Todos y cada uno de nosotros necesitamos sentirnos queridos, ser parte importante de un entorno. En situaciones adversas, esta búsqueda del hombre se ve incrementada y la sensación de ser querido se convierte en estímulo y a la vez, en apoyo para enfrentar situaciones difíciles. (Castillo en Violant, 2019, p.81)

Ya no solo hablamos aquí, por tanto, de atención y cuidado, sino que estamos hablando de la posibilidad de los afectos y, entonces, estamos hablando de una pedagogía de la disponibilidad, de la escucha, del vínculo. ¿No es la creatividad la materia más fecunda para enredarnos en el oficio educativo desde el amor y el afecto? ¿No estamos hablando de ofrecer posibilidades-de-ser en el aula en el devenir del ejercicio creativo? ¿No es el encuentro creativo-pedagógico lo que siembra la raíz del aprendizaje genuino, aportando bienestar físico y emocional para el ser-humano? Por otra parte, al mismo tiempo que se pone una especial atención y cuidado en lo que una decide traer al aula y en el cómo hacerlo, bajo la responsabilidad y el compromiso pedagógicos, también es vital poner esa atención y ese cuidado al espacio que se habita y a las propuestas que este ofrece, en pocas ocasiones, inintencionadamente. Como apunta De la Torre (2012, p.264), en lo que corresponde a la tarea del profesor creativo: "La clave reside en crear espacios de libertad y reconocer esa 
creatividad espontánea de sus estudiantes." Y yo me pregunto cómo hacerlo cuando, por ejemplo, entre otras cosas, el aula mide no más que tres metros de ancho, los cuales están ocupados por una cantidad de sillas y mesas innecesarias, además de un tamaño inadecuado para los cuerpos de personas de 5 y 6 años, lo cual también incide en sus posturas, en su concentración o en su relación y emoción con el aula, entre otras cosas que seguro todavía se me escapan. "Los muebles pueden convertirse en verdaderos dinosaurios reductores de movimiento que bloquean el cuerpo. Ciertos enseres pueden empequeñecer, limitar y enclaustrar el espacio en el que se habita." (López, 2018, p.78)

Así se evidencia uno de los elementos a los que no se atiende, por lo general, en las escuelas, y, por lo concreto, en relación a las sesiones extraescolares, en las que normalmente se prioriza la disponibilidad del espacio a su propia adecuación para la actividad a desarrollar o para quiénes también nos desarrollamos ese espacio, espacio que a Dani frecuentemente se le quedaba muy pequeño y que lógicamente lo llevaba a agitarse y, entonces, a provocar también nuevas dinámicas en el aula, con sus respectivas posibilidades y sus dificultades.

Cada uno de nosotros tenemos una forma diferente de aprender, es decir, de vivir. Y es el espacio quien se adapta o modifica a las necesidades de quienes lo habitan. Todo espacio educativo ha de estar ob-ligado a la salud, al aprendizaje y a la creatividad. (Siro López, 2018, p.16)

¿Cómo puedo flexibilizar un espacio si apenas hay lugar para pasar entre las mesas, dejar fluir la creatividad, para la libertad de movimiento de los cuerpos? ¿Cómo ha influido esta disposición de los espacios y de los muebles en las dinámicas de nuestra aula? ¿Cómo influyen los espacios educativos en la salud? En este sentido, De la Torre (1995, p.64) asegura que "el lugar confortable invita, sin duda alguna, a un esfuerzo y concentración en la labor creativa. Un centro escolar debe disponer de aulas de distintas dimensiones, así como de espacios abiertos para ex- 
periencias y juegos." Supongo que de la misma manera que buscamos una piscina aclimatada para el buen desarrollo de las clases extraescolares de natación, deberíamos hacer el mismo esfuerzo por buscar espacios que fomenten la labor creativa en las sesiones de Arts\&Crafts, posibilitando la creación de ambientes, para una libre circulación de los cuerpos y de la creatividad.

Y, al hilo de lo anterior, se me plantean los siguientes interrogantes: ¿Qué podemos hacer desde las escuelas y en nuestros roles como profesoras no-escolares para crear ese espacio y ese ambiente que fomente la creatividad, la pedagogía y la salud para nuestras niñas y nuestros niños, bajo los mandatos y las expectativas de los contratantes? ¿Cuál es el nivel de autonomía y de toma de decisiones del que dispone el profesorado en las actividades extraescolares? En este sentido, parece pertinente abogar por el valor pedagógico de las sesiones a las que hago referencia y el papel educativo que juegan, con sus contradicciones y tensiones incluidas. Y, entonces, abogar por su propio sentido y no tan solo como un espacio de 'entretenimiento' de las niñas y los niños.

Por último, ya habiendo hecho alusión al espacio, un inciso sobre los materiales, también relevantes en el desarrollo de la creatividad y en la tarea educativa. En el relato se observa cómo, en esa ocasión, traigo al aula pintura verde y jugamos con la textura de la pintura en sus manos y la sensación del pincel recorriendo sus manos, así como la sensación de la presión de las manos en las cartulinas. Habiendo tenido facilidad para conseguir distintos materiales, gracias a los contratantes, se plantearon las clases como la exploración de diferentes texturas y habilidades en relación a la psicomotricidad. Siendo esto así, procuré llevar al aula diferentes materialidades y texturas y pensar con ellas el diseño de las actividades. Por nombrar algunas: la lana, los papeles de colores, las pinzas, el alambre flexible recubierto, la témpera... Materiales que albergan también en sí mismos infinidad de posibilidades para el uso y la recreación. "Los materiales juegan un papel decisivo como instrumentos que se pueden manipular para generar experiencias. Cuando son utilizados por el profesor o alumnos con esta intención, se está potenciando el pensamiento creativo, enriqueciendo el vivero de la expresión creadora." (De la Torre, 1995, p.65) 


\section{Conclusiones}

Lo primero que me gustaría poner de relieve que, pese a cómo se nos presenten las situaciones en un inicio (la acotación de los tiempos, el compromiso pedagógico por parte de organismos externos, los espacios poco cuidados y un sinfín de cuestiones que se han procurado sugerir en el cuerpo del texto) y la capacidad sobre articular reflexiones y críticas con ello, considero lo primordial como educadores, si queremos decirnos creativas y creativos, el de revertir o salvaguardar, dentro de nuestras posibilidades, esas situaciones y condiciones generales para posibilitar que el encuentro creativo-pedagógico suceda en el aula. A colación de ello, considero interesante y fértil poner una atención especial a la tríada creatividad-educación-salud, si lo que perseguimos como educadores es generar un bienestar integral a cada niña y niño que se presente en nuestra aula. Para ello, parece necesario afinar la mirada sobre algunas de las cuestiones que se han expuesto en los apartados anteriores, como la atención a las necesidades individuales y comunitarias en el grupo, sin que desatendamos unas por encima de las otras, así como a los tiempos y los espacios de los actos educativos, que en muchas ocasiones - yo la primera- pasamos por alto en la vorágine de lo cotidiano. No vale todo. $\mathrm{O}$, mejor dicho, no vale todo de cualquier manera.

Siguiendo con este hilo y tras lo expuesto, reflexionado y compartido, semeja interesante una evaluación de las propuestas extraescolares en relación a la actividad de Arts\&Crafts y las programaciones didácticas que desde aquí se hacen. Por tanto, si lo que se está buscando es una manera creativa de enseñar inglés, sí, quizás podríamos estar hablando de creatividad en ese sentido. Sin embargo, a mí parecer, si lo que se está proponiendo es el desarrollo de la creatividad de los niños y las niñas, bueno, quizás deberíamos seguir evolucionando la fórmula propuesta hasta el momento — siempre haciéndonos cargo también de qué es eso que hacemos con las fórmulas que se nos entregan para ser ejecutadas. Así mismo, a colación de lo anterior, cabe destacar que las preguntas más repetidas en el aula eran “¿Esto está bien? ¿Esto está correc- 
to?", pese a que una de las premisas de nuestra convivencia era, precisamente, que no había un "bien" y un "mal" y que todas sus producciones eran igualmente valiosas. No obstante, el considerar que únicamente existe una respuesta única y correcta, aún en niños tan pequeños, resulta sintomático del funcionamiento del sistema educativo, donde predomina el pensamiento convergente y la dualidad del bien-mal en relación a los productos, por sobre la valoración de los procesos creativos.

En relación a las preguntas que se dejan en abierto, ojalá que creando nuevas posibilidades de exploración, y retomando una de las cuestiones que se dejaban inconclusas en el presente artículo: aunque no pueda aseverar si podríamos hablar o no del fenómeno de la creatividad en relación a estas prácticas educativas, en las extraescolares de Arts\&Crafts, por falta de una investigación sobre esta cuestión, lo que sí me atrevería a afirmar es que se produjo un encuentro creativo-pedagógico en el aula, ya que creamos una comunidad juntas, experimentamos con muchas materialidades, texturas, sonidos, movimientos, así como con nuestras propias posibilidades y limitaciones, compartimos las unas con las otras las artes y las artesanías. La motivación y las ganas de seguir aprendiendo y asistir a clase siempre estuvieron presentes, destacando, por ejemplo, la actividad de Henri Matisse, en la que exploramos el fovismo con la elaboración de una escultura. También hubo un despliegue educativo en torno a la salud, sobre la conexión con una misma y la conexión con las demás a través de nuestras producciones y reproducciones, en el diálogo abierto del aula. "Experimentar el arte que crean otras personas es la forma más vibrante de ver y sentir el mundo como ellas." (Robinson, 2015, p. 195). 


\section{Bibliografía}

Alfonso-Benlliure, V. y Valadez, M. (2013). Intereses académicos, extraescolares y desempeño creativo en educación primaria según género, tipo de escuela y contexto escolar. Revista Mexicana de Psicología, 30(1), 41-52. Recuperado de http://bit. y/2YraU5B

Arufe-Giráldez, V., Chachón, R., Zurita, F., Lara, A. J., y Castro, D. (2017). Influencia del tipo de centro en la práctica deportiva y las actividades de tiempo libre de escolares. Revista Electrónica Educare, 21(1), 1-19. DOl: 10.15359/ree.21-1.6

Betancourt, J. (2006). El entorno creativo. Condiciones necesarias e indispensables para propiciar una atmósfera creativa. En S. De la Torre y V. Violant. (Coords). Comprender y evaluar la creatividad. Un recurso para mejorar la calidad de la enseñanza, 1 (197-204). Málaga: Ediciones Aljibe

ByMe. (s. f.). Primary. Arts\&Crafts. Programaciones. On-line: Macmillan Education y Edelvives. Recuperado de http://bit.ly/369zsmm

Carmona, C., Sánchez, P. y Bakieva, M. (2011). Actividades extraescolares y rendimiento académico: diferencias en autoconcepto y género. Revista de Investigación Educativa, 29(2), 447-466. Recuperado de http://bit.ly/36fiRhb

Cladellas, R., Cariana, M., Badía, M. y Gotzens, C. (2013). Actividades extraescolares y rendimiento académico en alumnos de primaria. European Journal of Investigation in Health, Psychology and Education, 3(2), 87-97. Recuperado de http://bit.ly/36fiRhb

Clariana, M., Cladellas, R., Gotzens, C., Badia, M. y Dezcallar, T. (2013). Tipología de actividades extraescolares y procrastinación académica en alumnado de educación primaria. Electronic journal of research in educational psychology, 12(33), 419-446. DOl: 10.25115 /ejrep.33.14006 
CsikszentmiHaly, M. (1998). Creatividad: el fluir y la psicología del descubrimiento y la invención. Barcelona: Paidós

De LA TorRe, S. (1995). Creatividad Aplicada. Recursos para una formación creativa. Madrid: Editorial Escuela Española

De la ToRRe, S. (2006). Creatividad en la educación primaria. Una mirada desde la complejidad. En S. De la Torre y V. Violant. (Coords). Comprender y evaluar la creatividad. Un recurso para mejorar la calidad de la enseñanza, 1 (253-266). Málaga: Ediciones Aljibe

De LA ToRRE, S. (2012). Profesor creativo, aula creativa. Linguagens. Revista de Letras, Artes e Comunicação, 6(3), p.264-266. Recuperado de http://bit.ly/35040XB

Hernández, E. y Conejo, J. A. (2010). Motivación a la actividad física a través de las actividades extraescolares. TRANCES. Transmisión del Conocimiento Educativo y de la Salud, (3), 153-164. Recuperado de http://bit.ly/36a6KSa

KLIMT, G. (1909). El árbol de la vida [Pintura]. Bruselas: Palacio Stoclet

LARROSA, J. (2016). Experiencia y alteridad en educación. En C. Skliar y J. Larrosa. (Comps.). Experiencia y alteridad en educación. Rosario: HomoSapiens

LóPEz, S. (2018). Esencia. Diseño de espacios educativos. Aprendizaje y Creatividad. Madrid: Ediciones Khaf

Marín, R. (2000). La enseñanza creativa de las artes plásticas. En R. Marín y S. De la Torre. (Coords.). Manual de la creatividad. Aplicaciones educativas. Barcelona: Vicens Vives

Mitú́Ns, A. (2002). Creatividad y salud en los individuos y en las organizaciones. Creatividad y Sociedad. Revista de la Asociación para la Creatividad, (1), 25-32. 
Artes y artesanías: Un encuentro creativo-pedagógico

Morales, J. G. (Coord.). (Septiembre de 2013). Creatividad y arte. Creatividad y Sociedad. Revista de la Asociación para la Creatividad (20). Recuperado de http://www. creatividadysociedad.com/numeros/cys20.html

Morin, E.; Roger, E. y Motta, R. D. (2003). Educar en la era planetaria. Barcelona: Gedisa

Pérez, A. (Coord.). (Diciembre de 2013). Creatividad y educación. Creatividad y Sociedad. Revista de la Asociación para la Creatividad (21). Recuperado de http://www. creatividadysociedad.com/numeros/cys21.html

Plaza, D., Jové, M. C., Hernández, V. y Reverter, J. (2013). Valoración de los docentes de educación física de las actividades deportivas extraescolares. EmásF: Revista Digital de Educación Física, (21), 69-78. Recuperado de http://bit.ly/36hhcHX

Pujol, M. A., De la Torre, S. y Lorenzo, N. (Coords). (2014). Escuelas y aulas creativas. Reflexiones y experiencias. Barcelona: Institut de Ciències de l'Educació-Universitat de Barcelona. Recuperado de http://bit.ly/2LwfESn

Robinson, K. (2015). Escuelas creativas. La revolución que está transformando la educación. Barcelona: Penguin Random House

RodríGuez, E. (1978). Tiempo libre y actividades extraescolares. Salamanca: Ediciones Anaya

Rogers, C. (1986). Libertad y creatividad en la educación en la década de los 80. Barcelona: Paidós Educador

Tonuccl, F. (1979). La escuela como investigación. La creatividad. Barcelona: Editorial Avance

TrilLA, J. (1998). Nuevos espacios y tiempos de la pedagogía. En M. Beas, J. García, J. J. Luengo, A. Sánchez, D. González (Coords.), Atención a los espacios y tiempos extraescolares, 33-47. Granada: Grupo Editorial Universitario 
Violant, V. (2006). Creatividad y salud. En S. De la Torre y V. Violant. (Coords). Comprender y evaluar la creatividad. Un recurso para mejorar la calidad de la enseñanza, 1 (483-491). Málaga: Ediciones Aljibe

Violant, V. (Coord.). (2019). Educación y Salud. La pedagogía hospitalaria como un puente entre ambas. Hergué Editorial

Violant, V., Molina M. C. y Pastor, C. (2011). Pedagogía Hospitalaria. Bases para la atención integral. Barcelona: Laertes Educación

Vino, G., Valero-Valenzuela, A. y Manzano, D. (2018). Actividades acuáticas en educación, la actividad deportiva extraescolar y el nivel de actividad física deportiva. Revista de investigación en actividades acuáticas, 2(3), 22-26. DOl: 10.21134/riaa.v2i3.1313 


\section{Creatividad \\ y Sociedad}

Creatividad y educación

no 32 - enero 2020

¿Se puede fomentar el orden desde la creatividad? Estudio de caso: aplicación Dr. Panda Casa

Can you promote order from creativity?

Case study: Dr. Panda Casa app

Romina Caluori Funes

Universidad Complutense de Madrid rcaluori@gmail.com https://orcid.org/0000-0002-4128-7306 
Resumen

Una forma de fomentar el orden a los niños y niñas de 2 a 4 años es a través de los nuevos formatos de entretenimiento, en concreto mediante la aplicación Dr. Panda Casa. Esta generación multipanalla aprende, se distrae y entretiene de forma hiperconectada porque su estilo de vida ha evolucionado así. Este artículo tiene como objetivo analizar si a través de esta aplicación se fomenta el orden desde una perspectiva creativa. Interesa conocer si dicho juego es capaz de faciliatr la adopción de rutinas afectando a la creatividad. Aportar un número variado de ideas y proporcionar un plan original e ingenioso para ordenar permitirá a niños y niñas ser menos estructurados y esquemáticos, ser capaces de generar nuevos puntos de vista y de encontrar distintas soluciones para alcanzar una meta. Para demostrar si dicha aplicación fomenta el orden desde la creatividad se realizó una investigación de tipo descriptivo analizando cinco de los factores de creatividad propuestos por Guilford (1977): fluidez, flexibilidad, originalidad, elaboración y coherencia interna evaluando tres de las actividades principales propuestas por la aplicación.

\section{Palabras clave}

Niños multipantalla $\cdot$ Valores · Entretenimiento

$\cdot$ TIC $\cdot$ Creatividad

\section{Abstract}

One way to promote order to children aged 2 to 4 years is through new entertainment formats, specifically through the application Dr. Panda Casa. This multichannel generation learns, is distracted and entertained in a hyperconnected way because its lifestyle has developed that way. The objective of this article is to analyze if, through this application, order is promoted from a creative perspective. It is interesting to know if this game is capable of facilitating the adoption of routines affecting creativity. Providing a varied number of ideas and stimulating an original and ingenious plan to order will allow children to be less structured and schematic, be able to generate new points of view and find different solutions to achieve a goal. To demonstrate if this application fosters order from creativity, a descriptive research was carried out analyzing five of Guilford's (1977) creativity factors: fluidity, flexibility, originality, elaboration and internal coherence by evaluating three of the main activities of the app.

\section{Key words}

Multi-screen children · Values · Entertainment $\cdot \mid \mathrm{ICT} \cdot$ Creativity 


\section{Introducción}

El uso de las pantallas y de los formatos de entretenimiento han cambiado el consumo de los medios y ha afectado a los estilos de vida, que resultan ser muy atractivos para los jóvenes que pertenecen a la generación multipantalla. Esta generación se caracteriza por vivir permanentemente conectada a Internet a través de distintos medios, pantallas, plataformas, apps y programas, que está en relación con los diversos dispositivos informáticos que van creciendo cada vez más. Prensky (2001) refiere que estas generaciones han nacido rodeadas de la nueva tecnología, han crecido utilizándola y es parte esencial de sus vidas. Se multiplican las pantallas, los ordenadores personales, los móviles, las tabletas, la televisión y las videoconsolas. Tal y como apuntan Olaortua, Arrillaga y Sesumaga (2018): "estos jóvenes constituyen un público amplio que ha sabido desarrollar usos y hábitos de consumo y creación audiovisual propios en el marco de este universo interconectado" (p. 62).

Los medios interactivos ayudan a estimular la imaginación, despiertan la curiosidad y fomentan el aprendizaje. Mediante este artículo comprobaremos si se puede fomentar el orden en los niños y niñas de una forma creativa, original y poco esquemática utilizando las nuevas tecnologías.

\section{Teorías previas y estado de la cuestión}

\subsection{El uso adecuado de las pantallas en niños y niñas}

Tanto la edad de los niños y niñas que utilizan las pantallas como las TIC guardan una relación de juventud, son medios ante todo para el entretenimiento y esto favorece su popularidad entre los más jóvenes. Christakis (2015) habla de cuestiones de interés cuyo resumen se traduce y expone a continuación. Sostiene que los niños y 
niñas nacen con el cerebro sin estar completamente desarrollado, y en los dos primeros años aumenta en relación a la estimulación externa. Si se estimula a los niños y niñas desde edades muy tempranas con dispositivos electrónicos y pantallas, se acostumbrarán a un tipo de respuesta inmediata y una entrada de la información de alto nivel, lo que hará que su realidad le parezca aburrida y no lo suficientemente rápida. Si interactúan con demasiada tecnología muy pronto, esperarán que el mundo funcione así, cuando en realidad no lo hace. El cerebro trata de adaptarse a un mundo que en realidad no existe y así resulta más difícil concentrarse en las cosas que pasan a un ritmo normal, lo que puede generar déficit de atención. Los adultos aprovechan los dispositivos electrónicos para distraer y entretener a los niños y niñas, es lo que se conoce como "efecto babysitter" denominado por Nielsen Group (2012) y citado por Grané (2015): "cuando los medios, antes la televisión y ahora más los dispositivos móviles, se utilizan como niñera para mantener a los niños entretenidos" (p. 47), pero esta tecnología sin pedagogía equivale a un conjunto vacío. Las familias juegan un papel clave para ayudar a los niños y niñas a desenvolverse en el entorno hiperconectado y para no utilizarla como "apagañinos", lo cual se producce, como explica Dans, citado por Costa (2017): "al darles una videoconsola, un smartphone o cualquier otro dispositivo tecnológico, cuando consideran que sus hijos empiezan a presentar una actitud molesta" (p. 50). La introducción de las pantallas requiere paciencia y una incorporación gradual ya que su efecto cognitivo y ventajas sólo se harán efectivas al utilizarse de forma correcta, prudente y en la edad adecuada. Los niños y niñas deben estar acompañados por un adulto fomentando la creatividad y el desarrollo cognitivo, como dice Roca (2015):

Nuestros niños han nacido en la era digital, pero eso no significa que sepan hacer un buen uso de lo digital. Es responsabilidad de padres y educadores facilitar que hagan una incorporación positiva de la tecnología y un buen uso de la misma. Las potencialidades son infinitas, los riesgos evitables. Es responsabilidad de todos nosotros favorecer el crecimiento saludable y pleno de los niños, ya que ellos serán los padres y educadores del futuro. (p.4) 
Los dispositivos electrónicos son adictivos, ya que estimulan la producción de la dopamina. Las pantallas generan adicción a través de un círculo de recompensa. No se produce atención sostenida, sino una actitud pasiva, una actitud de "embotamiento" que genera falta de atención. La Asociación de pediatría Canadiense recomienda cero pantallas antes de los dos años, y de los dos a los cinco años, menos de una hora de pantalla al día. La clave está en desarrollar las virtudes y los valores (como la templanza, el saber esperar, la paciencia, el esfuerzo, la planificación, la atención y la fortaleza) antes de usar las tecnologías, para saber hacer un uso razonable y responsable en el momento en que se comiencen a utilizar. La mejor preparación para el mundo online es el mundo real. (L'Eccuyer, 2018)

\subsection{Educar en valores: el orden}

La inteligencia crece con el ejercicio y práctica de las capacidades y valores personales y éstos permiten el desarrollo armónico de la persona. El orden es una virtud que sienta las bases para formar la identidad y personalidad de los niños y niñas y los cimientos para poder tomar decisiones responsables, tanto en el ámbito real como en el digital. La sociedad actual reclama una educación moral para los jóvenes. "Educar es el proyecto más importante de una familia. La familia es la responsable de que un niño y posteriormente adolescente, llegue a la edad adulta con unos u otros valores" (Robert y Botella, 2015, p. 135).

Para sentar las bases de una buena educación hay que centrar los esfuerzos en crear hábitos, los cuales formarán las virtudes. Tal y como afirma Alcazar (2001): "la educación integral de los hijos busca promover en ellos hábitos que les permitan obrar bien en cualquier circunstancia y por voluntad propia, estén o no sus padres presentes, (...)" (p. 13)

Robert y Botella (2015) sostienen que: "es de los cero a los cinco años que los niños incorporan los hábitos de manera natural, así que lo que observen y practiquen duran- 
te esta fase quedará arraigado como base de aprendizaje" (p. 139). Siguiendo este concepto, partimos de la idea de que los niños y niñas tienen una edad determinada y un momento para aprender cada cosa: son los períodos sensibles o períodos sensitivos, término acuñado por Montessori (1998), que lo define de la siguiente manera:

Al niño en sus diversas etapas le llaman la atención diversas cosas. Si no conocemos sus periodos sensibles, sus intereses, su naturaleza y se intenta enseñarle lo mismo a los cinco años y a los ocho, el último no aprenderá tan rápido. Lo que les interesa a una edad, luego deja de importarles. La edad ideal para aprender el abecedario son los cuatro años. A esa edad les encanta escribir y por eso, este fenómeno se llama "el estallido de la escritura", pero si se enseña a los seis años no va a haber ningún estallido. (p. 134)

Estos períodos sensitivos se consideran los "poderes" que tienen los niños y niñas para absorber todo el aprendizaje. Si no se aprovechan estos momentos, no quiere decir que luego sea demasiado tarde para aprender algo, pero les costará más que si lo hacen de manera natural cuando están preparados para ello. En la tabla a continuación se observan los períodos sensibles más importantes de los 0 a 6 años, según Montessori (1998):

\begin{tabular}{|c|c|c|c|c|c|c|c|}
\hline PERÍODO SENSIBLE & \multicolumn{5}{|c|}{ EDAD } \\
\hline & 0 & 1 & 2 & 3 & 4 & 5 & 6 \\
\hline Movimiento & & & & & & & \\
\hline Agudización de los sentidos & & & & & & & \\
\hline Lenguaje & & & & & & & \\
\hline Orden y organización & & & & & & & \\
\hline Comportamiento social & & & & & & & \\
\hline Sensibilidad musical & & & & & & & \\
\hline Descubrimiento matemático & & & & & & & \\
\hline Lectura y escritura & & & & & & & \\
\hline Relación con el espacio & & & & & & & \\
\hline
\end{tabular}

Tabla 1. Períodos sensitivos. Fuente: elaboración propia siguiendo la teoría de Montessori (1998) 
Los hábitos, los valores y las virtudes se alcanzan mediante la repetición de actos libres, frecuentes y conscientes. Como hemos dicho anteriormente, cada virtud tiene su momento y, en concreto, el hábito del orden debe fomentarse entre los dos y los cuatro años, tal y como podemos ver en la Tabla 1 según la teoría de Montessori, si bien se puede iniciar en cualquier momento de la vida y su vigencia exige que se practique a lo largo de la misma.

El orden es la virtud primera, pues es fundamental no sólo para conseguir acomodar lo material, sino también para alcanzar una armonía interior y un autodominio. Es el orden de la persona, el equilibrio, la moderación, y se encuentra en la base de todos los demás valores humanos. (Alcazar, 2001, p. 13)

El orden es, entre otras cosas, la manera en que se colocan y guardan los objetos, pero la disposición de las cosas se puede hacer de diferentes formas y se pueden elegir distintas opciones para completar el proceso. Si se ordena de forma creativa, se encontrarán diversas soluciones para conseguir el resultado deseado y así se asociará esto como algo placentero y positivo. El orden se manifiesta en diferentes facetas y no sólo consiste en tener ordenados los juguetes o dejar el uniforme preparado para el día siguiente, sino que se muestra en la manera en que se reparten las actividades, cómo se organiza el tiempo de estudio, la puntualidad, y cómo se fomenta la higiene y limpieza, entre otras cosas. Es la base de la disciplina, fomenta la autoestima, la tranquilidad y paz interior. Las personas ordenadas son mas equilibradas interiormente, mejor organizadas y más prudentes. Como dice Gil (2007): "el orden no es propiamente una virtud moral, sino el sustento o fundamento de todas las virtudes. Virtud sin orden, rara virtud" (p. 5). 


\subsection{La creatividad}

La creatividad es la capacidad de crear algo distinto y original y de aportar diferentes soluciones a un problema, rompiendo los modos convencionales o estereotipados de actuar. Sáez (2011) la define como: "una manera distinta, peculiar y subjetiva que el individuo posee de analizar y elaborar situaciones y, por otro lado, como un conjunto de resultados objetivos y tangibles del actuar de una persona considerada creativa" (p. 145). Para Guilford (1977) lo creativo se resume en las siguientes aptitudes: la fluidez, capacidad de proponer un gran número de ideas nuevas; la flexibilidad, capacidad de adaptarse a los cambios; la originalidad, capacidad de aportar ideas que sorprendan; la elaboración, capacidad de completar un proceso aportando ideas elaboradas atendiendo a los detalles y la coherencia interna, la concordancia entre la sustancia y la forma aportando ideas que tengan sentido (García y Morales, 2011). Por otro lado, Guilford (1977), citado por Castillo (1980), afirma que: "la creatividad radica en el campo cognitivo, en el "pensamiento divergente», que recibiendo los datos de la realidad se orienta en múltiples direcciones" (p. 52). Este pensamiento es la facultad de generar una respuesta innovadora y alternativa a partir de ciertos datos contenidos en la memoria.

Para que el orden se lleve a cabo de forma creativa es importante que los jóvenes se sientan motivados. Consiste en aportar algo innovador e ingenioso y no sólo generar rutinas. Csikszentmihalyi, citado por Sáez (2011) lo denomina como: "el estado de "flow" (o de flujo), definido como un estado en el que la persona se encuentra completamente absorta en una actividad" (p. 149). Desde esta motivación intrínseca es dónde se despierta la ilusión, el ingenio y la imaginación. El entorno puede influir en el desarrollo creativo, pero, sobre todo, es importante el contexto estimulante. Los nuevos géneros y formatos de entretenimiento son fundamentales porque a través de éstos se desarrollan las capacidades creativas de los niños y niñas y aprenden habilidades motoras, cognitivas y emocionales e intelectuales. 


\subsection{Nuevos formatos de entretenimiento: apps}

La forma de entretenerse ha cambiado por completo y surgen nuevos géneros y formatos a través de los dispositivos electrónicos. Las aplicaciones móviles son uno de los mayores usos que le dan los niños y niñas al servicio de Internet (Bringué, Sádaba y Tolsá, 2011). Se entiende por aplicación de entretenimiento, un software que se descarga en un aparato electrónico, por lo general un móvil o tableta, que propone diversión para los usuarios a través de lo que sucede en la pantalla.

El juego es una actividad fundamental para todo niño y niña, pues es la manera de aprender a socializar, a desarrollar aspectos físicos y emocionales y a entender el mundo que les rodea.

Si bien han surgido nuevos formatos y formas de entretenimiento con la aparición de las TIC, la esencia del juego es la misma y los efectos positivos que tiene el jugar en los niños y niñas sigue latente. Torres (2002) sostiene que:

La didáctica considera al juego como entretenimiento que propicia conocimiento, a la par que produce satisfacción. El juego favorece y estimula las cualidades morales en los niños y en las niñas como son: el dominio de sí mismo, la honradez, la seguridad, la atención se concentra en lo que hace, la reflexión, la búsqueda de alternativas para ganar, el respeto por las reglas del juego, la creatividad, la curiosidad, la imaginación, la iniciativa, el sentido común y la solidaridad con sus amigos, con su grupo (...) (p. 290).

Una de las formas de entretenimiento propia del siglo XXI es a través de las aplicaciones y la utilización de las pantallas. El debate sobre sus efectos sigue abierto y presenta puntos de vista opuestos entre sus ventajas y desventajas. Con un uso responsable, guiado por adultos, con normas claras sobre los tiempos de utilización, evitando el aislamiento, no antes de los 2 años y menos de una hora por día, las pan- 
tallas tienen muchas ventajas y fomentan unas competencias y posibilidades en los niños y niñas que hay que aprovechar. Tal y como afirman Martínez y Prendes (2004): "favorecen las relaciones sociales, el aprendizaje cooperativo, el desarrollo de nuevas habilidades, nuevas formas de construcción del conocimiento y el desarrollo de las capacidades de creatividad, comunicación y razonamiento" (p. 8).

\subsection{Educación a través de apps}

Las pantallas, móviles y tabletas, con sus distintas aplicaciones o juegos, aparte de ser un medio de entretenimiento, educan y fomentan una serie de competencias y manipulaciones en niños y niñas que interesa conocer. Los menores de edad de entre 2 a 4 años, que han nacido en un mundo completamente digital, construyen sus referentes a partir de la tecnología que les rodea; su concepto de distancia, tiempo, espacio, comunicación y entretenimiento se han transformado por completo. Prensky (2001) sostiene que hoy en día los más jóvenes se entretienen, aprenden y se divierten de forma muy diferente a cómo se hacía años atrás, pues su forma de pensar y su cultura han cambiado.

Para poder aprovechar las ventajas que tienen las aplicaciones, uno de los aspectos más importantes es que los padres y las madres se informen sobre cuáles son los programas más adecuados para la madurez cognitiva de sus hijos. Crescenzi y Grané (2016), publicaron un artículo basado en su investigación previa, dónde analizaron las 100 aplicaciones educativas para niños y niñas de hasta 8 años mejor evaluadas y recomendadas por expertos y concluyeron que:

La calidad de aplicaciones móviles destinadas a la primera infancia depende entonces de dos condiciones. Tener en cuenta el desarrollo evolutivo del niño en el planteamiento de los contenidos y actividades; emplear un diseño interactivo adecuado a este mismo desarrollo cognitivo y psicomotor. Porque las características forma- 
les del mensaje audiovisual y multimedia pueden potenciar o pueden obstaculizar la comprensión y la interacción por parte de niños pequeños. (p. 78)

De entre las 100 apps mejor evaluadas a nivel mundial, un 61\% especifican la edad adecuada para la cual fue desarrollado dicho juego, sólo un 16\% de la muestra está libre de publicidad intrusiva, el 54\% son aplicaciones gratuitas y el $87 \%$ puede ser utilizado sin Internet (Crescenzi y Grané, 2016).

\section{Diseño de la investigación}

\subsection{Objetivo}

Analizar la aplicación de Dr. Panda Casa como medio y recurso educativo para los niños y niñas de 2 a 4 años desde una perspectiva creativa con la finalidad de fomentar el orden, desarrollando tareas domésticas, cuidando la higiene y la correcta disposición de los objetos.

\subsection{Metodología}

A través de un estudio de caso de la aplicación Dr. Panda Casa, se analizará cómo se desarrolla dicho juego para que niños y niñas interactúen y aprendan sobre el uso del orden como valor, desde una perspectiva creativa ayudando a desarrollar la imaginación y el ingenio. Interesa conocer no sólo cómo la app facilita la adopción de rutinas, sino sobretodo cómo afecta a la creatividad.

Para conseguir el objetivo se plantea una investigación descriptiva, de tipo cualitativo, analizando la aplicación Dr. Panda Casa. En este momento no se utilizó con niños, lo cual queda pendiente por contrastar en una investigación experimental. 
Siguiendo a Sandelowski (2000), citado por Aguirre y Jaramillo (2015), reivindica el papel de la descripción cualitativa en la investigación social y considera que: "el estudio descriptivo cualitativo es el método que se puede elegir cuando se deseen descripciones rigurosas de los fenómenos". Afirma que: "la descripción es protagónica a la hora de responder preguntas cualitativas con un interés específico, sin necesidad de adornarla con otros enfoques" (p. 181) y al igual que Namakforoosh (2005) consideran que la investigación descriptiva es la forma para saber quién, dónde, cuándo, cómo y por qué del sujeto del estudio.

Se ha elegido este juego en concreto, ya que dentro del grupo de aplicaciones de Dr. Panda, está diseñado y pensado para enseñar a los niños y niñas a fomentar el hábito del orden, ayudando en las tareas domésticas y aprendiendo a ser autónomos y responsables. Estas aplicaciones son muy populares, ya que tienen millones de descargas, y su target, contenido y temática se corresponden con lo que se buscaba en la investigación.

Para analizar el uso de la app y ver si se fomenta el orden de una forma creativa, se estudiará si cumple con cinco de los factores propuestos por Guilford (1977) sobre creatividad, fluidez, flexibilidad, originalidad, elaboración y coherencia interna. Mediante una valoración del 1 a 5, correspondiendo 1 a la valoración más baja y 5 a la más alta, tal y como puede observarse en la tabla a continuación:

\begin{tabular}{|l|l|l|l|l|}
\hline Fluidez: & Flexibilidad: & Originalidad: & Elaboración: & $\begin{array}{l}\text { Coherencia } \\
\text { Interna: }\end{array}$ \\
\hline Muy poco fluido: 1 & Muy poco flexible: 1 & Muy poco original: 1 & $\begin{array}{l}\text { Muy poco } \\
\text { elaborado: } 1\end{array}$ & $\begin{array}{l}\text { Muy poco } \\
\text { coherente: } 1\end{array}$ \\
\hline Algo fluido: 2 & Algo flexible: 2 & Algo original: 2 & Algo elaborado: 2 & Algo coherente: 2 \\
\hline $\begin{array}{l}\text { Moderadamente } \\
\text { fluido: } 3\end{array}$ & $\begin{array}{l}\text { Moderadamente } \\
\text { flexible: } 3\end{array}$ & $\begin{array}{l}\text { Moderadamente } \\
\text { original: } 3\end{array}$ & $\begin{array}{l}\text { Moderadamente } \\
\text { elaborado: } 3\end{array}$ & $\begin{array}{l}\text { Moderadamente } \\
\text { coherente: } 3\end{array}$ \\
\hline Fluido: 4 & Flexible: 4 & Original: 4 & Elaborado: 4 & Coherente: 4 \\
\hline Muy fluido: 5 & Muy flexible: 5 & Muy original: 5 & Muy elaborado: 5 & Muy coherente: 5 \\
\hline
\end{tabular}

Tabla 2. Criterios de evaluación atendiendo a la escala de Likert. Elaboración propia 
Se llevará a cabo una "jerarquización de los criterios" en cinco niveles, considerando este análisis el más oportuno, tal y como defienden García (1984) y Baños (2003) y utilizando la escala de Likert de 5 opciones. Se estudiarán las tres primeras actividades de la app: hacer la colada, preparar el desayuno y lavarse los dientes puntuando los factores de Guilford presentes en cada actividad. Se completará la siguiente tabla:

\begin{tabular}{|c|c|c|c|c|c|}
\hline & \multicolumn{5}{|l|}{ Aptitudes de Guilford sobre creatividad atendiendo a la escala de Likert } \\
de 5 rangos
\end{tabular}

Tabla 3. Valoración de la aplicación según los factores de Guilford. Elaboración propia

La observación del contenido permitirá señalar si dicha aplicación es una oportunidad para fomentar ciertas conductas creativas y valores en los niños y niñas.

\section{Caso de estudio: Aplicación Dr. Panda Casa}

En este artículo se pone en valor el juego de Dr. Panda Casa. Según datos de Google Play la aplicación tiene una valoración de 4,2 sobre 5 en base a los 1.826 usuarios que han opinado. La misma ha sido descargada más de 50.000 veces, lo cual la sitúa como un juego popular. Su última actualización corresponde a febrero de 2016 y está disponible tanto para Android como para IOS. Se sitúa dentro de la categoría "educativa" y tiene un código PEGI 3 (Pan European Game Information), tal y como puede verse en la figura 1. 


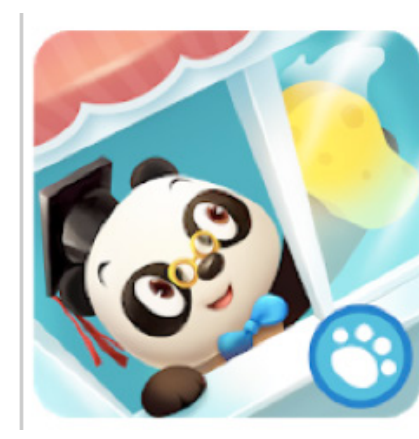

\section{Dr. Panda Casa}

Dr. Panda Educativo Juegos simulados

$\star \star \star \star \star 1.826$ உ

1. PEGI 3 画 Hasta 8 años

Añadir a la lista de deseos

Comprar por $4,49 €$

Figura 1. Aplicación Dr. Panda Código PEGl.

Fuente: Recuperado de: https://play. google.com/store/apps/details?id=com. tribeplay.pandahousework\&hl=es [23/02/19]

Éste corresponde con el código que permite clasificar los juegos tecnológicos según el contenido y la edad recomendada y dónde se determina el nivel de madurez mínima para utilizar dicha aplicación (Guerra y Revuelta, 2016). En este caso, el código 3 significa que es una app que se puede utilizar a partir de los 3 años y es apta para todos los públicos. Sin embargo, este juego puede resultar complejo para niños y niñas tan pequeños si no juegan acompañados de un adulto. La mejor forma para incorporar las habilidades y aptitudes que fomenta es llevarlos a la práctica junto con la ayuda de los padres y las madres. No es suficiente con ver los vídeos de Dr. Panda de forma pasiva. Las apps de Dr. Panda consisten en una colección pensada para la etapa infantil, de entre 2 a 6 años, donde los personajes ejemplifican situaciones cotidianas para enseñar distintas lecciones de forma didáctica e interactiva. Tal y como afirma Ramírez (2008): "el niño de educación infantil es un niño deseoso de resolver los problemas por sí mismo, se enfrenta a situaciones nuevas y busca soluciones a veces inesperadas. Se encuentra en una etapa ideal para el desarrollo de su creatividad" (p. 10).

La colección presenta 18 juegos diferentes, que en total suman más de 15 millones de descargas y algunos premios internacionales.

Dr. Panda se representa como un oso curioso que se embarca en aventuras en su día a día reforzando así el aprendizaje básico de diferentes materias y enseñando a los niños y niñas a desenvolverse en distintas circunstancias: en el supermercado, en un centro comercial, en un restaurante, en la escuela o en el hogar. Cada app representa una situación particular y permite a los niños y niñas jugar en diferentes 
¿Se puede fomentar el orden desde la creatividad? Estudio de caso: aplicación Dr. Panda Casa

escenarios. Según Varona (2014), experto en aplicaciones, sostiene que Dr. Panda "es sin duda una de las series de aplicaciones infantiles mejor desarrolladas y más divertidas que puedes encontrar". Diez (2013) afirma que las ventajas y enseñanzas que hay detrás de dichas apps son las siguientes:

"Anticipar situaciones desconocidas y preparar a los niños para enfrentarlas: aeropuerto, supermercado, guardería...

Desarrollar esquemas de acción sobre tareas de la vida diaria: higiene personal, ir al cole, cocinar, arreglar objetos...

Favorecer el juego interactivo conjunto y la toma de decisiones.

Adquisición de vocabulario y léxico relacionado con cada espacio.

Aprender el orden y la secuencia de determinados eventos."

El juego de Dr. Panda Casa, hace referencia a las cuestiones cotidianas del día a día en el hogar, y es una forma de otorgar responsabilidades y fomentar ciertos hábitos desde pequeños, como la higiene, el orden, la ayuda en los quehaceres domésticos y la autonomía. La aplicación tiene una estética moderna, con colores llamativos y representa los distintos escenarios propios de una casa de una forma muy realista, lo cual genera cercanía con los jugadores. Tal y como puede verse en las imágenes a continuación, cada habitación está muy bien representada y en cada una se llevan a cabo distintas actividades, como por ejemplo en la cocina es dónde se recogen los platos o se prepara el desayuno, en la habitación se cambian, se ordenan los juguetes y en jardín se corta el césped.

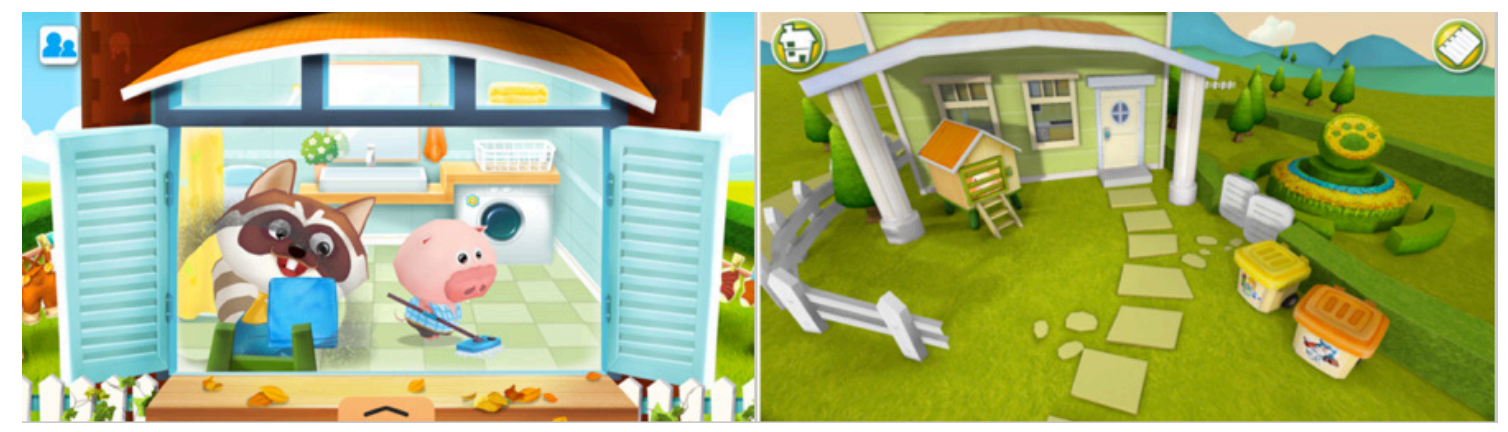

Figura 2. Escenas de Dr. Panda Casa. Elaboración propia (pantallazo del juego) 
El objetivo de dicha app es que los niños y niñas ayuden a completar las tareas del hogar que va a realizar cada personaje familiarizándose con los diferentes encargos de la casa de una forma divertida. Mientras realizan estas actividades, podrán ir recolectando monedas para ahorrar en una hucha e intercambiar luego por juguetes $u$ objetos virtuales como recompensa. Se transmite también la importancia de trabajar en equipo sin caer en discriminaciones sexistas. Por primera vez, adquieren más protagonismo los amigos de Dr. Panda, que son distintos animales (un hipopótamo, un elefante, un cerdo o un mono) y los niños y niñas entienden que es necesario distribuirse las tareas y ayudar en casa. En concreto, se describen 20 situaciones diferentes, entre las que destacan, hacer la colada, limpiar la cocina, cortar el césped, quitar el lavavajillas, sacar la basura y reciclar, ordenar los juguetes, ordenar la habitación, preparar el desayuno, poner el despertador e irse a dormir pronto, lavarse lo dientes, ducharse y vestirse. Se deberán ir completando cada una para poder pasar de nivel. Estas acciones se identifican muy bien con los niños y niñas de este rango de edad, ya que se presentan como cadenas de sucesos, al igual que en la vida real.

\section{Resultados de la investigación}

En la tabla 4 se observa el resultado del análisis en profundidad de dicha aplicación atendiendo a los factores de Guilford después de puntuar las tres actividades principales del juego que han sigo elegidas.

\begin{tabular}{|c|c|c|c|c|c|}
\hline & \multicolumn{6}{|c|}{ Aptitudes de Guilford sobre creatividad atendiendo a la escala de Likert } \\
de 5 rangos
\end{tabular}

Tabla 4. Resultado de la valoración de la aplicación según los factores de Guilford. Elaboración propia 
Para comprender mejor este análisis y los resultados obtenidos, se hará una descripción detallada sobre cada factor explicando la valoración correspondiente y deduciendo, según la puntuación final, si dicha app fomenta el orden a través de la creatividad.

La fluidez es la habilidad para transmitir distintas ideas u operaciones y es la cantidad de frases, expresiones o ideas que uno es capaz de producir. En la tabla observamos que dicha aptitud tiene un promedio de 3,6 sobre 5, lo cual se obtiene de hacer la media de las tres actividades. Hacer la colada tiene la puntuación máxima, ya que el personaje del juego enseña que se puede tender con total libertad eligiendo si se hace por color, tamaño o tipo de prenda (ver figura 3). De este modo, se pueden hacer " $x$ " número de combinaciones para ordenar la ropa atendiendo a distintos criterios. Se pueden agrupar opciones en secuencia de orden según las ideas que se tengan y la actividad se puede completar cada vez de una forma diferente, siendo así muy fluida. Los niños y niñas van eligiendo distintas soluciones durante esta actividad desarrollando la imaginación.

Preparar el desayuno tiene una puntuación de 4 sobre 5, por lo que consideramos que se presenta de forma fluida según los criterios de evaluación que hemos establecido. El personaje principal muestra que existen varias posibilidades a la hora de preparar el desayuno, entre otras, el café se puede tomar con o sin leche y las tostadas se pueden comer antes o después eligiendo el número de veces que se quiera repetir. A pesar de lo rutinario de esta actividad, la aplicación enseña que hay un número elevado de opciones a la hora de llevar a cabo dicha acción.

Lavarse los dientes es la actividad menos fluida, puntuada con un 2 sobre 5. La única idea que el juego aporta es cómo colocar el cepillo para lavarse los dientes, es decir, de arriba a abajo, en horizontal o de izquierda a derecha. Pero no se enumeran ideas para transmitir a los niños y niñas una forma diferente de llevar a cabo esta acción.

Aunque en esta última actividad se podrían haber aportado más ideas, en suma, es una aplicación que desarrolla la fluidez, sobretodo porque las dos primeras acciones 
aportan distintas opciones para conseguir los resultados, proporcionando un número elevado de ideas para llevar a cabo dichas actividades.

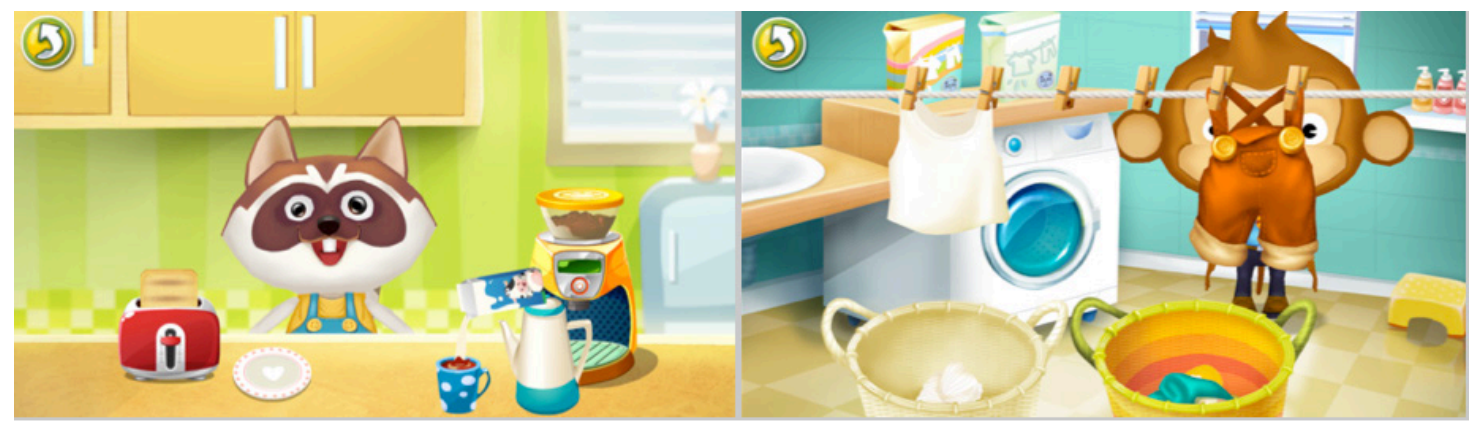

Figura 3. Escenas de Dr. Panda Casa, fluidez. Elaboración propia (pantallazo del juego)

La flexibilidad es la capacidad de adaptarse a los cambios y sustituir una idea por otra asumiendo cierto grado de diversidad. Si antes nos interesamos por la cantidad de ideas, ahora analizamos la variedad de las mismas. Para ello observamos la cantidad de opciones diferentes que ofrecen las tres actividades. En global, esta aptitud tiene una puntuación bastante baja, 2,3 sobre 5. Hacer la colada se ha puntuado con un 2, ya que sólo se puede hacer atendiendo a los colores, si es ropa blanca u oscura y la actividad se presenta como algo muy rutinario. A pesar de que es una actividad fluida, las ideas aportadas apenas varían la una de la otra y todo gira en torno a la misma opción de colocar la ropa por color sin tener posible variación.

Hacer el desayuno tiene un 3 de puntuación ya que los elementos de la escena no varían y sólo permite hacer café o tostadas. Si hubiesen dado opción de hacer té, coger un bizcocho, fruta o yogur, por ejemplo, se podría haber enriquecido el juego aportando diversidad en las ideas.

Por último, lavarse los dientes también tiene una puntuación baja, con un 2. Sólo puedes desempeñar la acción de una manera y varía únicamente la colocación del cepillo. Se debe seguir un orden establecido sin ofrecer soluciones diversas para desarrollar dicha tarea. (Ver imagen 4). Las actividades analizadas son rígidas y no presentan necesidad de adaptación e innovación, pues son acciones que se deben desarrollar de forma más esquemática. 


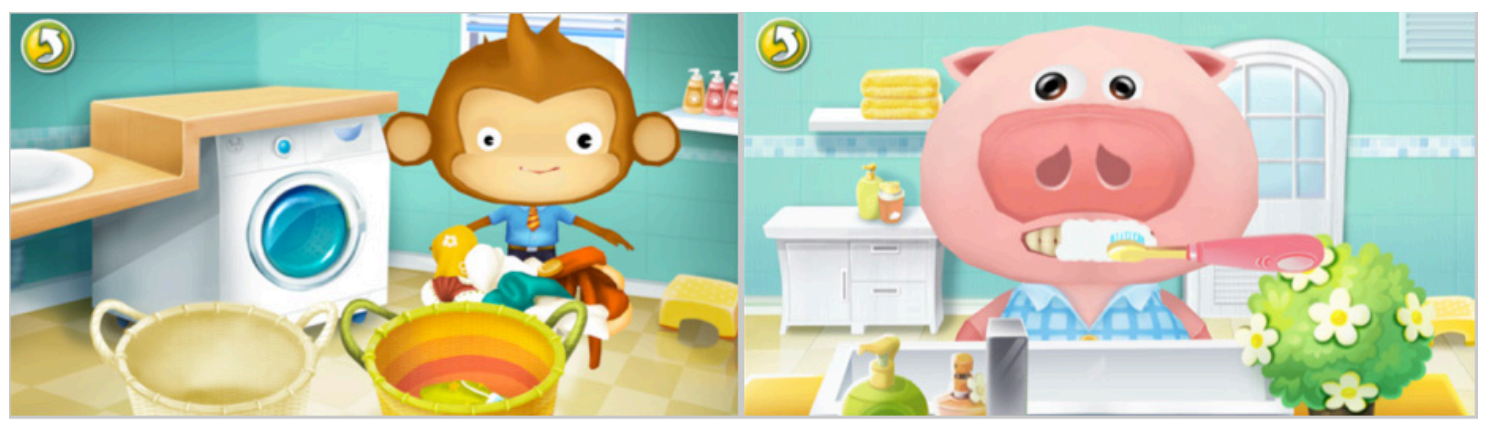

Figura 4. Escenas de Dr. Panda Casa, flexibilidad. Elaboración propia (pantallazo del juego)

La originalidad es la capacidad de dar respuestas poco frecuentes. La aplicación tiene una media de 1,6 en esta aptitud después de analizar las tres actividades ya que en general las ideas que se transmiten son evidentes y poco llamativas. Hacer la colada se ha puntuado con un 2 al igual que preparar el desayuno, y lavarse los dientes con un 1. Ninguna de éstas muestra elementos novedosos o ideas originales y las acciones no se representan de forma singular, sino más bien de forma estructurada y sin aportar ideas distintas. No hay nada peculiar o inusual en la forma de desarrollar ninguna de las tres acciones y no despierta ideas ingeniosas en los niños y niñas. Si bien son hábitos que de por sí reflejan moldes convencionales de actuar, el juego podría haber presentado ideas más llamativas y romper dichos esquemas con propuestas originales y nuevas. A la hora de hacer la colda, por ejemplo, se pordría haber incluido una opción para hacer un lavado a mano de ropa delicada, separar la ropa no solo por color, sino por tejido y ofrecer un secado a máquina. En el desayuno, se podría haber inlcuido la opción de comer fruta o de hacer un bizcocho casero facilitando una receta y al lavarse los dientes, se podría haber incluido una canción, para hacer la acción más amena y aprovechar la situación para explicar la importancia de beber agua o de lavarse las manos siempre que uno va al baño, entre otras cosas.

La elaboración tiene la puntuación más alta, 4,6 sobre 5, ya que la aplicación alcanza un nivel de detalle muy elevado. La primera actividad, hacer la colada, se ha puntuado con un 5, pues le representación pictórica atiende a todos los detalles (ver figura 5). Se puede escoger el jabón adecuado para lavar la ropa de color o blanca, hay dos cestas para no mezclar la ropa clara y oscura, la soga tiene las pinzas coloca- 
das para usar y colgar cada prenda de forma correcta. Preparar el desayuno también tiene la puntuación más alta. La cocina está perfectamente ambientada, con colores, muebles y electrodomésticos realistas. Por último, el acto de lavarse los dientes se ha puntuado con un 4, ya que la escena está elaborada y tiene algunos detalles, tales como que la pasta hace espuma, tiene un vaso para enjuagarse y el baño refleja un espacio real con las toallas colocaladas, el jabón y el espejo.

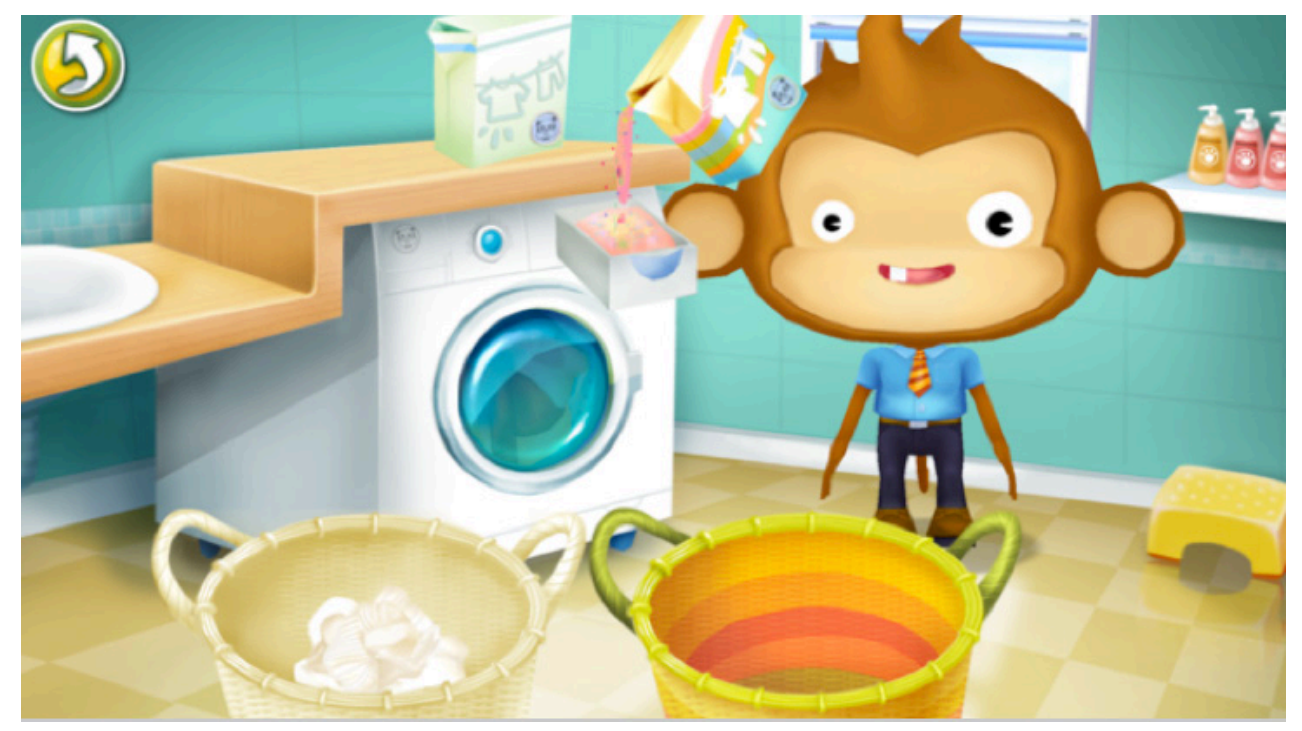

Figura 5. Escenas de Dr. Panda Casa, elaboración. Elaboración propia (pantallazo del juego)

Para poder avanzar se tienen que ir completando las tareas de forma correcta, fomentando así en los niños y niñas la habilidad para encontrar el resultado buscado a partir de una información básica y consiguiendo una producción perfecta. La elaboración implica un constante deseo de superación, pues materializa el nivel de detalle, desarrollo o complejidad de las ideas creativas.

Por último, la coherencia interna se ha puntuado con un 4 sobre 5 de media. Las tres actividades se presentan de forma coherente, simulando situaciones reales y los niños y niñas son capaces de organizar sus ideas y pensamientos para ver cómo deben llevar a cabo cada tarea. 
De forma global la aplicación tiene una media de 3,22 sobre 5, lo cual la sitúa como un juego creativo. A pesar de lo rutinario que resulta ordenar y hacer los quehaceres domésticos, la aplicación enseña a los niños y niñas a fomentar la imaginación ya que cada actividad aporta un número elevado de ideas, las cuales son variadas, muy elaboradas, coherentes y suficientemente originales. Es difícil fomentar el orden desde una perspectiva creativa, y si bien el juego tiene algunas carencias, con esta aplicación se anima a los jugadores a encontrar ideas y soluciones imaginativas ante los quehaceres domésticos. Los niños y niñas parten de unos objetivos muy básicos, cómo por ejemplo al hacer la colada sólo ven que hay dos pilas de ropa revuelta en el suelo y a partir de ahí deben encontrar la forma de ayudar a los personajes para llevar a cabo la acción, deben ir buscando distintas opciones y soluciones hasta llegar al objetivo final. Esto permite a los niños y niñas recorrer distintos caminos y estrategias para buscar las soluciones correctas. La aplicación enseña de forma entretenida a solucionar problemas fomentando así la creatividad y buscando que la misma no se asocie con el desorden. Al mismo tiempo, consigue captar la atención de los jugadores, ya que representa distintas situaciones cotidianas, lo cual es propio del juego simbólico característico de esta edad. Las rutinas, hábitos y costumbres que se adquieren de pequeños, acompañarán a los niños y niñas para siempre, por lo que los adultos deberán fomentar en sus hijos las virtudes necesarias para desarrollar estilos de vida adecuados, y esta aplicación es un modo divertido e interesante de poder hacerlo.

\section{Discusión y conclusiones}

Según los resultados obtenidos tras el análisis descriptivo de la aplicación de Dr. Panda Casa y siguiendo la jerarquización de Guilford se concluye que dicho juego fomenta el orden desde una perspectiva creativa, por la fluidez en las ideas, la elaboración y el nivel de detalle de dicho juego y la coherencia interna, pero es poco original y muy esquemática. Sin embargo, cabe destacar que para mejorar dicha in- 
vestigación se recomienda contrastar los estudios con una investigación experimental complementaria con niños y niñas que evalúe de manera empírica cómo influye esta aplicación en su creatividad a la hora de ordenar en su vida cotidiana más allá de la pantalla.

Ordenar siendo creativos no es una tarea fácil, ya que la propia acción requiere un comportamiento disciplinado y rutinario. Sin embargo la app ayuda a que los niños y niñas tengan que ir tomando decisiones, elijan un camino u otro y sepan resolver problemas de distinta forma, lo cual ayuda a entrenar su imaginación mientras sientan las bases de la virtud del orden.

Para sobreponer las carencias que presenta dicho juego, los padres y madres tienen un rol fundamental en aprovechar las situaciones que se describen en el juego para llevarlas a la práctica en el día a día de los niños y niñas y evitar que sean simplemente espectadores pasivos.

El momento adecuado para introducir los valores del orden, la armonía y la higiene, va de los dos a cuatro años, la misma edad en la que se pueden incorporar pantallas de forma responsable. Teniendo en cuenta el interés que generan los juegos interactivos en niños y niñas y que jugar es la forma de aprender preferida de los más pequeños, sostenemos que esta aplicación de Dr. Panda Casa puede ser muy útil para utilizar con estos, guiados por sus padres y madres y con normas de uso responsable, fomentando también la creatividad y la imaginación. 


\section{Bibliografía}

AguirRE, J.C, y JaRAMILlo, L. G. (2015). El papel de la descripción en la investigación cualitativa. Cinta de moebio, (53), 175-189.

https://dx.doi.org/10.4067/S0717-554X2015000200006

Alcazar, J. A. (2001). Virtudes Humanas. Editoral Palabra.

Baños, G. M. (2003). Métodos heurísticos y creación publicitaria. [Tesis]

Bringué, X. y Sábada, C. (2010). Niños y adolescentes españoles ante las pantallas: rasgos configuradores de una generación interactiva. CEE Participación Educativa, 15, pp. 86-104

Costa Román, O. (2017). Hábitos lectores e inteligencia creativa de los estudiantes de Educación Primaria.

CAstillo, M. (1980). La creatividad y su evaluación. Revista Española De Pedagogía, 38(149), 31-62. http://www.jstor.org/stable/23764038

Christakis, D. (2015, diciembre 21). Entrevista El Futuro es One: ¿Cuánto tiempo deben pasar nuestros hijos delante de las pantallas? Responde Dimitri Christakis. Recuperado en enero 2019 de https://bit.ly/2diLOwf

CrescenzI, L. y Grané, M. (2016). An Analysis of the Interaction Design of the Best Educational Apps for Children Aged Zero to Eight. [Análisis del diseño interactivo de las mejores apps educativas para niños de cero a ocho años]. Comunicar, 46, 77-85. https://doi.org/10.3916/C46-2016-08

Csikszentmihaly, M. (1998). Creatividad. El fluir y la psicología del descubrimiento y la invención, Paidós, Barcelona.

Díez, M. (2013). Dr.Panda Games, una app para aprender jugando. Recuperado en febrero 2019 de https://bit.ly/2IQaOB3 
García García, F. (1984). Estudios de creatividad en niños de edad escolar

Tomo 4 Universidad Complutense, Madrid.

García García, F. y Morales Quesada, J. G. (2011). El impacto de la creatividad en la valoración artística. Arte, Individuo y Sociedad, 23 (2), 69-84

GIL, P. G. (2007). Educar en el orden. Madrid: Ediciones Palabra S.A. Nuevas tecnologías y educación.

Grané, M. (2015). Infancia y pantallas, crecer con las TIC. En: Roca, G. (Coord.). Las nuevas tecnologías en niños y adolescentes. Guía para educar saludablemente en una sociedad digital. Barcelona: Hospital Sant Joan de Déu (ed). pp. 46-61.

Guerra, J. y ReVuelta, F.l. (2016). Análisis del conocimiento del código PEGl en la formación inicial del profesorado. En RELATEC Revista Latinoamericana de Tecnología Educativa, Vol. 15(1) (2016) 87-96

GuILFoRD, J.P. (1977). La naturaleza de la inteligencia humana. Buenos Aires, Paidós. GullForD, J.P. (1978). La Creatividad, presente, pasado y futuro. En Guilford, J.P y otros.- Creatividad y educación. Paidos. Buenos Aires.

L'ECUYER, C. (2018, enero 29). Entrevista Apredemos Juntos BBVA: Las pantallas perjudican la atención de los niños. Recuperado en marzo 2019 de https://bit.ly/2Teg6WL

Martínez, F. y M. Prendes (coords.) (2004). Nuevas Tecnologías y Educación, Pearson Educación, Madrid.

MontessoRi, M. (1998a). Educación y paz. Errepar: Buenos Aires.

Namakforoosh, M. (2005). Metodología de la investigación. México: Limusa. 
¿Se puede fomentar el orden desde la creatividad? Estudio de caso: aplicación Dr. Panda Casa

Nielsen (2012). American families see tablets as playmate, teacher, and babysitter. Nielsen. Recuperado de https://bit.ly/2ISFSVL

Olaortua, A., Arrillaga, I. y Sesumaga, E. (2018). Nativos digitales: Consumo, creación y difusión de contenidos audiovisuales online. Revista Comunicar, 57, 61-69 https:// doi.org/10.3916/C57-2018-06

Prensky, M. (2001). Digital Natives, Digital Immigrants, Revista On the Horizon, 1-6.

Ramírez, I. C. (2008). Desarrollo de la creatividad en Educación Infantil. Creatividad y sociedad, 20.

Robert, L. y Botella, M. (2015). Conectados en familia: buenas prácticas y recomendaciones. En: Roca, G. (Coord.). Las nuevas tecnologías en niños y adolescentes. Guía para educar saludablemente en una sociedad digital. Barcelona: Hospital Sant Joan de Déu (ed). pp. 135-147.

RocA, G. (Coord.) (2015). Las nuevas tecnologías en niños y adolescentes. Guía para educar saludablemente en una sociedad digital. Barcelona: Hospital Sant Joan de Déu (ed). Disponible en la web: http://faros.hsjdbch.org

Sáez, I. (2011). La gestión emocional como base de la creatividad, hacia una nueva cultura organizacional. Projectics / Proyéctica / Projectique, 8-9(2), 143-155. doi:10.3917/proj.008.0143

SANDELOWSKI, M. (2000). Whatever happened to qualitative description? Research in Nursing \& Health 23: 334-340. doi: 10.1002/1098-240X(200008)23:4<334::AID-NUR9>3.0.CO;2-G

ToRRES, M. (2002). El juego: una estrategia importante . Educere, 6 (19), 289-296 VARONA, A. (2014): Prepara sushi con el Restaurante del Dr Panda 2. Recuperado en febrero de 2019 de https://bit.ly/2m2EVdm 


\section{Creatividad \\ y Sociedad}

Exploración de lenguajes en la formación inicial del profesorado de Educación Infantil

\section{Languages exploration in the teacher training in Early Chilhood Education}

Montserrat Gonzalez Parera Universidad de Manresa

Universidad Autónoma de Barcelona montsegp80@gmail.com https://orcid.org/0000-0002-7929-6558 


\section{Resumen}

En este trabajo plasmamos la experiencia llevada a cabo con el alumnado del Grado de Educación Infantil de una universidad catalana con la finalidad de despertar sus lenguajes adormecidos.

Según Morin (2003) en la vida y en la historia, la sobreadaptación a condiciones dadas nunca han sido signo de vitalidad sino indicios de pérdida de inventiva y de creatividad. La universidad no solamente debe tratar de modernizar la cultura, sino también de culturalizar la modernidad. Para dirigirnos a estos fines y reformar la universidad no es suficiente democratizar los estudios universitarios, se trata de reformar también nuestra capacidad de organizar el conocimiento y sus representaciones. En educación, el concepto "conocimiento" ha de definirse de manera profunda y con mayor consciencia para que pueda desarrollarse y evolucionar en condiciones de mayor entusiasmo y vitalidad.

Representar el conocimiento a través de diferentes lenguajes es un hecho consustancial al ser humano. Desde pequeños y pequeñas, un individuo que se comunica con distintos lenguajes es una persona que aprende de modo transdisciplinar, entendiendo este concepto vinculado al paradigma ecosistémico. Este paradigma reviste y proyecta una nueva forma de generar conocimiento sobre la práctica educativa siempre en relación con el sujeto, la sociedad y la naturaleza.

\section{Abstract}

In this work we capture the experience of students from the Infant Education Degree of a Catalan University with the purpose of awakening their numbed languages. According to Morin (2003) in life and in history, over-adaptation to given conditions has never been a sign of vitality but an indication of loss of inventiveness and creativity. University should not only try to modernize culture, but also to culturize modernity. To address these goals and reform universities, it is not enough to democratize university studies; it is also about reforming our ability to organize knowledge and its representations. In education, the concept of "knowledge" has to be defined in a profound way and with greater awareness so that it can develop and evolve with more enthusiasm and vitality. Representing knowledge through different languages is part of who we are as human beings. From a very young age, an individual who communicates with different languages is a person who learns in a transdisciplinary way, understanding this concept linked to the ecosystem paradigm. This paradigm covers and projects a new way of generating knowledge about the educational practice always in relation to the subject, society and nature.

\section{Key words}

Creativity $\cdot$ Teacher preparation · Pedagogical methods . Theater

\section{Palabras clave}

Creatividad · Preparación de profesores

- Métodos pedagógicos · Teatro 


\section{Winston Churchill}

\section{Introducción}

A menudo nos encontramos una frontera entre las actividades de expresión creativa y las actividades de trabajo. Cómo si las primeras hicieran referencia al mundo lúdico y por tanto banal y las otras al mundo serio y por tanto sensato. Tonucci (1975) refleja muy bien este sentimiento cuando dice:

Para empezar, el niño, que hasta entonces había jugado y que a través del juego había conocido su mundo, se entera que no siempre se puede jugar, que también se tiene que comprometer, que se tiene que trabajar. Imaginémonos qué grande será la decepción y la humillación de este niño para quien el juego ha sido siempre lo único serio, por el cual merecía la pena cansarse hasta el punto de dormirse jugando u olvidar comer. (...) Para un niño que no hizo nunca dos veces la misma cosa empieza a entender: que no es cierto que él supiera tantas cosas; que el trabajo es necesario mientras que el juego es inútil y estúpido y que sirve solo para descansar entre trabajo y trabajo (p. 38).

Desde pequeños, se prefigura ya la alienación del trabajo y la banalidad del juego, aún sabiendo que durante la expresión libre y creativa es cuando culminan los principales campos de operaciones de la capacidad simbólica asociada a los lenguajes. Llegados a este punto, aclaramos que utilizamos el concepto "lenguaje" inspirándonos en la pedagogía de Reggio Emilia que se refiere no solamente a los lenguajes hablados, sino a todas las formas de comunicación a través de las cuales se lleva el pensamiento humano a reflexionar y a elaborar interpretaciones Necchi, 
2013). Cuando en la pedagogía de Reggio, con el conocido poema Los cien lenguajes de Loris Malaguzzi (1995) defienden que un niño o una niña posee cien lenguajes se hace referencia a las diferentes maneras de expresión y la multiplicidad de códigos que podemos manejar, lanzando la idea de que los procesos de aprendizaje tienen lugar donde interactúan varios de estos lenguajes. Según Vecchi (2013) "cada lenguaje tiene su propia gramática, su carácter específico, pero también tiene una estructura dispuesta para la comunicación y la relación" (p. 72).

La actitud de exploración libre de lenguajes comporta ya desde la infancia un impacto en las funciones del desarrollo que cabe resaltar (a partir de Piaget, 1973 y Boscaini, 1988):

- Proceso cognitivo: la interacción social entre los niños y niñas, potencia el desarrollo social y cognitivo. En la etapa más egocéntrica supone un ejercicio de descentralización. Tiene un valor potencial para provocar estrategias de razonamiento y transferirlas.

Competencia lingüística y escucha: el ambiente creativo favorece el uso de los diferentes lenguajes. El individuo pone en práctica elementos recientemente adquiridos y experimenta con nuevas formas lingüísticas. La comunicación oral es un factor importante para el éxito de las situaciones representadas.

Asimilación de la realidad conflictiva: la creatividad facilita el distanciamiento de una realidad difícil y puede servir como instrumento para afrontarla.

Aprendizaje ético y socialización: la expresión libre es la manera de relacionarse más común y natural que tienen los niños y niñas. La expresión potencia el sentido de cooperación, pues para lograr los hitos se tiene que compartir y el niño o niña comprueba la necesidad de llegar a acuerdos. Por lo tanto, le ayuda a considerar la perspectiva del otro. 
- Afirmación de la identidad: en situaciones de actividad expresiva se exploran y se ponen a prueba las aptitudes personales y las actitudes hacia los otros mientras que a su vez somos receptores de las expresiones de los demás.

Aprendizaje psicomotor: la facultad psicomotriz dibuja la identidad del sujeto actuando sobre la memoria de su cuerpo y sobre su psiquismo a través del cuerpo.

Estas funciones toman importancia en la expresión libre de los niños y niñas y se desarrollan en la actividad lúdica durante la infancia. Pero, ¿qué pasa cuando crecemos? Y ¿qué pasa en el caso del profesorado? ¿Tenemos maestros y maestras suficientemente entrenados en su expresión libre y conscientes de su multiplicidad de lenguajes? Cuando crecemos nos van ordenando esta expresión libre y nos fragmentan esa compleja representación del conocimiento. Así, nos llevan a romper la realidad en pequeñas piezas desconectadas, dañando el entrelazado de los múltiples lenguajes que poseíamos en la infancia y dejándonos, en último término, huérfanos de ellos. De esta manera, a menudo el concepto conocimiento en educación es banal y superficial. Como si faltara profundidad y conciencia, conexión vivaz y cultural. Algunos autores como Morin (2003) y Moraes (2008) proponen que aspiremos a combinar el conocimiento con otras palabras como transdisciplinario, solidario, tierno, elegante o bello.

\section{De artes, lenguajes y conocimiento}

Queremos abordar el arte como un acontecimiento epistemológico y pedagógico. El arte no debe estar confinado solamente a las galerías y museos. Si así fuera, desaparecería su complejo potencial. De acuerdo con Ceruti (citado por Vecchi, 2013, p. 69) "epistemología y estética son sinónimos".

Desde las edades tempranas, sin reducir su valor, tenemos que trascender los materiales y las técnicas para detenernos y observar los procesos de empatía y las 
intensas $\square$ relaciones con las cosas. Estos procesos se empiezan a manifestar en la variedad del juego en la infancia y según Read (2003), pueden desarrollarse hacia cuatro direcciones:

Desde el punto de vista del sentimiento, el juego puede evolucionar mediante la personificación, hacia el drama.

Desde el punto de vista de la sensación, el juego puede evolucionar mediante los modos de autoexpresión, hacia el diseño visual y plástico.

Desde el punto de vista de la intuición, el juego puede evolucionar mediante ejercicios rítmicos, hacia la danza y la música.

Desde el punto de vista del pensamiento, el juego puede evolucionar mediante las actividades constructivas, hacia la artesanía. (p. 222)

Desde una mirada compleja, en la línea de Morin (2003), estos aspectos podrían constituir el desarrollo armonioso de la personalidad ya que incluyen todas las disciplinas que la enseñanza escolar tan a menudo parcela, divide y desconecta. El drama abarca las disciplinas relacionadas con la comunicación y las habilidades sociales. El diseño visual y plástico incluyen el dibujo, la pintura, el pensamiento abstracto. La danza y la música integran el trabajo con el físico. Y la artesanía puede abarcar la geometría y las ciencias.

Si el ideal de la educación es conseguir que las personas crezcan en una armoniosa conjunción de todas estas funciones estimuladas, los procesos de aprendizaje deben estimular el cerebro para madurarlo hacia un proceso de desarrollo de la expresión que está cerca del arte. 


\section{Descripción de la experiencia}

\subsection{Orígenes}

Nos basamos en la idea de formación orientada a la adquisición de competencias profesionales (a la vez que culturales). El Ministerio de Educación y Ciencia de España establece los requisitos para habilitar el ejercicio profesional de Maestro de Educación Infantil y en el apartado donde se definen los objetivos-competencias plantea: "Conocer la evolución del lenguaje en la primera infancia, saber identificar posibles disfunciones y velar por su correcta evolución. Abordar como eficacia situaciones de aprendizaje de lenguas en contextos multiculturales y multilingües. Expresarse oralmente y con medio escrito y dominar el uso de diferentes técnicas de expresión."

El estudio de la expresión como competencia docente es un campo relativamente reciente. En el ámbito educativo, tras un periodo en el que la atención ha estado centrada en el análisis de las variables estructurales (planificación, recursos y evaluación), el interés se ha ido desplazando hacia los procesos de interacción humana que tienen lugar en su seno y que explican buena parte del funcionamiento docente (Domingo, Gallego et al., 2010).

Para abordar estos aspectos de la comunicación como competencia docente, el punto de partida es el aprendizaje vivencial. Según Motos (en Bercebal et al., 2000) el aprendizaje vivencial es un modelo de intervención basado en el principio de hacer y aprender mediante el procesamiento de las vivencias en situación. También, en otras palabras, es el proceso mediante el cual vamos construyendo nuevos significados de las cosas que nos rodean y del mundo, al mismo tiempo que mejoramos estructuras y habilidades cognitivas, desarrollamos nuevas competencias, modificamos nuestras actitudes y valores, proyectando estos cambios en la vida y en las relaciones con los otros (De la Torre y Moraes, 2005). 


\subsection{Naturaleza y objetivos}

La naturaleza de la propuesta busca experimentar la complejidad del aprendizaje de los lenguajes (artísticos). Y los objetivos del trabajo fueron:

1. - Investigar los múltiples lenguajes que tenemos a disposición como maestros y maestras.

2. -Entender la importancia de la vivencia personal de los lenguajes por parte del profesorado, para enriquecer la futura praxis en Educación infantil.

\subsection{Desarrollo}

Dentro del marco de la asignatura de Didáctica del lenguaje en el Grado de Educación Infantil de la Universidad de Manresa situada en Catalunya, desde hace tres años se lleva a cabo un proyecto de creación de escenarios expresivos, donde los futuros maestros y maestras exploran y van más allá de sus lenguajes habituales.

Primeramente, se hace una elección conjunta de una temática que hace de eje vertebrador de todos los trabajos. El primer año se eligió la temática de la muerte, el segundo año la maternidad y el tercer año el tiempo. A partir de aquí, cada persona, pareja o pequeño grupo tiene que buscar materiales inspiradores para desarrollar una propuesta de creación de un (y mediante un) escenario expresivo con un lenguaje que no sea de los más habituales para ello y ellas. Se les incentiva para que exploren los lenguajes artísticos como por ejemplo la fotografia, la pintura, el audiovisual, la performance o el teatro. Después de unos días de reflexión se entrega un primer esbozo de propuesta que les sirve para empezar a poner en marcha las ideas. Paralelamente se les pide un escrito siguiendo un guión facilitado: 
1. Nombre de las personas que realizan el proyecto.

2. ¿Qué razones éticas, estéticas y técnicas justifican el proyecto?

3. ¿Cuál es el posicionamiento del grupo al respecto?

4. ¿Qué se quiere transmitir?

5. ¿A quién va dirigido?

6. ¿Qué lenguajes utilizaremos?

7. Referentes y materiales

Tabla 1. Guión para la primera fase.

Fuente: Elaboración propia.

Durante cinco semanas que dura el proyecto se les acompaña en la elaboración de la propuesta y van actualizando su escrito. Mediante trabajo autónomo y tutorizado se va concretando la propuesta de cada grupo que finalmente es expuesta al gran grupo en la universidad.

Una vez expuestos los trabajos cada cual, individualmente, entrega un análisis de su proceso personal y también plasma su experiencia como receptor. Este análisis se puede ir redactando a medida que avanza el proceso creativo siguiendo un segundo guion facilitado:

1. Nombre de la persona que hace el análisis.

2. Descripción del proceso creativo.

3. ¿Cómo me he sentido? Justificación.

4. ¿Qué se quería expresar? ¿Se consiguió?

5. y 6. Puntos fuertes y puntos a mejorar del proyecto.

7. Referentes y materiales.

Tabla 2. Guión para la segunda fase. Fuente: Elaboración propia.

Después de compartir los trabajos con el grupo en la universidad, el segundo año el Museu Comarcal de Manresa nos invitó a exponer el proceso de trabajo y el tercer año se emitió el audiovisual de la permormance colectiva en la televisión

1 Exposición "Néixer a Manresa. Memòria, art, pedagogia". Temporada 2018. Museu Comarcal de Manresa. 
comarcal Canal Taronja². Esta difusión permitió visibilizar y poner en valor las aportaciones del alumnado.

\section{Resultados: seguimiento, valoración, difusión y polinización de la experiencia}

A partir de los análisis que han escrito las participantes, se ha realizado una compilación de los temas más relevantes relacionados con la experiencia de este proceso creativo y de aprendizaje transicisplinar.

\subsection{El miedo a salir de la zona de confort y asumir nuevas res- ponsabilidades}

Según Lavelle (citado por Nolin, 2008) los lenguajes artísticos nos descubren la presencia de la realidad, aquella presencia que queda escondida por la utilidad y las necesidades de la vida cotidiana. Estos sentimientos de inseguridad, de miedo y de nervios quedan plasmados en las palabras de las participantes cuando manifiestan:

"(...) disponíamos de poco tiempo para preparar todo lo necesario: guión -hacerlo y memorizarlo-, material, ensayar, etc. Este factor, me generó inseguridad, y a la hora de exponer la obra también mucho nerviosismo." (Aida)

"A pesar de haber tenido algunos miedos a la hora de preparar mi propuesta y por si obtendría el resultado esperado, he disfrutado mucho de este trabajo, me ha parecido muy interesante y profundo." (Àngels)

"(...) los sentimientos que he podido experimentar han sido mucho más complejos y diversos. En este punto del proyecto tuvimos que escoger el lenguaje que

2 El audiovisual de la performance disponible en:

http://www.canaltaronja.cat/central/manresa/didactica-del-llenguatge/ 
utilizaríamos y personalmente fue uno de los momentos donde me sentí más insegura puesto que surgió la posibilidad de realizar una obra teatral." (Neus)

"(...) sufrí muchos nervios en el momento de preparación de la escena y cierto miedo por la posibilidad de quedarme en blanco en el momento de la actuación." (Sara)

Los lenguajes artísticos tienen la capacidad de interrumpir las relaciones con la realidad, atraviesan las representaciones adquiridas y nos obligan a hacer un salto para encontrar un contacto más absoluto. Este salto da miedo porqué nos hace salir de nuestra zona de confort y nos obliga a asumir nuevas posiciones y responsabilidades ya que, de acuerdo con Doris Sommer (2014) fundadora del Cultural Agents en la Universidad de Harvard, quien se expresa a través del arte es agente activo y deja de ser víctima de las circumstancias.

\subsection{La satisfacción de explorar los lenguajes poco habituales}

Las participantes experimentan sensaciones placenteras en la investigación y la experimentación del acto creativo. Buscan relacionarse con la realidad a través del acto creador que les lleva a nuevas formas y a códigos poco habituales en su día a día:

"Una vez llevada a cabo la representación, la emoción fue el primer sentimiento que tuve, seguido de la gran liberación que implicaba finalizar con éxito nuestra propuesta creativa. A pesar de no conseguir la máxima perfección a la que aspirábamos, pienso que fue un éxito. Por este motivo, mi satisfacción era plena." (Aida)

"Cuando trabajas un tema que te causa interés y tienes ganas de trabajarlo, el trabajo no se hace nada pesado y te gusta hacerlo. Personalmente he disfrutado mucho de la preparación, la grabación y el montaje del documental. Aunque no tengo mucha experiencia con las aplicaciones para crear videos y nunca había hecho una entrevista grabada, me ha gustado vivir esta experiencia y probar un lenguaje de expresión nuevo." (Àngels) 
"(...) me sentí muy orgullosa y revolucionaria." (Júlia)

"Califico este proceso vivido como intenso y profundo." (María)

"(...) consideré esta oportunidad como un reto para explorar nuevos lenguajes, trabajar la creatividad y hacer frente a la vergüenza." (Cristina)

"(...) una vez acabada la representación, sentí una gran satisfacción por haber podido superar este pequeño reto personal." (Neus)

"(...) un trabajo donde hemos podido elegir el tema y por tanto, nos interesaba y estábamos motivadas. (...) Hemos podido ser libres para hacer lo que creíamos más útil para nuestro propósito." (Júlia)

"Valoro muy positivamente la elección del lenguaje teatral. A pesar de la inseguridad que me generó, fue una buena manera de explorar nuevos horizontes y de salir de la zona de confort. Trabajar a partir de retos hace más significativo el aprendizaje." (Neus)

"Considero que ha sido una experiencia enriquecedora y estimulante. La vivencia en primera persona de todo el proceso creativo me ha permitido tomar conciencia de la importancia de tener en cuenta todos los lenguajes del que dispone un/a maestro/a en su praxis." (Neus)

En la línea de Pineau (citado por Nolin, 2008), el hecho de vivir la experiencia y después reflexionarla aproxima a la conciencia de la autoformación, en la que el sujeto es considerado como un individuo consciente, capaz de dar sentido al mundo. En este sentido, Pineau ve la persona como confluencia de realciones y es precisamente gracias a esta capacidad de relacionar y relacionarse que el sujeto puede experimentar el goce de ampliar su experiencia. 


\subsection{La importancia de sentirse bien acompañados}

Toda y cualquier actividad pedagógica trae con ella misma una perspectiva teórica que la sostiene (Moraes, 2008). La manera de escuchar, la manera de atender, la manera de valorar o de dar feedback del professorado universitario que impartimos docencia en las Facultades de Educación nos delata. Morin nos advierte que la reforma del pensamiento exige la reforma de la universidad y de sus maneras de hacer (Morin, 2003).

Los y las estudiantes dan importancia a sentirse acompañados en el proceso. Para compartir las posibles desazones mencionadas anteriormente, valoran positivamente que la docente-guía de la experiencia les oriente y les deje libres pero no solos. Un entorno de trabajo estructurado pero libre genera seguridad y en consecuencia más tolernacia a la incertidumbre y al posible estrés que genera salir de la zona de confort:

"Un punto positivo ha sido la metodología de trabajo propuesta por la profesora y la entrega de revisiones y concreciones semanales de la propuesta base. Este hecho nos mantenía conectadas con el trabajo, haciendo que lo tuviéramos que repensar, concretar y perfeccionar." (Neus)

Este acompañamiento provocaba un diálogo continuo entre el imaginario y la realidad. A través del diálogo con una docente-guía, los intercambios hacían cuestionarse las ideas y obligaban a saberlas justificar. Unas veces este diálogo tenía forma de interrogación. Otras veces tenía forma de escucha. Pero en ambas formas, lo que siempre imperaba era una presencia a través del cuerpo, las emociones y el pensamiento. Una presencia llena de respeto, que no corregía ni penalizaba ninguna propuesta; una presencia auténtica que es el fundamento de toda comunicación y que al practicarla, reformamos la relación educativa y expandimos la praxis pedagógica. 


\subsection{La colaboración para llevar a cabo el propósito}

Tener un hito común hace necesario que el grupo tenga que planificar, organizar y clasificar los conocimientos en cooperación con las otras personas. Se aprende a desarrollar el trabajo en equipo y a integrar y gestionar las diferentes voluntades del grupo:

"(...) este trabajo ha hecho darme cuenta de muchas cosas y me he sentido muy a gusto haciéndolo. (...) Yo he dirigido el escenario, pero contar con tanta participación me ha llenado mucho, si la gente te anima, es que cree en ti y esto te hace seguir adelante." (Crisitna)

"(...) encuentro que ha sido un trabajo muy cooperativo donde gracias a la participación de todas hemos podido realizar el cortometraje. Durante algunas de las grabaciones de las escenas del corto he sentido pena por todo lo que le hacíamos a la protagonista (víctima) porque empatizaba con ella." (Helena)

"Esta decisión fue acompañada de muchas dudas sobre mi valía y capacidad para expresar el mensaje con suficiente contundencia, pero con el apoyo de mi compañero, que en todo momento confió en nuestra competencia y a medida que el proyecto iba cogiendo forma, fui adquiriendo la confianza necesaria para salir adelante y disfrutar del proceso." (Oriol)

Se ponen en práctica las habilidades para el desarrollo de una conducta que, bajo la constante toma de decisiones, se dirige hacia un hito concreto y común. Se interpreta el mundo con los otros, con múltiples miradas, posicionándonos en espacios de reflexión colectiva. Se aborda la realidad de manera conjunta y el aprendizaje se va tejiendo entre todos. En este sentido, desde una visión constructivista y desde un marco sociocultural (Vigotski, 2001) destacamos la importancia de las relaciones humanas en el desarrollo de las actividades mentales complejas y el papel que juegan los marcos de internalización, la transferencia y la zona de desarrollo próximo en el proceso de construcción del conocimiento. 


\subsection{La emoción en la recepción}

La experiencia contempla la emisión de un mensaje pero también la recepción de las propuesta ajenas y propias en algunos casos.

Las situaciones que favorecen un aprendizaje transdiciplinar son aquellas que estimulan los sentidos y van más allá de los aspectos cognitivos, incluyendo la imaginación, la intuición, la colaboración y el impacto emocional de sus participantes (Moraes, 2008). Ya Aristóteles (2004) en su clásica "Poética" nos hablaba del impacto emocional causado por la recepción de las tragedias griegas cuando se refería a la kátharsis de los espectadores.

En este proyecto, las participantes consideran que se establece un vínculo claro y directo con la observación de la actuación de los otros compañeros y compañeras. Se fomenta la emoción y esta enciende y mantiene la curiosidad y la atención, y con esto el interés por el descubrimiento de lo nuevo. Esta kátharsis, esta vivencia emocional es básica para la elaboración de las funciones mentales necesarias par adquirir conocimientos, y además, facilita vínculos sociales en el grupo (Mora, 2016). Como ya es sabido, el binomio emoción-cognición es indisociable para generar un espacio de aprendizaje:

"(...) ver la presentación de Irinia me marcó durante toda la tarde y me hizo estar con un nudo en la garganta. Creo que fue un muy buen trabajo y nos hizo remover cosas. (...) creo que nos hizo reflexionar y se lo agradezco." (Àngels)

Las investigaciones en el campo de las neurociencias confirman en qué medida nuestros pensamientos y sensaciones forman un continuo. En esta interacción se activan diferentes áreas de la estructura cerebral, facilitando así mayor riqueza e impacto del aprendizaje. 


\subsection{La importancia de la precisión y las ganas de seguir trabajando}

Las competencias profesionales no solo incluyen capacidades requeridas para el ejercicio profesional, sino también cualidades personales relacionadas con la exigencia, el rigor y la precisión para desarrollarse efectivamente. En este sentido, las persones participantes manifiestan un interés en el cuidado de los detalles y una voluntad de trabajar con profundidad:

"Fue todo un reto tomar la decisión del tipo de lenguaje. En mi caso, ya había realizado varías obras de teatro con un grupo amateur, por lo tanto, tenía ganas de volver a experimentar la adrenalina que se siente encima del escenario. El teatro es un lenguaje en el cual me siento cómoda y me gusta practicarlo. No obstante, también sentía mucha presión puesto que para que llegara el mensaje como queríamos hacía falta mucha precisión." (Aida)

"Pienso que cuidamos hasta el más mínimo detalle y esto proporcionó que el espectador se situara dentro de un contexto muy determinado." (Joan)

"El hecho de tener que concretar al máximo los detalles nos facilitó la gestión y control de los posibles imprevistos." (Neus)

"Los puntos fuertes de este trabajo han sido principalmente la motivación y las ganas de saber más." (Aida)

"El punto a mejorar de este trabajo podría ser la carencia de tiempo que hemos tenido al hacerlo, puesto que podríamos haber profundizado más." (Helena)

"Considero que si hubiéramos tenido más tiempo hubiéramos podido perfeccionar el texto para que el mensaje llegara más claramente al público." (Neus)

"(...) el teatro requiere mucha práctica, sobre todo si se quiere perfeccionar todos los detalles: aunque muchas veces parezca improvisación -es el arte del teatro- poco tiene de ello." (Aida) 
Esta motivación por querer seguir viene dada por la estimulante y nueva relación con el mundo real que experimentan más que por su relación con la utilidad (Lavelle citado por Nolin, 2008). Esto les confirma su necesidad de exploración de lenguajes y conecta a su vez con su sensibilidad y con su capacidad de resonancia hacia los demás. Cada lenguaje tiene sus propios códigos y sus técnicas, sus especificidades y sus riquezas.

Como recordábamos al inicio, cuando en la pedagogía de Reggio Emilia declaran con el poema Los cien lenguajes de Loris Malaguzzi (1995) que un niño o una niña posee cien lenguajes, se refieren a la multitud de posibilidades comunicativas con las que nuestra especie está dotada. Son muchos los autores que, apoyados en la neurociencia, sostienen que es precisamente en esa relación de lenguajes y sensaciones donde tiene lugar el aprendizaje.

En consecuencia, crear el hábito de la interacción constante de la expresión a través de diferentes lenguajes estimula las relaciones entre los procesos y la conexión de uno a otro activa distintas zonas del cerebro, dando así una riqueza de pensamiento. A su vez, es crucial que cada lenguaje sea rico y lleno de matices por él mismo, ya que cuanto más complejo sea un lenguaje más capaz será de establecer sinergias con otros.

Pero muy frecuentemente, la dificultad surge cuando el profesorado no se siente cómodo acompañando el descubrimiento de unos lenguajes que dejó adormecidos en su propia infancia. Es una paradoja y no es una cuestión fácil, ya que nosotros como adultos nos sentimos analfabetos en muchos de aquellos "cien lenguajes" que algún día vivimos. Este hecho limita nuestra capacidad como docentes de escuchar los procesos de exploración expresiva de nuestro alumnado y les puede condicionar y coartar su creatividad. 


\section{Conclusiones}

La universidad tiene la doble misión de adaptarse a las necesidades de la sociedad contemporánea y a la vez conservar y transmitir el patrimonio cultural. Durante el siglo XX ha existido la presión de enfocar las formaciones universitarias a demandas económicas y administrativas del mercado laboral y marginar la cultura humanística.

El estudio de las competencias relacionadas con la cultura humanística en el ámbito universitario es un campo de trabajo emergente. Este proyecto de experiencia vivencial y de posterior reflexión enmarcado dentro de la asignatura de Didáctica del lenguaje pretendía cuestionar y mejorar la competencia comunicativa que promovemos en la Facultad de Educación.

Como el profesorado es uno de los principales agentes de estos procesos educativos, en esta experiencia nos acerquemos a propuestas específicas que enriquecen su formación inicial, y en consecuencia nos acercaremos a polinizar la creatividad al sistema educativo. La construcción del rol de educador implica un proceso de reconstrucción de las experiencias, por lo tanto aquello en lo que se convierte un docente es el resultado del diálogo y de las influencias permanentes con su contexto.

Entendemos este proyecto como un abono transdisciplinario, lleno de vitalidad y entusiasmo, capaz de acoger distintas formas de pensar, sin miedo a la interferencia ni a la contaminación, sino valorándolas como oportunidades. Consideramos que la expresión mediante múltiples lenguajes es uno de los gérmenes de creatividad de los individuos. Para conseguir una formación integral y competente del profesorado capaz de transmitir y comunicar el aprendizaje de una didáctica creativa puede ser la semilla para estimular y favorecer el pleno desarrollo de los lenguajes en la escuela.

Teniendo en cuenta que el niño o la niña es una persona completa, un ser único con sus "cien lenguajes", es primordial darles múltiples y constantes oportunidades para explorarlos. Para llegar a este fin, antes hay que potenciar y despertar los lenguajes dormidos que tienen los y las maestras. 
El profesorado en formación se transforma en la universidad de manera crucial y determinante. Es durante esta formación que estos y estas maestras del futuro, a partir de sus propias experiencias, construyen su visión de la praxis profesional.

Finalmente, también entendemos que el trabajo de despertar la multiplicidad de lenguajes debe seguir dentro y fuera de la universidad y debe ser longitudinal en el tiempo, a lo largo de toda la vida del profesorado en activo, más allá de su formación inicial, para evitar así que vuelvan a caer en manos de Morfeo.

\section{Bibliografía}

Aristóteles. (2004). Poética. Buenos Aires: Colihue.

Bercebal, F., De Prado, D., Laferrière, G. y Motos, T. (2000). Sesiones de trabajo con los pedagogogos de hoy. Ciudad Real: Ñaque.

Boscaln, F. (1988). Psicomotricidad e integración escolar. Madrid: Nuñez.

De la Torre, S. y Moraes, M. C. (2005). Sentipensar. Fundamentos y estrategias para reencantar la educación. Archidona (Málaga): Aljibe.

Domingo, J., Gallego, J.L. et Al. (2010). Competencias comunicativas de mestros en formación. Profesorado. Revista de Currículum y Formación de Profesorado, 14(2), 303-323. Recuperado de http://www.redalyc. org/articulo.oa?id=56717074021

Elıot, A.D. y Dewck, C.S. (2008). Handbook of competence and motivation. New York: Guilford.

Josso, M.-C. (2011). Expériences de vie et formation. Paris: L'Harmattan.

Malaguzzı, L. (1995). Invece il cento c'è. En C. Edwards, L. Gandini i G. Forman (Ed.), I cento linguaggi dei bambini (pp. 76). Bérgamo: Junior. 
Exploración de lenguajes en la formación inicial del profesorado de Educación Infantil

Mora, F. (2016). Neuroeducación. Madrid: Alianza.

Moraes, M. C. (2008). Ecologia dos saberes. Complexidade, transdisciplinariedade e educação. São Paulo: Prolíbera.

Morin, E. (2003). Tenir el cap clar: Per organitzar els coneixements i aprendre a viure (3 $3^{\mathrm{a}}$ ed.). Barcelona: La Campana.

NoLIN, D. (2008). L'art comme processus de formation de soi. Paris: L'Harmattan.

Piaget, J. (1973). Psicología y pedagogía. Barcelona: Ariel.

READ, H. (2003). Educación por el arte. Barcelona: Paidós.

Sommer, D. (2014). The Work of Art in the World. Tenessee: Duke University Press.

Tonuccl, F. (1975). La escuela como investigación. Sant Adrià del Besòs: Avance.

VECCH, V. (2013). Arte y creatividad en Reggio Emilia. Madrid: Morata.

Vigotski, L. S. (2001). Psicologia da arte. São Paulo: Martins Fontes. 


\section{Creatividad \\ y Sociedad}

La creación e interpretación de partituras gráficas como recurso educativo para el desarrollo de la creatividad

The creation and interpretation of graphic scores as an educational resource for the development of creativity

Dra.Marina Buj Corral

Universitat de Girona

Universitat de Barcelona marina.buj@udg.edu, marina.buj@ub.edu https://orcid.org/0000-0002-5882-0744

Recibido: 29 de mayo de 2019

Aceptado: 15 de diciembre de 2019

Para citar este artículo: Buj Corral, M. (2020) La creación e interpretación de partituras gráficas como recurso educativo para el desarrollo de la creatividad. Escuelas creativas. Creatividad y Sociedad (32) 123-142.

Recuperado de http://creatividadysociedad.com/wp-admin/Artículos/32/32.6.pdf 


\section{Resumen}

El presente artículo describe el desarrollo de una experiencia educativa relacionada con la estimulación de la creatividad musical y artística: la creación e interpretación sonora de partituras gráficas. Esta experiencia se llevó a cabo en la asignatura "Artes, calidad y multiculturalidad", del Grado de Maestro de Educación Primaria de la Universidad de Girona, en las sesiones del bloque de música, durante curso académico 2018/2019.

La citada experiencia se basa en la capacidad de las partituras gráficas o visuales de actuar como imágenes de estimulación creativa, donde los grafismos son detonadores de nuevos procesos sonoros, fomentando la imaginación y la posibilidad de crear desarrollos musicales a partir de lo que los elementos gráficos sugieren.

A partir de la introducción de los conceptos de "sinestesia" y "partitura gráfica" y de la realización de una serie de ejercicios basados en la transposición de medios artísticos, se propone a los estudiantes la creación y posterior interpretación de una partitura gráfica. La intervención educativa da lugar a propuestas muy variadas y creativas, así como a desarrollos plásticos y sonoros sorprendentes. La polinización de la experiencia se realizará a través de la práctica docente de los futuros maestros. La experiencia educativa realizada presenta un doble valor: por una parte, el desarrollo de la propia creatividad musical y plástica de los estudiantes y, por otra, la adquisición de un recurso didáctico que podrán aplicar en el futuro en sus aulas de educación primaria para fomentar, a su vez, la creatividad de sus alumnos.

\section{Abstract}

This article presents the development of an educational experience related to the stimulation of musical and artistic creativity: the creation and sound interpretation of graphic scores. This experience was carried out in the subject "Arts, quality and multiculturalism", of the Primary Education Teacher Degree of the University of Girona, in the music block sessions, during the 2018/2019 academic year.

The aforementioned experience is based on the ability of graphic or visual scores to act as images of creative stimulation, where graphics act as detonators of new sound processes, fostering imagination and the possibility of creating musical developments from what graphic elements suggest.

After the introduction of the concepts of "synaesthesia" and "graphic score" and the performance of a series of exercises based on the transposition of artistic media, students are proposed to create and subsequently interpret a graphic score. The educational intervention gives rise to very varied and creative proposals, as well as surprising plastic and sound developments. The pollination of the experience will be done through the teaching practice of future teachers. The educational experience has a double value: on the one hand, the development of students' own musical and plastic creativity and, on the other, the acquisition of a didactic resource that they can apply in the future in their primary education classrooms to encourage, in turn, the creativity of its students.

\section{Key words}

Music $\cdot$ Visual arts · Interdisciplinarity · Graphic scores $\cdot$ Creativity

\section{Palabras clave}

Música · Artes visuales · Interdisciplinariedad

- Partituras gráficas · Creatividad 


\section{Introducción}

Las artes son importantes formas de autoconocimiento. Nos permiten expresarnos, comunicarnos y crear. La influencia de las artes entre sí, la transposición de medios artísticos, el establecimiento de analogías y correspondencias entre diferentes disciplinas artísticas actúa muchas veces como un importante estímulo de la creatividad. El diálogo entre las artes fomenta también la comprensión de los elementos artísticos de una manera más profunda y completa.

El presente artículo expone una experiencia creativa e innovadora desarrollada en el ámbito de la educación universitaria, concretamente en la Facultad de Educación y Psicología de la Universidad de Girona, dentro de la formación de los estudiantes de los Grados de Maestro/a de Educación Primaria y Doble titulación de Maestro/a de Educación Infantil y de Educación Primaria. Dicha experiencia consiste en la creación e interpretación musical de una partitura gráfica.

El objetivo principal de este artículo es, así, presentar el proceso de creación e interpretación de una partitura gráfica como forma de potenciar la creatividad plástica y musical del alumnado universitario. Este texto pretende también dar a conocer la partitura gráfica como recurso didáctico para una enseñanza integrada de las artes visuales y la música y, finalmente, valorar el poder de la interacción entre disciplinas artísticas como elemento detonador de procesos creativos.

La experiencia educativa presentada en este artículo se desarrolla en base a la convicción de que la actividad artística y el desarrollo de la creatividad completan y enriquecen nuestra personalidad, formándonos y aportándonos valor como seres humanos y, en el caso de los estudiantes de magisterio, también como futuros educadores. En este contexto, dicha experiencia utiliza el potencial creativo de la interacción entre disciplinas artísticas que está presente en las partituras gráficas para desarrollar la creatividad de los estudiantes.

Las denominadas partituras visuales o gráficas son partituras musicales que se 
alejan de los signos convencionales de notación y emplean elementos del lenguaje visual (formas, colores, grafismos, texturas, etc.) que no forman parte del sistema de notación tradicional. Estas partituras constituyen una expresión artística sinestésica, situada entre lo visual y lo sonoro'.

El proceso de creación e interpretación de una partitura gráfica como recurso educativo se inscribiría, así, dentro de una serie de propuestas didácticas encaminadas a la consecución de una educación integrada de las artes, en este caso, de la música y las artes visuales. En este sentido, resulta inspirador recordar las palabras de la profesora Sofía López-Ibor (2011) cuando, en la introducción de su libro B/ue is the sea, afirma:

En la antigua Grecia, la poesía, la música, la danza y las artes visuales eran valores nucleares de la cultura - en consecuencia, cultivar el cuerpo, la mente y el espíritu era el fin último de la educación. Parece que hemos perdido esta unidad en nuestras escuelas. (p.4).

La experiencia descrita en este artículo tiene como finalidad contribuir a recuperar parte de esta unidad entre las distintas artes y entre las distintas dimensiones del ser humano.

\footnotetext{
1 Nota: Se entiende aquí el término sinestesia como "metáfora en que una sensación correspondiente a un sentido se expresa por medio de otra correspondiente a otro". (Seco, M., Andrés, O, y Ramos, G.1999, p.4126). Conviene no confundir la acepción del término empleada en este artículo con el significado de sinestesia como fenómeno neurológico, según el cual, sinestesia es la -"sensación secundaria o asociada que se produce en una parte del cuerpo a consecuencia de un estímulo aplicado en otra parte de él". (Diccionario de la RAE. Actualización de 2019).
} 


\section{Metodología}

Para desarrollar el proceso de creación e interpretación de una partitura gráfica se ha empleado una metodología interdisciplinar. Las disciplinas implicadas han sido las artes visuales y la música, por lo que dicha metodología se ha basado en este caso en el diálogo y la interacción entre elementos visuales y gráficos y elementos sonoros.

Por otra parte, se ha hecho uso de una metodología participativa, en la cual los estudiantes han sido agentes activos en la construcción del conocimiento y del aprendizaje. El aprendizaje vivencial se ha relacionado con un marco conceptual en el que se ha profundizado en los conceptos de sinestesia y de partitura gráfica. Asimismo, se ha potenciado la reflexión sobre los procesos vivenciados.

El proceso se ha estructurado en cuatro fases: l: Introducción al concepto de partitura gráfica, II: del sonido al grafismo, III: del grafismo al sonido, N: creación e interpretación de una partitura gráfica. Se describe aquí también una fase previa correspondiente a la experimentación sonora y creación de paisajes sonoros, la cual ha servido de introducción al proyecto.

\section{Orígenes de la experiencia}

La notación gráfica como forma de representación visual del sonido, es un tipo de escritura musical y una expresión artística que tiene su origen a mediados del siglo XX. Las décadas de los años cincuenta, sesenta y setenta fueron las de mayor experimentación con este tipo de notación. Las partituras gráficas se han seguido desarrollando en el arte y la música contemporáneos desde la segunda mitad del siglo XX hasta nuestros días, siendo, actualmente, tanto un recurso compositivo utilizado por parte de los compositores como una expresión artística a la que se acercan creadores de otras disciplinas artísticas como el Arte Sonoro, etc. 
A pesar de que existen ejemplos de partituras visuales en otros momentos de la Historia de la Música (piénsese, entre otros casos, en las partituras en forma circular que se desarrollaron en el siglo XIV en el estilo conocido como Ars Nova), el concepto de notación gráfica (en inglés, graphic notation), hace referencia a un tipo de partituras que comienza a desarrollarse a comienzos de los años cincuenta del pasado siglo entre los compositores de vanguardia. Fueron pioneros de este tipo de obras el compositor norteamericano John Cage y su círculo, integrado, entre otros, por los compositores Earle Brown, Morton Feldman o Christian Wolff. También en Europa y en otros países del mundo, numerosos compositores experimentaron con estas nuevas formas de notación. Destacan, entre ellos, nombres como Roman Haubenstock-Ramati, Mauricio Kagel, György Ligeti, Krzysztof Penderecki, Karlheinz Stockhausen, lannis Xenakis o Josep Maria Mestres Quadreny.

Son varios los factores que estuvieron presentes en el origen y desarrollo de este tipo de escritura visual del sonido. Entre ellos, destaca el deseo de los compositores de vanguardia de conseguir una mayor libertad y apertura interpretativa, así como la búsqueda de una mayor implicación creativa por parte del intérprete. En las partituras gráficas la obra desafía al intérprete, cuestionando el concepto de partitura y de lo que ha de estar escrito en ella. A este respecto, es interesante comprender el cambio que se produce en este tipo de obras en la relación entre compositor e intérprete, convirtiéndose este último también en co-creador de la obra. Si bien puede argumentarse que en todas las épocas el intérprete ha ofrecido su versión propia de la obra interpretada, las partituras gráficas exigen una mayor implicación y toma de decisiones por parte de quien ejecuta la obra.

Aunque el grado de libertad ofrecido al intérprete varía según el tipo de la partitura gráfica y el concepto del compositor, muchas de ellas conllevan un número infinito de posibles interpretaciones. Así, uno de las características propias de la partitura gráfica es que ésta deja de ser un objeto totalmente acabado, cerrado y definido para convertirse en un proceso creador de múltiples versiones posibles. 
El compositor Ramón Barce explicaba así la forma de interpretar una partitura gráfica: "El intérprete (o los intérpretes) ha de transformar en música el gráfico buscando impulsos, sugerencias o correlatos entre la grafía no convencional y sus posibilidades de ejecución. Una gran libertad, pues, preside la interpretación de estas partituras" (Barce, citado en Villa Rojo, 2003, p.241). La función de la partitura gráfica cambia respecto a la tradicional y, tal como destaca Zugasti (2007), se convierte en un estímulo para la creatividad:

Lo que defiende Earle Brown, y con él toda una corriente que tiene su punto de partida a comienzos de los años 50, es que la partitura, en lugar de esforzarse en "conservar" las características de la composición, debe constituirse en catalizador del "juego musical" (p. 334).

La dimensión creativa de este tipo de obras se ha aplicado también en el ámbito de la Educación Musical. En las últimas décadas se han realizado experiencias de creación e interpretación de partituras gráficas en escuelas de educación primaria y secundaria, así como en escuelas de música y conservatorios. Estas experiencias siguen teniendo un carácter experimental, debido a la novedad que suponen respecto a la partitura tradicional. En muchos casos, los contextos de realización de partituras gráficas en el ámbito educativo están relacionados con metodologías experimentales e interdisciplinares.

Las partituras gráficas han sido un recurso explorado por los continuadores de la pedagogía Orff-Schulwerk, en su búsqueda de restituir la unidad primitiva que, tal como destacó el compositor y pedagogo alemán Carl Orff, existía entre las diferentes artes. En España, pedagogos musicales como Fernando Palacios, se han dedicado también a la exploración de las partituras gráficas en el campo educativo, a través de propuestas tales como la obra Piezas gráficas musicales para la educación. Palacios (1993) comenta la influencia que ha recibido la pedagogía musical de estímulos procedentes de la psicología, de la música contemporánea, de otras culturas, así como de corrientes como el minimalismo o de géneros como el cómic o la poesía. Para 
este autor, estas influencias han ido desarrollando nuevos procedimientos en la forma de enseñar la música, en muchos casos, más claros y cercanos a la naturaleza del sonido y de la música.

Todo un mundo de gestos, símbolos, líneas, espacios, dibujos, colores..., se ha ido abriendo ante nosotros con un enorme abanico de posibilidades. Gracias a la elementalización de procedimientos propios de la Música Contemporánea, de la Música Gráfica, de la Poesía Fonética, del Cómic... se ha ido obteniendo un rico material que, con una didáctica apropiada ha podido ser utilizado en la enseñanza con objetivos bien dispares: tanto para el conocimiento de fuentes sonoras, como para la confección de partituras elementales, para el estudio de la naturaleza del sonido y de la forma, realización de dictados. (Palacios, 1993, p.13).

En el mismo sentido, Isaza (2016) habla de los nuevos recursos de la educación musical, entre los que destaca la creación de partituras experimentales. Según el compositor, estos recursos de tipo experimental ofrecen otras formas de relacionarse con el sonido, más abiertas y enriquecedoras. Isaza insiste en activar el oído y la curiosidad musical de los más pequeños no desde un lenguaje específico, tal como se ha venido haciendo de forma tradicional, sino desde la confluencia de múltiples formas y maneras de abordar el fenómeno sonoro. Esto permite, en su opinión, un conocimiento más amplio del sonido y de la música y la gestación en los niños de un interés que no sólo se dirige hacia el sonido y la música "sino que se expande a su forma de interactuar con la realidad, relacionarse con otros seres vivos, concebir el mundo, representar sus emociones, comprender su realidad, expandirla, jugar con ella". (Isaza, 2016). En este sentido, el mismo autor hace referencia a propuestas pedagógicas innovadoras tales como Homosonorum, un taller colectivo chileno dedicado al desarrollo de la creatividad mediante la realización de partituras gráficas. 
Una de las partituras gráficas más conocidas y recreadas en el ámbito de la educación musical ha sido la de Stripsody (1966), de la compositora y cantante estadounidense Cathy Berberian. Esta obra, basada en los elementos sonoros de los cómics, las onomatopeyas, ha dado lugar a múltiples versiones y propuestas didácticas en las aulas de educación primaria y secundaria.

\section{Naturaleza de la experiencia}

La experiencia presentada se ha realizado en el marco de la asignatura "Artes, calidad y multiculturalidad", perteneciente al plan de estudios del segundo curso de los Grados de Maestro/a de Educación Primaria y Doble titulación de Maestro/a de Educación Infantil y de Educación Primaria de la Universidad de Girona. Se trata de una asignatura compartida entre las áreas de música, artes visuales y expresión teatral. La experiencia descrita se ha llevado a cabo dentro de las sesiones pertenecientes al área de música.

A través del consenso entre los profesores de la asignatura, se plantea como ejes fundamentales de la misma el trabajo de la diversidad - en sus múltiples enfoques y sentidos - y de la interdisciplinariedad entre los distintos lenguajes artísticos. En este contexto, el proceso de creación e interpretación de una partitura gráfica, pretende alcanzar los siguientes objetivos:

1.- Reflexionar acerca del concepto de diversidad en cuanto a la percepción y a la escritura del sonido.

2.- Desarrollar la propia creatividad e imaginación sonora y visual.

3.- Establecer una correspondencia entre el oído y la vista.

4. - Abordar el concepto de sinestesia en la percepción sensorial y en la expresión artística. 
5.- Desarrollar la experimentación sonora con objetos cotidianos y con instrumentos musicales.

6.- Ser capaces de crear una partitura gráfica.

7.- Asociar elementos gráficos con elementos sonoros.

8. - Despertar la creación sonora y ser capaces de improvisar pequeñas piezas sonoras a partir de los grafismos creados.

9. - Adquirir una herramienta artística y didáctica que fomenta la creatividad plástica y sonora.

En la descripción del proceso, se alude al concepto de "traducción sinestésica”. Tal como explica Riccò (2018): "Las traducciones sinestésicas (TS) son definibles como todas las transformaciones en las cuales el prototexto (es decir, el texto original) y el metatexto (es decir, el texto traducido) usan signos (verbales y / o no verbales) de diferentes registros sensoriales" (p.2). Este concepto hace referencia, pues, a la transformación de un contenido procedente de un sentido a otro sentido diferente. En el proceso expuesto en el presente artículo, se trabajan las traducciones sinestésicas desde el sonido a la percepción táctil y al signo gráfico (segunda fase de la experiencia) y del signo gráfico al sonido (tercera y cuarta fase de la experiencia).

Como se ha apuntado anteriormente, se trata de un proceso de naturaleza interdisciplinar, que implica estudiar de forma integrada las disciplinas de las artes visuales y la música, estableciendo asociaciones, nexos y paralelismos y una analogía constante entre los elementos gráficos y sonoros. Se trata de un enfoque que pretende encontrar la relación orgánica existente sonido y grafismo. 


\section{Descripción del proceso}

Para una mayor facilidad de comprensión, se ha dividido el proceso de creación e interpretación de una partitura gráfica en cuatro fases, que se presentan a continuación.

\subsection{Fase previa: experimentación sonora y crea- ción de paisajes sonoros}

Para la realización de esta experiencia, previamente se ha introducido el concepto de paisaje sonoro descrito por el compositor y pedagogo Murray Schafer. Schafer (2013) define el paisaje sonoro como un ambiente sonoro que hace referencia tanto a entornos naturales o urbanos reales como a construcciones abstractas. A partir de este concepto, se ha trabajado, por una parte, la escucha y percepción del entorno sonoro y, por otra, la experimentación y creación de paisajes sonoros con los instrumentos musicales del aula, objetos de uso cotidiano, la voz y la utilización de su cuerpo como instrumento. Esta fase no forma parte propiamente de la experiencia de creación e interpretación de una partitura gráfica, pero se ha incluido aquí para destacar el hecho de que, a través del trabajo previo con el paisaje sonoro, los estudiantes están ya familiarizados con la escucha atenta y con la creación y experimentación sonora, aspectos que les serán muy útiles durante el proceso de creación e interpretación de una partitura gráfica.

\subsection{Primera fase: introducción al concepto de partitura gráfica}

Una vez que los estudiantes se han familiarizado con la creación y la experimentación sonora, se introduce el concepto de partitura gráfica. Se visualizan y escuchan obras escritas con notación gráfica pertenecientes a compositores tales como 
Roman Haubenstock-Ramati, John Cage, Cornelius Cardew, Karlheinz Stockhausen, Murray Schafer, Hans-Christoph Steiner, Earle Brown, George Crumb, Sylvano Bussotti o Anestis Logothetis. Esta introducción va acompañada de un comentario y reflexión sobre las características más importantes de las partituras visuales. También se aborda aquí el concepto de "sinestesia", realizando un primer acercamiento al concepto y a su significado en el arte.

\subsection{Segunda fase: del sonido al grafismo.}

Tras una reflexión colectiva sobre la diversidad en la manera de entender y representar el sonido, se procede a la realización de ejercicios prácticos de creación. Se comienza trabajando la escritura gráfica de líneas melódicas, a partir de la adaptación de un ejercicio expuesto por la profesora Sofía López-Ibor en su libro Blue is the sea. Este ejercicio servirá de base para la traducción sinestésica y la trasposición de un medio artístico a otro.

La actividad consiste en realizar una doble traducción sinestésica: del oído al tacto y del tacto a la vista. En este caso, se comienza escuchando una melodía interpretada por la profesora con un pífano de caña (pequeña flauta travesera, instrumento originario de Brasil). En primer lugar, se pide a cada estudiante que escoja un color que represente para cada uno de ellos el sonido de este instrumento. Por parejas, un estudiante dibuja con la mano la línea de la melodía escuchada en la espalda de su pareja. Ésta, a su vez, traduce las percepciones táctiles a un contorno dibujado con un lápiz del color elegido sobre el papel. Después, se invierten los roles. Finalmente, se comparten y comentan los diversos resultados obtenidos. Esta actividad centra la atención y pone en marcha las distintas percepciones sensoriales: auditiva, táctil y visual y la traducción de un medio a otro. 


\subsection{Tercera fase: del grafismo al sonido}

A continuación, se lleva a cabo la segunda actividad, partiendo de un ejercicio que el compositor y pedagogo canadiense Murray Schafer presenta en su libro Cuando las palabras cantan. En dicha obra Schafer (2010) propone la realización de cantos a partir de partituras realizadas dibujando distintos horizontes del mundo sobre la base de un pentagrama. En esta ocasión, se pide a los estudiantes que realicen contornos de paisajes que son familiares para ellos y que, posteriormente, los interpreten con los instrumentos del aula: carillones, flautas o a través de la voz. El proceso es el contrario que en la actividad anterior: del grafismo al sonido, en vez del sonido al grafismo. Los estudiantes dibujan los horizontes de sus pueblos y ciudades y, a continuación, los interpretamos musicalmente en la clase, con el resto de compañeros como público.

\subsection{Cuarta fase: creación e interpretación de una partitura gráfica}

Para finalizar, tras el proceso de familiarización con las traducciones sinestésicas entre sonido y grafismo, se ofrece a los estudiantes una secuencia de pautas posibles para la realización de su propia partitura gráfica. Dicha secuencia se basa en la adaptación de la propuesta por Sofía López-Ibor (2011) y consta de los siguientes pasos:

1.- Elegir los instrumentos y los intérpretes (instrumentos Orff, otros tipos de instrumentos, voz, percusión corporal, objetos cotidianos, etc.).

2.- Poner un título a la pieza musical.

3.- Explorar los sonidos que los materiales pueden hacer. (Buscar

diferentes sonoridades posibles y elegir las más interesantes). 
4.- Dibujar unos signos para cada tipo de sonido que se utilizará en su composición. (Se pide que representen gráficamente las diferentes intensidades, alturas de los sonidos, su duración, los distintos efectos sonoros...).

5.- Crear una leyenda: dibujar los diferentes signos y explicar cómo suena cada uno de ellos.

6.- Decidir en qué orden se tocarán los diferentes sonidos. Crear una estructura para la composición.

7.- Decidir la forma de lectura (izquierda-derecha, arriba abajo, aleatoria ...)

\section{8.- Dibujar la partitura}

\section{9.- Interpretar la partitura}

Siguiendo la agrupación por parejas, los estudiantes crean su propia partitura gráfica que, posteriormente, interpretan delante de sus compañeros. Para la interpretación, son los propios alumnos los que deciden cómo traducir los gráficos a sonido, tomando decisiones acerca de aspectos tales como la duración de los grafismos, la amplitud de los intervalos, la intensidad de los sonidos, el punto de comienzo, los instrumentos con los que interpretar la pieza, etc.

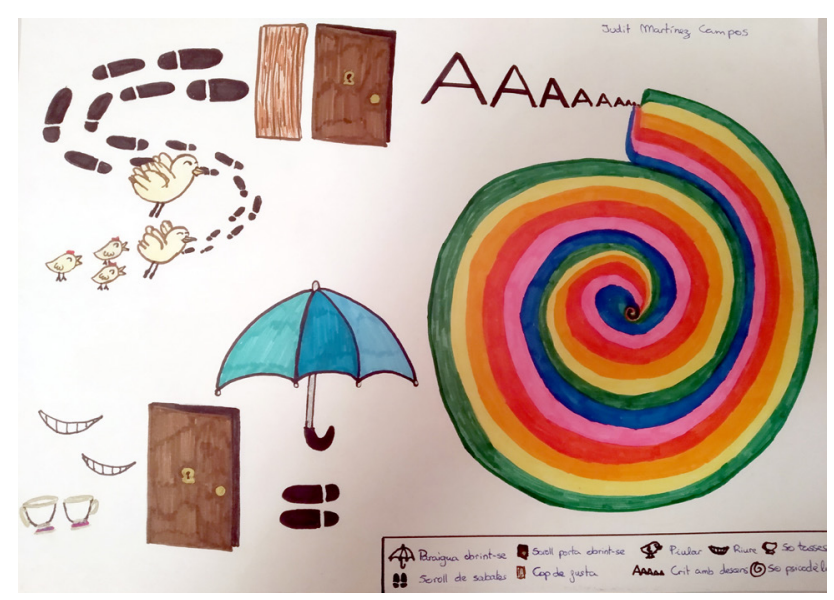

Figura 1. Judit Martínez Campos (2018). Partitura gráfica: "Caída de Alicia en el país de las maravillas". 


\section{Seguimiento y valoración}

La valoración de la actividad ha sido muy positiva. Desde un punto de vista artístico, el desarrollo de esta secuencia de actividades ha dado lugar a propuestas gráficas y sonoras muy interesantes y creativas. Las partituras realizadas han permitido a los estudiantes introducirse en la interpretación y la creación musical, un ámbito al que, de entrada, sin el estímulo de lo gráfico, hubiera resultado más difícil acceder. En el momento de la interpretación musical, el contenido sonoro creado a partir de los gráficos ha sido sorprendente por su originalidad tanto para los oyentes como para los propios creadores e intérpretes. En algunos casos, los resultados obtenidos han tenido un carácter experimental similar al de muchas producciones de arte de vanguardia.

Desde un planteamiento didáctico, la experiencia realizada ha requerido que los creadores e intérpretes de las partituras se impliquen creativamente en la toma de decisiones sobre la interpretación de la obra, elaboren un discurso y construyan su obra a partir de su propio criterio. Esto ha fomentado el desarrollo de capacidades de gran valor didáctico tales como analizar, planear, definir, evaluar, percibir...

En lo que se refiere a los contenidos actitudinales, durante la exposición e interpretación musical de las partituras se han trabajado valores como la espontaneidad, la desinhibición en la interpretación en público, la práctica performativa o la superación del miedo escénico. Es preciso puntualizar que, en este sentido, el ambiente en el que se han desarrollado las diferentes actividades planteadas ha sido de respeto hacia las creaciones de los demás. En algunos casos, los resultados de las interpretaciones sonoras de los grafismos no han estado exentos de humor, dado el carácter inesperado del proceso sonoro obtenido.

Otra de las actitudes que se ha visto favorecida por esta experiencia ha consistido en el desarrollo de la percepción sensorial y de la atención consciente. Durante la realización de estas prácticas visuales y sonoras ha sido necesaria una total impli- 
cación en el presente. La experiencia ha involucrado a los estudiantes de una forma activa y vivencial durante todo el transcurso de las diferentes actividades, mejorando su capacidad de atención.

Como aspectos de mejora o de desarrollo de esta secuencia didáctica se proponen las siguientes. En primer lugar, se sugiere la posibilidad de realizar un trabajo plástico posterior más detallado de las partituras realizadas. Éstas se han presentado, en muchos casos, como un primer esbozo visual. En caso de repetirse la experiencia educativa en posteriores ocasiones, las primeras versiones gráficas podrían realizarse de forma más elaborada, estimulándose así la adquisición de habilidades y procedimientos propios del lenguaje plástico y visual. Se podría, incluso, trabajar con la incorporación de otras técnicas o lenguajes visuales tales como el collage, la fotografía, el cómic, etc. para enriquecer visualmente la partitura desde un punto de vista estético.

En segundo lugar, se ha detectado que, en algunos casos, la partitura gráfica ha sido confundida con el concepto de "musicograma", con el que los estudiantes están más familiarizados y han trabajado en diversas asignaturas del área de música. Sobre este aspecto - la diferenciación entre partitura gráfica y musicograma - resultaría necesario incidir en una realización posterior de la experiencia.

Aunque ambos conceptos tienen puntos en común - fundamentalmente el uso del lenguaje visual y de recursos gráficos para representar elementos sonoros - el término "musicograma" hace referencia a una metodología de Audición Musical Activa. Dicha metodología fue propuesta por el pedagogo belga Jos Wuytack a comienzos de los años setenta para enseñar a escuchar la música clásica a los niños y jóvenes sin conocimientos musicales. Tal como explican Boal Palheiros y Wuytack (2009): "este sistema solicita la participación física y mental del oyente antes y durante la audición y también utiliza la percepción visual (el musicograma) para mejorar la percepción musical” (p.43). Según estos autores, los oyentes que no poseen una formación musical no pueden leer una partitura, pero sí les es posible comprender 
una representación visual general de la forma y los materiales musicales. Por lo tanto, puede verse cómo el concepto de musicograma es diferente al de partitura gráfica tal como ha sido presentado en esta ocasión. Es cierto que también existe un tipo de partituras gráficas denominadas partituras aurales o listening scores, creadas a posteriori en el caso de obras electrónicas para facilitar su escucha (Véase, por ejemplo, Artikulation, de G.Ligeti). El objetivo de estos listening scores es, salvando las distancias, similar al del musicograma. Sin embargo, en la propuesta que se presenta en este artículo, la intención de ambos es distinta: estimular la imaginación del intérprete y la creación de desarrollos sonoros a partir de los grafismos en el caso de la partitura gráfica, y fomentar la audición activa en el caso del musicograma.

La actividad realizada tiene otras posibilidades de desarrollo y de ampliación. Una posible continuación de la actividad consistiría en realizar diferentes interpretaciones de una misma partitura, para ver las diferencias y las particularidades interpretativas de cada una de las versiones y establecer una comparación entre las mismas. Con ello se incidiría, una vez más, en el concepto de diversidad y en la posibilidad de realizar múltiples interpretaciones a partir de una misma obra. La creación de múltiples versiones sobre una misma partitura permitiría también profundizar en la relación entre grafismo y sonido.

La duración total de esta experiencia educativa ha sido de tres sesiones de una hora y media cada una de ellas, más un tiempo de trabajo autónomo por parte de los estudiantes entre las distintas sesiones. La duración del proceso, sin embargo, es flexible y adaptable en función del grado de profundización que se pretenda en cada caso.

El proceso de creación e interpretación de una partitura gráfica es un planteamiento didáctico que puede ser ajustado a diferentes niveles educativos. En este caso, ha sido adaptado al nivel de educación superior para trabajar la creatividad artística y musical de los estudiantes. Este proceso, adaptado al nivel de enseñanza primaria, servirá a su vez como recurso didáctico en las aulas donde desarrollarán su 
actividad los actuales estudiantes de los Grados de Maestro/a de Educación Primaria y Doble titulación de Maestro/a de Educación Infantil y de Educación Primaria.

\section{Conclusiones}

La facilidad de lectura de los grafismos, su carácter accesible y exento del conocimiento de los códigos pertenecientes al sistema convencional de notación, convierte a las partituras gráficas en un recurso educativo de gran utilidad en el aula. El carácter intuitivo de este tipo de partituras facilita el trabajo con el elemento sonoro, acercando el fenómeno musical a los estudiantes de una manera más libre y espontánea que en el caso de la partitura convencional. De esta manera, la aproximación a la interpretación musical se ve favorecida, creándose una predisposición positiva hacia la interpretación y la experimentación con el sonido.

Como se ha podido comprobar, en el ámbito de la educación artística y musical, las partituras gráficas son un recurso de gran valor para crear propuestas que permitan experimentar las artes de forma vivencial y reconectar con la capacidad expresiva que, como niños, todos hemos tenido y que, en la adultez, muchas veces hemos bloqueado o dejado en un lugar apartado. Experiencias como la realizada en este curso permiten la reconexión con nuestra capacidad de expresar emociones y comunicarnos a través de lenguajes diferentes al verbal.

Por otra parte, si bien es cierto que en la actualidad está muy en boga la noción de interdisciplinariedad en la educación, en nuestra opinión, faltan aún espacios reales donde puedan llevarse a cabo experiencias que unan las distintas materias. Contextos donde el diálogo y unión establecidos entre disciplinas sea profundo y auténtico. En este sentido, experiencias tales como la que se presenta en este artículo permiten una integración real entre disciplinas artísticas y un desarrollo conjunto de ambas. 
La experiencia presentada es una muestra de que el educador musical actual cuenta con recursos muy variados para acercar a los niños al mundo sonoro desde la confluencia diferentes ámbitos y no sólo desde un único lenguaje. Las partituras gráficas son una de las maneras a través de las cuales realizar un acercamiento más abierto a la música.

Asimismo, el desarrollo de las capacidades artísticas en los estudiantes influirá en su crecimiento como personas y como futuros docentes, estimulando cualidades tan necesarias como la imaginación, la creatividad, la confianza en uno mismo, la apertura hacia nuevas formas de expresión, la percepción sensorial, la atención consciente o la capacidad de análisis. Cualidades que, integradas en ellos mismos, les serán muy útiles en su vida y en su profesión docente.

\section{Bibliografía}

Boal Palmeiros, G.y Wuytack, J. (2009). Audición musical activa con el musicograma. Eufonía Didáctica de la Música, 47, 43-55.

IsAZA, M. (2016). Tres interesantes propuestas de educación infantil mediante la exploración del sonido y la escucha. Recuperado de

https://www.hispasonic.com/reportajes/tres-interesantes-propuestas-educacion-infantil-mediante-exploracion-sonido-escucha/42399

López-IBOR, S. (2011). Blue is the sea. Music, dance and visual arts. San Francisco, California: Peter Greenwood.

Palacios, F. (1993). Piezas gráficas musicales para la educación. Gijón: Fundación Municipal de Cultura.

Real Academia Española. (2019). Diccionario de la lengua española (23.a ed.). Consultado en https://dle.rae.es/ 
Riccò, D. (2018). VI Congreso internacional de Sinestesia, Ciencia y Arte. Synaesthetic Translations: A Theoretical Framework. (p.1-10). Granada, España: Fundación Internacional Artecittà.

Seco, M., Andrés, O. y Ramos, G. (1999). Diccionario del español actual. Lexicografía. Madrid: Editorial Aguilar.

SchaFER, M. (2010). Cuando las palabras cantan. Buenos Aires: Melos Ediciones Musicales.

SCHAFER, M. (2013). El paisaje sonoro y la afinación del mundo. Bogotá: Intermedio Editores.

VILA Roso, J. (2003). Notación y grafía musical en el siglo XX. Madrid: Iberautor Promociones Culturales.

Zugast, A. (2007). Dibujar el sonido. En J.J.Gómez Molina (coord). La representación de la representación. Danza, teatro, cine, música (pp.319-349). Madrid, E s paña: Ediciones Cátedra. 


\title{
Creatividad \\ y Sociedad
}

Creatividad y educación

no 32 - enero 2020

El genio, el duende, el artesano: tres perspectivas estéticas sobre la creatividad

The Genius, the "Duende", and the Craftsman: three aesthetic perspectives on Creativity

\author{
Tania Alba Rios \\ Universitat de Barcelona \\ alba@ub.edu \\ https://orcid.org/0000-0002-5520-8250
}

Recibido: 30 de mayo de 2019

Aceptado: 12 de diciembre de 2019

Para citar este artículo: Alba Rios, T. (2020) El genio, el duende, el artesano: tres perspectivas

estéticas sobre la creatividad. Escuelas creativas. Creatividad y Sociedad (32) 143-163

Recuperado de http://creatividadysociedad.com/wp-admin/Artículos/32/32.7.pdf 


\section{Resumen}

Durante las últimas décadas, numerosos estudios se han dedicado al tema de la creatividad desde diferentes disciplinas, dentro de las áreas de las humanidades y las ciencias sociales, pero la literatura sobre el tema se remonta a la época moderna y podemos hallarla en textos filosóficos y literarios en el que hoy entendemos como el ámbito de la estética. Los tres conceptos seleccionados (genio, duende y artesano) proceden de diferentes cronologías y ámbitos de conocimiento. Con ellos no se pretende ofrecer un exhaustivo recorrido histórico, ni mucho menos abarcar o reducir la creatividad a tres elementos que constituyan su clave, sino analizarlos en vinculación con el contexto en el que fueron definidos para comprender así su alcance e influencia, prestando especial atención a cómo la manera de abordar la creatividad intenta en cada momento dar respuestas a las necesidades y particularidades de la sociedad.

\section{Palabras clave}

Creatividad - Estética de las Bellas Artes

- Estilo.y estética literarios · Sociología cultural

\section{Abstract}

Over the past few decades, many studies have been devoted to the subject of creativity from different disciplines in the areas of humanities and social sciences, but the literature on the subject dates back to the modern era, and we can find it in philosophical and literary texts within the field of aesthetics. The three selected concepts (Genius, Duende and Craftsman) come from different eras and fields of knowledge. Nevertheless, the aim of this paper is not to offer an exhaustive historical review of creativity, neither embrace or reduce creativity to those three key elements, but analyse them in connection with the context in which they were defined to understand their scope and influence. To this end, special attention will be given to the manner in which each moment has addressed creativity in response to the needs and particularities of society.

\section{Key words}

Creativity - Fine Arts Aesthetics - Literary style and aesthetics $\cdot$ Cultural sociology 


\section{Introducción}

El concepto de creatividad, de gran interés en la actualidad, entró de lleno en el léxico del ámbito de las artes a partir del siglo XVIII, y lo hizo en vinculación con las teorías del "genio", aplicadas a la figura del artista en la estética francesa e inglesa de la llustración, que cristalizarían con la denominada "Tercera crítica" kantiana. Fue el momento del nacimiento de las bellas artes; estas quedarían segregadas de cualquier otro tipo de saberes y prácticas, con el fin de especializarse (en lo "bello", pero no en lo "útil"), aunque también de distinguirse y elevarse tanto moral como intelectualmente. La creatividad quedaría pronto asociada, así, a la originalidad, pero también a la novedad, condición sine qua non del artista, para pasar desde el siglo XX a un ámbito de aplicación más extensa como un buen requisito en cualquier ámbito de actividad humana.

La literatura sobre el tema es extensa, y la manera de entenderla y abordarla sigue todavía abierta a propuestas de diferente índole. Dentro del área de la teoría del arte y la estética filosófica, cabe citar de entrada el recorrido de carácter histórico por las diferentes teorías de la producción (término de amplio abasto que aglutina diversas maneras, que no fases progresivas, de entender los procesos que hacen posible la existencia de las obras de arte) de Gerard Vilar (2003), y el extenso e intenso estudio de Pere Salabert sobre la Teoría de la creación en el arte (2013), en el que el autor se propone comprender en qué consiste y cómo se produce la creatividad artística, sin dejar de tener en cuenta otros ámbitos de actuación, para lo cual utiliza de manera analítica, en absoluto descriptiva, la producción de toda una serie de pensadores, literatos y artistas entre la antigüedad clásica y la actualidad. Un reciente estado de la cuestión para entender la creatividad desde una visión integral puede consultarse en el artículo de Campos y Palacios (2018). Si bien la pretensión de este escrito no es la de ofrecer una definición del concepto, cabe precisar sin embargo que, de un modo general, la creatividad se entiende aquí como facultad de elaborar, en acto o en idea, propuestas nuevas o inusuales susceptibles de aplicarse, para mejorarla, a una situación dada. 


\section{Objetivos y estructura}

El objetivo principal de la presente investigación es abordar el concepto de creatividad desde el ámbito de la estética y observar, asimismo, las repercusiones y consecuencias de la elaboración de dicho concepto. Respecto a los objetivos específicos se trataría de lo siguiente: en primer lugar, y en vinculación directa con el principal, examinar de manera sucinta el origen y desarrollo de la noción de creatividad y otros elementos afines. En segundo lugar, analizar y evaluar, teniendo en cuenta su contexto de producción y áreas de aplicación, tres propuestas teóricas que han supuesto un punto de inflexión en la comprensión del concepto. En tercer lugar, relacionar y cotejar las aportaciones de las mencionadas teorías para así verificar, finalmente, tanto las posibles limitaciones como la actualidad de las mismas.

Para ello, tras la elaboración de breve recorrido histórico por las teorías de la creatividad, en especial la artística, este trabajo se centrará en el análisis, comparación y examen de la actualidad de tres conceptos asociados a la misma, elaborados en momentos diferentes y por lo tanto como respuesta a necesidades (no solo filosóficas o artísticas, sino también sociales) de diversa índole que serán tenidas en consideración. Se trata, en primer lugar, del "genio" kantiano, trazado en su Crítica de la facultad de juzgar (1790), del cual destacan las dotes naturales e innatas para producir al margen de las reglas e imponerse, sin embargo, como norma a seguir. En segundo lugar, del "duende" poéticamente teorizado por Lorca en una conferencia pronunciada en Buenos Aires en 1933 como figura que difiere de las del "ángel" y la "musa", todas ellas relativas a la creatividad y la inspiración, pero con la particularidad de consistir aquel en una lucha interna que emerge desde las profundidades del individuo y una participación del cuerpo mucho mayor de lo que requieren estas últimas. El "duende" se manifiesta en la ejecución, no en la planificación o conceptualización de la obra. Por último, el "artesano" reivindicado por el sociólogo estadounidense Richard Sennett en un texto reciente (2008) que recupera la importancia de la techné, del saber hacer del artesano que vuelve a conectar la producción con la vida y cuya labor requiere de unos tempos alejados del frenesí de la hiperactividad contemporánea. 


\section{La creatividad y el artista: génesis de una relación}

Según Tatarkiewicz, si bien desde el siglo XX la creatividad es considerada como relativa a todo tipo de actividad humana (2004, p. 292), el siglo anterior estuvo marcado por la comprensión de aquella como competencia exclusiva del artista (p. 288), Io cual hemos de entender como la culminación de un proceso cuyas raíces hallamos en el Renacimiento italiano, vinculado con la defensa del prestigio social de la figura del artista, y que cristaliza con la idea romántica de dicha figura en busca de la libertad creativa por la vía de la autoexpresión.

A menudo se ha sobredimensionado el peso de la creación vinculada a la figura del artista en el siglo XV italiano. Así lo hace el mismo Tatarkiewicz, probablemente por haber tenido que sintetizar en pocas páginas el recorrido histórico del concepto de creatividad:

Es ampliamente sabido que los hombres del Renacimiento fueron conscientes de su independencia, libertad y creatividad propias. Este sentimiento tenía que manifestarse ante todo y por encima de todo, en la interpretación del arte (...) Los escritores del Renacimiento intentaron dar voz a este sentido de independencia y creatividad, buscando la palabra acertada. Probaron varias expresiones, pero la creatividad no se incluyó por el momento. (2004, p. 282)

De hecho, en la esmerada antología que recoge en su anterior Historia de la estética (1991), Tatarkiewicz nos transmite -y puede analizar con mayor profundidad-cómo durante el Quattrocento, en un primer momento, se trata, en el artista, del dominio de las artes liberales (con las matemáticas a la cabeza) desdeñando incluso, por engañosa, la imaginación. Así, por ejemplo, menciona cómo en su Comentario al Filebo (ca. 1469) sostiene Ficino que 
los saberes que se sirven de las manos han de llamarse artes: éstas adquieren su lucidez y perfección, en primer lugar, gracias a la facultad matemática de calcular, medir y pesar. (...) Sin su empleo todas las artes vacilan, confiadas a la engañosa sensación, a la imaginación, a la experiencia y a la conjetura. (citado en Tatarkiewicz, 1991, p. 138)

Nótese cómo se refiere específicamente al trabajo manual (que más adelante, pero no todavía, será despreciado), aunque este deba acompañarse del racionalismo matemático. Una combinación similar encontramos en otro texto de la misma época: en la primera parte de sus Comentarios (ca. 1452-1455), Ghiberti recomienda hacer uso simultáneo de la letra y el razonamiento, por una parte, y la mano, por otra parte. Las unas sin los otros impedirían hacer y acabar un trabajo autorizado; los otros sin la una darían como resultado la sombra de las cosas, pero no las cosas mismas (1912, pp. 4-5).

Sin embargo, el Quattrocento concede también un lugar importante al concepto de inspiración (entendida como influjo de la divinidad), recuperado de la antigüedad clásica: el anteriormente citado Ficino, por ejemplo, expresa: "Hemos llegado al acuerdo de que la opinión de Platón es la más veraz: que la poesía no surge a partir de la técnica sino partir de un cierto éxtasis" (Tatarkiewicz, 1991, p. 138).

Es más adelante, durante el Cinquecento, que la aplicación de los principios matemáticos se ve relegada por otras ideas, como la de "invención": para Leonardo y Miguel Ángel el arte era "cosa mental". En sus célebres Vidas, Vasari cuenta con la "invención" como aportación de su época en lo que plantea como una evolución del arte que ha logrado la perfección. Sostiene aquí que:

diseño, padre de nuestras tres artes (...) procediendo del intelecto, extrae de muchas cosas un juicio universal, similar a una idea o forma de todas las cosas de la naturaleza (...) y como de dicha 
cognición nace cierto juicio que en la mente se forma (...) es llamado diseño (...) no es otra cosa que una partente expresión y declaración del concepto que se tiene en el ánimo, así como de aquello que, captado en la mente, se hubiera imaginado y construido en la idea. (Tatarkiewicz, 1991, p. 270)

Más adelante, como se ha mencionado, los conceptos de creación y de genio quedarían unidos. Pero la vinculación de ambos con el artista aún habría de esperar. Según Rainer Rochlitz y Anne Souriau, la consideración sobre el genio la inicia Jean-Baptiste Dubos en sus Reflexiones críticas sobre la poesía y la pintura, de 1719 (Rochlitz y Souriau, 1998, p. 613). Sin embargo, como antecedentes de Dubos es preciso mencionar, en primer lugar, El examen de ingenios para las ciencias, de Huarte de San Juan (1594), quien al acudir a la etimología aúna ingenio (el que engendra) y creador:

En cuanto al nombre ingenio, el cual desciende de este verbo ingenero, que quiere decir engendrar dentro de sí una figura entera y verdadera que represente al vivo la naturaleza del sujeto cuya es la ciencia que se aprende. (Huarte de San Juan, 2000, Capítulo I)

Y, en segundo lugar, cabe también tener en cuenta los escritos Baltasar Gracián, que Dubos conoció y citó. Mencionemos, por ejemplo, el elogio del ingenio (vinculado con el entendimiento) y el genio (derivado del primero y relativo al temperamento, al ánimo, al saber hacer), o la sugerencia de deuda aristotélica según la cual el arte es un segundo creador. Sobre aquellos sostiene Gracián en el elogio de El discreto, de 1646, que "La naturaleza los alterna y el arte los realza" (2001, p. 49-51); sobre el arte sostiene que es "complemento de la naturaleza y otro segundo ser que por extremo la hermosea y aun pretende excederla en sus obras" (Gracián, 1998, p. 179). 
Sin embargo, estos autores no aplican estos términos exclusivamente en relación con los artífices de las que hoy consideramos bellas artes y, del mismo modo, en Dubos no se da la separación entre artista y artesano. Como señala Larry Shiner, dicha escisión se produce durante las décadas siguientes al escrito de Dubos en algunos diccionarios dedicados a las bellas artes, no sin reparos por parte de algunos intelectuales del siglo. El ascenso del artista vendría, además, favorecido por la afluencia de las academias, instituciones protectoras de las artes, y la sustitución de los mecenazgos por el sistema de mercado, el cual ofrecería al artista una mayor autonomía. Es a finales del XVIII que el genio se separó tanto de la habilidad como de las reglas, tan valoradas estas en el siglo XV, en pro de la libertad (2010, pp. 149-165). Según Shiner, de hecho, en la estética francesa e inglesa dieciochesca, responsable de estos cambios, todavía había, sin embargo, algunas resistencias al empleo del vocablo "creación". La fortuna ascendente de este término estaría vinculada con el rechazo paulatino de la imitación (Shiner, 2010, pp. 167-169).

\section{El genio kantiano}

Con su famosa definición, Kant vino a fijar la teoría del genio:

Genio es el talento (don natural) que le da la regla al arte. Dado que el talento, como facultad productiva innata del artista, pertenece, él mismo, a la naturaleza, podría uno entonces expresarse también así: genio es la innata disposición del ánimo (ingenium) a través de la cual la naturaleza le da la regla al arte (...) Por consiguiente, que la originalidad debe ser su primera propiedad. (Kant, 1992, pp. 216-217. En esta cita y las subsiguientes, las cursivas pertenecen al original)

Cristalizaron de este modo los elementos que hemos ido observando: a) la desvinculación de la imitación y de las reglas (aunque esta independencia se refiere - matiza - a las ideas del artista, pues para la realización de la obra es requerida 
su formación académica, renegando con ello de la mera rebelión del artista que reivindicaría una libertad absoluta en su quehacer al margen de cualquier restricción o precepto); b) las cualidades innatas (dadas por naturaleza), ahora no adquiridas, pero también c) la aportación del genio (como modelo a seguir) "no a la ciencia, sino al arte" (Kant, 1992, p. 217), lo cual justifica a continuación a partir de la confrontación entre los procesos que siguen el científico y el poeta: el primero parte de un conocimiento y habilidades adquiridas y le es posible explicar los pasos que ha seguido; el segundo es incapaz de exponer cómo surgieron en él la ideas, puesto que no ha aprendido a-y por ende no puede enseñar cómo - generarlas. Ello se debe al deslinde que establece en esta obra entre la belleza, y por consiguiente las "ideas estéticas", y el conocimiento conceptual.

Puesto que "el arte bello es arte del genio", según reza el título del parágrafo cuarenta y seis de la Crítica, es preciso tener en cuenta la consideración sobre el arte que expone páginas atrás (pp. 213-216). Este debe producirse, sostiene, por libertad, y se distingue de la artesanía (a la que también denomina "arte remunerado") en causas y efectos. Así, el arte resulta de una ocupación agradable, como el juego, elaborado libremente y causante de placer. La artesanía, sin embargo, la entiende "como una ocupación que es por sí desagradable (gravosa) y que sólo seduce por su efecto (la remuneración, por ejemplo), pudiendo ser, por tanto, impuesta coactivamente" (p. 214). Al definir Kant la belleza (objetivo del arte) como "desinteresada", esto es, ajena a supuestos conceptos que nos la harían comprensible, y sobre todo separada de la vida práctica, de la misma existencia del objeto - en el juicio de gusto nos hemos de conformar con la mera representación, puesto que el placer se produce a partir de la contemplación - (p. 122-123), la artesanía no puede sino quedar relegada a un nivel inferior, lejos del "auténtico" (y sublimado, podemos añadir) placer estético, tanto por parte de su productor como del consumidor. Como sostenía Shiner, el destino del artesano a partir de las teorías del genio que se suceden a lo largo del siglo XVIII implica su paulatina degradación (2010, p. 169-170). 
Si es que puede hablarse de algún tipo de utilidad del arte en el sistema kantiano, se sugiere que esta se referiría, como más adelante expondrá en sus Cartas para la educación estética del hombre ya de un modo claro y contundente el pensador, poeta y dramaturgo Friedrich Schiller, a la sociabilidad. Según Schiller (2000), el "impulso de juego" aúna y concilia dos principios humanos opuestos que resultan dolorosos si entran en contradicción: el impulso formal y el sensible que - para exponerlo de manera sintética - responden al deber y a la inclinación personal, respectivamente. El juego (como el arte) se ejercita por placer (por inclinación) y estimula la sensibilidad; en el juego, asimismo, aceptamos de buen grado las reglas a seguir. De este modo, los dos impulsos se dan de un modo equilibrado y sin coerciones, lo cual ofrece como resultado la belleza, lo cual repercute en un individuo equilibrado, sociable y feliz. Sin llegar todavía a este punto, Kant sostiene que: "Arte bello es (...) un modo de representación que es en sí mismo conforme a fin y que, aun carente de fin, promueve la cultura de las fuerzas del ánimo con vistas a la sociable comunicación" (Kant, 1992, p. 215).

El arte del genio requiere no solo una dotación "natural", sino también de "espíritu", al que define como "principio vivificante en el ánimo", el cual genera "ideas estéticas", que a diferencia de las de la razón, las cuales proporcionan conocimiento, promueven un tipo de pensamiento sin concepto, pero que aviva la imaginación (p. 222). Así pues, si los productos del genio proceden del "uso libre de sus facultades de conocimiento" (p. 226) y el placer del juicio estético proviene del "libre juego de las facultades de conocimiento", esto es, entendimiento e imaginación (pp. 133-135), puede decirse que el genio, con su obra, amplía nuestras facultades cognitivas sin proporcionarnos, sin embargo, un conocimiento de tipo conceptual. Y, como ya hemos visto, influido por Kant, Schiller lleva mucho más allá lo que en el primero queda insinuado, a saber: el placer que conlleva dicho juego de nuestras facultades sociabiliza al ser humano puesto que, como afirmaba Kant, el efecto de la belleza, aunque subjetivo, ha de ser universalmente comunicable (p. 128-133).

Kant ha heredado de sus predecesores el problema del placer estético en su 
relación con las facultades humanas, y ha pretendido solucionarlo situándolo como puente entre el abismo - de otro modo infranqueable - entre las cosas tal y como son en sí mismas y su representación como único acceso a ellas (el abismo entre la realidad y el fenómeno). Si bien los demás sujetos se nos presentan únicamente como fenómenos, el "sentir con" ellos el placer compartido suscitado por el juicio estético nos proporciona un acercamiento que de otro modo sería imposible. Pero, como subraya el crítico cultural Terry Eagleton, "si lo estético ha de cargar con el peso de la comunidad humana, es porque la sociedad política, cabría sospechar, no debe ser un importante objeto de deseo" (2006, p. 133). Además, la crítica marxista le reprocharía las desigualdades sociales que estas teorías habrían comportado realmente (p. 160). Desigualdades tan visibles en la distinción trazada por Kant entre artista y artesano al devaluar la producción de este para elevar la del genio. Desigualdades que, como indica Shiner, se dan también en el ámbito del espectador: si bien el ideal de la razón emancipadora del individuo que el filósofo busca en sus textos, y aún considera lejana, se vislumbra sin embargo como posible (y tendente hacia aquella universalidad del juicio estético), en la práctica pocos tenían acceso a esa cultura humanizadora, y muchos autores del siglo XVIII, entre los que se encontraba Kant, consideraban que algunos grupos de individuos, determinados por su raza o por su sexo, estaban exentos de la delicadeza necesaria que les permitiría pasar del gusto vulgar al más excelso juicio estético (Shiner, 2010, pp. 195-199).

\section{El duende de Lorca}

Voy a ver si puedo daros una sencilla lección sobre el espíritu oculto de la dolorida España. (García Lorca, 2004 p. 150)

Lorca, simpatizante del pueblo llano, identificado con los perseguidos como él mismo sostiene cuando expresa "yo creo que el ser de Granada me inclina a la comprensión simpática de los perseguidos. Del gitano, del negro, del judío..., del morisco, que todos llevamos dentro" (citado en García Posada, 1986, p. 739), utiliza 
una expresión popular vinculada al folclore, en particular el flamenco y la tauromaquia que, como arguye José Martínez Hernández, expone sin romanticismo, exotismo o pedantería (Martínez Hernández, 2011, p. 92). También sin pretensiones, asegura el mismo autor, nivela, autorizándolos, a folclóricos, toreros y analfabetos con reputados pensadores y poetas como Goethe, Nietzsche o Cervantes (2011, p. 92-93). Con este préstamo inaugura una categoría estética de la cual es más responsable de lo que reconoce. Así lo demuestra un riguroso estudio léxico-semántico del duende llevado a cabo por José Javier León Sillero (2017). El autor sostiene que, partiendo de "una voz del argot flamenco bajoandaluz", da un nuevo sentido a la expresión y especula, más que demuestra, con sus ejemplos (p.1530). Con dicha categoría Lorca democratiza, por así expresarlo, el intelectualizado pero igualmente inasible genio kantiano. Cabe precisar de entrada, sin embargo, que aquella categoría, a diferencia del genio y el artesano, no es un apelativo aplicado a quien destaca por sus cualidades o por su oficio, sino que se relaciona más bien con otras nociones afines a las teorías estéticas de la creación en la explicación de sus causas o de los factores que intervienen en ella, como la inspiración y el furor poético.

Así, "el duende es un poder y no un obrar, es un luchar y no un pensar (. . .) no es cuestión de facultad, sino de verdadero estilo vivo; es decir, de sangre; de viejísima cultura, y, a la vez, de creación en acto" (García Lorca, 2004, p. 151). El duende sería, así un principio irracional que recuerda la fuerza dionisíaca que Nietzsche encuentra en el origen del arte, y que vincula con la voluptuosidad y el amor por la vida incluso -y especialmente - en sus momentos más dolorosos y terribles (Nietzsche, 1997). Contrariamente a Kant, Nietzsche aboga por el más alto interés en el arte y en la experiencia de la belleza, no exenta de deseo y voluntad.

El duende procede de las entrañas y se relaciona con el dolor profundo y la melancolía - aunque alejada de la desidia - , como ya advierte en la introducción al tema señalado en la cita inicial de este apartado. Como se ha indicado en la introducción, lo distingue de las figuras del ángel, el cual guía e ilumina, y la musa, que inspira e insufla formas. Ambos permiten avanzar sin esfuerzo, se imponen (para agraciarlo) 
al individuo y proceden del exterior. En cambio, con el duende solo es posible la lucha que procede del interior del individuo (el duende "necesita un cuerpo vivo que interprete, porque son formas que nacen y mueren", p. 154). Si el genio kantiano vivificaba el espíritu, el duende produce una gran emoción - sin él, esta no es posible-, es más, "llega a producir un entusiasmo casi religioso" (p. 153). El duende desplaza a la musa y al ángel: es ajeno a la técnica y al talento, a las limitaciones del intelecto y de la corrección poética, pero es auténtico, ya que procede del cuerpo, entregado en extremo y que se expresa, de preferencia, en la "música, en la danza, y en la poesía hablada" (p. 153-154). Al conceder el relevo al intérprete, el duende se aleja así de aquel artista conceptual que hemos visto se reivindicaba desde el Renacimiento. El "estilo vivo" (que podemos entender en contraposición con espíritu "vivificado" de Kant) y la "creación en acto" (antes que juego en danza entre la imaginación y el intelecto) son, pues, los conceptos clave que ha ofrecido en la definición del duende, antes referida.

Pese al vitalismo dionisíaco (con el cuerpo en intensa acción efímera), el duende habita preferentemente en España "como país abierto a la muerte (...) el duende no llega si no ve posibilidad de muerte, si no sabe que ha de rondar su casa, si no tiene seguridad que ha de merecer esas ramas que todos llevamos, que no tienen, que no tendrán consuelo" (pp. 154-155). Podemos entender al duende, de este modo, como esa lucha desgarrada que se alza por encima del fatalismo y contagia en su furor. Porque "el duende hiere, y en la curación de esta herida que no se cierra nunca está lo insólito, lo inventado de la obra de un hombre" (p. 155). Pero más que crear algo nuevo de la nada, va "en busca de nuevos paisajes y acentos ignorados (...) anuncia el constante bautizo de las cosas recién creadas" (p. 157). El duende, pues, causa dolor, pero de este emerge lo insólito, y con él "es más fácil amar, comprender, y es seguro ser amado, ser comprendido" (p. 155). La localización geográfica del duende, así como los múltiples ejemplos que Lorca utiliza, del denominado arte culto, así como del popular, demuestra, como concluye García Posada, que "el poeta tuvo una agudísima conciencia de la realidad cultural de España; realidad muy compleja, que sintió e incorporó a su obra" (1986, p. 743), la España incierta y convulsa que 
las clases humildes siempre han sufrido con mayor intensidad. Al quedar atravesadas y participar del duende, de manera directa o por contagio, han sido dotadas de una nueva fuerza vital. La solidaridad no procede aquí, como en Kant, del placer co-sentido a partir del juego de las facultades mentales, sino del amor cuyo trasfondo procede de una fuerza que le es contraria, pero que lo agita. Y aunque comparta con el genio kantiano su rareza - este procede de la naturaleza individual; la originalidad del genio es considerada por el filósofo como un don especial; al duende no se lo busca y solo se manifiesta en una auténtica lucha - , el duende difiere del genio en su procedencia de unos parámetros comunes y compartidos, aquella "viejísima cultura" que canaliza el dolor, presente y heredado.

\section{El artesano de Sennett}

La separación de la cabeza y la mano no es sólo de naturaleza intelectual, sino también social. (Sennett. 2009, p. 62)

No es accidental que el autor de El artesano haga notar, hacia el final de su obra, cómo a lo largo de esta ha utilizado lo menos posible el término "creatividad" (Sennett, 2009, p. 356). Sin embargo, en una entrevista reciente responde afirmativamente a la pregunta de si la creatividad es actualmente la clave de todos los trabajos. Ahora bien - añade - , si lo "creativo es buscar una voz propia", "uno solo la tiene cuando le habla a alguien" (Zabalbeascoa, 2018); esto es, no se trata, con la creatividad entendida a su modo, de un ejercicio individualista, sino de la búsqueda de un espacio común. Con estos matices y la elusión del término en El artesano, Sennett rehúye la carga idealista y romántica que la génesis del concepto, que aquí se ha perfilado, ha conllevado y todavía persiste. Pues su intención es rescatar precisamente aquellas facetas del artesano que el denominado Siglo de las Luces infravaloraba e iba relegando a una posición inferior a la del artista, cuyas aptitudes debían ser en consecuencia de muy diferente naturaleza. Una idealización que dejaba en lo inexpli- 
cable los procesos internos de la creatividad que Sennett, por el contrario, pretende desentrañar y comunicar, al menos parcialmente. El punto de partida es la distinción elaborada por su maestra, Hanna Arendt, entre Animal laborans (el cual elabora su trabajo sin pensar en las consecuencias de lo que hace) y Homo faber (productor que analiza las producciones y supervisa las tareas del laborans), una distinción que le parece falsa porque en el trabajo, por metódico y rutinario que sea, se da también un pensar, y a menudo un deseo no solo de producir, sino de hacerlo bien. Como en el duende lorquiano, el quid del artesano recae también en el ejecutante (no solo en el ideólogo), y tiene como elemento clave la experiencia, el cuerpo no separado ni subordinado al "espíritu"; pero, a diferencia del duende, el artesano no se ve poseído por una fuerza misteriosa; por el contrario, son la dedicación y la voluntad que, en un entorno adecuado, le permiten desplegar su creatividad en el hacer. Cabe tener en consideración que Sennett enmarca su obra en el materialismo cultural y el pragmatismo,el cual se basa en un retorno a lo concreto y a la experiencia, en el sentido tanto de vivencia como de habilidad adquirida por la práctica (Sennett, 2009, p. 356), lo cual no excluye la reflexión y la imaginación, que han de venir aunadas al trabajo que posibilita el compromiso ético, y con el fin de no caer en la trampa del irreflexivo Animal laborans (p. 363). Es en este marco que Sennett expone, mediante toda una serie de ejemplos interdisciplinares y a través de la historia, no solo las características del artesano y su devenir, sino la importancia de los procesos que este sigue, así como las consecuencias sociales de todo ello. Comenzando por el compromiso con la tarea realizada que conlleva la satisfacción de un trabajo bien hecho. Sennett recupera el elogio al artesano que la Grecia arcaica dedicó a la habilidad en el Himno homérico a Hefesto, y recuerda cómo un concepto clave aunado al de habilidad era el de comunidad (del arcaico demioergos — el que trabaja para el público - se pasa, en época clásica, al jeirotejnon — trabajador manual-). Cabe añadir en primer lugar la etimología del término demioergos, que el mismo Sennett (2009, p. 34) proporciona: demios, público, y ergon, productivo. Este paso ya implica una degradación del artesano, pues al jeirotejnon, como indica Sennett, lo consideraba Aristóteles inferior al arquitecto (2009, p. 36). En segundo lugar, no hay que perder de vista que Platón 
(2000, p. 165, 28a) emplea el término demiurgo para referirse al creador del universo. Sennett destaca para reivindicarlo, así, el trabajo cooperativo del cuerpo de artesanos que a pesar de su infravaloración histórica - que también pasa por momentos de celebración y elogio, como la del esteta e intelectual de época victoriana John Ruskin en reacción al industrialismo desaforado - todavía encontramos, en la actualidad, en colectivos "al margen" del sistema mayoritario, como los programadores de Linux, a los que define como un "cuerpo de artesanos que parece ser un tipo de comunidad insólita, marginal" por trabajar de manera horizontal y utilizar una comunicación clara y directa, contrariamente al secretismo de los ámbitos competitivos, los cuales también requieren de una velocidad productiva que no siempre permite la calidad necesaria (Sennett, p. 38).

La sociabilidad que hemos encontrado en los anhelos de Kant y Lorca se produce en este caso en el mismo seno del trabajo colectivo. "Era la comunidad la que establecía los patrones del buen trabajo, mientras que las habilidades se transmitían de generación en generación" (Sennett, 2009, p. 38), una cooperación que debe darse entre iguales y con los superiores, evitando tanto la burocratización como la competitividad que impiden la circulación de ideas y la transferencia del conocimiento, y que apuesta por la búsqueda del beneficio común a partir de la transmisión de un conocimiento "tácito", consolidado por el hábito, que no siempre se verbaliza o es codificable en palabras (p. 101). Se trata de una labor progresiva que ha de mejorarse mientras avanza, para lo cual es necesario un contacto directo con el producto - la mano que "piensa" y aprende a partir de la experiencia (p. 220) - que un exceso de tecnificación de los medios impediría (por ejemplo, con el arquitecto que se basara más en el diseño asistido por ordenador que en el propio dibujo y la adecuación del proyecto a las contingencias de su materialización).

El artesano es perfeccionista y su labor es lenta; ello implica el reconocimiento de sus imperfecciones y de las resistencias que va hallando por el camino, y ante las que en lugar de vencer o sortear, el artesano exitoso readapta su conducta identificándose con el problema hallado (p. 272). Para lo cual, podemos añadir, es ne- 
cesaria la creatividad. Sin embargo, a diferencia del genio, la habilidad del artesano puede ser aprendida y, sobre todo, mejorada; lo que sí tendría en común con aquel es el juego que se halla en su base: si Kant había asignado (pero no desarrollado) el placer del juego (aunque fuera de las facultades mentales) al artista, negándoselas al artesano, para Sennett,

La capacidad para trabajar bien es amplia y equitativamente compartida por los seres humanos; aparece primero en el juego y se elabora en las capacidades para localizar, indagar y desvelar problemas (...) la motivación es más importante que el talento. (2009, p. 350)

Y aquí radica la dignidad del artesano, que como el Hefesto deforme está "orgu"loso de su trabajo, aunque no de sí mismo" (p. 363). De nuevo hallamos, aquí, la huida del individualismo que es propio de la teoría ilustrada y romántica de la creatividad.

Una entrevista contemporánea a El artesano lleva el título "La sociología como una de las bellas artes". Lejos de entender esta referencia como una paradoja, incluso contradicción, con lo expuesto en el mencionado libro, nuevamente, debemos recurrir a algunos atributos clave que el sociólogo, como artista y artesano, ostentan: la empatía, el conocimiento adquirido a través de la experiencia — es decir, no alejado de la vida - y la (auto)disciplina como "fuerza psicológica" que rehúye las compensaciones fugaces del capitalismo actual (Olmo, 2006, pp. 47-49).

\section{Conclusión: resultados del análisis}

Recurrir tanto a la etimología como a la genealogía de los conceptos en uso resulta de gran provecho para una mayor comprensión de los mismos. La consideración actual de las nociones de creación y creatividad proceden, y todavía conservan, gran parte de la tradición teórica que cristaliza en la estética kantiana en relación con el genio: la originalidad, su rareza, su condición de posibilidad al situarse fuera o al 
margen de lo establecido y, por último, su consecuente ejemplaridad. Asimismo, dicha teoría cuenta con importantes limitaciones, comenzando por la restricción kantiana de la aplicación del genio al ámbito de las bellas artes - las cuales, dicho sea de paso, han demostrado tener una aplicación mucho más allá del placer estético — , alejándolo así del pragmatismo con el que sí que cuenta en la actualidad. Además, al considerar el genio, y por ende la creatividad, como un "don natural", apunta a un elitismo que reduce la posibilidad de su manifestación. La actual creciente importancia conferida a la creatividad en todos los ámbitos de la sociedad, comenzando por la educación - véase, al respecto, el artículo de Elisondo (2018), que insiste, además, en la complejidad del fenómeno de la creatividad y apunta a la superación de los paradigmas clásicos - , busca precisamente su realización. Dicho de otro modo: que la creatividad implique una cierta anomalía (en el hacer y en el pensar) no significa que esta deba restringirse a un reducido número de individuos, o que sea una característica innata imposible de fomentar. Otros puntos de vista, lejos de limitarse a indicar los puntos débiles de la mencionada teoría ilustrada, han venido a añadir al concepto de creatividad otras cualidades que han abierto sus posibilidades de existencia y su ámbito de aplicación.

Las tres perspectivas adoptadas proceden de momentos históricos y sociales diferentes, con preocupaciones dispares como trasfondo (el genio kantiano, el duende de Lorca y el artesano de Sennett responden, respectivamente, a la búsqueda de un nuevo orden sociopolítico basado, no en el derramamiento de sangre producido durante la Revolución francesa, sino en el uso de la emancipación de la razón como arma; a la reivindicación del arte popular y su potencial vitalista; a la apuesta por la responsabilidad del pensar en el hacer y su repercusión en una sociedad más equitativa). Estas perspectivas han sido producidas, además, desde diferentes áreas de conocimiento: la del filósofo, la del poeta y la del sociólogo. Sin embargo, no hemos podido dejar de observar determinados elementos comunes, como los beneficios que la creatividad puede aportar a la sociedad, desde la unión de los individuos a la superación de obstáculos y contratiempos (por bien que estos puedan tener, en 
cada caso, diferente naturaleza). La comunidad es la misma base del trabajo tradicional del artesano; cuando en el Renacimiento los artistas comenzaron a reclamar su plena autonomía, se volvieron también vulnerables (Sennett, 2009, pp. 95-96). Asimismo, el individualismo de la llustración, que tan hondo calaría durante el Romanticismo, no acababa de concretarse, como hemos visto en el apartado dedicado al genio kantiano, con la comunicación universal que habilitaba el juicio estético. Una mayor cohesión, sin embargo, conseguía el duende lorquiano en su contagio.

El recorrido trazado tiene una estructura circular: de la superación de la figura del artesano en beneficio del auge de la figura individual del artista, a su reinserción como elemento indispensable de la sociedad, al ofrecer una comprensión de la creatividad más acorde con las necesidades de la actualidad. Pasando por el intérprete Iorquiano que, si bien todavía conecta con el furor romántico de raíz platónica, expone algunas de las incongruencias de la teoría kantiana y amplía sus posibles manifestaciones y consecuencias. Con Sennett hay un retorno al cuerpo y una fáctica conexión social, ya presente en Lorca, que la intelectualización de la llustración había ido abandonando a lo largo del siglo. Sin haber pretendido una correlación causal entre los tres autores, no obstante podemos aducir que, para restaurar el valor de la mano, que puede funcionar como sinécdoque del cuerpo, era necesario sacudirlo en primer lugar: el cuerpo y la corporeidad, relegados y denostados inicialmente en el pensamiento filosófico para ser progresivamente recuperados y finalmente exaltados (Rivera y López, 2002; Memmi, Guillo y Martin, 2009), adquieren un creciente protagonismo también en el arte (Salabert, 2003), sobre todo el comprometido políticamente, a partir de la segunda mitad del siglo XX. Las primeras Vanguardias de principios de siglo, artísticas, filosóficas y literarias, tuvieron ese impacto movilizador en las segundas al (utilizando la terminología de André Breton) "convulsionarlo".

En definitiva, podemos constatar que las tres propuestas ofrecen, de un modo u otro, beneficios que se extienden más allá de su pertenencia a una época y contexto determinado. 


\section{Bibliografía}

Campos Cancino, G., y Palacios Picos, A. (2018). La creatividad y sus componentes. Creatividad y Sociedad (27), 167-183. Recuperado de: https://bit.ly/2EcvqO5

Eagleton, T. (2006). La estética como ideología. Madrid: Trotta.

Elisondo, R. M. (2018). Creatividad y educación: llegar con una buena idea. Creatividad y Sociedad (27), 145-166. Recuperado de: https://bit.ly/2tcfdGz

García Lorca, F. (2004). Juego y teoría del duende. Litoral (238), 150-157.

García Posada, M. (1986). Lorca y la realidad cultural española. Cuadernos Hispanoamericanos (435-436), 735-744. Recuperado de: https://bit.ly/2KJ2jG5

GHIBERTI, L. (1912). I Commentarii. Berlín: Verlag.

Gracián, B. (1998). El criticón. Madrid: Espasa Calpe.

Gracián, B. (2001). El héroe. El Discreto. Oráculo manual y arte de prudencia. BarceIona: Planeta.

Huarte de San Juan, J. (2000). Examen de ingenios para las ciencias. Alicante: Biblioteca Virtual Miguel de Cervantes. Recuperado de: https://bit.ly/2XBXrl3

Kant, E. (1992). Crítica de la facultad de juzgar. Venezuela: Monte Ávila.

León Sillero, J. J. (2017). La construcción léxico-semántica del duende lorquiano. Bulletin of Spanish Studies, XCIV(9), 1503-1531. doi:10.1080/14753820.2017.140 1346

Martínez HernándeZ, J. (2011). La teoría estética de Federico García Lorca. En M. J. Alcaraz, M. Carrasco, y S. Rubio (Eds.), Art, Emotion and Value. Proceedings of the 5th Mediterranean Congress of Aesthetics (91-100). Cartagena: Universidad de Murcia. Recuperado de: https://bit.ly/2K/5Js|

Memmi, D., Guillo, D., y Martin, O. (Eds.). (2009). La tentation du corps, corporéité et sciences sociales. Paris: Éditions de l'EHESS. 
Nietzsche, F. (1997). El nacimiento de la tragedia. Madrid: Alianza.

Oımo, C. D. (junio de 2006). La sociología como una de las bellas artes. Entrevista con Richard Sennett. Minerva (2), 46-49. Recuperado de: https://bit.ly/2D8Y2qU

Platón. (2000). Diálogos VI. Filebo. Timeo. Critias. Madrid: Gredos.

Rivera Rosales, J., y López Sáenz, M. (Eds.). (2002). El cuerpo. Perspectivas fiosóficas. Madrid: Uned.

Rochlitz, R., y Souriau, A. (1998). Genio. En É. Souriau, Diccionario de Estética (613616). Madrid: Akal.

Salabert, P. (2003). Pintura anémica, cuerpo suculento. Barcelona: Laertes.

SalaberT, P. (2013). Teoría de la creación en el arte. Madrid: Akal.

SchilleR, J. C. (2000). Escritos sobre estética. Madrid: Tecnos.

Sennett, R. (2009). El artesano. Barcelona: Anagrama.

SHINER, L. (2010). La invención del arte. Una historia cultural. Madrid: Paidós.

Tatarkiewicz, W. (1991). Historia de la estética. III. La estética moderna. Madrid: Akal.

TataRikiewicz, W. (2004). Historia de sesis ideas. Arte, belleza, forma, creatividad, mímesis, experiencia estética. Madrid: Tecnos / Alianza.

VILAR, G. (2003). La producción estética. En R. Xirau, y D. Sobrevilla, Estética (101122). Madrid: Trotta, Consejo Superior de Investigaciones Científicas, Enciclopedia Iberoamericana de Filosofía.

Zabalbeascoa, A. (18 de agosto de 2018). Entrevista a Richard Sennett. El País Semanal. Recuperado de: https://bit.ly/2qyTxDy 


\section{Creatividad \\ y Sociedad}

Creatividad y educación

no 32 - enero 2020

\section{La Realidad Aumentada como recurso creativo en la educación: una revisión global}

\section{Augmented reality as a creative resource in education: a global review}

Mariana-Daniela González-Zamar Universidad de Almería mgz857@ual.es https://orcid.org/0000-0003-1187-8970 Emilio Abad-Segura Universidad de Almería eas297@ual.es https://orcid.org/0000-0001-8624-103X

Recibido: 10 de noviembre de 2019 Aceptado: 15 de diciembre de 2019

Para citar este artículo: González-Zamar, M-D. y Abad-Segura, E. (2020) La Realidad Aumentada como recurso creativo en la educación: una revisión global. Escuelas creativas. Creatividad y Sociedad (32) 164-190.

Recuperado de http://creatividadysociedad.com/wp-admin/Artículos/32/32.8.pdf 


\section{Resumen}

En los últimos años, el incremento de las interfaces digitales aplicadas a diferentes propósitos ha supuesto una revolución en la sociedad, en general, y en el ámbito académico, en particular. Las posibilidades didácticas que ofrecen las nuevas tecnologías a los contextos educativos como recurso creativo, las convierten en una herramienta con gran potencial. En este contexto, la Realidad Aumentada (RA) como variante de experiencia virtual e inmersiva, se caracteriza por combinar la información digital y la información física en tiempo real. De esta manera, el proceso de aprendizaje se ve favorecido al incorporar un valor añadido a la educación y a temáticas en ocasiones complejas de abordar. El objetivo de este estudio es identificar las publicaciones científicas relacionadas con la RA aplicadas a la educación durante el período 2000 a 2018, además de la red de colaboración entre autores, países y un análisis de las relaciones entre las principales palabras clave. Para esto, se realizó un análisis bibliométrico de la literatura científica de la base de datos Scopus. Se identificaron 1.197 documentos sobre la temática de investigación. Los resultados del análisis revelaron que, la productividad se ha incrementado considerablemente desde el año 2007. Por último, se ha detectado que, entre las principales tendencias de investigación, se prevé avanzar en el impacto de la RA sobre los procesos cognitivos y emocionales de los estudiantes.

\section{Palabras clave}

Realidad aumentada · Educación · Recurso

- Creatividad · Bibliometría · Innovación

\section{Abstract}

In recent years, the increase in digital interfaces applied to different purposes has led to a revolution in society, in general, and in the academic field, in particular. The didactic possibilities offered by new technologies to educational contexts as a creative resource, make them a tool with great potential. In this context, Augmented Reality (AR) as a variant of virtual and immersive experience, is characterized by combining digital information and physical information in real time. In this way, the learning process is favored by incorporating added value to education and on issues that are sometimes complex to address. The objective of this study is to identify the scientific publications related to RA applied to education during the period 2000 to 2018, in addition to the network of collaboration between inter-operators, countries and an analysis of the relationships between the main keywords. For this, a biometric analysis of the scientific literature of the Scopus database was performed. 1,197 documents on the subject of research were identified. The results of the analysis revealed that, the productivity has increased considerably since 2007. Finally, it has been detected that, among the main research trends, it is expected to advance in the elimination of AR on the cognitive and emotional processes of students.

\section{Key words}

Augmented reality $\cdot$ Education $\cdot$ Resource

- Creativity · Bibliometrics · Innovation 


\section{Introducción}

En las últimas décadas, del mismo modo que ocurre con otras tecnologías experimentales que nacen para responder a investigaciones científicas, la realidad aumentada (RA) ha traspasado la barrera de la ciencia para acceder a desarrolladores de contenido y consumidores finales haciéndose más accesible.

En este contexto digital, la realidad virtual (RV) y la RA son tecnologías que están despertando gran interés por su enorme potencial estratégico. En la actualidad, la RV y la RA, están marcando tendencia con gran impacto en diversos estudios y propuestas aplicadas al ámbito de la educación y en su proceso creativo (Wei, Weng, Liu y Wang, 2015; Wu, Lee, Chang y Liang, 2013). En cualquier caso: innovación, creatividad, inmersión, fascinación, tecnología e información, son palabras que definen y acompañan al concepto de la RA. En los últimos años, se ha comprobado un aumento relevante en las publicaciones científicas (Akçayır y Akçayır, 2017), haciéndose eco del impacto el ámbito académico español (Cabero, Barroso y Llorente, 2019).

La RV y la RA son sistemas tecnológicos basados en ordenadores y dispositivos que incluyen la digitalización de imágenes. Su finalidad es producir una realidad virtual, donde el usuario tenga la percepción de formar parte ella, ya sea mediante una inmersión total o parcial. En este sentido, existen diferencias notables entre ambas. La RV es una práctica digital inmersiva que sustituye el entorno real por otro simulado. Aunque existen diversos conceptos sobre RV, nos interesa destacar aquel que deriva de la combinación de tres perspectivas: la filosófica, la técnica y la psicológica. Según definen Brudniy y Demilhanova (2012), la RV es:

La forma más avanzada de relación entre una persona y un sistema informático, dicha relación permite una interacción directa entre el usuario y el ambiente generado artificialmente, ambiente que está destinado a estimular alguno o todos los sentidos humanos, caracterizándose principalmente por crear una ilusión a nivel cerebral de participación directa en dicho ambiente (p.6). 
Es decir, el usuario se encuentra inmerso en un escenario tridimensional artificial, generado por el ordenador y no observa nada de lo que se encuentra a su alrededor (Chandrasekera y Yoon, 2018).

Por su parte, la RA es una variante de experiencia virtual y se entiende como: "una tecnología que facilita la combinación de la información digital y la información física en tiempo real (...) permite a los usuarios ver e interactuar en tiempo real con imágenes virtuales superpuestas sobre el mundo real" (Cabero, Barroso y Llorente, 2019, pp.106-107). En este caso, el sujeto convive entre lo real y lo virtual complementándose un entorno con el otro. Es decir, existe una superposición de objetos virtuales sobre el entorno físico real. Esto supone, el uso de dispositivos móviles, como smartphones o tablets, lo que facilita su incorporación al ámbito educativo y su predisposición ante los estudiantes como una herramienta motivadora (Acosta, Navarro, Gesa y Kinshuk, 2019).

La percepción positiva de la RA se debe a las posibilidades que ofrecen las interfaces digitales para penetrar en la mente del usuario/estudiante a través de experiencias visuales atractivas, proporcionando un valor añadido a la educación y a temáticas en ocasiones complejas de abordar.

Kesim y Ozarslan (2012) describen algunas de las características básicas para poder hablar de tecnología de RA. La primera condición es que debe integrarse el entorno real con el virtual. Como segunda cuestión, debe hacerse en tiempo real; y, por último, todo ello, debe poder ser aplicado en un espacio con tres dimensiones generando un registro preciso de los elementos reales y virtuales. Asimismo, podría decirse que la RA es muy similar a otras interfaces digitales, en el sentido que permite que mediante la combinación de una serie de tecnologías se traslade la información virtual a la percepción visual del usuario (Hein y Rauschnabel, 2016).

El propósito de este estudio es explorar el uso de la RA y su vinculación en la educación, con la finalidad de conocer las experiencias y el impacto de la RA durante el proceso y el desarrollo creativo de los alumnos. 
La Realidad Aumentada como recurso creativo en la educación: una revisión global

Nos interesa conocer la aplicación de la RA y el interés que suscita como herramienta didáctica para incorporarla al ámbito educativo y a los procesos de enseñanza; además de descubrir cuáles son las ventajas e inconvenientes de su aplicación.

En la revisión de la literatura realizada se han encontrado estudios que abordan esta temática, de modo que la pregunta de investigación se refiere a determinar si la implantación de la RA en la educación ha supuesto un creciente interés en la producción académica a lo largo de los últimos años.

Así, en consecuencia, el objetivo de este estudio es identificar las publicaciones científicas relacionadas con la realidad aumentada aplicadas a la educación durante el período 2000 a 2018, además de la red de colaboración entre autores, países y un análisis de las relaciones entre las principales palabras clave.

El análisis bibliométrico se empleó para explorar las características de las publicaciones en el área de RA y comprender las tendencias de investigación. La base de datos utilizada fue Scopus. Se examinaron publicaciones sobre RA en todos los niveles del ámbito educativo. Asimismo, se tuvo en cuenta la formación de los clústeres que se originaban según el acoplamiento bibliográfico atendiendo a los países y los autores más productivos, y las palabras clave.

Se utilizaron métodos de visualización bibliográfica para analizar y visualizar las características de las publicaciones seleccionadas. Un total de 1.197 publicaciones fueron seleccionadas siguiendo los criterios de investigación en el período que va del año 2000 a 2018. Los resultados revelaron que la RA es una de las herramientas tecnológicas que más ha impactado de forma positiva en la educación.

Por último, destacar que entre las líneas de investigación que se están desarrollando actualmente en relación con el tema de estudio, éstas se refieren, entre otras, a implementar prácticas curriculares que otorguen solidez y madurez a la aplicación de la RA y aportar mayor investigación en los entornos educativos. 


\section{Marco teórico}

La transcendencia que está adquiriendo la RA en la actualidad, ha supuesto que ésta sea presentada como una tecnología emergente con grandes posibilidades de incorporación al sistema educativo. A pesar de ello, desde el punto de vista conceptual y tecnológico, aumentar la realidad no resulta una idea nueva.

En la década de los años 60, surgieron precursores que, con su ingenio y creaciones, diseñaron precedentes de gafas inteligentes (Sutherland, 1965) o gafas de RA, que más adelante desarrollarían con mayor sofisticación Google. También resulta interesante la propuesta del artista Krueger que, desarrolló interesantes trabajos interactivos, considerándose uno de los investigadores iniciales de RV y RA. En 1969, propuso una interfaz de sonido de luz controlada por ordenador, que respondía a las personas que se encontraban dentro de él. A mediados de 1970, estableció un laboratorio de realidad artificial: videoplace, aquí avanzó en la creación de una realidad artificial que rodeaba a los usuarios, y respondía a sus movimientos y acciones, sin verse obstaculizado por el uso de gafas o guantes. El trabajo realizado en el laboratorio formaría la base del libro publicado en 1983, Realidad artificial (Kalawsky, 1999).

De este modo, se puede reconocer que, estos ejemplos y casos de estudio, sirvieron de inspiración para avanzar en el desarrollo de soluciones técnicas y conceptuales que han dado como resultado la actual RA.

Según Carmigniani y Furht (2011), la RA puede definirse como una vista directa o indirecta en tiempo real de un entorno real que ha sido mejorado por tecnologías virtuales asistidas por ordenador. Es decir, un conjunto de dispositivos que añaden información virtual a la información física existente. No sustituye la realidad física, sino que sobreimprime los datos informáticos al mundo real. En este contexto, también se plantean términos para referirse al fenómeno de la RA, como entorno sintético, realidad artificial y tecnología de simulación. 
Considerando la relevancia de la RA como recurso creativo y como herramienta para dar cauce a la creatividad, reconocemos las posibilidades de aprendizaje que brinda sin salir del aula. En este sentido, ofrece al alumno la posibilidad de experimentar de manera directa sus estímulos dotando al aprendizaje de un gran valor significativo (Akçayır y Akçayır, 2017).

Por otro lado, a lo largo de la historia, el término de creatividad, ha sido definido por numerosos autores, artistas, científicos, psicólogos y profesionales provenientes de diversas áreas y disciplinas. Así, la arquitecta Leski (2015) la describe como:

(...) una tormenta que lentamente comienza a acumularse y tomar forma hasta que te supera, siempre que estés dispuesto a dejarla actuar (...) así, surge la necesidad de hacer, inventar o producir, en lugar de imitar, caracterizándose todo ello por la originalidad e imaginación. (p.7)

Del mismo modo, nos interesa destacar la consideración que Gardner (2001) hace del individuo creativo como "una persona que resuelve problemas con regularidad, elabora productos o define cuestiones nuevas en un campo de un modo, que, al principio, es considerado nuevo, pero al final llega a ser aceptado en un contexto cultural concreto" (p.126). Aza (1999) se centra en la persona creativa y manifiesta que, "la creatividad es una capacidad humana que, en mayor o menor medida, todo el mundo posee" (p.25). En esto coincide Menchén (2001), quien plantea que "la creatividad es una característica natural y básica de la mente humana y que se encuentra potencialmente en todas las personas" (p.62). "La imaginación es el motor de la creatividad. Nos permite pensar cosas que no percibimos a través de los sentidos", nos plantea Robinson (2015, p.139).

Tras todos estos términos subyace el concepto de escuela creativa (Rogers y Freiberg, 1996). Una escuela creativa, es aquella capaz de desarrollar la esencia de cada individuo. Sin el temor que supone el desempeño académico como finalidad única del aprendizaje. Las escuelas creativas conciben el aprendizaje como un 
hecho espontáneo, de exploración, diálogo, razonamiento y socialización. Robinson (2015), educador y experto en calidad, creatividad e innovación educativa, propone un modelo de enseñanza basado en la creatividad. La educación actual debe preparar al individuo para el cambio. Debe aprender a pensar.

Las investigaciones de Winner, Hetland, Veenema, Sheridan, Palmer y Locher (2006) se apoyan en estudios como el de Eisner (2002). Estos autores demuestran cómo las artes ayudan a los estudiantes a desarrollar la creatividad y, por lo tanto, la flexibilidad, expresividad y la capacidad de adaptación en situaciones de la vida. Así, existe una evidencia clara de que el aprendizaje creativo no es sólo una disciplina emotiva, sino que requiere de una profunda reflexión y rigor intelectual y, por tanto, se aprende.

Es importante entender la enseñanza del pensamiento creativo como ámbito general de la educación. Touriñán-López (2011) afirma que:

(...) la educación artística es susceptible de ser tratada como un problema pedagógico general, que permite desarrollar competencias, que implica destrezas, hábitos, actitudes y conocimientos, vinculadas al carácter y sentido propios del significado de educación, es decir, con el mismo carácter y sentido que corresponde a toda educación. (p.53)

En este contexto, resulta ineludible incorporar como objetivo en los centros educativos el desarrollar el pensamiento artístico como juego libre de la sensibilidad, imaginación y creatividad. Enseña a hacer, crear y realizar, pero no desde la mera capacitación técnica, porque en lugar de enfatizar la uniformidad, lo que se busca es acentuar la diferencia e individualidad de las personas y sus creaciones (García, 2017). Educar artísticamente es educar más allá de una disciplina de conocimiento, puesto que busca el sentido de identidad; es decir, identificarse con lo diferente, lo único y lo original. De este modo, la Educación Artística es importante para que los 
alumnos mejoren, no sólo en el rendimiento de otras asignaturas como, por ejemplo, matemáticas, sino más bien se enseña esta disciplina porque es necesaria para posibilitar el máximo desarrollo personal. Por esto, las artes se constituyen como un vehículo para la instrucción sobre la tolerancia, la diversidad y la importancia del entendimiento humano. Podría decirse que, la importancia de la creatividad para el desarrollo personal y profesional resultan clave en la vida de cualquier individuo.

Lowenfeld (1961), conocido como el padre de la Educación Artística, defendió el uso del arte en la educación y dedicó su temprana carrera docente a una escuela para niños ciegos, donde desarrolló proyectos demostrando, además, el uso terapéutico de la creatividad y el arte. La creatividad capacita a las personas para que aprendan nuevos conocimientos y descubran nuevas posibilidades y experiencias. Esto da una ligera idea de que la creatividad no debe ser un evento especial, sino una práctica común, una condición cotidiana para responder a diario.

Debemos ser creativos desde cada partícula de nuestro organismo y no tomar la creatividad como un rasgo que solo algunas personas poseen como muchas veces se considera. Se debe fomentar el poder de la creación artística como una fuerza que puede traducirse a otras áreas. Por ello, los planes de estudios que fomenten el pensamiento creativo, permiten a los estudiantes comunicarse de forma efectiva con otros y entenderse, empatizar y ver los problemas sociales desde otra mirada. Como resultado, podremos ver a los estudiantes continuamente dispuestos a asumir nuevos y más difíciles retos, aprendiendo de los errores y avanzando en los aciertos.

En este escenario, la RA puede favorecer el pensamiento creativo (Hsu, Wenting y Hughes, 2018). Plantear la imaginación como motor de la realidad. Así lo demuestran investigaciones como la llevada a cabo por Di Serio, Ibáñez y Kloos (2013), que analizaron el impacto de un sistema de RA en la motivación de los estudiantes para un curso de arte visual de secundaria. Los resultados demuestran altos niveles de satisfacción en los cuatro factores motivacionales analizados: atención, relevancia, confianza y satisfacción. Al realizar las prácticas con un módulo de realidad 
aumentada, independiente del nivel de estudios del que se tratase, generaron más atención de los estudiantes que uno tradicional, comprendieron procesos difíciles de explicar e imaginar, crearon y manipularon objetos y descubrieron procesos y elementos del entorno.

En una pedagogía basada en la creatividad, se aseguraría que los alumnos pudieran adquirir, como parte natural de su experiencia, las habilidades necesarias para comprender el aprendizaje profundo, el valor del pensamiento crítico, el desarrollo del pensamiento divergente y convergente y la motivación.

El educador y filósofo, Dewey (1934) fue un defensor de la integración de las artes en la educación como medio para desarrollar la creatividad. El autor declaró que las artes deberían ser una parte fundamental del currículo porque desarrollan la creatividad, la autoexpresión y la apreciación de la expresión de los demás. Además, Dewey argumentó que los niños necesitan una educación que sea auténtica y les permita crecer mental, física y socialmente; al tiempo de brindarle oportunidades para ser creativos, pensadores críticos y entender el mundo que los rodea (Heilig, Cole y Aguilar, 2010).

La importancia del pensamiento creativo en los alumnos radica porque involucra dos procesos consecutivos: divergencia y convergencia. El pensamiento divergente implica expandir pensamientos e ideas, hacer nuevas conexiones y abrir múltiples áreas posibles para la exploración. Es cuando se generan nuevos pensamientos y posibilidades.

Por su parte, el pensamiento convergente es cuando los alumnos pueden establecer conexión con la sociedad y la realidad que les rodea mediante la progresión en este pensamiento, evaluando las posibilidades que les ofrece el entorno y desechando aquellas ideas débiles o que no les reportan ningún beneficio.

La creatividad vinculada al aprendizaje puede, por lo tanto, proporcionar una plataforma ideal para mejorar el bienestar general de los alumnos, permitiendo desde 
pequeños contribuir a la innovación desde su círculo escolar entendiendo la creatividad como base de su futuro (Klimenko, 2008). Fomentar desde niños el desarrollo de la creatividad e imaginación mediante la práctica creativa regular, resulta más beneficioso que la producción de una calificación satisfactoria.

En este sentido, la creatividad aumentada o creativity augmented, está siendo considerada por sus posibilidades educativas (Grigorenko, 2019; Su, 2019; Ibáñez, y Delgado, 2018; Yilmaz y Goktas, 2017; Yuliono y Rintayati, 2018; Zünd, Ryffel, Magnenat, Marra, Nitti, Kapadia y Sumner, 2015), reconociendo entre sus ventajas la de ser una realidad mixta que se integra en tiempo real e incorpora información proveniente de diversas fuentes digitales. Esto la dota de un alto nivel interactivo, lo cual la enriquece y distingue de otros entornos virtuales conectando positivamente con los estudiantes (Di Serio, Ibáñez y Kloos, 2013) y su motivación (Chiang, Yang y Hwang, 2014; Radu, 2014).

La mayoría de los estudios sobre RA en educación se basan en las teorías de aprendizaje, especialmente en la teoría constructivista y de aprendizaje situado (Radosavljevic, Radosavljevic y Grgurovic, 2018). Hay que señalar que, el enfoque constructivista anima a los estudiantes a comprender y construir su conocimiento utilizando la información que perciben del mundo exterior (Phillips, 1995). Por su parte, la teoría del aprendizaje hace referencia al contexto sociocultural como elemento clave para la adquisición de habilidades y competencias, buscando la solución de los retos diarios siempre con una visión colectiva (Quay, 2003). El conocimiento es desarrollado activamente por los alumnos a través de procesos sociales en un entorno mejorado En este contexto, las aplicaciones RA emplean entornos reales y virtuales, alentando a los estudiantes a desarrollar y construir conocimiento en colaboración con otros compañeros.

Eisner (2002) justifica los beneficios de la enseñanza de las artes para una educación integral en sus diez lecciones de la enseñanza de las artes. Así, el autor señala que "las artes enseñan a los niños a tomar buenas decisiones sobre relacio- 
nes cualitativas, a que los problemas pueden tener más de una solución y que las preguntas pueden tener más de una respuesta. Las artes muestran múltiples perspectivas" (pp.70-92). Cualquiera de las lecciones justifica la integración de las artes en otras asignaturas.

Esto ha supuesto que en los últimos años y, principalmente, en los países desarrollados, la RV haya ganado presencia en los entornos educativos como un enfoque alternativo a las experiencias de aprendizaje tradicionales (Billinghurst, 2002; Billinghurst y Duenser, 2012), debido a que, a diferencia de otras aplicaciones informáticas, la RV le brinda al usuario/alumno, un entorno visual en tres dimensiones altamente interactivas muy parecidas a las que ofrece el mundo real. Esto permite, además, que los estudiantes experimenten no sólo la sensación de estar presentes dentro del entorno con la posibilidad de interactuar con los objetos dentro de él, sino que también algo suceda dentro de dicho entorno sin que esto necesariamente sea resultado de una acción que él efectúe (Chandrasekera y Yoon, 2018), todo ello a través de sus dos componentes clave: la inmersión y la interacción (Lytridis y Tsinakos, 2018).

Existe un gran volumen de investigaciones que se han centrado en analizar los resultados beneficiosos del uso de RA en entornos educativos. Es necesario señalar como ventajas los niveles más altos de rendimiento académico, la motivación a la hora de aprender, el interés por el tema y la participación en el contenido (Billinghurst y Duenser, 2012; Koçak, Yilmaz, Küçük y Göktas, 2019; Lee, 2012; Pi y Lee, 2016). La retención de contenido y mayor facilidad en la adquisición de los contenidos, son otras de las ventajas que ofrecen las experiencias con RA (Cabero y García, 2016). La Figura 1 muestra los términos clave de la búsqueda realizada en Scopus en este campo de investigación. 


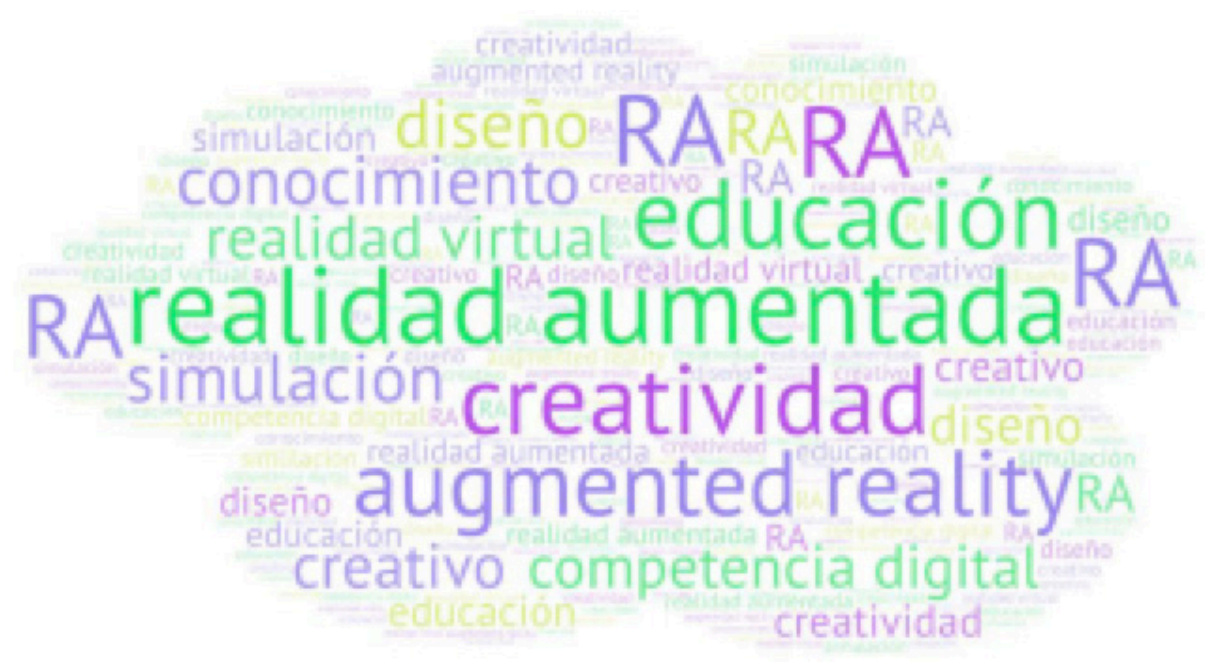

Figura 1. Nube de palabras con los términos clave de las publicaciones sobre Realidad Aumentada, Educación y Creatividad. Fuente: elaboración propia.

Algunos estudios también mostraron evidencia que las aplicaciones de RA pueden ayudar a atraer los intereses de las niñas y otros grupos desfavorecidos a los temas de ciencias e ingeniería (Del Giudice, 2017).

En definitiva, cada año la calidad y la cantidad de publicaciones de RA en entornos educativos ha ido en aumento. Esto supone que, el interés por esta temática para los investigadores en educación, especialmente en cuanto a ensayos prácticos realizados en el aula, resulta de gran interés.

Las oportunidades que brindan las tecnologías virtuales permiten romper los límites de la educación formal (Squires, 2019). De este modo, la RA ha roto las barreras de la educación formal haciendo posible acceder a una educación de calidad, de manera informal y a través de tecnologías ubicuas accesibles para todos (Fauzi, Afaa, Ali y Amirudin, 2019).

\section{Metodología}

Este trabajo tiene como objetivo mostrar una visión general del estado del arte de la realidad aumentada y su aplicación en la educación como recurso creativo. Mediante el uso de herramientas matemáticas, estadísticas y de mapeo se ha lleva- 
do a cabo un análisis bibliométrico. Así, la bibliometría se define como la aplicación de métodos matemáticos y estadísticos a libros y otros medios de comunicación (Pritchard, 1969). El objetivo de esta metodología es identificar, organizar y analizar los componentes principales dentro de un campo de investigación específico. Asimismo, permite presentar la evolución del interés por la temática objeto de estudio, al reflejar los autores, países, revistas y palabras clave más relevantes durante los últimos años (Durieux y Gevenois, 2010).

Los artículos de investigación en una disciplina científica se pueden clasificar a través del análisis bibliográfico de acuerdo con su información bibliográfica, como citas, palabras clave, instituciones, países, autores, fuentes y títulos (Abad-Segura y González-Zamar, 2019).

Usando estas técnicas se pueden crear, visualizar y explorar mapas bibliográficos. Un mapa, generalmente, consta de un solo tipo de elemento. También hay enlaces entre pares de artículos. Los enlaces muestran las conexiones o relaciones entre elementos. En este estudio, se ilustran enlaces de acoplamiento bibliográfico y enlaces de concurrencia. Los enlaces y los artículos forman una red bibliográfica juntos (Perianes-Rodriguez, Waltman y Van Eck, 2016; Waltman, Van Eck y Noyons, 2010; Van Eck y Waltman, 2009).

Se realizó un análisis de la literatura cientifica mediante el índice de citas Scopus. Esta base de datos contiene una amplia cobertura llegando a casi 25.000 revistas publicadas por más de 5.000 editores internacionales, y con cobertura de hace más de dos décadas. La ecuación de la búsqueda utilizada incluyó los siguientes términos que aúnan la producción de este campo de investigación: "augmented reality", "creative", "teaching", "education", "higher education" y "learning".

La elección de los campos de búsqueda atiende a aquellos con mayor valor descriptivo dentro de cada registro y que resultan más representativos, de acuerdo con la revisión de la literatura realizada. Así, se incluyen los campos de Título, Re- 
La Realidad Aumentada como recurso creativo en la educación: una revisión global

sumen y Palabras Clave. Por otro lado, se ha considerado enriquecer los registros a partir de los Tesauros propios o externos en el campo Index Terms. La cobertura temporal considerada corresponde al período de 19 años, es decir, desde 2000 hasta 2018.

Así, la muestra final incluyó con un total de 1.197 artículos, con una amplia diversidad de variables a analizar para cada registro, como son: el año de publicación, la revista, el área temática, el autor y coautores del trabajo, la afiliación institucional de los autores, así como el país de afiliación y las palabras clave que definen el artículo.

Es necesario subrayar que no se aplicaron límites en el idioma del documento. Asimismo, se incluyeron documentos, además de los propios de investigaciones científicas, de Trade Publications, Conference Proceedings y Book Series.

\section{Resultados y discusión}

Los resultados del análisis bibliométrico se presentan agrupados con objeto de responder al acoplamiento bibliográfico de países, autores y coincidencias de las palabras clave. También se incluye la productividad, según las unidades de análisis y temporalidad. En este primer apartado, es necesario mencionar que existe una prevalencia mayoritaria de artículos (1.142; 95,4\%), seguido de los capítulos de libros (35; 2,9\%), las publicaciones comerciales $(13 ; 1,1 \%)$ y, por último, las comunicaciones en congresos (5; 0,4\%).

Así, la distribución temporal de la producción científica es un dato relevante, puesto que permite observar el flujo de publicaciones y la importancia o profundidad que va adquiriendo una temática en la investigación.

En la Figura 2 se muestra la evolución durante 19 años de la producción científica en este campo de investigación, es decir, desde el año 2000 hasta 2018. El año de mayor producción científica en Scopus es 2018, con 288 documentos; mientras 
que en 2017 se publicaron 219 documentos, en el campo de la realidad aumentada en la educación. Se puede apreciar una tendencia creciente en la producción, que inicia un ascenso continuado desde el año 2010. Entre el período 2010-2018 se han documentado un total de 1.108 publicaciones, demostrando el interés creciente de la temática en cuestión en los últimos ocho años estudiados.

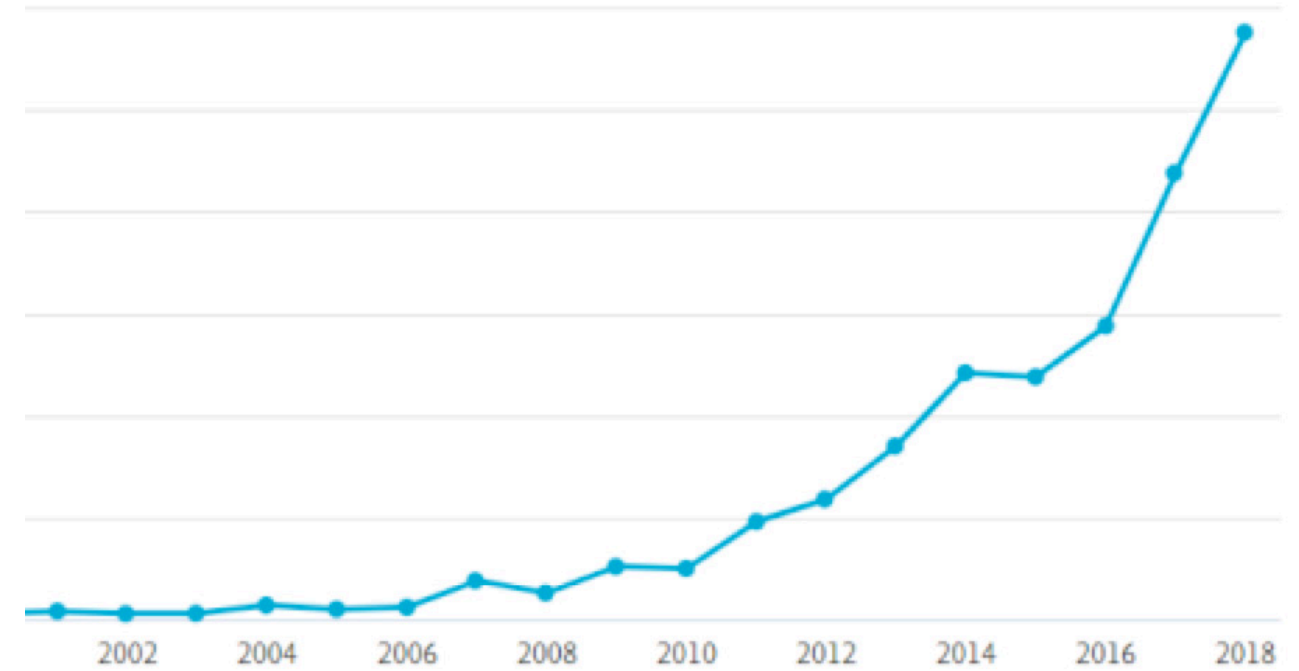

Figura 2. Evolución de la producción científica en el campo de investigación (2000-2018). Fuente: Scopus.

La Figura 3 presenta la colaboración entre países basado en la co-autoría de sus autores más productivos. Los resultados revelaron el acoplamiento en siete clústeres o grupos. Los colores representan cada grupo conformado por diferentes países, y el tamaño del círculo simboliza el número de artículos cuya autoría representa. El primer grupo incluye a 11 países; el segundo, tercer y cuarto grupo lo integran 9 países, cada uno de ellos; los grupos quinto y sexto están conformado por 5 países, cada uno de ellos; y, finalmente, el séptimo grupo, con 2 países.

El clúster 1 (color rojo) lo lidera Taiwán junto con China, Dinamarca, Hong Kong, India, Holanda, Noruega, Portugal, Singapur, Corea del Sur y Vietnam. Mientras, el clúster 2 (color verde) está encabezado por Alemania y coopera con Brasil, Chipre e Italia, entre otros. El clúster 3 (color azul) está encabezado por España, y 
conforma el grupo con Argentina, Venezuela y Chile, entre otros. El clúster 4 (amarillo) lo lidera Australia junto con Japón. El clúster 5 (color violeta) está liderado por Estados Unidos e incluye a Canadá, México, Arabia Saudita e Irlanda; le sigue el clúster 6 con Reino Unido y Francia, entre otros; y, por último, el clúster 7 (color naranja) lo conforman Israel y Nueva Zelanda.

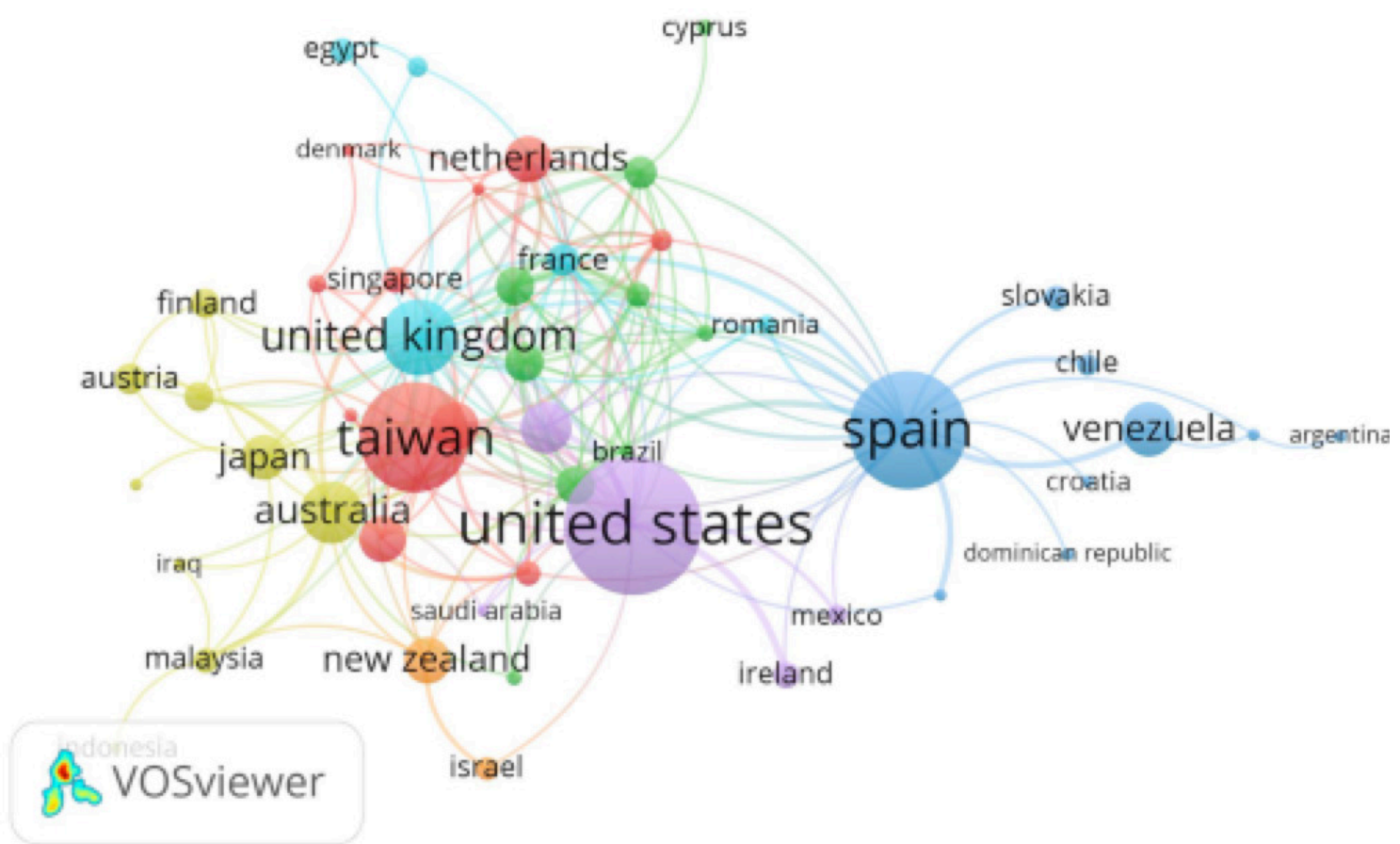

Figura 3. Red de cooperación basada en co-autoría entre países desde 2000 a 2018.

Fuente: VOSviewer.

Los resultados obtenidos en la cooperación basada en co-autoría entre países, en relación con el propósito de promover la interacción social entre los usuarios ubicados en el mismo espacio físico, la investigación en la RA colaborativa incide en el acceso a un espacio compartido de objetos virtuales, mientras permanecen conectados al mundo real (Kaji et al., 2018). Así, la movilidad de estudiantes y docentes entre distintos países supone la oportunidad de vincular la realidad aumentada entre distintas culturas y países, con la finalidad de observar las variables física y temporal en entornos educativos distanciados (Nascimbeni, 2015). Además, estos resultados se relacionas con iniciativas como el aprendizaje de los acontecimientos históricos entre países, con la RA como protagonista (Azhar et al., 2019). 
En cuanto a la colaboración entre los principales autores que han publicado sobre la temática de la RA en educación, basado en la co-autoría, la Figura 4 indica que están conformados en cuatro clústeres. El clúster 1 (color rojo) está liderado por Rizzi, mientras que el grupo 2 (color verde) lo encabeza Charbel. Así, el clúster 3 (color azul) lo encabeza Luciano, y el clúster 4 (color amarillo) presenta la colaboración entre Banerjee, Andolfi, Kania, Plana, Shakut, Slavin y Small.

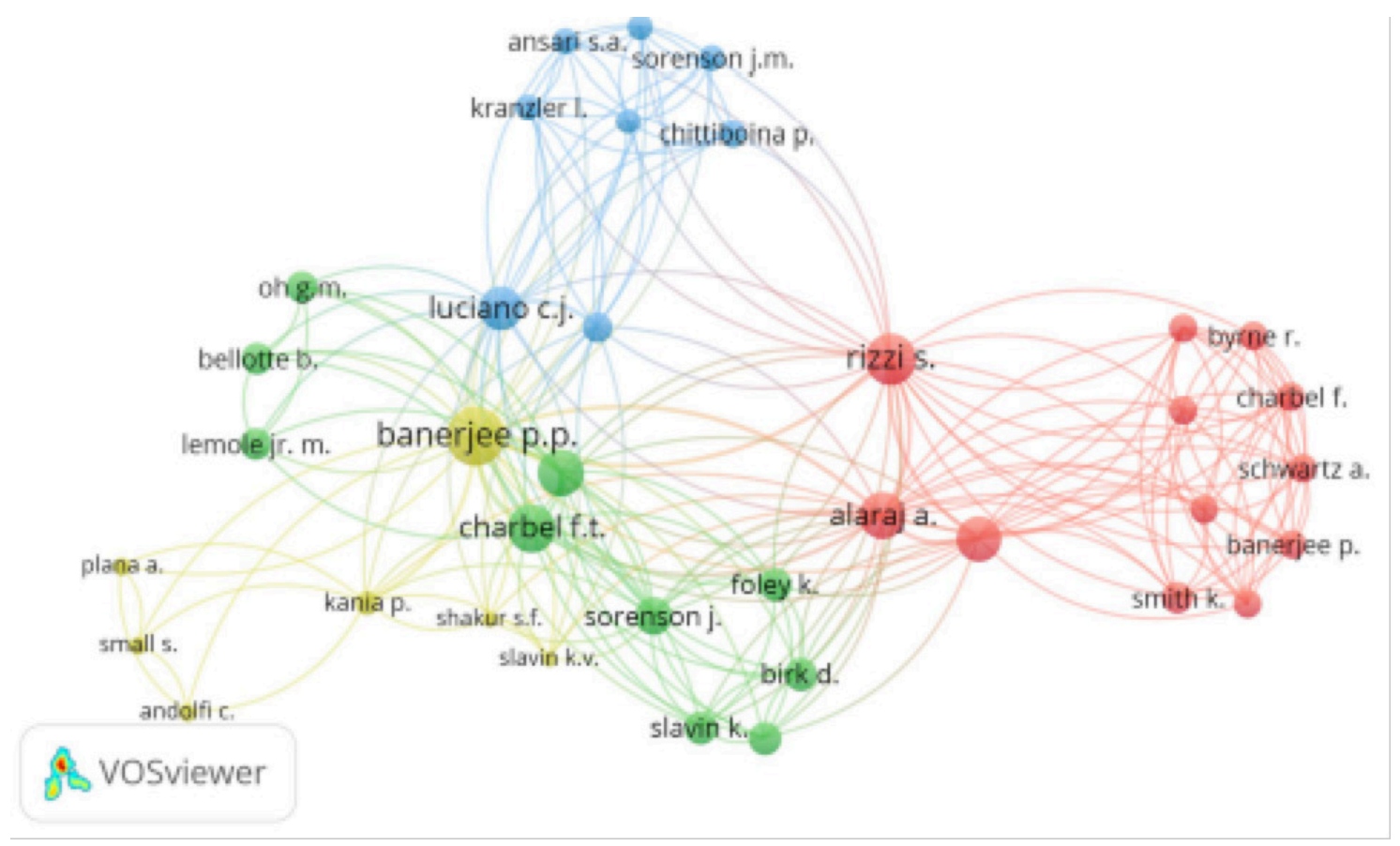

Figura 4. Red de cooperación basada en co-autoría entre países desde 2000 a 2018.

Fuente: VOSviewer.

La Figura 5 presenta la red de palabras clave en co-ocurrencia en el período analizado, asociadas en cinco clústeres. El primer grupo (rojo) está compuesto por las palabras, en inglés, realidad aumentada, creatividad, educación, educación superior, estudiantes, gamificación, diseño, educación a distancia e inteligencia artificial, entre otras. El grupo 2 (verde) está liderado por la palabra clave: competencia clínica, junto con creativo, estudio piloto y metodología, entre otras. A continuación, el grupo 3(azul) está conformado por robótica, procedimiento o cirujano. El grupo 4 (amarillo) está liderado por la palabra clave, humano, seguido de algoritmo o aprendizaje. Por último, el grupo 5 (violeta) está compuesto por simulación o realidad virtual. 
La Realidad Aumentada como recurso creativo en la educación: una revisión global

Al analizar palabras clave (Figura 5) en este campo de investigación, se observa que los términos "augmented reality", "human", "creativity", "students", "motivation" y "technology" son los más representativos. Las investigaciones en esta temática que relacionan la tecnología con la creatividad y la motivación son las que mayor volumen de producción científica han realizado en los últimos años (Akçayır, y Akçayır, 2017; Cabero et al., 2019; Hsu et al., 2018; Kocak et al., 2019; Sánchez y Toledo, 2017).

Este resultado está relacionado con la línea de desarrollo de un modelo de clase convergente de realidad aumentada (Pi, y Lee, 2006), y revisiones sistemáticas en este campo de investigación (Ibáñez, y Delgado-Kloos, 2018; Akçayır, y Akçayır, 2017). En este contexto, las tendencias como Flipped Classroom (FC), aula invertida, y Bring Your Own Devid (BYOD), trae tu propio dispositivo, posibilitan incluir distintos procesos metodológicos en el aula. Así, su fusión con la RA da lugar a cambios interesantes en el modelo de aprendizaje, especialmente en el valor que aportan. Mediante la exploración de las nuevas tecnologías, se logra abordar los retos que supone esta integración (Sánchez-García y Toledo-Morales, 2017; Abad-Segura, y González-Zamar, 2019).

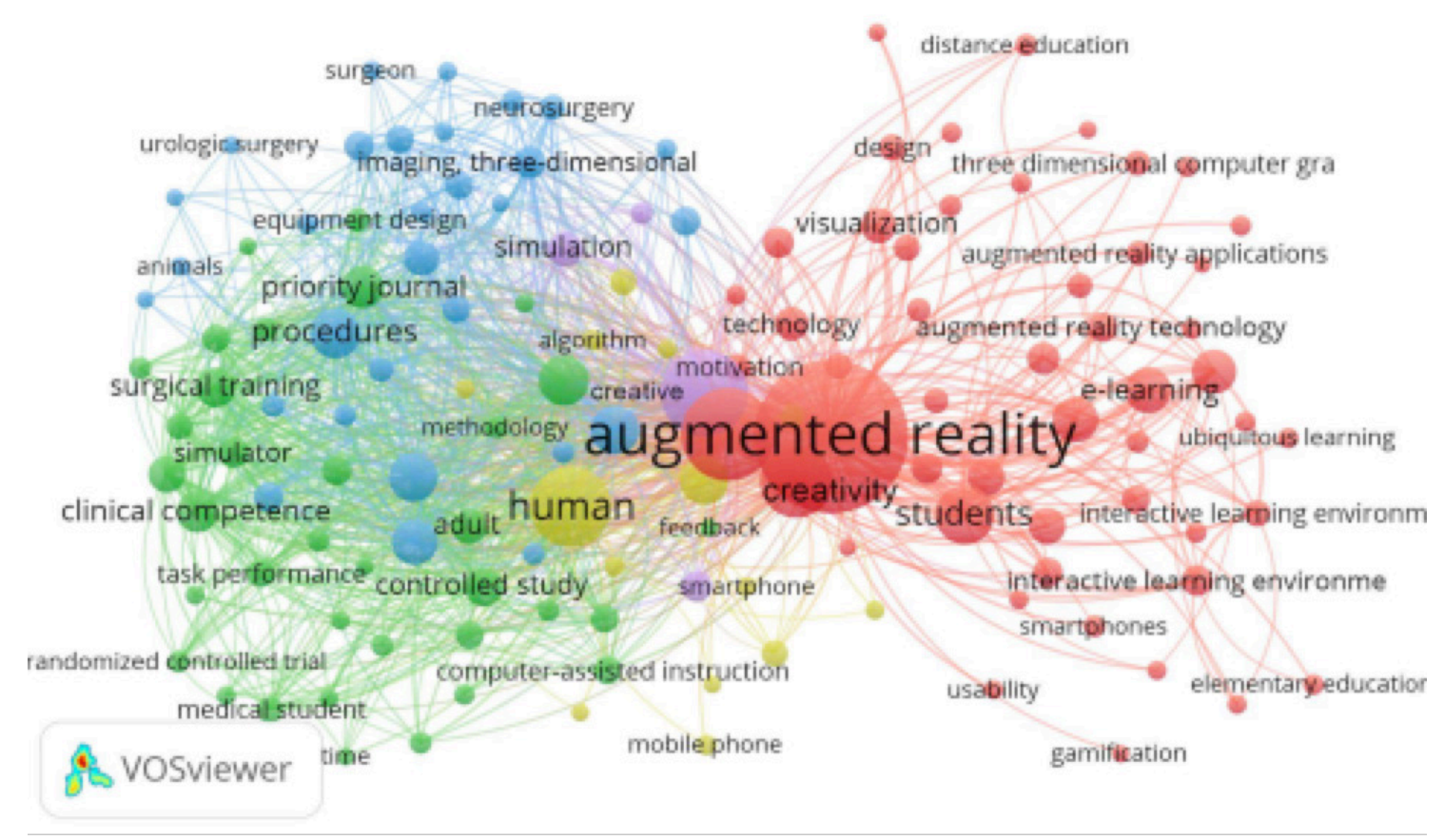

Figura 5. Red de palabras clave basada en co-ocurrencia desde 2000 a 2018.

Fuente: VOSviewer. 


\section{Conclusiones}

El objetivo de este estudio fue analizar las tendencias de investigación sobre la realidad aumentada en la educación como recurso creativo durante los últimos 19 años. Se ha desarrollado un análisis bibliométrico de 1.197 artículos obtenidos de la base de datos Scopus. El número de artículos científicos por año durante el período 2000-2018 se ha incrementado, especialmente, desde 2007, mientras que en los últimos dos años se han publicado 507 artículos, que representan el 42,36\% de las contribuciones sobre este tema de investigación.

En cuanto a los países que han realizado una mayor colaboración internacional en sus trabajos han sido Estados Unidos, España, Reino Unido y Taiwán. Asimismo, los principales autores que han publicado sobre la temática de la RA en educación en colaboración internacional son: Rizzi, Charbel, Luciano y Banerjee. Por otro lado, las principales palabras clave que se relacionan para registrar publicaciones con la misma línea temática son: realidad aumentada, creatividad y educación.

En consecuencia, la investigación de la RA debe continuar desarrollándose en los próximos años, y habrá nuevas y productivas líneas que exploren las distintas investigaciones. En este sentido, los investigadores de RA tienen la oportunidad de ayudar a establecer la dirección de cómo será la colaboración en el futuro. Este trabajo muestra que existe un vínculo fuerte entre autores y países, de modo que se debe invertir más trabajo en la revisión de los marcos de colaboración con la finalidad de describir, clasificar e identificar nuevas oportunidades.

Las futuras líneas de investigación sobre este tema se centrarán, entre otras, en estudiar el impacto de la RA sobre los procesos cognitivos y emocionales de los estudiantes; en el aprendizaje interactivo y aumentado para la orientación en educación superior; en la mejora y transformación de comunidades de aprendizaje global con realidad aumentada; en las relaciones entre la motivación del estudiante, la inmersión y los resultados del aprendizaje en entornos de realidad aumentada basados en la 
La Realidad Aumentada como recurso creativo en la educación: una revisión global

ubicación; y, en las consideraciones de diseño para combinar la realidad aumentada con tutores virtuales.

Este campo de investigación infiere que las habilidades espaciales presentan un componente importante de la inteligencia humana, de modo que las futuras investigaciones deben dirigirse a determinar cómo se vinculan tanto la percepción espacial como la visualización espacial, las rotaciones mentales, y las orientaciones espaciales.

En este sentido, la perspectiva de incluir a la neurociencia en entornos educativos que apliquen la RA supone comprender mejor el funcionamiento del cerebro de los estudiantes. En este sentido, la aplicación de nuevos estímulos al educando demanda recursos multisensoriales, como la RA, actitudinales y sociales que interactúan con las habilidades cognitivas, con el objeto de percibir, aprehender los objetos propios de la enseñanza y establecer una ruta para consolidar lo aprendido.

\section{Bibliografía}

Abad-Segura, E., González-Zamar, M.-D. (2019). Análisis de las competencias en la educación superior a través de flipped classroom. Revista Iberoamericana de Educación, 80(2), 29-45. doi:10.35362/rie8023407

Abad-Segura, E., González-Zamar. M.-D. (2019). Effects of Financial Education and Financial Literacy on Creative Entrepreneurship: A Worldwide Research. Education Sciences, 9(3), 238. doi:10.3390/educsci9030238

Acosta, J. L. B., Navarro, S. M. B., Gesa, R. F., y Kinshuk, K. (2019). Framework for designing motivational augmented reality applications in vocational education and training. Australasian Journal of Educational Technology, 35(3).

AKÇAYIR, M. , Y AKÇAYIR, G. (2017). Advantages and challenges associated with augmented reality for education: A systematic review of the literature. Educational Research Review, 20, 1-11. doi:10.1016/j.edurev.2016.11.002 
AzA, E. T. (1999). Creatividad y motricidad (16). Barcelona, España: Inde.

Azhar, N. H. M., Diah, N. M., Ahmad, S., Elsmall, M. (2019). Development of augmented reality to learn history. Bulletin of Electrical Engineering and Informatics, 8(4), 14251432.

BILINGHURST, M. (2002). Augmented reality in education.New horizons for learning, 12(5), 1-5. doi:10.1093/obo/9780199756810-0216

BilunghuRst, M., y Duenser, A. (2012). Augmented reality in the classroom. Computer, 45(7), 56-63.

Brudniy, A., y Demilhanova, A. (2012). The Virtual Reality in a Context of the" Mirror Stage". International Journal of Advances in Psychology, 1(1), 6-9.

Cabero, J., Barroso, J., y Llorente, C. (2019). La realidad aumentada en la enseñanza universitaria. REDU. Revista de Docencia Universitaria, 17(1), 105-118.

Cabero-Almenara, J., y García, F. (2016). Realidad aumentada. Tecnología para la formación, Madrid, España: Síntesis.

CarmignanN, J., y Furht, B. (2011). Augmented reality: an overview. En Handbook of augmented reality (pp. 3-46). Springer, New York, NY. doi:10.1007/s11042-0100660-6

ChandRAsekERA, T., y Yoon, S. Y. (2018). Augmented Reality, Virtual Reality and Their Effect on Learning Style in the Creative Design Process. Design and Technology Education, 23(1), n1.

China, T. H. C., Yang, S. J., y Hwang, G. J. (2014). An augmented reality-based mobile learning system to improve students' learning achievements and motivations in natural science inquiry activities. Educational Technology y Society, 17(4), 352-365. 
La Realidad Aumentada como recurso creativo en la educación: una revisión global

Del Giudice, M. (2017). Pink, blue, and gender: An update. Archives of sexual behavior, 46(6), 1555-1563.

Dewey, J. (1934). Art as experience. New York, Estados Unidos: Perigree Books.

Dı Serio, Á., IBÁÑNEZ, M. B., y Kloos, C. D. (2013). Impact of an augmented reality system on students' motivation for a visual art course. Computers y Education, 68, 586-596.

Durieux, V. y Gevenois, P.A. (2010). Bibliometric indicators: Quality measurements of scientific publication 1. Radiology, 255, 342-351.

EISNER, E. (2002). The arts and the creation of mind. New Haven, Connecticut, Estados Unidos: Yale University Press.

FauzI, AfaA, Alı, K. N. y Amirudin, R. (2019). Evaluating students readiness, expectancy, acceptance and effectiveness of augmented reality based construction technology education. International Journal of Built Environment and Sustainability, 6(1), 7-13.

García, C. E. F. (2017). Neuroeducación en entornos de realidad aumentada. Temática Psicológica, 13(1), 43-50.

GaRDNER, H. (2001). La inteligencia reformulada: las inteligencias múltiples en el siglo XXI (No. 159.955 G171i Ej. 1 020338). Barcelona, España: Paidós.

Grigorenko, E. L. (2019). Creativity in Digital Reality/Creatividad en la realidad digital. Estudios de Psicología, 1-23.

Heilig, J., Cole, H. y Aguilar, A. (2010). De Dewey to No Child Left Behind: The evoIution and devolution of public arts education. Arts Education Policy Review, 111(4), 136-145.

Hein, D. W. y Rauschnabel, P. A. (2016). Augmented reality smart glasses and knowledge management: A conceptual framework for enterprise social networks. En Enterprise social networks (pp. 83-109). Wiesbaden, Germany: Springer Gabler. 
Hsu, H. P., Wenting, Z., y Hughes, J. E. (2018). Developing elementary students' digital literacy through augmented reality creation: Insights from a longitudinal analysis of questionnaires, interviews, and projects. Journal of Educational Computing Research, 57(6), 1400-1435.

Ibánez, M. B., y Delgado-Kloos, C. (2018). Augmented reality for STEM learning: A systematic review. Computers y Education, 123, 109-123.

Kau, S., Kolnand, H., Madani, R., Salehina, M., y Shafaie, M. (2018). Augmented reality in smart cities: applications and limitations. Journal of Engineering Technology, 6(1), $28-45$.

KALAWSKY, R. S. (1999). VRUSE-a computerised diagnostic tool: for usability evaluation of virtual/synthetic environment systems. Applied ergonomics, 30(1), 11-25.

KesIM, M., Y OZARSLAN, Y. (2012). Augmented reality in education: current technologies and the potential for education. Procedia-Social and Behavioral Sciences, 47, 297302.

KumenKo, O. (2008). La creatividad como un desafío para la educación del siglo XXI. Educación y educadores, 11(2), 191-210

KoçAK, Ö., YLLMAZ, R. M., KüçüK, S., y GÖKTA凹, Y. (2019). The Educational Potential of Augmented Reality Technology: Experiences of Instructional Designers and Practitioners. Journal of Education and Future, (15), 17-36.

LEE, K. (2012). Augmented reality in education and training. TechTrends, 56(2), 13-21. doi:10.1007/s11528-012-0559-3

LESKI, K. (2015). The Storm of Creativity, Cambridge, Massachusetts, Estados Unidos: The MIT Press.

LowenfelD, V. (1961). Desarrollo de la capacidad creadora. Buenos Aires, Argentina: Kapelusz. 
La Realidad Aumentada como recurso creativo en la educación: una revisión global

LYTRIDIS, C., Y TSINAKOS, A. (2018). Evaluation of the ARTutor augmented reality educational platform in tertiary education. Smart Learning Environments, 5(1), 6.

MenCHÉn, F. (2001). Descubrir la creatividad. Desaprender para volver a aprender. Madrid, España: Ediciones Pirámide.

NascimbenI, F. (2015). The increased complexity of Higher Education collaboration in times of Open Education. Campus virtuales, 3(1), 102-108.

Perianes-Rodriguez, A., Waltman, L., y Van Eck, N. J. (2016). Constructing bibliometric networks: A comparison between full and fractional counting. Journal of Informetrics, 10(4), 1178-1195.

PHILLIPS, D. C. (1995). The good, the bad, and the ugly: The many faces of constructivism. Educational researcher, 24(7), 5-12.

PI, S. Y., Y LEE, M. S. (2016). Developing a Convergent Class Model of Augmented Reality and Art. Journal of digital Convergence, 14(5), 85-93.

Pritchard, A. (1969). Statistical bibliography or bibliometrics. Journal of documentation, 25(4), 348-349.

QuAY, J. (2003). Experience and participation: Relating theories of learning. Journal of Experiential Education, 26(2), 105-112.

Radosavljevic, S., Radosavluevic, V., y Grgurovic, B. (2018). The potential of implementing augmented reality into vocational higher education through mobile learning. Interactive Learning Environments, 1-15.

Radu, I. (2014). Augmented reality in education: a meta-review and cross-media analysis. Personal and Ubiquitous Computing, 18(6), 1533-1543.

Robinson, K. (2015). Escuelas creativas, Barcelona, España: Ed. Grijalbo. 
Rogers, C. R., y FreiberG, H. J. (1996). Libertad y creatividad en la educación. Barcelona, España: Paidós Ibérica.

Sánchez-García, J. M., y Toledo-Morales, P. (2017). Tecnologías convergentes para la enseñanza: Realidad Aumentada, BYOD, Flipped Classroom. Revista de Educación a Distancia, (55).

SquiRES, D. R. (2019). Immersive Learning Experiences: Technology Enhanced Instruction, Adaptive Learning, Augmented Reality, and M-Learning in Informal Learning Environments. i-Manager's Journal of Educational Technology, 15(4), 17.

Su, C. H. (2019). The Effect of Users' Behavioral Intention on Gamification Augmented Reality in STEM (GAR-STEM) Education. Journal of Baltic Science Education, 18(3).

SUTHERLAND, I. (1965). The ultimate display. Recuperado de: http://worrydream.com/ refs/Sutherland\%20-\%20 The\%20Ultimate\%20Display.pdf

Touriñ̃́n-LópEZ, J. M. (2011). Claves para aproximarse a la educación artística en el sistema educativo: educación "por" las artes y educación "para" un arte. Estudios sobre educación, 21, 61-81

VAN ECK, N., Y WALtMAN, L. (2009). Software survey: VOSviewer, a computer program for bibliometric mapping. Scientometrics, 84(2), 523-538.

Waltman, L., Van Eck, N. J., y Noyons, E. C. (2010). A unified approach to mapping and clustering of bibliometric networks. Journal of Informetrics, 4(4), 629-635.

WeI, X., WEng, D., LIU, Y., Y WANG, Y. (2015). Teaching based on augmented reality for a technical creative design course. Computers y Education, 81, 221-234.

Winner, E., Hetland, L., Veenema, S., Sheridan, K., Palmer, P., y Locher, I. (2006). Studio thinking: How visual arts teaching can promote disciplined habits of mind. New directions in aesthetics, creativity, and the arts, 189-205. 
La Realidad Aumentada como recurso creativo en la educación: una revisión global

Wu, H. K., Lee, S. W. Y., Chang, H. Y., y Liang, J. C. (2013). Current status, opportunities and challenges of augmented reality in education. Computers y education, 62, 41-49.

YILMAZ, R. M., Y GoKTAS, Y. (2017). Using augmented reality technology in storytelling activities: examining elementary students' narrative skill and creativity. Virtual Reality, 21(2), 75-89.

YULIONO, T., y RINTAYATI, P. (2018). The promising roles of augmented reality in educational setting: A review of the literature. International Journal of Educational Methodology, 4(3), 125-132.

Zünd, F., Ryffel, M., Magnenat, S., Marra, A., Nitti, M., Kapadia, M., y Sumner, R. W. (2015). Augmented creativity: bridging the real and virtual worlds to enhance creative play. En SIGGRAPH Asia 2015 Mobile Graphics and Interactive Applications (p. 21). ACM. 


\title{
Creatividad \\ y Sociedad
}

Creatividad y educación

no 32 - enero 2020

\section{Nuevas cartografías: Una aproximación a Canal*accessible de Antoni Abad}

\section{New cartographies: An approach to Canal *accessible by Antoni Abad}

\author{
Laia Manonelles Moner \\ Universitat de Barcelona \\ laiamanonelles@ub.edu \\ https://orcid. org/0000-0003-0738-0811
}




\section{Resumen}

La producción artística puede convertirse en un altavoz para enfocar ciertas problemáticas sociales y el artista Antoni Abad, desde el marco del proyecto Megafone (2004-2014), ha trabajado creando canales de comunicación con varios colectivos con riesgo de exclusión social para dar visibilidad a su cotidianidad. Antoni Abad, en Canal*accessible (2006-13), invitó a personas con movilidad reducida para que fotografiaran con teléfonos móviles las barreras arquitectónicas que les impedían el paso. Asimismo, Canal*accessible se relaciona con Blindwiki, desvelando aquello que no se ve (2014-2019), en el que se construyó una red de audio en la que personas invidentes o con baja visión comparten sus recorridos publicando grabaciones sonoras. En dichas propuestas la creación deviene una herramienta para construir colectivamente cartografías digitales en las que pueden conocerse las zonas accesibles e inaccesibles de diversas metrópolis. Canal*accessible se analizará en relación a las "micro-utopías" propuestas por Nicolas Bourriaud, siendo esencial el proceso, la creación de espacios de reflexión y las dinámicas relacionales y participativas. Dentro de tales parámetros se ahondará en la creatividad y el compromiso como elementos esenciales de ciertas prácticas artísticas que tienen como objetivo articular nuevos canales de comunicación e intervenir la realidad para conseguir mejoras inclusivas.

\section{Abstract}

The artistic production can become a radiator of sound to focus on certain social problems and the artist Antoni Abad, in the context of the Megafone project (2004-2014), has been working creating communication channels with several groups at risk of social exclusion in order to give visibility to their daily life. Antoni Abad, in Canal*accessible (2006-13), invited people with reduced mobility to photograph with mobile phones the architectural barriers that impeded them their passage. Canal*accessible will be related with Blindwiki unveiling the Unseen (20142019), in which an audio network was built in which blind or low vision people share their tours publishing sound recordings. In these proposals the creation becomes a tool to collectively build digital cartographies in which they can know the accessible and inaccessible areas of various metropolises. Canal*accessible will be analysed in relation to the "micro-utopias" proposed by Nicolas Bourriaud, being essential the process, the creation of spaces for reflection and the participatory and relational dynamics. Within these parameters, we will get deeper into creativity and commitment as essential elements of certain artistic practices that aim to articulate new channels of communication and intervene reality to achieve inclusive improvements.

\section{Key words}

Antoni Abad $\cdot$ Canal ${ }^{\star}$ accessible $\cdot$ Relational art - Collaborative practices · Creativity · Cultural sociology

\section{Palabras clave}

Antoni Abad · Canal ${ }^{\star}$ accesible $\cdot$ Arte relacional

- Prácticas colaborativas · Creatividad

- Sociología cultural 


\section{Introducción}

En el curso de mi vida me he encontrado sólo con una o dos personas que comprendiesen el arte de Caminar, esto es, de andar a pie; que tuvieran el don, por expresarlo así, de sauntering (deambular): término de hermosa etimología, que proviene de "persona ociosa que vagaba en le Edad Media por el campo y pedía limosna so pretexto de encaminarse à la Sainte Terre". (...) Porque cada caminata es una especie de cruzada, qué algún Pedro el Ermitaño predica en nuestro interior para que nos pongamos en marcha y reconquistemos de las manos de los infieles esa Tierra Santa. (Thoreau, 2017, pp.7-8).

Henry David Thoreau reflexiona sobre el "arte de deambular" vinculándolo con la libertad, con la independencia, con la naturaleza del sautener, del pelegrino. El acto de peregrinar queda definido en la determinación de andar de un lugar a otro buscando o resolviendo alguna cosa, siendo el proceso esencial. Nietzsche propuso en su filosofía los "pensamientos caminados" como una de las vías para encontrar la naturaleza originaria del individuo, de rumiar y digerir la realidad (Nietzsche, 1986, p. 35) y, a lo largo de la historia, varios pensadores han reivindicado la importancia del caminar en la construcción de ideas. Cabe recordar tanto los flanêurs del siglo XIX, buscando experiencias estéticas transitando la ciudad, como las derivas (dérives) propuestas por Guy Debord en el marco de la Internacional Situacionista, concebidas como caminatas por la metrópolis siguiendo las emociones y creando una psicogeografía (Debord, 2001). En tales contextos, los pensadores se salen de los itinerarios pautados para adentrarse en nuevos recorridos, yendo más allá de los mapas establecidos (Manonelles Moner, 2017). Explorar es la condición fundamental de toda travesía, sobrepasar los horizontes previamente delimitados. Dentro de tales parámetros, se ahondará en el proyecto Canal*accessible del artista Antoni Abad (Lérida, 1956) que parte de la voluntad de recorrer la ciudad para cartografiarla desde otra perspectiva, proponiendo construir colectivamente mapas digitales -realizados 
por personas con movilidad reducida - que señalan las zonas accesibles e inaccesibles de varias metrópolis. El uso de los smartphones permite registros audiovisuales geolocalizados, que se publican en la página web zexe.net ${ }^{1}$, empleando las nuevas tecnologías para forjar colaboraciones activas y reivindicar unas ciudades inclusivas. Canal ${ }^{\star}$ accessible, llevado a cabo en BARCELONA*accessible (2006), GENEVE*accessible (2008) y MONTRÉAL**in/accessible (2012-13), se fundamenta en la participación, en el trabajo grupal, siendo esencial el proceso, el recorrido. En dichas propuestas el arte deviene un instrumento para crear espacios de encuentro y para articular unas cartografías digitales que visibilizan las barreras arquitectónicas y las dificultades de movilidad. El artista se transforma en un mediador, adaptando tales iniciativas a distintos grupos y contextos con la voluntad de compartir experiencias y articular una conciencia crítica.

El objetivo del presente artículo es ahondar en la potencialidad de la creación de enfocar ciertas problemáticas sociales con el fin de transformarlas². Para profundizar en dicho propósito general se analizará Canalªccessible vinculándolo con la estética relacional de Nicolas Bourriaud (2013), puesto que dicho pensador reflexionó -en su praxis filosófica y curatorial- sobre cómo generar nuevas sinergias en las instituciones artísticas (mediante "tentativas microscópicas") que cuestionen ciertas dinámicas propias de la sociedad de consumo capitalista (2013, pp. 8-9). En primer lugar, se examinará Canal*accesible como caso de estudio para, en segundo lugar, proceder a relacionarlo con la praxis del arte relacional, esbozando las potencialidades, las ambivalencias y las contradicciones de los proyectos participativos y colaborativos. Puesto que no hay que obviar que una de las principales críticas dirigidas a tales iniciativas es el riesgo de reproducir el mismo "entretenimiento" -característico del engranaje de la sociedad del espectáculo- que denuncian, desactivando de este modo cualquier cambio posible (Bishop, 2004). De este modo se podrá finalmen-

1 Matteo Sisti Sette ha desarrollado la programación y el desarrollo de los proyectos de comunicación móvil audiovisual en la página Web.

2 Justamente, esta voluntad de aglutinar la experiencia vital y la artística fue desarrollada por el Dadaísmo, el Surrealismo y la Internacional Situacionista, una genealogía que Nicolas Bourriaud recoge para repensar cómo abrir intersticios sociales mediante la praxis artística. 
te valorar si Canal*accessible, que se vertebra a partir de dinámicas relacionales y se despliega mediante tejidos sociales colaborativos, logra abrir una brecha en la cotidianidad para intervenirla. Dentro de tales parámetros la metodología será interdisciplinar, aglutinando el pensamiento, la sociología cultural y los estudios artísticos, subrayando especialmente las reflexiones del propio artista. De este modo, a partir de Canal*accessible se explorarán las relaciones entre la creatividad y el activismo y se bosquejará la potencialidad de la creación para buscar alternativas que mejoren la realidad.

\section{Canal*accessible y Blindwiki, desvelan- do aquello que no se ve}

Antoni Abad, desde el año 2003 cuando inició Megafone.net, empezó a experimentar con el uso de teléfonos móviles -con diversos grupos con riesgo de exclusión social- para generar registros audiovisuales (publicados en la página web zexe.net), proyectando sus reflexiones, sus reivindicaciones y compartiendo su cotidianidad. Megafone.net, como su propio nombre indica, se transforma en un megáfono digital donde toman la palabra los colectivos que la sociedad ignora o margina. Algunos de Ios proyectos que se han llevado a cabo dentro de dicha estructura son Sitio*TAXI (México DF, 2004) en que colaboraron 17 taxistas utilizando los teléfonos móviles con cámaras para narrar su realidad, CanalGITANO (Lérida y León, 2005) en que los jóvenes de dicha comunidad fueron los cronistas de su cotidianidad y Canal*/NVISIBLE (Madrid, 2005) en que el artista contactó con prostitutas para que compartieran sus reflexiones. En la misma dirección cabe destacar Migrantes nicaragüenses transmiten desde celulares en San José de Costa Rica (2006), Canal*MOTOBOY (Sao Paulo, 2007) en que 12 mensajeros en motocicleta narraron sus vivencias, Cana/*TEMPORAL (Colombia, 2009) donde personas desplazadas trasmitieron sus expectativas después de abandonar sus comunidades indígenas debido al conflicto armado en Colombia, Canal`SAHARAUI (Tinduf, Argelia, 2009) en que jóvenes de los 
campamentos de refugiados explicaron sus experiencias, y Canal*PLURAL (Nueva York, 2011) donde un grupo de inmigrantes del barrio de Queens compartieron su día a día. Cada proyecto se adapta a la realidad de cada colectivo, siendo la participación y el proceso fundamentales para vertebrar estas narrativas que cuestionan y neutralizan los estereotipos que, con frecuencia, se difunden en los medios de comunicación sobre tales grupos. Es preciso recalcar que los procesos comunitarios se articulan mediante asambleas -a modo de consejo de redacción- en las que se consensuan los temas a tratar. Tales comunidades adoptan el rol de emisores y la interactividad e inmediatez de las plataformas digitales dan mayor alcance a aquello que quieren compartir y denunciar.

A continuación, se ahondará en BARCELONA*accessible (2006) que parte de la determinación de enfocar y transformar distintas problemáticas en relación a la movilidad. Abad y sus colaboradores distribuyeron octavillas en la calle invitando a personas con movilidad reducida a participar en una primera reunión, en el Centro de Arte Santa Mónica, que desencadenó el efecto "boca oreja" para acabar de constituir el grupo final de cuarenta personas (Abad y Györik, 2008, p. 24). El grupo se reunía semanalmente, durante dos meses, en la sede del Centro de Arte Santa Mónica donde se realizaban las asambleas y se expuso la documentación del proceso ${ }^{3}$. Abad revela -en relación al método de trabajo- que se organizaron "patrullas", formadas por personas que se desplazaban en silla de ruedas, para recorrer diversas zonas y así confeccionar un plano físico y navegable en el que se marcaban, con puntos rojos, las barreras arquitectónicas (Abad y Merino, 2006, p.55). El grupo fotografió (con teléfonos móviles con dispositivos GPS y cámaras) y ubicó en el mapa físico y digital 2006 obstáculos, señalando -de manera muy concreta- las deficiencias urbanas que les dificultaban e impedían la circulación por la ciudad. Intervinieron el espacio urbano desde la práctica cotidiana de pasear, mapeando la Barcelona inaccesible para crear una cartografía crítica. Abad explica:

3 Antoni Abad reflexiona sobre la relevancia de las reuniones y la dimensión pedagógica del proyecto: "Dans ces de réunion, la table est devenue à chaque fois le symbole du processus du projet: la diffusion collective à travers Internet des thèmes qui ont été discutés pendant ces réunions. La table étant aussi la trace visible pour les visiteurs des centres d'art de la manière dont le projet s'est construit, cette installation possède donc une forte charge pédagogique". (Abad y Györik, 2008, pp. 24-26-29). 
De hecho, uno de los emisores en una reunión previa opinaba que el plano de Barcelona acabaría cubierto por los puntos rojos con los que el dispositivo marca cada obstáculo publicado. El planteamiento inicial consistía en marcar simplemente los lugares de la ciudad por dónde no es posible pasar. Y han empezado a marcar tiendas, bancos y oficinas a las que no pueden acceder. No contaba con ello, pensaba que sólo se referirían a la calle. Pero, claro, los espacios inaccesibles son muchos más de los que son responsabilidad del Ayuntamiento o el transporte público. (Abad y Torres, 2006).

Es importante apuntar que Canal*accessible se relaciona estrechamente con Blindwiki, desvelando aquello que no se ve (2014-2019), que ha sido llevado a cabo en Venecia, Roma, Wroclaw, Sydney y Berlín, entre otras ciudades. En la Bienal de Venecia (2017), en el proyecto comisariado por Roc Parés y Mery Cuesta, Abad propuso a colectivos de invidentes -en colaboración con estudiantes universitarios de Cà Foscari y la Universidad de Arquitectura (IUAV) - que se reunieran para compartir sus recorridos sensoriales por los espacios, publicando grabaciones sonoras a partir de una aplicación en los teléfonos móviles y la página web BlindWiki. Unos sesenta emisores relataron tanto las barreras urbanísticas y ciertos peligros (un ejemplo son las calles que terminan en un canal) como anécdotas e historias. Desvelaron lo que no se ve y se convirtieron en guías tal y como indica Manuel Forcano, el director del Instituto Ramón LIull: "En aquest projecte els cecs guien els pigalls. I no es queda en un pavelló, sinó que s'escampa per tota la ciutat". (Serra, 2017).

En Canal*accessible y Blindwiki Antoni Abad invitó a personas con movilidad reducida y a invidentes para que fotografiaran aquello que les dificultaban el paso en su cotidianidad y, entre todos, construyeron unos mapas digitales -publicados en las páginas webs de los proyectos (zexe.net y en blind.wiki)- que daban a conocer las zonas accesibles e inaccesibles de sus ciudades a la vez que compartían experiencias e indicaciones para realizar recorridos. Tales proyectos parten del trabajo de grupos que pasean, recorren y deambulan por la ciudad, retransmitiendo y compartiendo 
sus vivencias al mismo tiempo que cartografían lo que se debe cambiar. Dichas propuestas retornan la palabra a la ciudadanía, a las comunidades con dificultades de movilidad, interviniendo la realidad, generando nuevos mapas e inventando canales de comunicación y pensamiento alternativos, abiertos, en construcción continua, que alumbran las dificultades de quienes el sistema invisibiliza. El artista se convierte en un moderador una vez iniciado el proyecto tal y como Abad explica: "Una vez he planteado y entregado el proyecto mi función pasa a ser la de moderador. Me parece justo que sean los propios afectados los que expresen sus problemas. La administración tiene que aprender a escuchar a los ciudadanos" (Abad y Torres, 2006). De hecho, la imagen del megáfono -utilizada para aglutinar distintos proyectos- recalca la idea de amplificar la voz de diversos grupos para que tengan presencia pública más allá de los medios de comunicación tradicionales (Abad y Merino, 2006, p. 56).

Los emisores se reúnen, analizan y debaten sobre los contenidos a publicar y reflexionan sobre las experiencias vividas. El proceso, como ya se ha apuntado, es esencial en la construcción de dichos proyectos, subrayando la dimensión cooperativa que permite cartografiar la realidad desde ángulos distintos. Tales iniciativas se llevan a cabo en espacios públicos físicos y en la red virtual para lograr una mayor visibilidad. Los portales de internet transmiten la información recogida, generando un lugar de encuentro entre emisores y usuarios, potenciando el uso social de las redes digitales. Pues hay que remarcar que la conectividad potencia que el público se implique con tales propuestas participativas, apelando a la colaboración y a responsabilizarnos colectivamente de los procesos de transformación que son necesarios para vivir en unas ciudades inclusivas. Tales iniciativas actúan como altavoces que proponen repensar los modelos preestablecidos, enfocando aquello que debe mejorar. 


\section{Prácticas relacionales y cartografías colectivas}

Los proyectos presentados, dentro del marco de Megafone.net, pueden vincularse con la estética relacional (1999) de Nicolas Bourriaud, quien se pregunta si es posible -en el campo del arte- generar interacciones dentro del contexto de la "sociedad del espectáculo", descrita por Guy Debord, y de lo que él denomina "la sociedad de los figurantes" en relación a unos marcos virtuales en los que aparece la ilusión de una democracia interactiva estipulada por las estructuras hegemónicas que mediatizan los dispositivos electrónicos y virtuales (Bourriaud, 2013, p.28). Asimismo, Bourriaud sostiene que el arte puede crear espacios para la experimentación en los que pueden generarse otros modos de hacer: "la realización artística aparece hoy como un territorio rico en experimentaciones sociales, como un espacio parcialmente preservado de la uniformidad de los comportamientos. Las obras sobre las que hablaremos aquí dibujan, cada una, una utopía de proximidad" (2013, pp. 8-9). Tales "utopías de proximidad", "micro-utopías" o "pequeñas resistencias", que pretenden buscar cauces fuera de lo pautado por el sistema establecido, devienen las bases de lo que denomina estética relacional. Dentro de tales parámetros la creación conecta la experiencia individual con la colectiva, fomentando la colaboración. Bourriaud recoge el término intersticio utilizado por Karl Marx, para definir a las comunidades de intercambio que buscan otros modelos alternativos al sistema económico capitalista, basándose en nuevos espacios para otros tipos de relaciones y trueques alternativos. El arte como intersticio social es una de las premisas fundamentales de Bourriaud que relaciona la potencialidad del intersticio con determinadas prácticas artísticas:

Este de la exposición de arte contemporáneo en el campo del comercio de las representaciones: crear espacios libres, duraciones cuyo ritmo se contrapone al que impone la vida es justamente el carácter cotidiano, favorecer un intercambio humano diferente al de las "zonas de comunicación" impuestas. (2013, p. 16). 
Es importante señalar que -en las propuestas esbozadas de Antoni Abad- las "utopías de proximidad" vertebran su práctica artística. Abad explora crear tejidos conectivos, relacionales, en los que la participación y el proceso son determinantes, siendo una de las finalidades dar que pensar y movilizar a la audiencia ${ }^{4}$. No obstante, hay que recordar que la "eficacia" de las prácticas relacionales es cuestionada por algunos críticos, sobretodo en relación a cómo las instituciones pueden llegar a neutralizar o convertir dichas iniciativas en espacios para el entretenimiento (Bishop, 2004) $)^{5}$. Justamente, la crítica de arte Montse Badía se pregunta si el arte puede ser un instrumento de transformación social y si puede un artista dirigir su trabajo hacia comunidades concretas y analizar sus conflictos sin que su trabajo sea considerado como de etnógrafo, sociólogo o antropólogo amateur:

Hace unos años, el teórico norteamericano Craig Owens advertía del riesgo de la "indignidad de hablar por otros" (en su texto "The Indignity of Speaking for Others: An Imaginary Interview", publicado en Beyond Recognition. Representation, Power and Culture. Berkeley: University of California Press, 1992), en relación a proyectos artísticos que se erigen en portavoces de grupos sociales discriminados o reprimidos, no tanto para solucionar sus problemas, como para estetizarlos y convertirlos en material tranquilizador de conciencias. Todas estas reflexiones vienen al caso a propósito del proyecto Canal*ACCESIBLE, iniciado por el artista Antoni Abad, que se presenta estos días en el Centro de Arte Santa Mónica. No se trata tanto de que Canal*ACCESIBLE ejemplifique estos problemas que acabamos de mencionar, sino que debido a su voluntad y formalización

4 En relación a prácticas artísticas que reflexionan sobre la política y el activismo véase Modos de hacer, arte crítico, esfera pública y acción directa (2001) y Polititzaciones del malestar (2017).

5 Cabe recordar que la estética relacional de Nicolas Bourriaud ha sido ampliamente debatida por distintos autores -como Claire Bishop, Stephen Wright, Anthony Downey, Stewart Martin, Hal Foster, Jacques Rancière y Joe Scanlan- que cuestionan su supuesta potencialidad política y el tipo el relaciones que puede generar que difícilmente van más allá de unas audiencias "homogéneas" (Prado, 2011). 
roza peligrosamente alguno de estos aspectos, al tiempo que se aleja claramente de otros (2006).

Badia cita la reflexión de Craig Owens sobre el riesgo de las representaciones de colectivos marginales por parte de la cultura dominante, interfiriendo en que dichas comunidades tomen la palabra al mismo tiempo que subrayan la "Otredad"6. Precisamente, como se ha indicado previamente, una de las principales críticas a las prácticas relacionales y colaborativas -que son ejecutadas dentro de las instituciones artísticas- es su neutralización por el mismo sistema museístico, perdiendo así la capacidad contestataria y crítica. Oriol Fontdevila destaca la relación que se establece entre el arte y la mediación y se pregunta sobre la capacidad disruptiva del arte, señalando los giros que se introducen en el museo moderno (cita a modo de ejemplo el "giro social", el "giro afectivo", el "giro de archivo", el "giro narrativo", etcétera) (2017, p.15). Fontdevila advierte sobre el poder del white cube puesto que éste pauta que tales giros aparezcan sólo representados ${ }^{7}$. Con todo, Montse Badía recuerda que Abad no se convierte en portavoz de nadie sino que ofrece herramientas tecnológicas a diversos colectivos, con escasa presencia en los medios de comunicación dominantes, para que expliquen su realidad y muestren lo que hay detrás de la "marca" Barcelona; sus grietas (2006).

6 Owens expone: "In our culture there is, of course, no lack of representations of women -or, for that matter, of other marginalized groups (blacks, homosexuals, children, criminals, the insane...). However, it is precisely in being represented by the dominant culture that these groups have been rendered absences within it. Thus, it is not the ideological content of representations of these Others that is at issue. Nor do contemporary artists oppose their own representations to existing ones; they do not subscribe to the phallacy of the positive image. (To do so would be to oppose some "true" representivity to a "false" one.) Rather, these artists challenge the activity of representation itself which, by denying them speech, consciousness, the ability to represent themselves, stands indicted as the primary agent of their domination". (1992, p. 85).

7 Fontdevila reflexiona: "El white cube se descubre, así como un dispositivo preparado para olvidar cualquier input con que pueda verse interpelada su mediación fundacional. Y, mientras esto sea así, tendremos que admitir que la incidencia de discursos como el queer, la decolonialidad o el desantropoceno van a tener allí una incidencia más ilustrativa que performativa. En un museo anclado en las mediaciones de la modernidad, los discursos que presenten formes alternativas de gobernar y de gestionar la vida solo encontrarán allí la posibilidad de representarse, pero nunca de realizarse". (2017, p.15). 
Aquí hay que apuntar que Canal*accessible es articulado por los grupos de afectados que quieren denunciar la inaccesibilidad de la ciudad, estos colectivos en riesgo de exclusión social se auto-representan y comparten su cotidianidad. También es preciso remarcar que una de las estrategias para lograr un mayor impacto es ocupar las redes de comunicación para explicar unos relatos que son omitidos. De este modo, la utilización de las redes sociales -en dichos proyectos- potencia emisores activos, críticos, contraponiéndose a la crítica de Bourriaud de una sociedad de figurantes, de ciudadanos pasivos y alienados por los dispositivos virtuales. Llegados a este punto es pertinente recoger las reflexiones de Antoni Abad sobre la potencialidad de la creación para generar micro-utopías:

Una de las preguntas que me hacían los primeros días algunos emisores discapacitados era que si canalACCESSIBLE servirá para algo. Las revoluciones ya no tienen lugar, pero quiero creer que existe la posibilidad de que se cambie la percepción que se tiene de determinados colectivos. Seguramente las barreras con la que se encuentran cada día no desparecerán inmediatamente, pero quizá se produzca un cambio de sensibilidad en la gente que visite el canal en internet o en el CASM. Sea como sea, tendremos la oportunidad de comprobar si esta ciudad está tan bien adaptada, como se dice, a las necesidades de los discapacitados físicos. Y lo sabremos sin filtros, a partir de la propia experiencia del colectivo emisor. (Abad y Torres, 2006).

En tal proyecto puede verse otro modo de recorrer la ciudad, generando unas 4500 imágenes y señalando 2006 obstáculos que impiden circular a personas con silla de ruedas y movilidad reducida. En el catálogo de barreras arquitectónicas de la Barcelona inaccesible se encuentran: 19 baños adaptados fuera de servicio, 73 transportes en los que no hay ascensores o plataformas, 146 aparcamientos incí-

8 En relación a las micro utopías de lo cotidiano y su relación con diversas prácticas performativas contemporáneas véase Manonelles Moner (2016). 
vicos obstaculizando el paso, 210 escaleras, 257 aceras, 358 rampas mal adaptadas y 1106 escalones. Es importante mencionar la relevante visibilidad del proyecto Canal*accessible, no sólo en la red virtual sino en los medios de comunicación y en la prensa escrita, destacando la obtención del premio Ars electrónica el año 2006. Aquí es interesante apuntar, como expone la gestora cultural independiente Mijo Miquel, que si bien existe una proliferación de convocatorias y cierta banalización de la producción colectiva como "espectáculo" también se llevan a cabo propuestas que generan nuevas sinergias y abren transformaciones sociales ${ }^{9}$.

\section{Consideraciones finales}

A menudo me preguntan qué hago como artista. Evidentemente, en estas experiencias la autoría está desplazada. Son los propios participantes los que publican los contenidos que consideran adecuados a sus objetivos. Como artista mi trabajo consiste en crear dispositivos de comunicación móvil audiovisual en internet para que colectivos sin presencia activa en los medios de comunicación se expresen con total libertad. (Abad y Torres, 2006).

La autoría se desplaza y el móvil deviene un "arma" (Torres, 2014) dentro de los parámetros de la "Guerrilla de la comunicación" que altera, subvierte y parasita los medios y el orden imperante para cuestionar las fisuras de las estructuras de poder a la vez que muestra otros modos de hacer (A.F.R.I.K.A, 2000, p. 7). La guerrilla de la comunicación hibrida la praxis artística con la política, el activismo, entendiendo la creación como un instrumento para cuestionar las fisuras del sistema hegemónico de poder y para suscitar preguntas y debates. El colectivo A.F.R.I.K.A remarca la táctica

9 Miquel expone: "Per tant, es tractaria de reduir l'egocentrisme artístic sense renunciar a la qualitat de la representació, activant totes les capacitats pròpies de les arts al servei d'un procés comunitari que exigeix implicació, respecte per les temporalitats, inclusivitat i doble rigor, de manera que s'entengui que la participació és un moviment d'anada i tornada, que en lloc de cooptar processos socials, aprengui com fomentar un moviment participatiu autònom". (2016, p. 23). 
del "Detóurnement", propio de la Internacional Situacionista, por su potencialidad de desarticular las reglas preestablecidas, distorsionando los significados, transformándolos, utilizando los códigos dominantes -como pueden ser las redes sociales- para emitir otros discursos y enfocar problemáticas sociales (2012). Dentro de estas premisas se promueve un uso transformador de las tecnologías digitales y se invita a que diversas comunidades se impliquen con el objetivo de mejorar la cotidianidad de muchas personas que padecen las barreras urbanísticas.

Asimismo, hay que remarcar la destacada presencia de Canal*accessible en las calles, en las redes virtuales, en los circuitos expositivos y, también, su amplia cobertura de en los medios de comunicación digitales e impresos. Cabe recalcar que los proyectos mencionados se adaptan a cada entorno, parten de la investigación local propuesta por cada comunidad. El tiempo y los procesos, como ya se ha apuntado, pautan los espacios de encuentro creados, siendo las dinámicas relacionales esenciales para llevar a cabo tales iniciativas y activar una conciencia social, otros canales de comunicación y nuevas cartografías colaborativas gracias al uso de lo que el artista denomina un "software social" (Badia, 2012).

A modo de conclusión hay que subrayar varios aspectos. En primer lugar cabe apuntar que Canal*accessible se ha llevado a cabo con el apoyo de instituciones artísticas pero traspasa los muros de los museos y los centros artísticos para ocupar las calles e intervenir así directamente en el espacio social. El propio artista expone su voluntad de parasitar las instituciones artísticas, estableciendo lazos entre éstas y colectivos que difícilmente acceden a museos y centros artísticos (Abad, 2019). Además, Abad explicita que quiere dar la palabra a los colectivos que protagonizan Canal*accessible, adoptando un rol de mediador, de moderador, no de portavoz (Abad y Torres, 2006). La decisión de tomar la palabra para denunciar diversas problemáticas políticas, sociales y urbanísticas puede articularse de modos distintos, generando vasos comunicantes entre las prácticas artísticas y el activismo que comparten la disposición de visibilizar y denunciar las injusticias que las sociedades neoliberales ejecutan 
sobre la ciudadanía. Canal*accesible propone a colectivos marginados por el sistema hegemónico un megáfono en el que trasmitir sus experiencias, evitando mediadores externos para estrechar las distancias entre sus discursos y los receptores. Dicho proyecto se nutre de las relaciones, de los consejos editoriales asamblearios organizados por las comunidades, de los encuentros y de las conversaciones sostenidas. En segundo lugar, es importante remarcar que Canal*accesible desarrolla unas "micro-utopías" cotidianas con el objetivo de impulsar cambios, de pensar nuevas tácticas de intervención para lograr una transformación social y urbanística. En este contexto la micro-utopía deviene micro-política puesto que, justamente, después de dicho proyecto el Ayuntamiento de Barcelona lanzó un mapa de la "Barcelona accesible", siendo un primer paso en el camino de construir una ciudad inclusiva (Abad, 2019).

A partir de este recorrido puede verse el compromiso de fundir la experiencia vital con la artística, politizando y poetizando la cotidianidad. Canal*accessible abre unos procesos que se articulan desde el cuidado, las relaciones y la empatía en un contexto neoliberal que individualiza y desteje los vínculos afectivos. En tal escenario la creatividad puede devenir un detonador para compartir vivencias y conectar las experiencias íntimas, individuales, con una dimensión pública, política. Según Thoreau "cada caminata es una especie de cruzada" (2017, pp.7-8) y - en el contexto de las prácticas artísticas bosquejadas- los grupos de personas en sillas de rueda e invidentes ocupan, "reconquistan" y se reapropian del espacio público, de las calles, transitándolas y compartiendo las dificultades que se encuentran en su día a día para desplazarse. En definitiva, tales propuestas enfocan la potencialidad de las "utopías concretas" y recuerdan la capacidad de polinizar propia de la creatividad y del trabajo colaborativo para transformar la realidad. Canalªccesible reivindica unas ciudades inclusivas que todos podamos recorrer, transitar y deambular. 


\section{Bibliografía}

Abad, A. (Noviembre 2019). Cartografies col.laboratives a megafone. net i blind.wiki. En Alba; Manonelles Moner; Mercader y Ramírez (Coordinadores). Jornada Prácticas procesuales i transformaciones sociales. Acciones, interpretaciones, teorías. Universidad de Barcelona, Barcelona.

Abad, A. (2019). Zexe.net. Recuperado de: Http://www.Zexe.Net/

Abad, A. (2019). Blind.wiki. Recuperado de: $\underline{\text { Http://www.Blind.Wiki/ }}$

Abad, A. y Torres, D. (2006). Entrevista a Antoni Abad per D. G. Torres. Boletín Santa Mónica, Centre d'Art Santa Mònica. Generalitat de Catalunya, Departament de Cultura (20). Recuperado de: http://www. davidgtorres.net/spip/spip.php?article168

Abad, A. y Merino, I. (10-16 marzo de 2006). Antoni Abad. Entrevista. Presència (1776), pp. 16-19.

A.F.R.I.K.A / Blisset, L. \& Brünzels, S. (2000). Manual de guerrilla de la comunicación. Barcelona: Virus editorial.

A.F.R.I.K.A (2012). A.f.r.i.k.a gruppe. En Enmedio, arte, política y nuevas tecnologías (Coordinadores). Jornadas Cómo acabar con el mal”. Teatre Antic, Barcelona. Recuperado de: http://comoacabarconelmal.net/

Ancarola, N.; Gasol, D. y Manonelles, L. (Eds). (2017). Polititzaciones del malestar. Barcelona: Rayo verde.

Badía, M. (6 de febrero 2006). Canales de comunicación y detonantes de dudas Antoni Abad "Canal* ACCESIBLE" CASM. A-Desk.org, 1. Recuperado de: http:// montsebadia.net/spip/spip.php?article

BAdiA, M. (29 de octubre 2012). Software social. Una entrevista con Antoni Abad. A*Desk. Recuperado de http://www.adesk.org/spip/spip.php?article1556. 
Bishop, C. (2004) Antagonism and Relational Aesthetics. October (110), pp. 51-79.

Bosco, R. (25 de febrero de 2006). Un plano recoge los 2006 obstáculos de la Barcelona inaccesible. El País. Recuperado de: https://elpais.com/diario/2006/02/25/ catalunya/1140833257 850215.html

BourRiAud, N. (2013). Estética relacional. Buenos aires: Adriana Hidalgo.

Blanco, P.; Carrillo, J.; Claramonte, J. y Expósito, M. (Eds.). (2001). Modos de hacer, arte crítico, esfera pública y acción directa. Salamanca: Universidad de Salamanca.

Debord, G. (1999). La sociedad del espectáculo. Valencia: Pre-Textos.

Debord, G. "et AL." (2001) Revista Internationale Situationniste \# 1-6, (1958-1969), vol 1, Madrid.

FontDEVILA, O. (2017). El arte de la mediación. Bilbao: Consonni.

GröRiK, L. (2008) Tag, mode d'emploi (Entretien avec Antoni Abad)! Propos recueillis par Laura Györik Costas au Parc des Bastions de Genève. Zexe. net une cartographie numérique du monde. Gèneve: Centre d'art Contemporaine Genève.

Manonelles Moner, L. (2017). Pensamientos caminados: nuevos horizontes y peregrinaciones en el arte contemporáneo. En D. García del Rincón y L. Manonelles Moner (Eds), Arte, naturaleza y política en la creación contemporánea, pp.183-196. Barcelona: Edicions UB.

Manonelles Moner, L. (2016). Micro-Utopías de lo cotidiano, Espacios de encuentro en el arte relacional: una aproximación ciertas acciones de Marina Abramovic y Tino Sehgal. Espacio, Tiempo y Forma. Serie VII, Historia del Arte, (4), pp. 329349. https://doi.org/10.5944/etfvii.4.2016.16030. Recuperado de: http://revistas.uned. es/index.php/ETFVII/article/view/16030 
Nuevas cartografías: Una aproximación a Canalªccessible de Antoni Abad

Mıquel, M. (2016) Contra la participación y otros términos afines. En W. García Puchades y M. Miquel (Eds), La cultura de lo común, prácticas colectivas del siglo XXI, pp. 13-23. Valencia: Universitat Politècnica de València.

Nietzsche, N. (1986). El crepúsculo de los dioses. Madrid: Alianza Editorial.

Owens, C. (1992). The Indignity of Speaking for Others: An Imaginary Interview, Beyond Recognition. Representation, Power and Culture. Berkeley: University of California Press, 83-85.

Prado, M. (2011). Debate crítico alrededor de la Estética Relacional. Revista digital Disturbis, 10. Recuperado de: http://www. disturbis.esteticauab.org/Disturbisll/Pra$\underline{\text { do.html }}$

SerRA, L. (28 de abril de 2017). Catalunya mostrarà a la Biennal com sona Venècia Antoni Abad crea un mapa sensorial per a invidents. Ara. Recuperado de: https://www. ara.cat/cultura/Catalunya-mostrara-Biennal-sona-Venecia $0 \quad$ 1786021396.html

Thoreau, H. D. (2017). Caminar. Madrid: Árdora Exprés.

TorRES, D. (28 de febrero de 2014). El móvil como arma. El Cultural. Recuperado de: https://www.elcultural.com/revista/arte/Antoni-Abad-el-movil-como-arma/34212 


\section{Creatividad y Sociedad}

\section{"Marca 007" y su gestión creativa en los Títu- los de crédito de las películas de James Bond}

\section{"Brand 007" and its creative management in the Credit Titles of the James Bond movies}

Dra. Belén Ramírez Barredo

Profesora del área de Comunicación Audiovisual y Publicidad.

Centro Universitario Villanueva bramirez@villanueva.edu, https://orcid.org/0000-0001-9403-8613

Dra. Josefa Elisa López Gómez Profesora Asociada del Departamento de Ingeniería Mecánica. Universidad Carlos III jlopezg@ing.uc3m.es, https://orcid.org/0000-0003-0003-1029

Francisca García Bazago Doctoranda. Universidad Complutense 


\section{Resumen}

Las marcas son símbolos universales de la era moderna, una promesa para el consumidor. Su adquisición viene determinada, en gran medida, por su estilo y personalidad: un conjunto de valores, de intangibles, con los que el usuario se identifica y por los que está dispuesto a pagar. La comunicación de la personalidad de la marca ha de gestionarse creativamente a través de los signos que componen e integran su sistema semiótico. Entendidos de manera integral, permiten conceptualizar e inventar la marca en todas sus dimensiones, haciendo de ella una auténtica experiencia creativa. El agente 007 no es sólo un personaje de ficción: es un icono cultural, una marca global, integrada por una serie de rasgos creativos que traspasan la ficción para anidar en la mente del espectador y entablar con él una relación personal de tipo emocional. Entre los atributos que definen la marca Bond se encuentran dos piezas audiovisuales: la secuencia Gunbarrel y los títulos de crédito iniciales. Este artículo tiene como finalidad analizar si los segundos contribuyen a la gestión creativa de la "marca 007", siendo al tiempo un componente de la misma. Se examinarán once secuencias desde un enfoque semiótico con el fin de contrastar si la simbología de las mismas está en función de la trama del filme al que preceden, dependen del director del mismo o del diseñador de la secuencia, o bien los trascienden al servicio de la personalidad de "marca 007".

\section{Abstract}

Brands are universal symbols of the modern era, a promise for the consumer. Their acquisition is determined, to a large extent, by their style and personality: a set of values, of intangibles, with which the user identifies and for which he is willing to pay. The communication of the personality of the brand has to be managed creatively through the signs that make up and integrate its semiotic system. Comprehensively understood, they allow conceptualizing and inventing the brand in all its dimensions, making it an authentic creative experience. The agent 007 is not just a fictional character: it is a cultural icon, a global brand, integrated by a series of creative features that transcend the fiction to nest in the mind of the viewer and engage in a personal relationship of an emotional type. Among the attributes that define the Bond brand are two audiovisual pieces: the Gunbarrel sequence and the initial credit titles. The purpose of this article is to analyze whether the latter contribute to the creative management of the "007 brand", while being a component of it. Eleven sequences will be examined from a semiotic approach in order to contrast whether the symbology of the sequences is a function of the plot of the film they precede, depend on the director of the film or the designer of the sequence, or transcend them to the service of the "brand 007" personality.

\section{Key words}

James Bond $\cdot$ Brand $\cdot$ Creativity $\cdot$ Marketing

- Credit Titles · Design

\section{Palabras clave}

James Bond · Marca $\cdot$ Creatividad · Marketing

- Títulos de crédito $\cdot$ Diseño 


\section{Introducción}

Las marcas son signos. Y la función del signo es representar a otro. La transición del signo al significado nos conduce de lo puramente sensorial, el nombre y el grafismo de la marca, a lo mental, donde emerge el significado en el intelecto de los individuos: un paso que implica a un tiempo la semiótica y la psicología. Esto nos permite hablar del sistema semiótico de la marca, que, como recoge Costa (2012, p.23), está constituido por las combinaciones de unos signos de base que son de diferente naturaleza:

1. Lingüísticos: se trata del nombre de la marca. Es el aspecto más duradero. La identidad de marca empieza por el nombre, convirtiéndose en el sustrato de su cultura y de su imagen pública. "El nombre da a las cosas su verdadera realidad y su identidad comunicable. La identidad verbal es el primero de los recursos que da existencia real a la marca: la hace concebible, comunicable, reconocible, identificable y memorizable" (Bassat Coen, 2006, p.79). La combinación de signos en este área son el nombre, la denominación y la designación.

2. Escriturales: en estos signos encontramos el trazo alfabético. Cada fuente y familia tipográfica tienen características que las distinguen de otras, haciéndolas únicas, y dotando de personalidad al texto. Sus diferentes rasgos permiten clasificarlas en categorías. Siguiendo a Martínez Castillo (2008) encontramos tipografías serif, reconocibles por sus remates; sans serif o de palo seco, caracterizadas por su trazo uniforme y vértices rectos; manuscritas o script, con apariencia de caligrafía o letra cursiva; de exhibición, con alto grado de asociación y referencia mediática; y dingbats \& dingfonts, también conocidas como símbolos e imágenes.

3. Icónicos: en este ámbito hablamos de símbolo, icono, imagen, representación y representante. David Aaker (como se citó en Ra- 
mírez Barredo, 2016, p.144), gran estratega de marcas, destaca la importancia de los símbolos en las marcas cuando afirma que un símbolo poderoso puede dar cohesión y estructura a una identidad, y facilitar en gran manera su reconocimiento y recuerdo. La semiótica de las marcas percibe los logotipos como parte del sistema de señales que una empresa utiliza para comunicarse con su audiencia, mientras que la identidad corporativa los percibe como la firma de la empresa en todos sus materiales. "El proceso de expansión de los símbolos corporativos implica un aspecto social, pues tales símbolos no sólo buscan la expresión visual de la identidad comercial de una marca, sino también todos los valores socio-culturales que definen a esa marca. La globalización del logo-símbolo se convierte, de esa manera, en un instrumento para las marcas, al permitir su mundialización" (García García et al., 2010, p. 142). Toro Martín apunta distintos tipos de símbolos según su significado intrínseco: nombre igual al logo con asociación aprendida; nombre igual al logo con asociación natural y nombre distinto del logo (Toro Martín et al. 2009, p.103). En lo tocante al grado de iconicidad, Villafañe y Mínguez-Arranz distinguen entre fotografía, representación figurativa o realista, representación figurativa no realista, pictograma y representación no figurativa (Villafañe y Mínguez-Arranz, 1996, p.47).

4. Cromáticos: son principalmente señales. Su proceso pasa del estímulo luminoso (señal cromática) al signo funcional (el color significa la marca). El color es un elemento constitutivo o identificador de la marca, al que recurren las mismas con el fin de diferenciarse y llenarse de contenido (Toro Martín et al., 2009, p.110). Son parte fundamental de la identidad y un elemento básico en el diseño. Introduce connotaciones estéticas y emocionales al sistema gráfico de identidad, e incorpora su fuerza óptica a las expresiones de la 
marca. Transmite valores psicológicos decisivos, además de impactar ópticamente, convirtiéndose en ocasiones en un valor connotativo básico que trasciende el símbolo. Los colores están profundamente arraigados en la psicología humana; el lenguaje los utiliza con frecuencia para describir sentimientos (Dabner et al., 2005, p.34). Su combinación no es accidental: sus asociaciones están enraizadas en experiencias universales adquiridas en nuestro lenguaje y en nuestro pensamiento. Por ejemplo: "me puse morado de comer" o "estaba verde de envidia". Además, ningún color aparece aislado. Cada uno está rodeado de otros, de forma que en un efecto intervienen varios colores al mismo tiempo: actúa un acorde cromático (Heller \& Chamorro Mielke, 2007, p.18). Como señala en la introducción de su libro Josef Albers (como se citó en Bayo Neira, s.f., p.1), la interacción de un color con otro depende de la forma y ubicación de los mismos, su cantidad, sus cualidades (intensidad, luminosidad y tonalidad) y su acentuación (según los límites que los unen o los separan). Casi nunca vemos un color aislado; percibimos un conjunto total, una relación con un flujo continuo que posee condiciones cambiantes.

De lo dicho hasta aquí se deduce que el concepto marca es superior a la idea de producto: es una promesa para el consumidor. Como señala Ramírez Barredo identifica, califica y, sobre todo, cualifica, aporta valor añadido (Ramírez Barredo, 2016, p.79). Entramos en contacto con la marca a través del producto; y ambos, marca y producto, afloran juntos en la conciencia de los individuos. Para Costa el proceso comprendería los siguientes pasos: el producto hace nacer la marca; ésta se llena de valores gracias al primero; y llega un momento en el que la marca es capaz de crear valor por sí misma (Costa, 2012, p.148). Esta transformación se encuentra estrechamente vinculada a la denominada "ley general ligada al conocimiento": aquella que lleva a las personas de la percepción a la experiencia, o de los signos y las cosas 
"Marca 007" y su gestión creativa en los Títulos de crédito de las películas de James Bond

a las emociones. Así, podemos afirmar que una marca es una entidad visible, una historia en la mente del consumidor, una sensación emocionante ante la posibilidad de ver, tocar o adquirir una cosa en particular.

La marca pertenece a las empresas, pero sobre todo, a los usuarios, que buscan, con su adquisición, satisfacer una doble necesidad: integrarse en un grupo y diferenciarse del resto. Ese requisito es canalizado mediante una gestión creativa de su discurso. Es decir, entendiendo y poniendo "en práctica que la comunicación es el negocio de las personas. Y la creatividad es el negocio de las ideas. (...) Gestionar creativamente la comunicación significa, primero pensar, en segundo lugar significa saber/ conocer, y en tercer lugar significa discernir/ elegir. En definitiva, (...) significa responder" (Ricarte Bescós, 2006, p.3). La marca busca dar respuesta a un público que demanda una oferta personalizada para un comportamiento individualizado. mensaje se verá reforzado en la medida en que los signos que conforman el sistema semiótico de la marca transmitan creatividad, entendida ésta como "atributo de la personalidad" (Rodríguez R. y Mantilla C., 2013, p.286). Las señales externas, si bien no conforman por sí solas la singularidad de la marca, han de irradiar la esencia de la misma, siendo fuente y reflejo del patrón creativo que las sustenta.

El reto del branding creativo pasa por comprender que hablar de marca es hacerlo de experiencia, y traducirlo de manera integral y en todas sus propiedades: texturas, colores, sabores, olores, sonidos, navegación (física y virtual). "El Director Creativo debe ser capaz de conceptualizar y diseñar la marca en su expresión básica de identidad corporativa e inventarla en todas sus dimensiones. La marca en sus cinco sentidos" (Borrero, Interbrand 2013, p.67). De este modo constituirá una verdadera experiencia de $360^{\circ}$, entablando diálogo con el consumidor. Porque para entender qué es una marca debemos preguntarnos qué significado tiene el producto en la vida del usuario. Walter Landor (como se citó en Bassat Coen, 2006, p.29), respetado diseñador, pionero en el terreno del branding y fundador de Landor Associates, afirmaba que los productos se hacen en las fábricas pero las marcas se crean y viven en la mente. Tienen un componente humano: una visión, un tono de voz, unos valores, 
una identidad. Los clientes esperan que se les entregue la promesa de marca que aguardan recibir; y el branding creativo, más allá de los logotipos, nombres y lemas, ayuda a hacer realidad este deseo. Cuando la marca es capaz de conectar en un plano emocional, traspasando la experiencia y superando las expectativas que hay detrás del producto o servicio, y no simplemente cubrir una necesidad, genera fidelidad y prescripción. Entre la identidad -la esencia propia y diferencial- y la imagen -la representación mental- se construyen asociaciones: relaciones entre la creatividad (personalidad) de marca y el consumidor. Son vinculaciones que surgen de la percepción de atributos o beneficios de la marca que el consumidor va adquiriendo y asimilando a medida que se crea una relación, más o menos profunda, entre marca y consumidor (Toro Martín et al., 2009, p.57).

El terreno cinematográfico, en el que nos centraremos a continuación, no es ajeno a este proceso: la comercialización de las películas está en manos de departamentos de marketing, para quienes el cine es, habitualmente, un producto más a vender. En palabras de Solana y Boneu "para estudiar el desarrollo histórico del diseño gráfico en el cine, hay que asumir el cine como lo que en realidad es: un negocio de entretenimiento que de vez en cuando llega a niveles artísticos" (Solana y Boneu, 2008, p.12). "La narrativa audiovisual desvela las claves para contar historias con los distintos elementos expresivos a su alcance: imagen, sonido, textos...." indica Isidro Moreno (como se citó en Baños González, 2006, p.16). El lenguaje audiovisual es una forma de procesar la realidad. Y el diseño gráfico una de sus herramientas. Hace años su papel en el cine se reducía, habitualmente, al cartel de la película. Hoy en día el diseñador experimenta una presencia creciente en el ámbito cinematográfico, con una formación técnica y cultural ad hoc: las habilidades requeridas para el diseño de secuencias de títulos abarcan numerosos campos, manteniendo un pulso constante entre apostar por lo que se sabe que funciona y tiene éxito, o decidirse por la creatividad.

Para diseñar bien no basta saber la técnica ni manejar las herramientas. Steve Jobs (como se citó en Bartolomé y Ortiz de Solórzano 2011) afirmaba que para diseñar algo verdaderamente bien es necesario previamente entender en profundidad de qué 
"Marca 007" y su gestión creativa en los Títulos de crédito de las películas de James Bond

se trata, realidad que requiere un compromiso apasionado. Los títulos de crédito suponen para el diseñador un reto en la gestión creativa de la comunicación. El primer motivo es su brevedad; y el segundo la obligada relación que han de mantener, por débil que sea, con la narración a la que pertenecen. Para que exista este nexo, es necesario que el diseñador comprenda el espíritu y la personalidad del filme, trasladando ambos al diseño de la secuencia de títulos, de modo que éstos construyan el ambiente adecuado.

Las secuencias de créditos experimentaron un elevado reconocimiento a partir de los años treinta del siglo pasado, momento en que el cine pasó a ser un fenómeno de ámbito global y se convirtió en un gran negocio (Solana y Boneu, 2008, p.51). Vieron la luz los grandes estudios cinematográficos, al tiempo que nacieron y se desarrollaron negocios colaterales al cine. Previamente los títulos ya habían evolucionado en su función, pasando de ser un mero requisito de identificación a convertirse en el prólogo del filme. En esta década asumieron un nuevo rol acorde al intento de los productores de distinguirse de la competencia: diferenciar los productos. Con este fin los títulos de las películas se transformaron en logotipos, de modo que, nada mas comenzar, los espectadores tuviesen claro el género de la cinta. "La secuencia de créditos tenía que actuar como una clave musical y tenía que dar el tono" (Solana y Boneu, 2008, p.52). Poco después los títulos pasarían a ocupar un lugar secundario, tras la aparición estelar del logotipo del estudio cinematográfico. En la actualidad "Ios títulos de crédito se han convertido en una parte de la película de la que no podemos prescindir" (Gamonal Arroyo, 2005, p.3). El aprecio por los títulos de crédito se deriva del hecho de que "su autor puede crear unos cortometrajes que, a modo de comentario, introducción, publicidad u otra cosa sin término definido, pueden tener un elevado valor plástico, narrativo o simbólico relacionado de manera más o menos estrecha con la obra audiovisual a la que nacen unidos" (Labaig Fuertes, 2006, p.8).

En las secuencias de créditos intervienen tres elementos: tipografía, imagen y sonido o música. Según Nicole de Mourgues, tres propiedades: Io "livisaudible", esto es, lo que se lee, lo que se ve y lo que se oye (de Mourgues, 1994, p.35). Los títulos 
son esencialmente información escrita: en ellos el texto puede cobrar vida e interactuar con el resto de elementos de la pantalla. La tipografía posee características expresivas que le hacen susceptible de convertirse en imagen y adquirir significado, experimentando un efecto multiplicador al combinarse con la animación. Gamonal señala que "en la Tipografía se producen dos figuras retóricas como la personificación y vivificación. Por un lado, se dota a entidades abstractas como las letras de cualidades humanas y, por otro, se les confiere movimiento mediante la animación" (Gamonal Arroyo, 2005, p.4). Las imágenes desempeñan un papel esencial, tanto para transmitir el mensaje que el director desea como para que el espectador perciba dicha información. Podemos clasificarlas, siguiendo a de Mourgues en las siguientes categorías: imagen fija; plano único con movimiento en la imagen; movimientos de cámara; plano secuencia; y sobre muchos planos (de Mourgues, 1994, p.51). "Cualquier imagen admite su división, y no pocas veces este principio se ha convertido en una estrategia altamente expresiva" (García García, 2003, p.4). En función del uso que el diseñador quiera dar a los títulos de crédito varía la iconicidad de los mismos. Las secuencias en muchas ocasiones reflejan los movimientos artísticos predominantes en el momento en que se diseñaron; y muchas veces los diseñadores optan por utilizar formas o dibujos frente a fotografías, porque pueden ser más efectivos a la hora de evocar determinadas imágenes en la mente del espectador. La función expresiva de la música es vital para recrear la atmósfera conveniente, con el fin de incidir en el estado de ánimo del espectador en la dirección deseada. Para asegurar la efectividad del mensaje es esencial la fase de sincronización, donde se provee de simultaneidad a la tipografía, las imágenes y el sonido. Gamonal aporta una serie de consideraciones sobre el proceso de creación de una secuencia. Entre éstas señala que, para que los títulos formen una unidad con la película es necesaria la colaboración e implicación del director de la misma en el procedimiento: nadie como él posee una visión completa y global de sus múltiples aspectos y componentes (Gamonal Arroyo, 2005, p.5). 


\subsection{La marca James Bond. Características}

Cuanto más larga sea la vida del producto, más se ha de cuidar la marca. El caso que nos ocupa es paradigmático en este sentido, considerando que "es la franquicia cinematográfica más longeva, con veinticuatro películas desde el estreno de Dr. No hace cincuenta y tres años" (Ruiz-Mediavilla, 2015, p.298), y que a finales de la década de los ochenta ya habían agotado el material disponible (Radatz et al., 2012). Sin embargo, gracias a la gestión creativa de los atributos que conforman la personalidad del Agente 007, ésta ha hecho realidad el objetivo perseguido por ingleses y norteamericanos desde el principio: "la ambición de hacer de 007 un icono a escala planetaria. O, en términos de marketing, una marca global" (Ruiz-Mediavilla, 2015, p.298).

El personaje de ficción del MI6 saltó a la gran pantalla en 1962 de mano de los productores Albert R. Broccoli y Harry Saltzman, con la adaptación de la sexta novela de su creador, el periodista y oficial de inteligencia de la ll Guerra Mundial, Sir lan Fleming. Desde entonces hasta nuestros días, como indican Radatz et al. (2012), han circulado por la franquicia seis actores principales, once directores y dos generaciones de productores. La saga, mas que una adaptación literal, recrea el espíritu que anida en las obras originales de Fleming. Las películas filmadas hasta el momento incorporan una serie constante de signos lingüísticos, escriturales, icónicos y cromáticos, que constituyen el ADN exclusivo de la marca. El universo 007 se nutre de conspiración internacional y espionaje, acción, villanos y mujeres, lugares exóticos, artículos de alta tecnología, automóviles, bebidas, elegancia. Y marcas: Omega, Martini, Ford, Aston Martin, Sony o Lotus forman parte de la imagen de 007.

"De hecho, es posible que el mayor invento de la saga de James Bond - desde luego el gran hallazgo a nivel comercial - haya consistido en la integración de distintas marcas en sus guiones. (...) La

- marca Bond, un caso único en el mundo del entretenimiento, se ha beneficiado históricamente de los anunciantes asociados con ella y viceversa: "007" es una marca construida a base de otras marcas" 
- (Ruiz-Mediavilla, 2015, p.298).

Entre los flujos de información responsables de la creación de "marca 007" se encuentran dos piezas audiovisuales no originarias de Fleming: la secuencia "Gunbarrel" y los títulos de crédito iniciales. En la primera, creada por Maurice Binder, unos puntos blancos animados atraviesan la pantalla y se transforman en el cañón de un arma que apunta a Bond. "La secuencia, encargada de iniciar todas las películas, es una de las características más distintivas de la serie" (Archivo 007, 2008) y ejemplo de gestión creativa del discurso de marca. Los segundos, que se han convertido en género en sí mismos (Radatz et. al, 2012) están integrados por un conjunto de elementos que, si bien son aplicados con libertad en cada entrega, están presentes en todas y cada una de las secuencias: formas femeninas, violencia, armas, fotografía creativa, formas gráficas en movimiento y un uso purista de la tipografía (Radatz et. al, 2012). Todos se dan la mano formando una unidad, con el fin de anticipar, narrativa y simbólicamente, el argumento del filme al que preceden. Una particularidad en los openings de Bond es su ubicación en el conjunto de la obra: su aparición en escena va precedida, habitualmente, por una secuencia que introduce el filme. Los títulos se presentan así como una unidad indivisible en el conjunto narrativo, facilitando al espectador una serie de claves que le preparen psicológica y emocionalmente para los siguientes minutos de metraje.

\subsection{Objetivo}

La finalidad de este artículo es estudiar si los títulos de crédito de las películas de James Bond contribuyen a la gestión creativa de la "marca 007", además de constituir per se elementos de la misma.

\section{Objetivos específicos}

Identificar e interpretar los signos que aparecen de forma recurrente en las secuencias y valorar su consistencia en la gestión creativa del 
discurso de "marca 007".

Identificar las variables eventuales de las secuencias de crédito en función de la temática del filme y su contribución a la gestión creativa de la "marca 007".

\subsection{Justificación}

Las películas de Bond han tenido un impacto cultural significativo en el transcurso de cinco décadas. A través de las secuencias de crédito los diseñadores han colaborado al crecimiento, desarrollo y evolución en el tiempo del personaje de ficción. Como el propio Binder observaba, estas piezas audiovisuales anticiparon ya en su origen el formato de video clip moderno, combinando el cine experimental y elementos narrativos abstractos con la cultura y música pop (Radatz, 2013). Se han convertido en género en sí mismos, influenciando el panorama del diseño de títulos gracias a su creatividad y técnica.

\subsection{Hipótesis}

Las secuencias de títulos iniciales de las películas de la franquicia James Bond contribuyen a la gestión creativa de los atributos que conforman la personalidad de "marca 007" con independencia de la trama argumental del filme al que preceden, el director o el diseñador. Al tiempo, trascienden la obra audiovisual para constituir por sí mismas un elemento de "marca 007".

\section{Método}

Se han seleccionado once secuencias de la franquicia 007 tomando como referencia que en las veinticuatro entregas han participado seis actores principales, once di- 
rectores y cuatro diseñadores de crédito. El criterio elegido ha sido una combinación de los mismos, intercambiando las variables entre sí. En esta selección es necesario tener en cuenta la siguiente proporción:

1. Cuatro diseñadores de las secuencias. Maurice Binder y Daniel Kleinman abarcan un total de veintiuna secuencias. Catorce el primero y siete el segundo. Robert Brownjohn diseñó sólo dos secuencias, y MK12 una.

2. Seis actores que han encarnado el papel de James Bond.

3. Once directores.

Se analizarán los signos que integran el sistema semiótico de la marca: elementos lingüísticos, escriturales, icónicos y cromáticos. Dado que la música es un elemento esencial en las secuencias de crédito, y un distintivo en las películas de James Bond, se incorporará al estudio dentro de los signos lingüísticos.

Conjugando estas variables tenemos la siguiente selección:

1. Dr. No (1962). 111 minutos.

https://www.artofthetitle.com/title/dr-no/

Dirección: Terence Young. Diseñador de créditos: Maurice Binder. Actor principal: Sean Connery.

Sinopsis: James Bond llega a Jamaica con la misión de investigar los asesinatos de un agente especial británico y su secretaria, pero descubre la existencia de una siniestra organización en la isla Crab Key. Su enemigo, el Doctor No, con la ayuda del profesor Dent se propone ejecutar un siniestro plan: desviar la trayectoria de los co- 
"Marca 007" y su gestión creativa en los Títulos de crédito de las películas de James Bond

hetes de Cabo Cañaveral. (Filmaffinity)

1. Goldfinger (1964). 108 minutos.

https://www. artofthetitle.com/title/goldfinger/

Dirección: Guy Hamilton. Diseñador de créditos: Robert Brownjohn. Actor principal: Sean Connery.

Sinopsis: El agente británico 007 se deberá ver las caras con Auric Goldfinger, un malvado magnate que hace contrabando a escala internacional y que está fascinado por el oro. James oirá por primera vez hablar sobre la operación "Grand Slam", que parece ser un plan para desestabilizar toda la economía mundial. (Filmaffinity)

1. On Her Majesty's Secret Service (1969). 140 minutos.

https://www.artofthetitle.com/title/on-her-majestys-secret-service/

Dirección: Peter R. Hunt. Diseñador de créditos: Maurice Binder. Actor principal: George Lazenby.

Sinopsis: En esta ocasión 007 se asocia a un mafioso para unir sus fuerzas en la lucha contra la malvada organización Spectra. El malvado Stavro Blofeld amenaza al mundo entero con lanzar una peligrosa bacteria que podría acabar con la producción agraria de todo el planeta. (Filmaffinity)

1. The Spy Who Loved Me (1977). 125 minutos.

https://www.artofthetitle.com/title/the-spy-who-loved-me/

Dirección: Lewis Gillbert. Diseñador de créditos: Maurice Binder. Actor principal: Roger Moore. 
Sinopsis: La misteriosa desaparición de dos submarinos nucleares exige la colaboración de los mejores agentes de los servicios secretos británico y soviético: James Bond y la mayor Amasova. Detrás de todo se encuentra el magnate Stromberg, que se propone destruir a la humanidad para fundar una nueva civilización bajo el mar. (Filmaffinity)

2. Licence to Kill (1989). 135 minutos.

\section{https://www.artofthetitle.com/title/licence-to-kill/}

Dirección: John Glen. Diseñador de créditos: Maurice Binder. Actor principal: Timothy Dalton.

Sinopsis: El agente 007 a la caza y captura de un peligroso narcotraficante latinoamericano, con implicaciones personales de por medio: el capo de la droga mató a un amigo suyo, y Bond desea vengarse. (Filmaffinity)

3. Tomorrow Never Dies (1997). 119 minutos.

https://www.artofthetitle.com/title/tomorrow-never-dies/

Dirección: Roger Spottiswoode. Diseñador de créditos: Daniel Kleinman. Actor principal: Pierce Brosnan.

Sinopsis: Elliot Carver, un gran magnate de los medios de comunicación, sólo necesita conseguir los derechos de publicación en China para completar su emporio global. Su maquiavélico plan consiste en provocar una guerra entre Gran Bretaña y China. James Bond emprenderá una misión contrarreloj para descubrir quién está detrás del peligroso incidente. (Filmaffinity) 
"Marca 007" y su gestión creativa en los Títulos de crédito de las películas de James Bond

4. The World Is Not Enough (1999). 128 minutos.

https://www.artofthetitle.com/title/the-world-is-not-enough/

Dirección: Michael Apted. Diseñador de créditos: Daniel Kleinman. Actor principal: Pierce Brosnan.

Sinopsis: Tras la muerte del magnate británico del petróleo en un atentado en el cuartel general del Ml6, su hija Elektra hereda sus fabulosos yacimientos petrolíferos del mar Caspio. El agente 007 se convierte en su guardaespaldas. Su astronómica fortuna atrae la atención del asesino, un hombre con una bala alojada en el cerebro que le impide sentir dolor físico y cuya única obsesión es la venganza. (Filmaffinity)

1. Die Another Day (2002). 123 minutos.

\section{https://mww.artofthetitle.com/title/die-another-day/}

Dirección: Lee Tamahori. Diseñador de créditos: Daniel Kleinman. Actor principal: Pierce Brosnan.

Sinopsis: El agente 007 investiga los planes de Zao, el hijo del pacifista coronel Moon del ejército de Corea del Norte. 007 descubre que Zao planea unificar los ejércitos de las dos Coreas para atacar Japón y enfrentarse a los Estados Unidos, y que Gustav Graves, un misterioso millonario que tiene negocios con Zao, representa una gran amenaza para el mundo, pues ha fabricado un satélite que le permite dirigir la luz solar a su antojo. (Filmaffinity)

1. Casino Royale (2006). 144 minutos.

https://mww.artofthetitle.com/title/casino-royale-2006/ 
Dirección: Martin Campbell. Diseñador de créditos: Daniel Kleinman. Actor principal: Daniel Craig.

Sinopsis: La primera misión del agente británico James Bond como agente 007 lo lleva hasta Le Chiffre, banquero de los terroristas de todo el mundo. Para detenerlo y desmantelar la red terrorista, Bond debe derrotarlo en una arriesgada partida de póquer en el Casino

\begin{tabular}{|c|c|c|c|c|}
\hline Película & Lingüístico & Escritural & Icónico & Cromático \\
\hline $\begin{array}{l}\text { Dr. No (1962) } \\
\text { T. Young. } \\
\text { M. Binder. } \\
\text { Sean Conery. } \\
\text { Compositor: Mon- } \\
\text { ty Norman (Reino } \\
\text { Unido) }\end{array}$ & $\begin{array}{l}\text { Dr. No: nombre del } \\
\text { villano. } \\
\text { En la versión ori- } \\
\text { ginal no introduce } \\
\text { el nombre de la } \\
\text { "marca 007". } \\
\text { Tema musical: } \\
\text { Tema } 007 .\end{array}$ & $\begin{array}{l}\text { Tipografía Sans } \\
\text { Serif. Similitud con } \\
\text { Arial Rounded MT } \\
\text { Bold. } \\
\text { Interacción con la } \\
\text { imagen gráfica. } \\
\text { Color blanco. }\end{array}$ & $\begin{array}{l}\text { Símbolos que } \\
\text { identifican a 007: } \\
\text { Puntos: proyec- } \\
\text { tiles disparados. } \\
\text { Siluetas mujeres. } \\
\text { Símbolo } 007 . \\
\\
\text { Símbolos propios } \\
\text { trama argumental } \\
\text { del filme: silue- } \\
\text { tas bailando con } \\
\text { melodía ritmo } \\
\text { Jamaicano. } \\
\text { Siluetas de los tres } \\
\text { ciegos. }\end{array}$ & $\begin{array}{l}\text { Blanco y negro: } \\
\text { espionaje. } \\
\text { Elegancia. Smo- } \\
\text { king. } \\
\text { Rojo, verde y azul, } \\
\text { cian, magenta y } \\
\text { amarillo. } \\
\text { Emplea colores } \\
\text { primarios. }\end{array}$ \\
\hline $\begin{array}{l}\text { Goldfinger (1964) } \\
\text { Guy Hamilton. } \\
\text { R. Brownjohn. } \\
\text { Sean Conery. } \\
\text { Intérprete: Shirley } \\
\text { Bassey (Reino } \\
\text { Unido) }\end{array}$ & $\begin{array}{l}\text { Goldfinger: nom- } \\
\text { bre del villano. } \\
\text { En la versión ori- } \\
\text { ginal no incorpora } \\
\text { el nombre de la } \\
\text { "marca 007". } \\
\text { Tema musical: } \\
\text { Goldfinger. Re- } \\
\text { fuerza nombre del } \\
\text { filme y la trama } \\
\text { argumental del } \\
\text { mismo. }\end{array}$ & $\begin{array}{l}\text { Tipografía Sans } \\
\text { Serif. Similitud con } \\
\text { Arial Rounded MT } \\
\text { Bold. } \\
\text { Interacción con la } \\
\text { imagen gráfica. } \\
\text { Color blanco. }\end{array}$ & $\begin{array}{l}\text { Símbolos que } \\
\text { identifican a 007: } \\
\text { proyección de } \\
\text { imágenes sobre la } \\
\text { silueta de la actriz } \\
\text { Margaret Nolan: } \\
007 \text { y las mujeres. } \\
\text { Imágenes acción, } \\
\text { disparos, explosio- } \\
\text { nes. Pistola. } \\
\text { Símbolos propios } \\
\text { trama narrativa } \\
\text { del filme: silueta } \\
\text { mujer cubierta de } \\
\text { oro. Rostro actor } \\
\text { 007, rostro actriz } \\
\text { chica Bond, rostro } \\
\text { villano. }\end{array}$ & $\begin{array}{l}\text { Blanco y negro: } \\
\text { espionaje. Elegan- } \\
\text { cia. Smoking. } \\
\text { Rojo: sangre, } \\
\text { violencia. } \\
\text { Dorado: oro. } \\
\text { Verde. }\end{array}$ \\
\hline
\end{tabular}




\begin{tabular}{|c|c|c|c|c|}
\hline Película & Lingüístico & Escritural & Icónico & Cromático \\
\hline $\begin{array}{l}\text { On Her Majesty's } \\
\text { Secret Service } \\
\text { (1969) } \\
\text { Peter R. Hunt. } \\
\text { M. Binder. } \\
\text { G. Lazenby. } \\
\text { Compositor: } \\
\text { John Barry (Reino } \\
\text { Unido) }\end{array}$ & $\begin{array}{l}\text { Al servicio de su } \\
\text { Majestad: introdu- } \\
\text { ce la misión. } \\
\text { En la versión ori- } \\
\text { ginal no incorpora } \\
\text { el nombre de la } \\
\text { "marca 007". } \\
\text { Tema musical: } \\
\text { Instrumental. }\end{array}$ & $\begin{array}{l}\text { Tipografía Sans } \\
\text { Serif. Similitud con } \\
\text { Arial Rounded MT } \\
\text { Bold. } \\
\text { Interacción con la } \\
\text { imagen gráfica. } \\
\text { Color blanco. }\end{array}$ & $\begin{array}{l}\text { Símbolos que } \\
\text { identifican a 007: } \\
\text { copa de Martini, } \\
\text { reloj, Siluetas } \\
\text { mujeres. } \\
\text { Imágenes de } \\
\text { películas anterio- } \\
\text { res: Explosiones, } \\
\text { villanos, chicas } \\
\text { Bond. } \\
\text { Símbolos propios } \\
\text { trama narrativa } \\
\text { del filme: Bandera } \\
\text { inglesa } \\
\text { Corona, reloj de } \\
\text { arena. }\end{array}$ & $\begin{array}{l}\text { Blanco y negro: } \\
\text { espionaje. Elegan- } \\
\text { cia. Smoking. } \\
\text { Rojo: sangre } \\
\text { Azul } \\
\text { Verde. } \\
\text { Emplea colores } \\
\text { primarios. }\end{array}$ \\
\hline $\begin{array}{l}\text { The Spy Who Lo- } \\
\text { ved Me (1977) } \\
\text { Lewis Gilbert. } \\
\text { M. Binder. } \\
\text { Roger Moore. } \\
\text { Intérprete: Carly } \\
\text { Simón (EEUU) }\end{array}$ & $\begin{array}{l}\text { La espía que me } \\
\text { amó: profesión y } \\
\text { mujeres. } \\
\text { No incorpora el } \\
\text { nombre de la } \\
\text { "marca 007”. } \\
\text { Tema musical: No- } \\
\text { body does it bet- } \\
\text { ter. Título diferente } \\
\text { a la película. En la } \\
\text { segunda estrofa } \\
\text { nombra el título de } \\
\text { la película. }\end{array}$ & $\begin{array}{l}\text { Tipografía Sans } \\
\text { Serif. Similitud con } \\
\text { Arial Rounded MT } \\
\text { Bold. } \\
\text { Interacción con la } \\
\text { imagen gráfica. } \\
\text { Color blanco. }\end{array}$ & $\begin{array}{l}\text { Símbolos que } \\
\text { identifican a 007: } \\
\text { Pistola. } \\
\text { Silueta mujer. } \\
\text { Acción. } \\
\text { Símbolos propios } \\
\text { trama narrativa del } \\
\text { filme: Siluetas fe- } \\
\text { menina con gorro } \\
\text { ruso. Manos que } \\
\text { acarician. Referen- } \\
\text { cias a escenas de } \\
\text { la película. Rostro } \\
\text { actor 007. Rostro } \\
\text { actriz chica Bond. }\end{array}$ & $\begin{array}{l}\text { Blanco y negro: } \\
\text { espionaje. Elegan- } \\
\text { cia. Smoking. } \\
\text { Rojo: sangre } \\
\text { Azul } \\
\text { Verde } \\
\text { Magenta. } \\
\\
\text { Emplea colores } \\
\text { primarios. }\end{array}$ \\
\hline $\begin{array}{l}\text { Licence to Kill } \\
\text { (1989) } \\
\text { John Glen. } \\
\text { M. Binder. } \\
\text { T. Dalton. } \\
\text { Intérprete: Gladys } \\
\text { Knight (EEUU) }\end{array}$ & $\begin{array}{l}\text { Licencia para } \\
\text { matar: agente } \\
\text { secreto. Temática: } \\
\text { venganza. } \\
\text { No incorpora el } \\
\text { nombre de la } \\
\text { "marca 007". } \\
\text { Tema musical: } \\
\text { Licence to Kill. } \\
\text { Refuerza nombre } \\
\text { del filme. }\end{array}$ & $\begin{array}{l}\text { Tipografía Sans } \\
\text { Serif. Similitud con } \\
\text { Arial Rounded MT } \\
\text { Bold. } \\
\text { Interacción con la } \\
\text { imagen gráfica. } \\
\text { Color blanco. }\end{array}$ & $\begin{array}{l}\text { Símbolos que } \\
\text { identifican a 007: } \\
\text { Símbolo 007, } \\
\text { pistola, } \\
\text { siluetas femeninas } \\
\text { en movimiento, } \\
\text { objetivo lente de } \\
\text { disparo. } \\
\text { Símbolos propios } \\
\text { trama narrativa fil- } \\
\text { me: cámara fotos, } \\
\text { mesa de juego. } \\
\text { Rostro actor 007. } \\
\text { Rostro actriz chica } \\
\text { Bond }\end{array}$ & $\begin{array}{l}\text { Blanco y negro: } \\
\text { espionaje. } \\
\text { Elegancia. Smo- } \\
\text { king. } \\
\text { Rojo: sangre } \\
\text { Dorado } \\
\text { Verde } \\
\text { Azul } \\
\text { Amarillo } \\
\text { Cian } \\
\text { Emplea colores } \\
\text { primarios. }\end{array}$ \\
\hline
\end{tabular}




\begin{tabular}{|c|c|c|c|c|}
\hline Película & Lingüístico & Escritural & Icónico & Cromático \\
\hline $\begin{array}{l}\text { Tomorrow Never } \\
\text { Dies (1997) } \\
\text { R.Spottiswoode } \\
\text { D. Kleinman. } \\
\text { P. Brosnan. } \\
\text { Intérprete: Sheryl } \\
\text { Crow (EEUU) }\end{array}$ & $\begin{array}{l}\text { El mañana nunca } \\
\text { muere. } \\
\text { No incorpora el } \\
\text { nombre de la } \\
\text { "marca 007". } \\
\text { Tema musical: } \\
\text { Tomorrow Never } \\
\text { Dies. Refuerza } \\
\text { nombre del filme. } \\
\text { Hace referencia a } \\
\text { aspectos caracte- } \\
\text { rísticos de Bond. }\end{array}$ & $\begin{array}{l}\text { Tipografía Sans } \\
\text { Serif. Similitud con } \\
\text { Arial Rounded MT } \\
\text { Bold. } \\
\text { Interacción con la } \\
\text { imagen gráfica. } \\
\text { Color blanco. }\end{array}$ & $\begin{array}{l}\text { Símbolos que } \\
\text { identifican a 007: } \\
\text { reloj, Pistola, } \\
\text { puñales } \\
\text { Balas. Siluetas } \\
\text { mujer en movi- } \\
\text { miento. Acción, } \\
\text { explosiones. } \\
\text { Símbolos propios } \\
\text { trama narrativa } \\
\text { del filme: mapas } \\
\text { de comunicación, } \\
\text { Lenguaje binario. } \\
\text { Lentes. Pantallas. } \\
\text { Rostro actriz chica } \\
\text { Bond. Imágenes } \\
\text { color invertido. } \\
\text { Diamantes } \\
\text { Espejos rotos. }\end{array}$ & $\begin{array}{l}\text { Blanco y negro: } \\
\text { espionaje. } \\
\text { Elegancia. Smo- } \\
\text { king. } \\
\text { Rojo: sangre. } \\
\text { Azul } \\
\text { Verde } \\
\text { Cian } \\
\text { Morado } \\
\text { Amarillo } \\
\text { Naranja. } \\
\text { Emplea colores } \\
\text { primarios. }\end{array}$ \\
\hline $\begin{array}{l}\text { The World Is Not } \\
\text { Enough (1999) } \\
\text { Michael Apted. } \\
\text { D. Kleinman. } \\
\text { P. Brosnan. } \\
\text { Intérprete: Garba- } \\
\text { ge (EEUU, Edim- } \\
\text { burgo, Escocia, } \\
\text { Reino Unido) }\end{array}$ & $\begin{array}{l}\text { El mundo no es } \\
\text { suficiente. } \\
\text { No incorpora el } \\
\text { nombre de la } \\
\text { "marca 007". } \\
\text { Tema musical: } \\
\text { The World Is Not } \\
\text { Enough. Refuerza } \\
\text { nombre del filme. }\end{array}$ & $\begin{array}{l}\text { Tipografía Sans } \\
\text { Serif. Similitud con } \\
\text { Arial Rounded MT } \\
\text { Bold. } \\
\text { Interacción con la } \\
\text { imagen gráfica. } \\
\text { Color blanco. }\end{array}$ & $\begin{array}{l}\text { Símbolos que } \\
\text { identifican a 007: } \\
\text { siluetas mujeres } \\
\text { en movimiento. } \\
\text { Bala. } \\
\text { Símbolos propios } \\
\text { trama narrativa del } \\
\text { filme: Gotas de } \\
\text { Petróleo y Siluetas } \\
\text { de mujer cubier- } \\
\text { tas de petróleo. } \\
\text { Explosión pozo } \\
\text { petróleo. Mundo. } \\
\text { Maquinaria pozos } \\
\text { de extracción de } \\
\text { petróleo. Rostro } \\
\text { actriz chica Bond. }\end{array}$ & $\begin{array}{l}\text { Blanco y negro: } \\
\text { espionaje. } \\
\text { Elegancia. Smo- } \\
\text { king. } \\
\text { Rojo: sangre. } \\
\text { Negro: petróleo. } \\
\text { Magenta } \\
\text { Verde } \\
\text { Azul } \\
\text { Amarillo } \\
\text { Cian } \\
\text { Naranja. } \\
\text { Emplea colores } \\
\text { primarios. }\end{array}$ \\
\hline $\begin{array}{l}\text { Die Another Day } \\
\text { (2002) } \\
\text { Lee Tamahori. } \\
\text { D Kleinman. } \\
\text { P. Brosnan. } \\
\text { Intérprete: Madon- } \\
\text { na (EEUU) }\end{array}$ & $\begin{array}{l}\text { Muere otro día. } \\
\text { No incorpora el } \\
\text { nombre de la } \\
\text { "marca 007". } \\
\text { Tema musical: Die } \\
\text { Another Day. Re- } \\
\text { fuerza nombre del } \\
\text { filme. Pone de re- } \\
\text { lieve la capacidad } \\
\text { de supervivencia } \\
\text { de Bond. }\end{array}$ & $\begin{array}{l}\text { Tipografía Sans } \\
\text { Serif. Similitud con } \\
\text { Arial Rounded MT } \\
\text { Bold. } \\
\text { Interacción con la } \\
\text { imagen gráfica. } \\
\text { Color blanco. } \\
\text { Amarillo y Rojo. } \\
\text { Los dos últimos } \\
\text { hacen referencia } \\
\text { a la temática del } \\
\text { filme. }\end{array}$ & $\begin{array}{l}\text { Símbolos que } \\
\text { identifican a 007: } \\
\text { Explosiones. } \\
\text { Siluetas mujer en } \\
\text { movimiento. } \\
\text { Torturas. } \\
\text { Elementos propios } \\
\text { trama narrativa del } \\
\text { filme: escenas tor- } \\
\text { tura. Escorpiones. } \\
\text { Rostro actor 007. } \\
\text { Rostro actriz chica } \\
\text { Bond. }\end{array}$ & $\begin{array}{l}\text { Blanco y negro: } \\
\text { espionaje. } \\
\text { Elegancia. Smo- } \\
\text { king. } \\
\text { Rojo: sangre } \\
\text { Rojo y amarillo: } \\
\text { fuego luz solar. } \\
\text { Negro y gris: frío. } \\
\text { Dureza. }\end{array}$ \\
\hline
\end{tabular}




\begin{tabular}{|c|c|c|c|c|}
\hline Película & Lingüístico & Escritural & Icónico & Cromático \\
\hline $\begin{array}{l}\text { Casino Royale } \\
\text { (2006) } \\
\text { M. Campbell. } \\
\text { D. Kleinman. } \\
\text { Daniel Craig. } \\
\text { Intérprete: Chris } \\
\text { Cornell (EEUU) }\end{array}$ & $\begin{array}{l}\text { Casino Royale: } \\
\text { lugar. } \\
\text { No incorpora el } \\
\text { nombre de la } \\
\text { "marca 007". } \\
\text { Tema musical: You } \\
\text { Know My Name. } \\
\text { Nombre diferente } \\
\text { al título del filme. } \\
\text { Refuerza la narrati- } \\
\text { va del filme: Bond } \\
\text { se convierte en } \\
\text { agente } 007 .\end{array}$ & $\begin{array}{l}\text { Tipografía Sans } \\
\text { Serif. Similitud con } \\
\text { Arial Rounded MT } \\
\text { Bold. } \\
\text { Interacción con la } \\
\text { imagen gráfica. } \\
\text { Color blanco. }\end{array}$ & $\begin{array}{l}\text { Símbolos que } \\
\text { identifican a 007: } \\
\text { Elementos de ac- } \\
\text { ción y espionaje: } \\
\text { Pistolas, objetivo } \\
\text { lente disparo. } \\
\text { Siluetas sicarios. } \\
\text { Símbolos propios } \\
\text { trama narrativa del } \\
\text { filme: juego: palos } \\
\text { baraja francesa, } \\
\text { cartas baraja, Rey } \\
\text { de Picas } \\
\text { Reina de Corazo- } \\
\text { nes } \\
\text { Ruleta, dinero. } \\
\text { Mensaje 007 STA- } \\
\text { TUS CONFIRMED. } \\
\text { Rostro actor 007. } \\
\text { Rostro actriz chica } \\
\text { Bond. }\end{array}$ & $\begin{array}{l}\text { Blanco y negro: } \\
\text { espionaje. Elegan- } \\
\text { cia. Smoking. } \\
\text { Rojo: sangre. } \\
\text { Violencia. } \\
\text { Verde: tapete jue- } \\
\text { go casino. } \\
\text { Azul, amarillo, } \\
\text { naranja. } \\
\text { Emplea colores } \\
\text { primarios. }\end{array}$ \\
\hline $\begin{array}{l}\text { Quantum of Sola- } \\
\text { ce (2008) } \\
\text { Marc Forster. } \\
\text { MK12. } \\
\text { Daniel Craig. } \\
\text { Intérprete: Alicia } \\
\text { Keys (EEUU) } \\
\text { Jack White (EEUU) }\end{array}$ & $\begin{array}{l}\text { Quantum of So- } \\
\text { lace. } \\
\text { Hace referencia } \\
\text { a los sucesos } \\
\text { acaecidos en el } \\
\text { filme anterior y la } \\
\text { situación anímica } \\
\text { de Bond. No incor- } \\
\text { pora el nombre de } \\
\text { la "marca 007". } \\
\text { Tema musical: } \\
\text { Another Way to } \\
\text { Die. Refuerza la } \\
\text { trama del filme } \\
\text { aunque no el nom- } \\
\text { bre de la película. }\end{array}$ & $\begin{array}{l}\text { Variación tipográ- } \\
\text { fica respecto al } \\
\text { resto de películas. } \\
\text { Algunas letras } \\
\text { aparecen primero } \\
\text { como puntos blan- } \\
\text { cos sólidos. Refe- } \\
\text { rencia a los puntos } \\
\text { de la Secuencia } \\
\text { Gunbarrel. } \\
\text { Sans Serif. } \\
\text { Color blanco. }\end{array}$ & $\begin{array}{l}\text { Símbolos propios } \\
\text { trama narrativa } \\
\text { del filme: Desier- } \\
\text { to. Arena. Fuego } \\
\text { desierto. Rostro } \\
\text { actor 007. Rostro } \\
\text { actriz chica Bond. } \\
\text { Siluetas mujeres } \\
\text { como montañas } \\
\text { arena del desier- } \\
\text { to. Líneas globo } \\
\text { terráqueo. } \\
\text { Símbolos que } \\
\text { identifican a 007: } \\
\text { Balas. Pistola. } \\
\text { Explosiones. } \\
\text { Siluetas femeninas } \\
\text { en movimiento. } \\
\text { Puntos rojos re- } \\
\text { cuerdan secuencia } \\
\text { Gunbarrel. }\end{array}$ & $\begin{array}{l}\text { Blanco y negro: } \\
\text { espionaje. Elegan- } \\
\text { cia. Smoking. } \\
\text { Rojo: sangre } \\
\text { Verde } \\
\text { Naranja. } \\
\text { Colores solariza- } \\
\text { dos: efecto del sol } \\
\text { en el desierto. }\end{array}$ \\
\hline
\end{tabular}




\begin{tabular}{|c|c|c|c|c|}
\hline Película & Lingüístico & Escritural & Icónico & Cromático \\
\hline $\begin{array}{l}\text { Skyfall (2012) } \\
\text { Sam Mendes. } \\
\text { D. Kleinman. } \\
\text { Daniel Craig. } \\
\text { Intérprete: Adele } \\
\text { (Reino Unido) }\end{array}$ & $\begin{array}{l}\text { Skyfall: lugar rela- } \\
\text { cionado con } 007 . \\
\text { No incorpora el } \\
\text { nombre de la } \\
\text { "marca 007". } \\
\text { Tema musical: } \\
\text { Skyfall. Refuerza } \\
\text { nombre y narrativa } \\
\text { del filme. }\end{array}$ & $\begin{array}{l}\text { Tipografía Sans } \\
\text { Serif. Similitud con } \\
\text { Arial Rounded MT } \\
\text { Bold. } \\
\text { Interacción con la } \\
\text { imagen gráfica. } \\
\text { Color blanco. }\end{array}$ & $\begin{array}{l}\text { Símbolos propios } \\
\text { trama narrativa } \\
\text { del filme: Muerte. } \\
\text { Puñales. Silue- } \\
\text { tas de tiro con la } \\
\text { imagen de Bond. } \\
\text { Pasado de Bond: } \\
\text { silueta casa, en- } \\
\text { trada finca, interior } \\
\text { mansión. Tumbas. } \\
\text { Cementerio. Cala- } \\
\text { veras. } \\
\text { Dragones (lugar); } \\
\text { mujer; man- } \\
\text { chas Rorschach } \\
\text { (subconsciente). } \\
\text { Rostro actor 007. } \\
\text { Rostro actriz chica } \\
\text { Bond. } \\
\text { Símbolos que } \\
\text { identifican a 007: } \\
\text { pistolas, Agujeros } \\
\text { de disparos. Silue- } \\
\text { ta mujer. }\end{array}$ & $\begin{array}{l}\text { Blanco y negro: } \\
\text { espionaje. Elegan- } \\
\text { cia. Smoking. } \\
\text { Rojo: sangre. } \\
\text { Violencia. } \\
\text { Azul: hundimiento, } \\
\text { profundidad. } \\
\text { Amarillo, morado, } \\
\text { naranja, verde. } \\
\text { Emplea colores } \\
\text { primarios. }\end{array}$ \\
\hline
\end{tabular}

Tabla 1. Elaboración propia a partir de Costa (2012), Ramírez Barredo (2016) y Heller, E. \& Chamorro Mielke, J. (2007). 
Royale. (Filmaffinity)

2. Quantum of Solace (2008). 106 minutos.

https://www.artofthetitle.com/title/quantum-of-solace/

Dirección: Marc Forster. Diseñador de créditos: Ben Radatz. James Ramirez. MK12. Actor principal: Daniel Craig.

Sinopsis: Traicionado por Vesper, la mujer a la que amaba, 007 se plantea su nueva misión como algo personal. Durante su investigación interroga a Mr. White, que le revela que la organización que chantajeó a Vesper es mucho más compleja y peligrosa de lo que imagina. El servicio de inteligencia forense vincula a un traidor del Ml6 con una cuenta bancaria en Haití. Allí Camille pone a Bond tras la pista de Dominic Greene, un despiadado hombre de negocios y miembro importante de la misteriosa organización. Su objetivo es controlar uno de los recursos naturales más importantes del mundo; pero, para ello, tiene que derrocar al gobierno de un país sudamericano. (Filmaffinity)

2. Skyfall (2012). 143 minutos.

\section{https://www.artofthetitle.com/title/skyfall/}

Dirección: Sam Mendes. Diseñador de créditos: Daniel Kleinman. - Actor principal: Daniel Craig.

Sinopsis: La lealtad de James Bond por su superiora M se verá puesta a prueba cuando episodios del pasado de ella vuelven para atormentarla. Al mismo tiempo, el Ml6 sufre un ataque, y 007 tendrá que localizar y destruir el grave peligro que representa el villano Silva.

- (Filmaffinity) 


\subsection{Análisis de secuencias}

\section{Resultados}

(1)

Signos Lingüísticos:

No incorpora explícitamente en los títulos originales de las películas el término James Bond o 007.

Las melodías que acompañan la secuencia de créditos en su mayoría tienen letra.

En general el título de la canción coincide con el de la película. En los casos en que no sucede así la letra hace referencia a la temática o trama narrativa del filme.

Signos escriturales:

Tipografía Sans Serif, color blanco, sin ornamentación. Sólo en la secuencia de Quantum of Solace incorpora una ligera variación, ha- ciendo un guiño a la secuencia Gunbarrel.

Signos icónicos:

Elementos permanentes: Arma: pistola. Acción: explosiones y movimiento. Siluetas de mujeres, habitualmente en movimiento con un arma en la mano.

Otros elementos recurrentes: Reloj. Martini. Puñales. Villanos. Balas. Objetivo lente de disparo.

Simbología propia de la trama argumental de la película. 
"Marca 007" y su gestión creativa en los Títulos de crédito de las películas de James Bond

Signos Promáticos:

En todas las secuencias aparece el negro, blanco y rojo.

- En la gran mayoría se utilizan los colores primarios: cian, magenta, amarillo, verde, azul y rojo. La proporción de los mismos varía en función del argumento de la película.

En algunas aparecen colores secundarios: morado y naranja.

Según la temática del filme se introducen colores ad hoc: oro, gris.

En las secuencias más actuales en el tiempo se aplican efectos visuales.

Signos que aparecen reiteradamente en las secuencias con independencia de la temática del filme:

Signos lingüísticos: intérpretes y compositores célebres ingleses y estadounidenses. Contribuye a asentar la condición de icono uni-

- versal de la "marca 007".

Signos escriturales: Tipografía Sans Serif color blanco sin ornamentación. Símbolo de modernidad, fuerza, dinamismo, potencia (Santin, s.f.).

Signos icónicos permanentes: pistola, explosiones y movimiento, siluetas femeninas. Emblemas de violencia, acción, suspense, y el aspecto seductor de 007.

Signos icónicos recurrentes: Reloj. Martini. Puñales. Villanos. Balas. Objetivo lente de disparo. Destacan el género de thriller a estrategia de personificación de marca, que permite a los anunciantes pasar de la personalidad a la personificación de marca. Establecen el tono 
en que se va a desarrollar la trama narrativa.

Signos cromáticos permanentes: blanco, negro y rojo. Referencia al género de espionaje, al smoking de Bond y a la sangre.

Signos cromáticos recurrentes: colores primarios

Elementos que aparecen en las secuencias en función de la temática del filme:

Signos lingüísticos: título y letra de las canciones. Mantienen estrecha relación con la trama de la película. Facilita la creación de una atmósfera apropiada para la inmersión en el filme. Las melodías son una fuente de identidad de marca. "Las canciones ayudan a recordar lo que se aprende" (Toro Martín et al., 2009, p.120). La música pertenece al ámbito del marketing sensorial: interpela nuestros sentidos y genera emociones que se asocian con el producto (Ramírez Barredo, 2016, p. 157).

Signos icónicos: simbología propia de la trama argumental de la película. Incorporación de efectos visuales con imágenes creativas e impactantes. Anticipan aspectos esenciales del filme siguiendo una estética afín, asentada sobre la identidad de 007, que contribuye a construir una sólida imagen de "marca 007".

Signos cromáticos: los acordes cromáticos están compuestos, en su mayoría, por los colores primarios y dos o tres añadidos en función de la temática de la película. Esta regla se repite en las secuencias, estableciendo una norma de identidad visual.

\section{Conclusiones}


"Marca 007" y su gestión creativa en los Títulos de crédito de las películas de James Bond

1. Las secuencias analizadas ponen de manifiesto que los títulos de crédito de las películas del Agente 007, con independencia de la trama argumental del filme, incorporan unos signos comunes que forman parte del universo James Bond: son atributos de personalidad de la "marca 007". La inclusión permanente de los mismos, combinados con ingredientes particulares que referencian al filme correspondiente, revela una gestión de la "marca 007" coherente y creativa.

2. Los signos que incluyen las secuencias de crédito contribuyen a reforzar en la mente del espectador la imagen de "marca 007". Los símbolos con presencia invariable hacen referencia a particularidades del personaje de ficción, integrando aspectos relacionados con la estrategia de construcción de marca 007 como icono universal. Los emblemas que se incorporan en función de la temática y narrativa del filme cooperan en la creación de imagen y valor de marca del universo Bond, siguiendo un mismo patrón de identidad visual.

3.. Las diferencias visuales en las secuencias vienen determinadas, fundamentalmente, por el estilo personal de cada diseñador y las técnicas empleadas. No obstante, la pieza audiovisual siempre pivota sobre el "eje 007" y su personalidad, obteniéndose un equilibrio entre reinventar este elemento de marca a través de la interpretación individual del diseñador y conservar el legado de Fleming durante décadas.

4. Los títulos de crédito de las películas de Bond contienen los atributos que conforman el sistema semiótico de la "marca 007". En lo referente a los signos lingüísticos cabe destacar que los títulos de las películas no incorporan el nombre de la marca: se centran en la trama argumental del filme. Las canciones que acompañan las secuencias incorporan en sus letras elementos coincidentes con la temática narrativa de la película y rasgos distintivos que referencian a 007. Interpretadas por diferentes estrellas del panorama musical, aportan valor de marca. La melodía que se escucha en los créditos de Dr. No. se conoce con el nombre de Tema Bond, y conforma por sí misma un elemento de marca. Los signos escriturales reflejan el empleo en todas las secuencias de la misma tipografía o similar, sans serif de color blanco. Sólo se introduce una variante en el opening de Quantum of Solace, con el fin de reforzar 
un elemento de marca: los puntos de la secuencia Gunbarrel. Este estilo visual, que emana seguridad y modernidad, se mantiene en el aspecto compositivo del título del filme, a excepción de Dr. No., Tomorrow Never Dies, The World is not Enough, y Die Another Day, que presentan variaciones en este sentido. En cuanto a la iconicidad de los elementos de las secuencias, todas combinan atributos de identidad del personaje 007 con elementos que anticipan la temática del filme. Por último, las secuencias utilizan una misma gama cromática. Es interesante destacar el significado que encierran estas combinaciones: blanco y negro, propio del género de espionaje, que al tiempo evoca el smoking de Bond; el color rojo de la sangre que combinado con el negro alude a la violencia. El azul, rojo y blanco, característicos de la bandera británica. En gran medida se utilizan los colores primarios, variando su empleo en número y extensión en función del argumento de la película. En algunos casos se incorporan colores en relación al mismo.

5. Respondiendo a la hipótesis de partida podemos afirmar que los títulos de crédito de las películas de Bond gestionan creativamente los atributos de "marca 007": introducen los signos que integran el sistema semiótico de la misma, con independencia de la narrativa del filme al que preceden, el director del mismo o el diseñador. Trascienden la obra audiovisual, potenciando la personalidad de "marca 007" y constituyendo al tiempo un elemento de la misma per se.

6. "Para hacer branding emocional hay que crear un cóctel de antropología, experiencias sensoriales, imaginación y enfoque visionario de cambio" (Gobé, citado en Toro Martín et al., 2009, p.123). Los títulos de crédito de las películas de James Bond incorporan estos ingredientes, conformando una estrategia de marketing de experiencia o branding emocional. 
"Marca 007" y su gestión creativa en los Títulos de crédito de las películas de James Bond

\section{Bibliografía}

Baños González, M. (2006). Vayamos por partes... dijo Jack El Destripador. Revista ICONO14. Revista Científica De Comunicación Y Tecnologías Emergentes, 6(5).

Bartolomé, Á., \& Ortiz de Solórzano, J. (2011). Títulos de crédito: diseño en movimiento. El legado de Maurice Binder en las películas de James Bond. Teccom Studies, 2. Recuperado de http://www.teccomstudies.com/numeros/revista-2/176-titulos-decredito-diseno-en-movimiento-el-legado-de-maurice-binder-en-las-peliculas-de- james-bond.

Bassat Coen, L. (2006). El libro rojo de las marcas. Barcelona: DeBolsillo.

Bayo Neira, Á. Josef Albers - La Interacción del Color. Academia.edu. Recuperado el 14 de marzo de 2015, de http://www.academia.edu/9863343/Josef Albers - La Interacci\%C3\%B3n del Color

Costa, J. (2012). La imagen de marca. Barcelona, España: Paidós.

Dabner, D., Rufas Yuste, E., \& Fradera, P. (2005). Diseño gráfico. Barcelona: Blume.

Gamonal Arroyo, R. (2005). Títulos de crédito. Píldoras creativas del diseño gráfico en el cine. Revista ICONO14 Revista Científica De Comunicación Y Tecnologías Emergentes, 3(2), 43-67. https://doi.org/10.7195/ri14.v3i2.418

García García, F. (2003). Posibilidades creativas de la imagen. Inteligencia y creatividad. Revista ICONO14 Revista Científica De Comunicación Y Tecnologías Emergentes, 1(2), 153-169. https://doi.org/10.7195/ri14.v1i2.459

García García F., Barroso llorente C., García Guardia M.L. (2010). La construcción globalizada del logo-símbolo y la globalización de la marca a través del mismo. Revista Historia y Comunicación Social, 15, 125-148. 
Gunbarrel - Archivo 007: Club James Bond. (2008). La secuencia gunbarrel: orígenes y evolución del preámbulo a las películas de James Bond Archivo007.com. Recuperado el 10 de marzo de 2019 de: https://archivo007.com/gunbarrel/

Heller, E. \& Chamorro Mielke, J. (2007). Psicología del color (7a ed.). Barcelona: Gustavo Gili.

Interbrand. (2013). Mejores Marcas Españolas 2013. Madrid: Interbrand.

Labaig Fuertes, F. (2006). Acerca de los títulos de crédito. Paperback, n 4. ISSN 1885-8007. Recuperado de http://www. paperback.es /articulos/labaig/creditos.pdf

Martínez Castllo, G. (2008). Clasificación tipográfica. Clasificaciontipografica.blogspot. com.es. Recuperado el 12 de Noviembre de 2014, de http://clasificaciontipografica.blogspot. com.es

Mourgues, N. (1994). Le Générique de Filme. París: Méridiens Klincksieck.

Radatz, B., Albinson, I., \& Landekic, L. (2012). James Bond: 50 Years of Main Title Design. Artofthetitle.com. Recuperado el 18 de abril de 2015, de http://www.artofthetitle. com/feature/james-bond-50-years-of-main-title-design/

RadaTz, B. (2013). Skyfall. Artofthetitle.com. Recuperado el 20 de abril de 2015, de https://www.artofthetitle.com/title/skyfall//

Ramírez Barredo, B. (2016). Los títulos de crédito, marca de las películas. Tesis Doctoral. Universidad Complutense de Madrid.

Ricarte Bescós, J.M. (2006). Gestión estratégica y creativa de la comunicación: valores, habilidades y modelos de la comunicación persuasiva. Clonica. net. Recuperado el 10 de abril de 2019 de https://www.clonica.net/usuario/img usuario/publiradio. net/Des Aula/276.pdf 
"Marca 007" y su gestión creativa en los Títulos de crédito de las películas de James Bond

Rodríguez R., M. y Mantilla C., W. 2013. De la creatividad a la innovación, de la innovación a la propiedad intelectual. Revista La Propiedad Inmaterial. 17 (nov. 2013), 283-324.

Ruiz-Mediavilla, A. (2015). La marca es Bond, James Bond. Dendra méd. Rev. Humanid, 2015; 14(2): 294-300.

SANTIN, L. (S.f.) ¿Qué transmiten las tipografias y cómo nos afectan emocionalmente? mediaclick.es. Marketing Online. Recuperado el 12 de marzo de https://www.mediaclick.es/blog/que-transmiten-las-tipografias-y-como-nos-afectan-emocionalmente/

Solana, G., \& Boneu, A. (2008). The art of the title sequence (2a ed.). Barcelona, Spain: Index Book.

Toro Martín, J., Clemente Tiemblo, A., \& Muñoz-Cobo, D. (2009). La marca y sus circunstancias. Barcelona: Deusto.

Villafañe, J., \& Mínguez-Arranz, N. (1996). Principios de teoría general de la imagen. Madrid: Ediciones Pirámide. 